\title{
Analytical aspects to the study of amino acid metabolism
}

Citation for published version (APA):

van Eijk, H. M. H. (1999). Analytical aspects to the study of amino acid metabolism. [Doctoral Thesis, Maastricht University]. https://doi.org/10.26481/dis.19990917he

Document status and date:

Published: 01/01/1999

DOI:

10.26481/dis.19990917he

Document Version:

Publisher's PDF, also known as Version of record

\section{Please check the document version of this publication:}

- A submitted manuscript is the version of the article upon submission and before peer-review. There can be important differences between the submitted version and the official published version of record.

People interested in the research are advised to contact the author for the final version of the publication, or visit the DOI to the publisher's website.

- The final author version and the galley proof are versions of the publication after peer review.

- The final published version features the final layout of the paper including the volume, issue and page numbers.

Link to publication

\footnotetext{
General rights rights.

- You may freely distribute the URL identifying the publication in the public portal. please follow below link for the End User Agreement:

www.umlib.nl/taverne-license

Take down policy

If you believe that this document breaches copyright please contact us at:

repository@maastrichtuniversity.nl

providing details and we will investigate your claim.
}

Copyright and moral rights for the publications made accessible in the public portal are retained by the authors and/or other copyright owners and it is a condition of accessing publications that users recognise and abide by the legal requirements associated with these

- Users may download and print one copy of any publication from the public portal for the purpose of private study or research.

- You may not further distribute the material or use it for any profit-making activity or commercial gain

If the publication is distributed under the terms of Article $25 \mathrm{fa}$ of the Dutch Copyright Act, indicated by the "Taverne" license above, 


\section{Analytical aspects to the study of amino acid metabolism}

\section{Proefschrift}

ter verkrijging van de graad van doctor

aan de Universiteit Maastricht,

op gezag van de Rector Magnificus, Prof. Dr. A.C. Nieuwenhuijzen Kruseman

volgens het besluit van het College van Decanen,

in het openbaar te verdedigen

op vrijdag 17 september 1999 om 14.00 uur

$$
\text { door }
$$

Hendrikus Maria Hubertus van Eijk

geboren 16 augustus 1959 te Heerlen 


\section{Promotor}

Prof.dr. P.B. Soeters

\section{Co-promotor}

Dr. N.E.P. Deutz

\section{Beoordelingscommissie}

Prof.dr. M.P. van Dieijen-Visser (voorzitter)

Prof.dr. P. Fürst (Universität Hohemheim, Duitsland)

Prof.dr. J.P.M. Geraedts

Prof.dr.ir. W.H.M. Saris

Prof.dr. P.Stehle (Universität Bonn, Duitsland)

ISBN: 90-5681-064-2
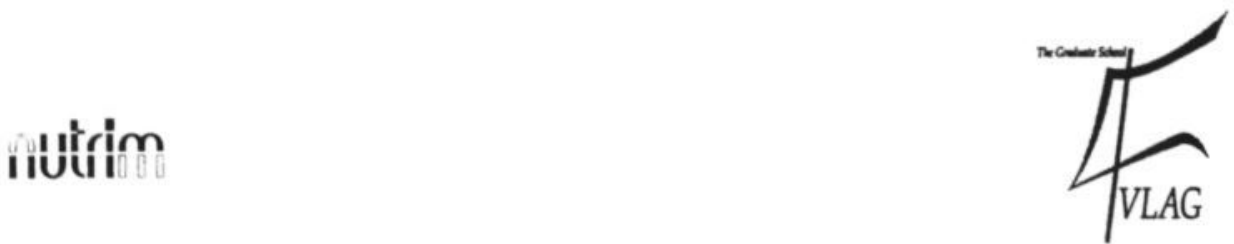

The study presented in this thesis was performed at the Nutrition and Toxicology Research Institute Maastricht (NUTRIM), which participates in the Graduate School VLAG-2 (Food Technology. Agrobiotechnology, Nutrition and Health Sciences) accredited by the Royal Netherlands Academy of Arts and Sciences.

De druk van dit proefschrift werd financieel mede mogelijk gemaakt door Alltech Applied Science en B\&L systems. 
Contents

Introduction

Chapter $1 \quad$ Basic setup for the determination of o-phthaldialdehyde derived amino acids

Chapter 2 Determination of amino acid metabolites

Chapter 3 Sample preparation and interpretation

Chapter 4 Isolation and quantitation of isotopically labelled amino acids from biological samples

Chapter 5 Automated isolation of high purity plasma albumin for isotope ratio measurements

Chapter $6 \quad$ Determination of amino acid isotope enrichment using Liquid Chromatography-Mass Spectrometry

Addenda

To chapters 1,3 and 4

Summary

Dankwoord

Curriculum Vitae

Publications 



\section{Introduction}

\section{General Introduction}

A basic requirement for the study of protein metabolism is to have access to techniques, which enable quantification of changes in the biological pathways of amino acids, their involvement in protein synthesis and breakdown. In this thesis, an overview is presented of the progress made by us in this field over the last 15 years, starting from the point were reversed phase chromatography began to take over the classical ion-exchange separation. The latter technique, first introduced by Spackman, Moore and Stein in 1956 (1), enabled researchers for the first time to quantitate plasma and tissue amino acid concentrations, and dominated for a long time metabolic research techniques. Even today, the technique is applied in many laboratories. It should therefore be no surprise that initially this technique was also used to perform our studies (2-5).

The growing number of samples and, especially in the animal experiments, the demand for a better sensitivity and precision could not be realized by ion-exchange chromatography. Furthermore, plasma or tissue (free) amino acid concentrations alone do not give an in-depth insight in metabolic processes. And although they improved our understanding of what was going on, the development and application of techniques to measure amino acid metabolites such as ammonia, urea, lactic acid in combination with the total nitrogen balance alone did not meet our requirements $(6-8)$. To get a more in-depth knowledge, protein (thus amino acid) production and degradation need to be quantitated. To enable this at organ level, a technique was required, precise enough to measure the small differences between arterial and venous amino acid concentrations in small sample amounts.

\section{Reversed phase chromatography}

At that time, the maturation of reversed phase high performance liquid chromatography (RP-HPLC) presented new alternatives to ion-exchange chromatography for amino acid concentration measurements. Because the stationairy phase (the silica matrix) used in this method has a much better mechanical strength compared to the polystyreen-divinylbenzene matrix of an ionexchange column, higher flow-rates were possible $(\mathrm{ml} / \mathrm{min})$. This enabled a drastic decrease of the analysis time. At the same time new derivatization probes were developed, which compared to ninhydrin, resulted in an enhanced sensitivity. Most popular probes at this time were fluorescamine $(9,10)$, dansylchlorine $(11-13)$, phenylisothiocyanate (PITC) $(14,15)$, 9-fluorenylchloroformiate (FMOC) (16-19) and o-phthaldialdehyde OPA (20-35). Application of these derivatization reactions prior to injection on the column had two effects. First it reduced polarity of the derivative compared to the unreacted amino acid, which is beneficial for a reversed phase separation. Furthermore, a post-column dilution with reagent is avoided, not only improving sensitivity, but also reducing reagent costs.

From the available derivatization reagents, we considered the OPA probe to be the best choice because of its easy and rapid reaction procedure, the resulting highly fluorescent derivatives and the non-fluorescent character of the reagent itself. However, still a number of problems had to be solved. In the eighties, no commercially available sample processor could execute the derivatization sequence 
with sufficient precision. Thus, standard systems were modified to achieve this $(25$, $28,29,35-37)$. Fortunately, high efficiency columns with a low particle size $(3 \mu \mathrm{m})$ just became available, enabling the development of the complete separation of all major amino acids (and their metabolites). And lastly, automatic data processing had just been introduced, but was not yet applied on a wide scale yet. Therefore, all the ingredients came together enabling us to develop a fully automated amino acid analysis employing OPA-pre-column derivatization (38).

With the resulting method, our goals discussed above could be reached and we were able to evaluate the massive amounts of sample data from clinical trials $(3$, 5 ) and those obtained from experiments using laboratory animals (4, 39-41). These measurements allowed calculation of net protein synthesis or breakdown and this exciting possibility increased the demand for an even more rapid analysis. We responded to this demand by replacing the analytical column by a continuous search for new and more efficient packing materials. This search resulted in implementation of a shorter, more efficient column which, in combination with an adapted gradient and solvent system, resulted in an almost two-fold reduction of the analysis time (42).

\section{Importance of sample preparation and normal values}

An important side effect of these developments was, that the enhanced analytical capacity provided the opportunity to take a closer look at the process of sample preparation and storage prior to analysis, both essential aspects of the analysis cycle. The question arose, how the concentration of especially glutamine, an important amino acid in metabolic research, is preserved best, because contradictional papers were published with respect to this subject (43-50). Usually, plasma deproteinization using 5-sulfosalycilic acid was recommended as being the best technique to exclude enzymatic activity. However, the acid $\mathrm{pH}$ was suspected to stimulate the spontaneous degradation to pyroglutamate. To elucidate this questions, a study was conducted to establish the most optimal sample processing technique. This study was expanded with the construction of a data base containing normal plasma amino acid concentrations in humans, because it was our belief that parameters like age, gender and the effects of feeding would definitely influence normal values (51). In this way we hoped to reduce the bias of a proper control group for a given patient population, thus increasing the sensitivity towards the effects of intervention.

\section{High sensitivity measurements and amino acid metabolites}

The increased (automated) analytical capacity also created more possibilities to broaden the study designs. Methods were designed to enable measurement of low concentrations of "marker" amino acids like 3-methylhistidine (for muscle protein breakdown) (52) and plasma $\gamma$-aminobutyricacid (GABA for hepatic encephalopathy) (53), because for both metabolites complications were encountered when literature methods were applied to plasma samples (54-58). Again, the OPA- method was used for this purpose and due to our increased knowledge with respect to the automated reaction procedure, only minor modifications were required to reach this goal. A separate analysis (59) was developed to measure plasma and tissue polyamine concentrations, important metabolites which are thought to play a role in the regulation of proliferation of specific tissues $(23,60,61)$. This application was especially challenging, as it required the development of an on-line purification to 
remove interfering amino acid derivatives, which had not been accomplished before. However, by combining our knowledge of the OPA derivatization reaction with the use of a new packing material, we were able to put the application into effect.

\section{Tracer technology}

The more answers are acquired, the more questions arise. Net protein synthesis is the resultant of synthesis and breakdown. Therefore, it is very well possible that the net effect is zero, while major changes occur in both processes. To answer these questions, it is necessary to get insight in both paths. This can be accomplished using tracer technology. Using either radioactively labeled amino acids or those enriched with stable isotopes, both aspects can be studied, first by using ion-exchange chromatography (62) and later by using semi preparative RP-HPLC (63). Using either of the two techniques, amino acid (derivatives) can be isolated and the radioactive or with stable isotopes enriched part can be determined. The radioactive radioctive application could be realized rather quickly, although the liquid scintillation process itself presented some unexpected problems.

The stable isotope applications are currently subject to an ongoing exciting development (64-74). However, due to the introduction of new ionization techniques like electrospray $(66,75-81)$, the direct coupling of a liquid chromatographic system to a mass spectrometer is now possible. In this way, many of the problems associated with difficult and expensive derivatization procedures required for the traditional gas chromatography-mass spectrometry coupling can be avoided and the full separation power of liquid chromatography can be used. This enables direct measurement of not only amino acids but of a whole spectrum of (often polar) metabolites which cannot, or only with a large effort, be studied with a GC-MS system.

Tracer technology itself opened possibilities to study the synthesis of selected proteins as a whole. The measurement of isotopically labeled amino acids incorporated into selected proteins enabled the direct calculation of their synthesis rates. However, this requires the collection of purified proteins and the development of biochemical separation techniques had to be developed for this $(62,63)$. For the future, we expect that LC-MS will play an increasingly important role in these applications. The growing mass range, which can be covered by the mass spectrometer, enables even today the study of intact proteins $(76,82)$. Together with the possibilities of MS-MS or even MS ${ }^{n}$ experiments, it might well become possible to study the incorporation of stable isotopes in intact proteins, without the necessity of a difficult and laborious purification procedure for either the protein and/or the target amino acid built into the protein.

\section{Scope of the Thesis}

The scope of this thesis is to present an overview of our contribution to the analytical progress made in metabolic research, starting with the classical ionexchange chromatography, going though reversed phase chromatography and ending with the exiting possibilities modern mass spectrometric methods add to this research. 


\section{References}

1. Spackman $\mathrm{DH}$, Stein WH, Moore S. Automatic recording apparatus for use in the chromatography of amino acids. Anal.Biochem. 1958;30:1190-1206.

2. Soeters PB, De Boer JEG, Oostenbroek RJ, Janssen MA. Carbohydrate metabolism in liver disease. In: Capocaccia L, Fisher JE, Rossi-Fanelli F, eds. Hepatic encephalopathy in chronic liver failure. Plenum, 1984:137-148.

3. Soeters PB, De Boer JEG. Why are plasam branched chain amino acid levels diminished in patients with liver cirrhosis? Branched chain amino and keto acids in health and disease. Basel: Karger, 1984:483-496.

4. Deutz NEP, Reijven PLM, Bost MCF, Van Berlo CLH, Soeters PB. Modification of the effects of blood on amino acid metabolism by intravenous isoleucine. Gastroent. 1991;101:16131620.

5. Vente JP, Von Meyenfeldt MF, Van Eijk HMH, et al. Plasma amino acid profiles in sepsis and stress. Ann.Surg. 1989;209:57-62.

6. Soeters PB, Van Leeuwen PAM, Janssen MA, et al. Metabolic generation of ammonia and amino acids in the intestinal wall and the influence of neomycin and lactulose. Advances in hepatic encephalopathy and urea cycle diseases. Basel: Karger, 1996:147-153.

7. Van Leeuwen PAM, Van de Boogaard AEJM, Janssen MA, De Boer JEG, Van Eijk HMH, Soeters PB. Ammonia production and glutamine metabolism in the small and large intestine of the rat and the influence of lactulose and neomycin. Advances in hepatic encephalopathy and urea cycle diseases. Basel: Karger, 1984:154-162.

8. Leweling H, Tschepe A, Holm E. Eine neue mikromethode zur bestimmung der ammoniak konzentration im volblut und plasma. LeberMagenDarm 1983;13:160-162.

9. Nakamura H, Pisano JJ. Fluorescamine derivatives of histidine, histamine and certain related imidazoles: unique fluorescence after heating in acid. Arch. Biochem.Biophys. 1976;177:334335.

10. Udenfriend S, Stein S, Bohlen P, Dairman W, Leimgruber W, Weigele M. Fluorescamine: A reagent for assay of amino acids, peptides,proteins and primary amines in the picomole range. Science 1972;178:871-872.

11. Bontemps J, Laschet J, Dandrifosse G. Analysis of dansyl derivatives of di-and polyamines in mouse brain,human serum and duodenal biopsy specimens by high-performance liquid chromatography on a standard reversed phase column. J.Chromatogr. 1984;311:59-67.

12. Tapuhi Y, Schmidt DE, Lindner W, Karger B. Dansylation of amino acids for high-performance liquid chromatography analysis. Anal.Biochem. 1981;115:123-129.

13. Bodsch W, Hossmann KA. A quantitative regional analysis of amino acids involved in rat brain protein synthesis by high performance liquid chromatography. J.Neurochem. 1983;40:371382.

14. Heinrikson RL, Meredith SC. Amino acid analysis by reversed-phase high-performance liquid chromatography: precolumn derivatization with phenylisothiocyanate. Anal.Biochem. 1984;136:65-74.

15. Cohen SA, Bidlingmeyer BA, Tarvin TL. PITC derivatives in amino acid analysis. Nature 1986;320:769-770.

16. Bétner I, Földi P. New automated amino acid analysis by hplc precolums derivatization with fluorenylmethoxycarbonylchloride. Chromatographia 1986;22:381-387.

17. Einarsson S, Josefsson B, Lagerkvist S. Determination of amino acids with 9fluorenylmethylchloroformate and reversed-phase high-performance liquid chromatography. J.Chromatogr. 1983;282:609-618.

18. Näsholm T, Sandberg H, Ericccon A. Quantitative analysis of amino acids in conifer tissues by high-performance liquid chromatography and fluorescence detection of their 9-fluorenylmethyl chloroformate derivatives. J.Chromatogr. 1987;396:225-236.

19. Carpino LA, Han GY. The 9-fluorenylmethoxycarbonyl amino protecting group. J.Org.Chem. 1972;37:3404-3409.

20. Jones BN, Gilligan JP. o-Phthaldehyde precolumn derivatization and reversed-phase highperformance liquid chromatography of polypeptide hydrolysates and physiological fluids. J.Chromatogr. 1983;266:471-480.

21. Deyl Z, Hyanek J. Profiling of amino acids in body fluids and tissues by means of liquid chromatography. J.Chromatogr.B 1986;379:177-250. 
22. Lindroth $\mathrm{P}$, Mopper K. High performance liquid chromatographic determination of subpicomole amounts of amino acids by precolumn fluorescence derivatization with o-phthaldialdehyde. Anal.Chem. 1979;51:1667-1674.

23. Skaaden T, Greibrokk T. Determination of polyamines by pre-column derivatization with ophthaldialdehyde and ethanethiol in combination with reversed phase high performance liquid chromatography. J.Chromatogr. 1982;247:111-122.

24. Godel H, Graser T, Földi P, Pfaender P, Fürst P. Measurement of free amino acids in human biological fluids by high-performance liquid chromatography. J.Chromatogr. 1984;297:49-61.

25. Pfeifer R, Karol R, Korpi J, Burgoyne R, McCourt D. Practical application of HPLC to amino acid analysis. Am.Lab. 1983;15:78-87.

26. Graser TA, Godel H, Albers S, Földi P, Fürst P. An ultra rapid and sensitive high-performance liquid chromatographic method for determination of tissue and plasma free amino acids. Anal.Biochem. 1985;151:142-152.

27. Abecassis J, David-Eteve C, Soun A. The separation of 24 OPA-AA of natural origin and quantitative analysis of tyrosine by means of HPLC. J.Liq.Chromatogr. 1985;8:135-153.

28. Smith RJ, Panico KA. Automated analysis of o-phthalaldehyde derivatives of amino acids in physiological fluids by reverse phase high performance liquid chromatography. J.Liq.Chromatogr. 1985;8:1783-1795.

29. O.Fleury M, Ashley DV. High-performance liquid chromatographic analysis of amino acids in physiological fluids: On-line precolumn derivatization with o-phthaldialdehyde. Anal.Biochem. 1983;133:330-335.

30. Eslami M, Stuart JD. Separation of orthophthalaldehyde/ethanol derivatives of taurine and closely eluting amino acids by high performance liquid chromatography. J.Liq.Chromatogr. 1984;7:1117-1131.

31. Turnell DC, Cooper DH. Rapid assay for amino acids in serum or urine by pre-column derivatizatioon and reversed phase liquid chromatography. Clin.Chem. 1982;28:527-531.

32. Hill D, Burnworth L, Skea W, Pfeifer R. Quantitative hplc analysis of plasma amino acids as orthophtaldialdehyde/ethanethiol derivatives. J.Liq.Chromatogr. 1982;5:2369-2393.

33. Hill DW, Walters FH, Wilson TD, Stuart JD. High performance liquid chromatographic determination of amino acids in the picomole range. Anal.Chem. 1979;51:1338-1341.

34. Cloete C. Automated optimised high performance liquid chromatographic analysis of precolumn o-phthaldialdehyde amino acid derivatives. J.Liq.Chromatogr. 1984;7:1979-1990.

35. Jones BN, Pääbo S, Stein S. Amino acid analysis and enzymatic sequence determination of peptids by an improved o-phthaldialdehyde precolumn labeling procedure. J.Liq.Chromatogr. 1981;4:565-586.

36. Haginaka J, Wakai J. Automated precolumn derivatization of amino acids with orthophthalaldehyde using a hollow-fibre membrane reactor. J.Chromatogr. 1990;502:317-324.

37. Lee HM, Forde D, Lee MC, Buchner DJ. Fluoremetric microbore amino acid analyzer: The construction of an inexpensive, highly sensitive instrument using o-phthalaldehyde as a detection agent. Anal.Biochem. 1979;96:298-307.

38. Van Eijk HMH, Van der Heijden MAH, Van Berlo CLH, Soeters PB. Fully automated liquid chromatographic determination of amino acids. Clin.Chem. 1988;34:2510-2513.

39. DeJong CHC, Deutz NEP, Soeters PB. Metabolic adatation of the kidney to hyperammonemia during chronic liver insufficiency in the rat. Hepatology 1993;92:890-902.

40. DeJong CHC, Deutz NEP, Soeters PB. Renal ammonia and glutamine metabolism during liver insufficiency induced hyperammonemia in the rat. J.Clin.Invest. 1993;92:2834-2840.

41. Van Berlo CLH, Van de Boogaard AEJM, Van der Heijden MAH, et al. Is increased ammonia liberation after bleeding in the digestive tract the consequence of complete absence of isoleucine in hemoglobin? A study in pigs. Hepatology 1989;10:315-323.

42. Van Eijk HMH, Rooyakkers DR, Deutz NEP. Rapid routine determination of amino acids in plasma by high-performance liquid chromatography with a 2-3 um Spherisorb ODS II column. J.Chromatogr. 1993;620:143-148.

43. Tritsch GL, Moore GE. Spontaneous decomposition of glutamine in cell culture media. Ex.Cell.Res. 1962;28:360-364.

44. Alfredsson G, Wiesel FA, Lindberg M. Glutamate and glutamine in cerebrospinal fluid and serum from healthy volunteers-analytical aspects. J.Chromatogr. 1988;424:378-384.

45. Kahn K, Hardy G, McElroy B, Elia M. The stability of L-glutamine in total parenteral nutrition solutions. Clin.Nutr. 1991;10:193-198.

46. Kahn K, Elia M. Factors affecting the stability of I-glutamine in solution. Clin.Nutr. 1991;10:186192. 
47. Ukida $\mathrm{M}$, Schäfer $\mathrm{K}$, Bode JC. Effect of storage at $-20^{\circ} \mathrm{C}$ on the concentration of amino acids in plasma. J.Clion.Chem.Clin.Biochem. 1981;19:1193-195.

48. Sahai S, Uhlhaas S. Stability of amino acids in human plasma. Clin.Chem.Acta 1985;148:255259.

49. Grossie VB, Yick J, Alpeter M, Welcourne TC, Ota DM. Glutamine stability in biological tissues evaluated by fluorometric analysis. Clin. Chem. 1993;39:1059-1063.

50. Da Fonseca Wollheim F. Deamidation of glutamine by increased plasma yglutamyltransferase is a source of rapid ammonia formation in blood and plasma specimens. Clin.Chem. 1990;36:1479-1482.

51. Van Eijk HMH, DeJong CHC, Deutz NEP, Soeters PB. Influence of storage conditions on normal plasma amino acid concentrations. Clin.Nutr. 1994;13:374-380.

52. Van Eijk HMH, Deutz NEP, Wagenmakers AJM, Soeters PB. 3-Methylhistidine determined in plasma by "High-Performance" Liquid Chromatography. Clin.Chem. 1990;36:556-559.

53. Van Berlo CLH, De Jonge H, Van de Boogaard AEJM, Van Eijk HMH, Janssen MA, Soeters PB. y-Aminobutyric acid production in small and large intestine of normal and germ-free wistar rats. Infulence of food intake and intestinal flora. Gastroenterology 1987;93:472-479.

54. Wassner SJ, Schlitzer JL, Li JB. A rapid, sensitive method for the determination of 3methylhiostidine levels in urine and plasma using high pressure liquid chromatography. Anal.Biochem. 1980;104:284-289.

55. Neuhäuser M, Fürst P. An automated method for determination of urinary 3-methylhistidine: normal values. Anal.Biochem. 1979;92:294-304.

56. Caudill WL, Houck GP, Wightman RM. Determination of y-aminobutyric acid by liquid chromatography with electrochemical detection. J.Chromatogr.B. 1982;227:331-339.

57. Durkin TA, Anderson GM, Cohen DJ. High performance liquid chromatographic analysis of neurotransmitter amino acids in brain. J.Chromatogr. 1988;428:9-15.

58. Griesmann GE, Chan WY, Rennert OM. Determination of y-aminobutyric acid by reversed phase high-performance liquid chromatography and pre-column labelling for fluorescence detection. J.Chromatogr. 1982;230:121-124.

59. Van Eijk HMH, Rooyakkers DR, Deutz NEP. Automated determination of polyamines by highperformance liquid chromatography with simple sample preparation. J.Chromatogr. A 1996;730:115-120.

60. Heideman RL, Flicking KB, Walker LJ. Free and total putrescine in cerebrospinal fluid quantified by reversed phase liquid chromatography. Clin.Chem. 1984;30:1243-1245.

61. Jeevanandam J, Holaday N, Ali MR. Altered tissue polyamine levels due to ornithine-aketoglutarate in traumatized growing rats. Metabolism 1992;41:1204-1209.

62. Van Eijk HMH, Huinck MPL, Rooyakkers DR, Deutz NEP. Automated simultaneous isolation and quantitation of labeled amino acid fractions from plasma and tissue by ion-exchange chromatography. J.Chromatogr.B 1994;660:251-257.

63. Van Eijk HMH, Rooyakkers DR, Wagenmakers AJM, Soeters PB, Deutz NEP. Isolation and quantitation of isotopically labeled amino acids from biological samples. J.Chromatogr.B 1997;691:287-296.

64. De Feo P, Haymond M. Principles and calculations of the labelled leucine methodology to estimate protein kinetics in humans. Diab.Nutr.Metab. 1994;7:165-184.

65. Fry B, Brand W, Mersch FJ, Tholke K, Garrit R. Automated analysis system for coupled $13 \mathrm{C}$ and $15 \mathrm{~N}$ measurements. Anal.Chem. 1992;64:288-291.

66. Goshe M, Anderson V. Determination of amino acid isotope ratios by electrospray ionizationmass spectrometry. Anal. Biochem. 1995;231:387-392.

67. Green LC, Wagner DA, Glogowski J, Skipper PL, Wishnok JS, Tannenbaum SR. Analysis of nitrate, nitrite and [15N]nitrate in biological fluids. Anal.Biochem. 1982;126:131-138.

68. Hellerstein MK, Neese RA. Mass isotopomer distribution analysis: a technique for measuring biosynthesis and turnover of polymers. Am.J.Physiol. 1992;263:E988-E1001.

69. Jahoor F, Sivakumar B, Del Rosario M, Frazer M. Isolation of acute-phase proteins from plasma for determination of fractional synthesis rates by a stable isotope tracer technique. Anal.Biochem. 1996;236:95-100.

70. Kapetanovic IM, Yonekawa WD, Kupferberg HJ. Use of stable isotopes and gas chromatography-mass soectrometry in the study of different pools of neurotransmitter amino acids in brain slices. J.Chromatogr. 1990;500:387-394.

71. Macko SA, Uhle ME, Engel MH, Andrusevich V. Stable nitrogen isotope analysis of amino acid enantiomers by gas chromatography/combustion/isotope ratio mass spectrometry.

Anal.Chem. 1997;69:926-929. 
72. Nissim I, Yudkoff M, Lapidot A. Simultaneous determination of [2-15N]- and [5-15N]glutamine with gas chromatography-mass spectroscopy: applications to nitrogen metabolic studies. Anal.Biochem. 1984;143:14-20.

73. Nissim I, Yudkoff M, Terwilliger T, Segal S. Rapid determination of [guanidino-15N] arginine in plasma with gas chromatography-mass spectrometry: application to human metabolic studies. Anal.Biochem. 1983;131:75-82.

74. Yu YM, Burke JF, Vogt JA, Chambers L, Young VR. Splanchnic and whole body L-[1$13 \mathrm{C}, 15 \mathrm{~N}$ ] leucine kinetics in relation to enteral and parenteral amino acid supply. Am.J.Physiol. 1992;262:E687-E694.

75. Ikonomou M, Blades A, Kebarle P. Electrospray-ion spray: A comparisation of mechanisms and performance. Anal.Chem. 1991;63:1989-98.

76. Smith R, Loo J, Edmonds C, Barinaga C, Udseth H. New developments in biochemical mass spectrometry: electrospray ionisation. Anal.Chem. 1990;62:882-99.

77. Zhou J, Hefta S, Lee T. High sensitivity analysis of phenylthiohydantoin amino acid derivatives by electrospray mass spectrometry. J.Am.Soc.Mass.Spectrom. 1997;8:1165-1174.

78. Van Berkel G, Quirke J, Tigani R, Dilley A, Covey T. Derivatization for electrospray ionization mass spectrometry. 3. Electrochemically ionizable derivatives. Anal.Chem. 1998;70:15441554.

79. Zhu M, DeCaprio A, Hauer C, Spink D. Characterization of glutathione conjugates of pyrrolated amino acids and peptides by liquid chromatography-mass spectrometryand tandem mass spectrometry with electrospray ionization. J.Chronmatogr.B 1997;688:187-196.

80. Cole R. Electrospray ionization mass spectrometry. Fundamentals, instrumentation \& applications. New ork: John Wiley \& sons, 1997.

81. De Hoffmann E, Charette J, Stroobandt V. Mass spectrometry. Principles and applications. Johm Wiley \& sons, 1996.

82. Opiteck GJ, Lewis KC, Jorgenson JW, Anderegg RJ. Comprehensive on-line LC/LC/MS of proteins. Anal.Chem. 1997;69:1518-1524. 


\title{
Basic setup for the determination of o-phthaldialdehyde derived amino acids
}

\author{
Published as: \\ 1) H.M.H. van Eijk, M.A.H. van der Heijden, C.L.H. van Berlo and P.B. Soeters. Fully automated liquid-chromatographic \\ determination of amino acids. Clin.Chem. 34/12 (1988) 2510 \\ 2) H.M.H. van Eijk, D.R. Rooyakkers and N.E.P. Deutz. Rapid routine determination of amino acids in plasma by high- \\ performance liquid chromatography with a 2-3 $\mu \mathrm{m}$ Spherisorb ODS II column. J.Chromatogr. B 620 (1993) 143
}

\section{Introduction}

The analysis of free amino acid concentrations in blood (plasma) and tissue specimens is of key importance in metabolic research. Traditionally, these measurements were performed using ion-exchange chromatography combined with ninhydrin detection $(1,2)$. This established and reliable method enables the determination of not only all major plasma and tissue amino and imino acids (proline, hydroxyproline)(3), but also less common amino acids or metabolites such as hydroxylysine, $\gamma$-aminobutyric acid, 3-methylhistidine and glutathione (4).

Unfortunately, this method is not very sensitive, analysis cycle times are long and dedicated chromatographic equipment and expensive reagents are required together with an intensive operator interaction. Especially the low sample throughput severely limits the number and type of experiments which can be performed, creating a growing demand for a faster and more sensitive method.

Two alternatives were considered to replace the ion exchange method: gas chromatography and liquid chromatography. In the mid 1980's, the separation of amino acids by gas chromatography was still troublesome as it was difficult to produce volatile derivatives from the polar amino acids with a constant recovery. Meanwhile, a number of publications already demonstrated the feasibility of a reversed phase high-performance liquid chromatographic separation of several amino acid derivatives (5-20). Furthermore, liquid chromatography was gaining popularity with the introduction of better and more standardized columns and equipment as a result of which we diverted our attention towards liquid chromatography.

In contrast to ion-exchange chromatography, it is difficult to separate amino acids as such by reversed phase liquid chromatography, as this technique is based on differences in (a)polarity. A second complication is that with the exception of the aromatic amino acids, amino acids do not absorb UV-visible light. Therefore, a reaction with a UV-adsorbing or fluorescent probe is required to enable detection, while the same probe can be used to decrease the derivative polarity, thus improving its properties for a reversed phase separation.

As pointed out before, several probes, like fluorescamine, o-phthaldialdehyde, 9-fluorenylchloroformiate, dansyl- and dabsylchlorine, were already available that could achieve this. From these options o-phthaldialdehyde (OPA) was chosen as it reacts within minutes at room temperature. Its highly fluorescent reaction products enable a very low level of detection, while the unreacted reagent does not interfere with the separation as it does not possess any fluorescence by itself. However, there are also some drawbacks. Secondary amino acids do not react and the reagent and its derivatives are not stable. 
This instability prohibits the processing of a batch of samples prior to automatic injection. Instead, optimal reproducibility could only be achieved by reacting each sample by hand, prior to its analysis. Considering that it was our intention to increase sample throughput, it was clear that we had to develop an automated procedure to guarantee an accurate analysis result and a maximal analysis capacity.

A second problem which had to be solved, was that at that point in time, there was no publication available, describing the separation of all major physiological OPA-amino acid derivatives which are of importance to us.

And last, we realized that an increase in analytic capacity would require a proportional increase in the amount of operator time for data processing. Therefore, a personal computer based integration software package was implemented, speeding up processing of the produced data.

These efforts, described in the following papers which are incorporated integrally in their published form, resulted in an increase in analytic capacity and an improvement in sensitivity. This enabled a reduction in sample volume, in term allowing the design of intervention studies in small laboratory animals.

However, the sensitive chemistry of the OPA reaction requires a careful approach to guarantee a successful performance of the analytical methods based on it. Unfortunately, as the scope of an analytical paper is to describe a successful route enabling an accurate determination of the target components, it is impossible to discuss extensively any source of trouble a potential user of the method may run into. An indept discussion of this subject would be beyond the scope of this thesis also. Considering its importance however, a summary of the potentially most dominant sources of problems is incorporated in an addendum at the end of this thesis. 


\title{
Fully Automated Liquid-Chromatographic Determination of Amino Acids
}

\author{
Hans M. H. van Ejjk, Marion A. H. van der Heljden, Charles L. H. van Berlo, and Peter B. Soeters'
}

This inexpensive method for fully automated amino acid analysis combines the advantages of automated precolumn derivatization with o-phthaidialdehyde and favorable analytical conditions to separate and quantify 30 amino acids found in normal plasma. The system can run unattended for almost four days, during which the data are processed automatically by a personal computer and a maximum of 76 samples and 19 standards can be processed (cycle time per analysis: 55 min). Only $1 \mu \mathrm{L}$ of deproteinized plasma is required per analysis. Coefficients of variation for retention times and areas measured for all relevant amino acids are less than $1 \%$ and $3 \%$, respectively. The system described is well suited for quick, sensitive operation in daily practice.

Metabolic or clinical studies requiring multiple analyses of amino acids are generally hindered by the fact that amino acid determinations are relatively expensive and time consuming. Many methods for determining amino acids in biological samples involve precolumn derivatization with 0 phthaldialdehyde (OPA), followed by high-performance liquid chromatography $(1-11)$. None, however, satisfactorily separates as many as 30 amino acids, including all the prominent amino acids in plasma, and has fully automated precolumn derivatization and data analysis. We describe a system that does have these features and can run unattended for $87 \mathrm{~h}$. During this period, 76 samples and 19 standards are processed.

\section{Materials and Methods}

Equipment. Our HPLC system consists of two pumps (both Model 2152), a Model 2152 controller, a Model 2156 solvent conditioner, and a Model 2155 column oven, all from LKB, Woerden, The Netherlands. The separation column is a Bisschoff Spherisorb ODS II column (3- $\mathrm{mm}$ particles), 25 $\mathrm{cm} \times 4.6 \mathrm{~mm}$ (i.d.), equipped with a $10 \mathrm{~mm} \times 4.6 \mathrm{~mm}$ (i.d.) guard column filled with the same packing material (Salm \& Kipp, Breukelen, The Netherlands). For automated precolumn derivatization we use a WISP 712B sample processor (Millipore/Waters, Etten-Leur, The Netherlands), equipped with a cooled sample-storage compartment. To monitor fluorescence we use a fluorescence detector equipped with a xenon lamp and a $12-\mu \mathrm{L}$ flow cell. Measurements are made

University Hospital Maastricht, Department of Surgery, P.O. Box 1918, 6201 BX Maastricht, The Netherlands.

${ }^{1}$ Address correspondence to this author.

Received April 20, 1988; accepted September 1, 1988. at an excitation wavelength of $330 \mathrm{~nm}$ and an emission wavelength of $445 \mathrm{~nm}$.

Data are collected on-line by a Model 763 SB 192 K interface (Nelson Analytical, CLI, Schijndel, The Netherlands) and processed by an Olivetti M24SP personal computer (Woltink, Kerkrade, The Netherlands) utilizing Nelson Analytical software.

Reagents and solvents. We use "ultra-pure" water, processed with a Milli-Q system (Millipore/Waters). All chemicals used are of analytical grade (primarily from Pierce Chemical Co., Oud Beijerland, The Netherlands). Solvents are of chromatographic grade (mostly from Merck, Amsterdam, The Netherlands). The derivatization reagent is prepared by dissolving $12.5 \mathrm{mg}$ of OPA in $0.25 \mathrm{~mL}$ of methanol, then adding $2.25 \mathrm{~mL}$ of petassium borate buffer $(1.0 \mathrm{~mol} / \mathrm{L}$, $\mathrm{pH} 10.4$ ) and $10 \mu \mathrm{L}$ of 3-mercaptopropionic acid. Solvent $\mathrm{A}$ is a $12.5 \mathrm{mmol} / \mathrm{L}$ phosphate buffer, $\mathrm{pH} 7.0$, containing $9 \mathrm{~mL}$ of tetrahydrofuran per liter. Solvent B consists of the phosphate buffer, acetonitrile, and tetrahydrofuran $(53 / 40 / 7$ by vol). Amino acid standards are prepared by dissolving pure amino acids in water to give a final concentration for each of $250 \mu \mathrm{mol} / \mathrm{L}$. These are then calibrated against $(a)$ acidic and neutral amino acid standards and (b) basic amino acid standards by using a Model 4400 amino acid analyzer (LKB) with lithium buffers as specified in the LKB operator's manual (12). These calibrations require a 2.5-h run.

Sample preparation. Heparinized blood samples are immediately centrifuged at $1500 \times g$ in a Sorvall GLC-2 centrifuge for $10 \mathrm{~min}$ at $4^{\circ} \mathrm{C}$. Plasma is deproteinized with sulfosalicyclic acid, $4 \mathrm{mg}$ per $100 \mu \mathrm{L}$ of plasma, and centrifuged for $10 \mathrm{~min}$ at $100000 \times \mathrm{g}$ in an Eppendorf 5414 centrifuge at $4^{\circ} \mathrm{C}$.

To obtain data on "normal" plasma amino acid concentrations in humans, we sampled blood from 30 healthy human volunteers in the postabsorptive (overnight fast) and fed state ( $1 \mathrm{~h}$ after an unspecified lunch). Samples and standards were stored at $-70^{\circ} \mathrm{C}$; before analysis, we diluted them 100-fold.

Chromatographic conditions. During the first $4.6 \mathrm{~min}$ of the run, the sample processor executes the automated precolumn derivatization. First, $5 \mu \mathrm{L}$ of the OPA reagent is injected into its sample loop, where it remains because the flow rate is still zero. One minute later, the sampler injects 5 $\mu \mathrm{L}$ of a sample into the loop, at which point the flow rate is slowly increased to $1.2 \mathrm{~mL} / \mathrm{min}$, thus allowing sample and reagant to $\mathrm{mix}$ and react for $2 \mathrm{~min}$ before the gradient elution starts.

The gradient is shown in Table 1. 
The pressure is $2.2 \mathrm{MPa}$ at the start of the gradient, increases to a maximum of $2.6 \mathrm{MPa}$ during the run, and returns to $2.2 \mathrm{MPa}$ after initial conditions are restored at the end of the analysis. From $t=44$ to $t=55 \mathrm{~min}$, the column is equilibrated. Then, after $55 \mathrm{~min}$, flow is stopped for about 1 min; then the sampler proceeds with the next cycle. The column is placed in an oven set at $22^{\circ} \mathrm{C}$, because some derivatives (e.g., that of histidine) are very temperature sensitive.

Data processing. The analog signal produced by the fluorescence monitor is digitalized and sent to a disk file, from which the software produces a report. The retention times and response factors used for detection and calculation are corrected after every four samples by an external standard method. Results are entered directly into a spreadsheet program, thus simplifying and speeding data management.

\section{Results}

We modified the solvents and gradient used by Godel et al. (1), to separate 30 amino acids, including tryptophan, in a plasma-based standard (Figure 1).

Furthermore, we adjusted the automated precolumn derivatization used by Smith and Panico (2) and Pfeifer et al. (3), combining this with the chromatographic separation already achieved. The combination resulted in an excellent reproducibility of retention times and peak areas for all amino acids measured (Table 2).

The cooled sample-compartment of the autosampler can be loaded with sample trays having 48 or 96 positions. As many as 95 analyses (one position is needed for the OPA reagent) can be done automatically and unattended.

Using the same OPA reagent, we tested sample and reagent stability by processing 80 aliquots of a diluted human plasma, stored in the sample processor for three and a half days. During this period, we did not observe any change in amino acid concentrations measured (Table 2).

We further validated analytical results by measuring amino acid concentrations in plasma of the 30 healthy human volunteers, ages 20 to 57 years (Table 2). The values we obtained correspond well with the literature (I).

We could not detect proline, hydroxyproline, and cysteine with this method, while aspartic acid was co-eluted with the sulfosalicyclic acid used for deproteinization.

Finally, we investigated the fluorescence response for all amino acids measured. For each amino acid, the response was linearly related to concentration from at least 1.25 to 50 pmol per injection.

\section{Diecussion}

We needed a fast, reliable method for determining many plasma amino acids, so we could perform clinical and

\begin{tabular}{cccccr}
\hline \multicolumn{7}{c}{ Table 1. Gradient Conditions } \\
Tme, & $\begin{array}{c}\text { Flow rate, } \\
\text { mL/min }\end{array}$ & \%B & $\begin{array}{c}\text { Time, } \\
\text { min }\end{array}$ & $\begin{array}{c}\text { Flow rate, } \\
\text { mL/min }\end{array}$ & \%B \\
0 & 0 & 0 & 14.0 & 1.20 & 10 \\
2.5 & 0.02 & 0 & 19.0 & 1.20 & 13 \\
2.7 & 0.04 & 0 & 26.0 & 1.20 & 28 \\
3.0 & 0.05 & 0 & 31.0 & 1.20 & 30 \\
3.5 & 0.10 & 0 & 36.0 & 1.20 & 40 \\
4.5 & 0.60 & 0 & 39.0 & 1.20 & 100 \\
4.6 & 1.20 & 0 & 41.0 & 1.20 & 100 \\
8.0 & 1.20 & 6 & 44.0 & 1.20 & 0 \\
10.0 & 1.20 & 8 & 54.0 & 0.60 & 0 \\
13.0 & 1.20 & 8 & 55.0 & 0 & 0 \\
\hline
\end{tabular}

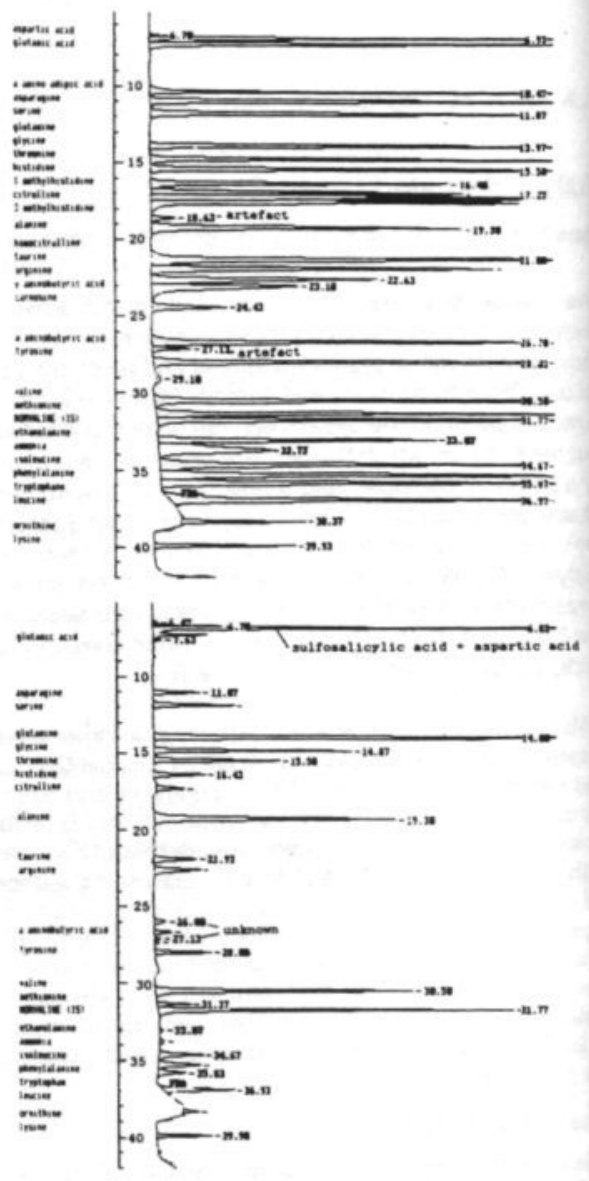

Fig. 1. Separation of amino acids in a plasma-based amino ac standard (top) and in a sample human plasma (bottom)

The standard contains 25 pmol of each amino acid per $5 \mu \mathrm{L}$ injected

metabolic studies (13-15). Many HPLC methods for amin acid measurement involving pre-or post-column derivatiz: tion techniques have been described $(1-11,16-18)$. Frot these, we chose the OPA precolumn derivatization tech nique, because it has several advantages, such as a relative ly simple derivatization procedure and great sensitivity compared with other techniques [9-fluorenylmethoxycar bonyl chloride $(15,16)$; phenylisothiocyanate (17)].

Derivatives formed with the OPA technique are unstabli and the fluorescent responses depend, among other facton on the reaction time with OPA. Consequently, we wantes an automated precolumn derivatization to improve repro ducibility of the method and minimize attention required 0 the operators. The few published automated techniques $(2$ $3,6,11$ ) either gave poor resolution of some importan amino acids or involved long cycle times per analysis.

Therefore, we developed the present system, with whic one sample is processed per $55 \mathrm{~min}$, which can run unat tended for almost four days, which measures 30 amino acid commonly found in plasma, and which requires only $1 \mu \mathrm{L} 0$ deproteinized sample per analysis. 
7. Jones BN, Paabo S, Stein S. Amino acid analysis and enzymatic sequence determination of peptides by an improved o-phthaldialdehyde precolumn labeling procedure. J Liq Chromatogr 1981;4:56586.

8. Hill D, Burnworth L, Skea W, Pfeifer R. Quantitative HPLC analysis of plasma amino acids as ortho-phthaldialdehyde/ethanethiol derivatives. J Liq Chromatogr 1982;5:2369-93.

9. Abecassis J, David-Eteve C, Soun A. The separation of 24 OPAAA of natural origin and quantitative analysis of tyrosine by means of HPLC. J Liq Chromatogr 1985;8:135-53.

10. Lindroth $P$, Mopper $K$. High performance liquid chromatographic determination of subpicomole amounts of amino acids by precolumn fluorescence derivatization with $\sigma$-phthaldialdehyde. Anal Chem 1979;51:1667-74.

11. Fleury MO, Ashley DV. High-performance liquid chromatographic analysis of amino acids in physiological fluids: on line precolumn derivatization with o-phthaldialdehyde. Anal Biochem 1983; 133:330-5.

12. Andrews RP. Operators manual LKB 4400 amino acid analyzer. Cambridge, UK: LKB Biochrom Ltd, 1980.
13. Vente JP, Meyenfeldt MF, Rouflart M, Berlo van CLH, van $\mathrm{HMH}$, Soeters PB. Plasma amino acid profiles in septic : stressed patients [Abstract]. Clin Nutr 1986;5:60.

14. Berlo van CLH, Jonge de HR, Bogaard van den AEJ, Eijk v HMH, Janssen MA, Soeters PB. Gamma-amino butyric acid duction in small and lange intestine of normal and germfree Wis rats: influence of food intake and intestinal flora. Gastroenterolo 1987;93:472-9.

15. Leeuwen van PAM, Berlo van CLH, Soeters PB. New mod action for lactulose. Lancet 1988; $: 55-6$.

16. Einarsson S, Josefsson B, Lagerkvist S. Determination amino acids with 9-fluorenylmethylchloroformate and reven phase high-performance liquid chromatography. J Chromat 1983;282:609-18.

17. Betner I, Foldi P. New automated amino acid analysis HPLC precolumn derivatization with fluorenylmethoxycarbe chloride. Chromatographia 1986;22:381-7.

18. Heinrikson RL, Meredith SC. Amino acid analysis by reven phase high-performance liquid chromatography: precolumn deri tization with phenylisothiocyanate. Anal Biochem 1984;136:65- 


\title{
Short Communication
}

\section{Rapid routine determination of amino acids in plasma by high-performance liquid chromatography with a $2-3 \mu \mathrm{m}$ Spherisorb ODS II column}

\author{
Hans M. H. van Eijk, Dennis R. Rooyakkers and Nicolaas E. P. Deutz* \\ Department of Surgery. Biomedical Center, University of Limburg. P.O. Box 616, 6200 MD Maastricht (Netherlands)
}

(First received May 26th, 1993; revised manuscript received July 9th, 1993)

\section{ABSTRACT}

A rapid fully automated method for the determination of amino acids is described based on high-performance liquid chromatography and pre-column $\sigma$-phthaldialdehyde derivatization. Using a $150 \mathrm{~mm} \times 4.6 \mathrm{~mm}$ I.D. HPLC column filled with a recently introduced 2-3 $\mu \mathrm{m}$ Spherisorb ODS II packing material, 30 physiological amino acids could be determined within 28 min (injection to injection). while 95 samples could be processed unattended within $45 \mathrm{~h}$. For most amino acids, the coefficient of variation (C.V.) for the peak areas measured was below $3 \%$, both in aqueous standards and in plasma. Providing a pre-column change every $200-300$ runs, the separation remained unaltered for about $1500-2000$ runs on a single column.

\section{INTRODUCTION}

Numerous methods have been described for the determination of amino acids using $o$-phthaldialdehyde (OPA) pre-column derivatization and high-performance liquid chromatography (HPLC). However, only a few describe automated systems which can run unattended on a routine basis [1-8]. Although protein hydrolysates could be analyzed in these systems within half an hour [5,8-10], the analysis of plasma samples still required about one hour [4-8].

Recently, a new batch of Spherisorb ODS II was introduced with a particle size between 2 and

\footnotetext{
- Corresponding author.
}

$3 \mu \mathrm{m}$, exhibiting $30-40 \%$ more theoretical plates, compared to the standard 3- $\mu \mathrm{m}$ material. Using this highly efficient packing material, a shorter column was prepared, enabling the development of a 28-min (injection to injection) plasma amino acid analysis without loss in resolution.

\section{EXPERIMENTAL}

\section{Equipment}

The separation column was a custom made Bischoff Spherisorb ODS II column (2-3 $\mu \mathrm{m}$ particles) $150 \mathrm{~mm} \times 4.6 \mathrm{~mm}$ (I.D.), equipped with a $10 \mathrm{~mm} \times 4.0 \mathrm{~mm}$ (I.D.) pre-column, filled with the same packing material (Applikon, Schiedam, the Netherlands). The analytical column was selected by the manufacturer (Bischoff) using the 
criteria that, in the Bischoff test system, employing acetonitrile-water 85:15 (v/v) and a flow-rate of $1.1 \mathrm{ml} / \mathrm{min}$, a minimum of 150000 theoretical plates/m should be measured for a toluene containing Bischoff test mixture, while the backpressure may not exceed 100 bar. In our system, using a column temperature set at $25^{\circ} \mathrm{C}$, this resulted in a back-pressure of $22 \mathrm{MPa}$ at the start and $25 \mathrm{MPa}$ at the end of the gradient.

Our HPLC system consisted of a Model 2248 pump, a Model 2252 controller, a Model 2256 solvent conditioner, a Model 2248-201 low pressure binary mixing panel and a model 2155 column oven, all from Pharmacia (Woerden, the Netherlands). For the automated pre-column derivatization a WISP 715 sample processor (Millipore/ Waters, Etten-Leur, the Netherlands) was used, equipped with a cooled sample storage compartment and a 96 position sample tray. Fluorescence was monitored with a Jasco Model 820FP fluorescence detector (B\&L systems, Zoetermeer, the Netherlands) equipped with a xenon lamp and a $12 \mu \mathrm{l}$ flow-cell. Measurements were made at an excitation wavelength of $335 \mathrm{~nm}$ and an emission wavelength of $440 \mathrm{~nm}$. Data were collected on-line by a model 900 interface (Perkin-Elmer/Nelson, Gouda, the Netherlands) and processed by a Tandon Model MCS 486/50 personal computer (Amsterdam, the Netherlands) running Model 2700 (Turbochrom: version 3.2) software (Perkin-Elmer/Nelson, Gouda, the Netherlands) under Microsoft Windows, version 3.1.

\section{Reagents and solvents}

All solutions were prepared with ultra-pure water, generated by a Super-Q system (Millipore/ Waters). All chemicals used were of analytical grade (Pierce, Oud Beijerland, the Netherlands), solvents of chromatographic grade (Janssen Chimica, Amsterdam, The Netherlands).

The derivatization reagent was prepared by dissolving $15 \mathrm{mg}$ of OPA in $0.25 \mathrm{ml}$ of methanol, adding $2.25 \mathrm{ml}$ of potassium borate buffer (1.0 $\mathrm{mol} / \mathrm{l}, \mathrm{pH} \mathrm{10.4)}$ and $15 \mu \mathrm{l}$ of 3-mercaptopropionic acid (3-MPA). This reagent was placed in a 1.2$\mathrm{ml}$ crimp-cap WISP vial with a self-sealing sil- icone rubber, teflon-coated stopper (Alltech, Bre$\mathrm{da}$, the Netherlands). Solvent A was a 12.5 mmol/l sodium phosphate buffer, $\mathrm{pH} 7.0$, containing $7 \mathrm{ml}$ of tetrahydrofuran (THF) per liter. Solvent B consisted of $12.5 \mathrm{mmol} / \mathrm{l}$ phosphate buffer, acetonitrile and THF, 57:40:3 (v/v).

Amino acid standards were prepared by dissolving pure amino acids in water to a final concentration of $250 \mu \mathrm{mol} / 1 \mathrm{each}$. These were then calibrated against a physiological standard (Sigma/Brunschwig, Amsterdam, the Netherlands), divided into $1-\mathrm{ml}$ portions and stored at $-80^{\circ} \mathrm{C}$.

\section{Sample preparation}

Heparinized blood samples were obtained from unrestrained, conscious female pigs [11] and collected on ice followed by immediate centrifugation at $8500 \mathrm{~g}$ in a Eppendorf model 5413 centrifuge for $10 \mathrm{~min}$ at $4^{\circ} \mathrm{C}$. Next, plasma was deproteinized with 5-sulfosalicylic acid (SSA), 4 $\mathrm{mg} / 100 \mu \mathrm{l}$ plasma, frozen immediately in liquid nitrogen and stored at $-80^{\circ} \mathrm{C}$. Before analysis, samples were thawed at $4^{\circ} \mathrm{C}$, vortex-mixed vigorously and centrifuged as described before. Ten microliters of the clear supernatant were, together with $10 \mu \mathrm{l}$ of a $1000-\mu M$ norvaline solution as internal standard, diluted with $980 \mu \mathrm{l}$ ice-cold water in a $1.2-\mathrm{ml}$ WISP vial.

\section{Automated pre-column derivatization}

Employing the WISP "auto-standards" method, with the OPA-reagent placed at position 1 of the tray, the automated pre-column derivatiza-

TABLE 1

\section{GRADIENT CONDITIONS}

\begin{tabular}{|c|c|c|c|c|c|}
\hline $\begin{array}{l}\text { Time } \\
\text { (min) }\end{array}$ & $\begin{array}{l}\text { Flow-rate } \\
\text { (ml/min) }\end{array}$ & $\begin{array}{l}\text { B } \\
(\%)\end{array}$ & $\begin{array}{l}\text { Time } \\
(\mathrm{min})\end{array}$ & $\begin{array}{l}\text { Flow-rate } \\
(\mathrm{ml} / \mathrm{min})\end{array}$ & $\begin{array}{l}\text { B } \\
(\%)\end{array}$ \\
\hline 0 & 0 & 0 & 15.0 & 1.500 & 30 \\
\hline 2.0 & 0.020 & 0 & 18.0 & 1.500 & 36 \\
\hline 2.5 & 0.050 & 0 & 20.5 & 1.500 & 48 \\
\hline 3.5 & 0.100 & 0 & 22.0 & 1.500 & 100 \\
\hline 3.9 & 0.750 & 0 & 23.0 & 1.500 & 100 \\
\hline 4.0 & 1.500 & 0 & 24.0 & 1.500 & 0 \\
\hline 6.0 & 1.500 & 11 & 27.5 & 0.750 & 0 \\
\hline 8.0 & 1.500 & 15 & 28.0 & 0 & 0 \\
\hline
\end{tabular}




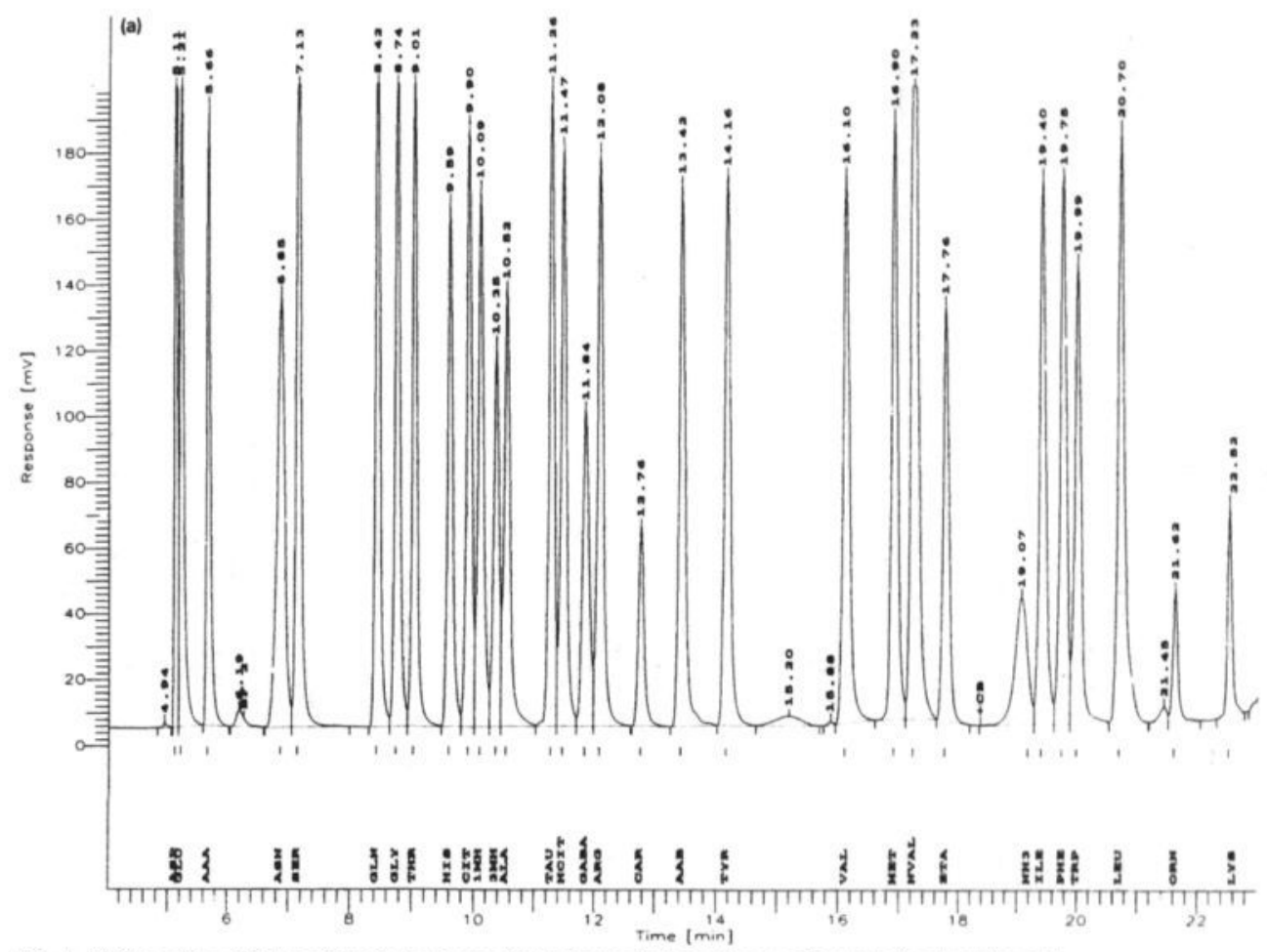

Fig. 1. (a) Separation of 30 physiological amino acids. This standard contains $c a .35$ pmol of each amino acid.

tion was executed during the first $4.0 \mathrm{~min}$ of the run under stop-flow conditions. First, $5 \mu \mathrm{l}$ of the OPA reagent was injected into the sample loop. One min later, $5 \mu \mathrm{l}$ of a sample was injected into the loop, at which point the flow-rate was slowly increased to $1.5 \mathrm{ml} / \mathrm{min}$, thus allowing sample and reagent to mix and react for 2 min before the gradient elution started. Gradient conditions are described in Table I.

\section{RESULTS}

In our system [4], we replaced the analytical column by the new high-efficiency column. Using a steeper gradient (Table I) and by increasing the flow-rate from $1.2 \mathrm{ml} / \mathrm{min}$ to $1.5 \mathrm{ml} / \mathrm{min}$, we were able to separate all 30 amino acids present in our aqueous standard (Fig. 1a) within $28 \mathrm{~min}$. In plasma, aspartic acid coëluted with the sulfosalicylic acid used for the deproteinization (Fig. lb).

The samples were placed in a WISP's 96 position tray and cooled to $7^{\circ} \mathrm{C}$ in the sample compartment of the system. This system processed the tray unattended within $45 \mathrm{~h}$, during which 84 samples and 11 standards were analyzed.

In order to determine the coefficient of variation (C.V.), 40 vials containing the aqueous standard and 20 vials containing a pooled plasma sample were randomly placed in a sample tray. No change in detector response or resolution was found between the first and last chromatograms (not shown). The C.V. for the peak areas measured (and thus the concentration) was below 3\% for most amino acids both for standard and plasma, while the C.V. for most retention times was below $0.5 \%$. The present method was compared 


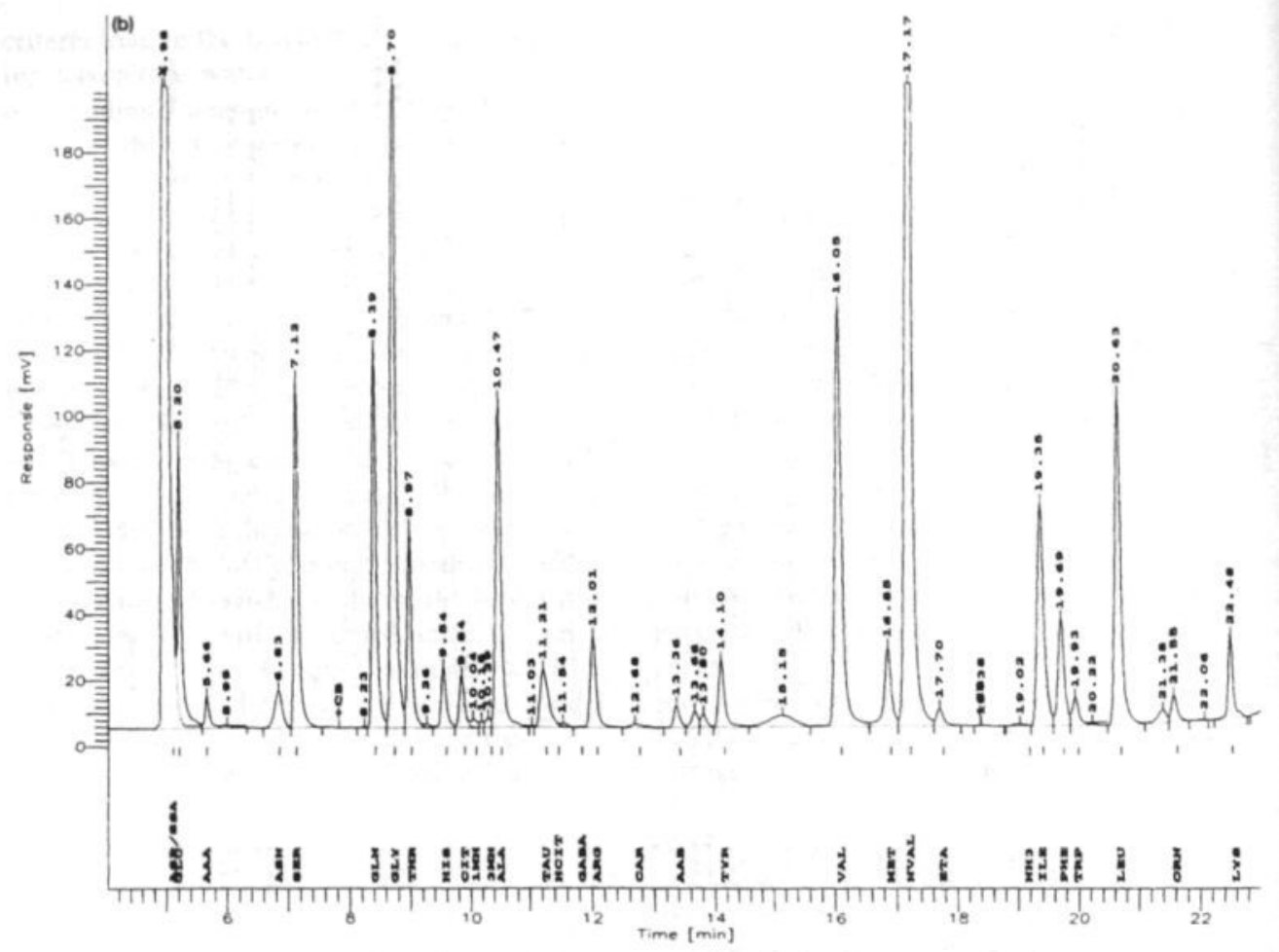

Fig. 1. (b) Free amino acids in arterial plasma obtained trom a conscious unrestrained pig [11].

with our previously described technique [4], by determining the amino acid concentrations in arterial blood of normal unrestrained pigs [11]. The data were in perfect agreement with each other (Table II).

Using a single column, the separation was unaltered during 1500-2000 runs, provided that the pre-column was changed after every 200-300 runs.

\section{DISCUSSION}

Previously, we used a $250 \mathrm{~mm} \times 4.6 \mathrm{~mm}$ I.D. analytical column packed with Spherisorb ODS II $3 \mu \mathrm{m}$ to separate 30 amino acids within $55 \mathrm{~min}$ [4]. The introduction of a newly developed highly efficient Spherisorb ODS II packing material, with a particle size between 2 and $3 \mu$ m enabled the production of columns with $30-40 \%$ more theoretical plates per meter. Using these columns, we expected an equal reduction in column length and thus analysis time to be possible. In order to obtain an optimum resolution we used the method described by Eslami et al. [10] to develop the gradient for this new column and achieved an excellent separation within $35 \mathrm{~min}$. The lower back-pressure of the column enabled us to increase the flow-rate from $1.2 \mathrm{ml} / \mathrm{min}$ to $1.5 \mathrm{ml} / \mathrm{min}$ resulting in a further reduction of the analysis time to $28 \mathrm{~min}$.

For routine applications the separation obtained must also be reproducible. Because it has been described that a rapid decrease in column efficiency may be found when columns with $3 \mu \mathrm{m}$ 
TABLE II

REPRODUCIBILITY AND NORMAL VALUES

Determination of the coefficient of variation (C.V.) for both aqueous standards and plasma. The normal values are arterial amino acid concentrations of conscious unrestrained pigs.

\begin{tabular}{|c|c|c|c|c|c|c|c|c|c|c|c|c|c|}
\hline \multirow[t]{3}{*}{ Amino acid } & \multicolumn{6}{|c|}{ Aqueous standard $(n=40)$} & \multirow{2}{*}{\multicolumn{3}{|c|}{$\frac{\text { Plasma }(n=25)}{\text { Conc }(\mu \mathrm{mol} / \mathrm{l})}$}} & \multirow{2}{*}{\multicolumn{4}{|c|}{$\begin{array}{l}\text { Normal values }(\mu \mathrm{mol} / \mathrm{l}) \\
\text { This study }(n=15) \operatorname{Ref} \text { [ [II] }(n=9)\end{array}$}} \\
\hline & \multicolumn{3}{|c|}{ Retention times (min) } & \multicolumn{3}{|c|}{ Peak area (mV s) } & & & & & & & \\
\hline & Mean & S.D. & C.V. $(\%)$ & Mean & S.D. & C.V. $(\%)$ & Mean & S.D. & C.V. $(\%)$ & Mean & S.E.M: & Mean & S.E.M. \\
\hline Aspartic acid & 5.06 & 0.01 & 0.25 & 631.3 & 21.2 & 3.4 & & & & & & & \\
\hline Glutamic acid & 5.19 & 0.03 & 0.56 & 567.7 & 17.4 & 3.1 & 248 & 13.1 & 5.3 & 238 & 9 & 207 & 22 \\
\hline$\alpha$-Aminoadipic acid & 5.73 & 0.03 & 0.44 & 556.8 & 13.1 & 2.4 & & & & & & & \\
\hline Asparagine & 6.89 & 0.03 & 0.39 & 754.8 & 28.6 & 3.8 & 38 & 1.3 & 3.5 & 38 & 2 & 35 & 2 \\
\hline Serine & 7.07 & 0.04 & 0.61 & 677.6 & 24.9 & 3.7 & 150 & 6.2 & 4.1 & 144 & 4 & 126 & 7 \\
\hline Glutamine & 8.43 & 0.04 & 0.51 & 753.3 & 17.1 & 2.3 & 351 & 19.4 & 5.5 & 365 & 16 & 335 & 18 \\
\hline Glycine & 8.72 & 0.03 & 0.33 & 634.0 & 17.9 & 2.8 & 804 & 15.5 & 1.9 & 685 & 35 & 650 & 57 \\
\hline Threonine & 8.97 & 0.02 & 0.21 & 673.9 & 20.3 & 3.0 & 98 & 2.0 & 2.0 & 97 & 5 & & \\
\hline Histidine & 9.56 & 0.03 & 0.29 & 595.0 & 12.1 & 2.0 & 59 & 1.9 & 3.2 & 53 & 3 & & \\
\hline Citrulline & 9.86 & 0.03 & 0.28 & 708.2 & 15.1 & 2.1 & 62 & 2.2 & 3.7 & 61 & 4 & 67 & 6 \\
\hline 1-Methylhistidine & 10.04 & 0.03 & 0.29 & 624.5 & 16.2 & 2.6 & & & & & & & \\
\hline 3-Methylhistidine & 10.29 & 0.03 & 0.29 & 489.7 & 16.6 & 3.4 & & & & & & & \\
\hline Alanine & 10.46 & 0.03 & 0.28 & 539.7 & 15.2 & 2.8 & 346 & 6.5 & 1.9 & 276 & 18 & 239 & 19 \\
\hline Homocitrulline & 11.28 & 0.03 & 0.29 & 745.2 & 19.8 & 2.7 & & & & & & & \\
\hline Taurine & 11.45 & 0.03 & 0.30 & 723.2 & 16.4 & 2.3 & 52 & 2.4 & 4.7 & 56 & 7 & 55 & 4 \\
\hline GABA & 11.84 & 0.04 & 0.31 & 487.2 & 12.4 & 2.6 & & & & & & & \\
\hline Arginine & 12.15 & 0.03 & 0.27 & 748.2 & 15.1 & 2.0 & 87 & 4.3 & 4.9 & 81 & 5 & 85 & 6 \\
\hline Carnosine & 12.79 & 0.04 & 0.28 & 243.1 & 6.3 & 2.6 & & & & & & & \\
\hline$\alpha$-Aminobutyric acid & 13.42 & 0.04 & 0.32 & 707.6 & 16.3 & 2.3 & 19 & 1.3 & 6.8 & 18 & 2 & & \\
\hline Tyrosine & 14.24 & 0.04 & 0.26 & 720.1 & 11.8 & 1.6 & 36 & 2.0 & 5.6 & 38 & 2 & 33 & 3 \\
\hline Valine & 16.17 & 0.04 & 0.26 & 767.1 & 14.4 & 1.9 & 256 & 6.1 & 2.4 & 241 & 7 & 233 & 9 \\
\hline Methionine & 17.03 & 0.04 & 0.23 & 806.5 & 13.3 & 1.7 & 59 & 5.2 & 8.7 & 51 & 2 & & \\
\hline Norvaline (i.s.) & 17.34 & 0.04 & 0.23 & 1499.0 & 25.9 & 1.7 & 1001 & 17.1 & 1.7 & 993 & 4 & & \\
\hline Ethanolamine & 17.89 & 0.04 & 0.22 & 569.9 & 21.6 & 3.8 & & & & & & & \\
\hline Isoleucine & 19.59 & 0.04 & 0.22 & 799.4 & 13.9 & 1.7 & 127 & 4.5 & 3.5 & 110 & 4 & 115 & 5 \\
\hline Phenylalanine & 19.97 & 0.04 & 0.21 & 780.6 & 13.4 & 1.7 & 65 & 2.7 & 4.1 & 60 & 2 & 52 & 3 \\
\hline Tryptophan & 20.26 & 0.04 & 0.20 & 699.6 & 12.9 & 1.9 & 16 & 1.3 & 8.0 & 16 & 1 & & \\
\hline Leucine & 20.94 & 0.04 & 0.20 & 973.8 & 32.3 & 3.3 & 129 & 4.0 & 3.1 & 120 & 3 & 109 & 7 \\
\hline Ornithine & 21.89 & 0.03 & 0.12 & 192.6 & 5.9 & 3.1 & 65 & 4.4 & 6.7 & 45 & 6 & 55 & 5 \\
\hline Lysine & 22.73 & 0.02 & 0.10 & 251.5 & 7.4 & 2.9 & 118 & 6.2 & 5.3 & 84 & 12 & 87 & 11 \\
\hline
\end{tabular}

- S.E.M. = standard error of the mean. 
Spherisorb ODS II packing material [8] are used, the constancy of the resolution was tested. Indeed, a slight increase in back-pressure and/or the occurrence of "ghost peaks" was found when analyzing plasma samples. However, this problem could be avoided by changing the pre-column regularly.

In conclusion, we achieved an excellent resolution of all major plasma amino acids within 28 $\min$. Combined, with the automated pre-column derivatization, the method has a good reproducibility of both retention times as well as peak areas, making it suitable for routine plasma amino acid analysis.

\section{REFERENCES}

I M. O. Fleury and D. V. Ashley, Anal. Biochen., 133 (1983) 330.

2 C. Cloete, J. Liq. Chromatogr., 7 (1984) 1979.

3 R. J. Smith and K. A. Panico, J. Liq. Chromatogr., 8 (1985) 1783.

4 H. M. H. van Eijk, M. A. H. van der Heijden. C. L. H. van Berlo and P. B. Soeters, Clin. Chem., 34/12 (1988) 2510.

5 P. Fürst, L. Pollack, T. A. Graser and P. Stehie, J. Chromatogr., 499 (1990) 55.

6 J. Schmidt and C. J. McClain, J. Chromatogr., 568 (1991) 207.

7 A. M. Uhe, G. R. Collier, E. A. McLennan, D. J. Tucker and K. O'Dea, J. Chromatogr., 564 (1991) 81.

8 G. Georgi, C. Pietsch and G. Sawatzki, J. Chromatogr., 612 (1993) 35.

9 T. A. Graser, H. G. Godel, S. Albers, P. Foldi and P. Furst, Anal. Biochem., 151 (1985) 142.

10 M. Eslami, J. D. Stuart and K. A. Cohen, J. Chromatogr., 411 (1987) 121.

11 N. E. P. Deutz, P. L. M. Reijven, G. Athanasas and P. B. Soeters, Clin. Sci., 83 (1992) 607. 


\section{Determination of amino acid metabolites}

Published as:

1) H.M.H. van Eijk, N.E.P. Deutz, A.J.M. Wagenmakers and P.B. Soeters. 3-Methylhistidine determined in plasma by high-performance liquid chromatography. Clin. Chem. 36/3 (1990) 556

2) C.L.H. van Berlo, H.R. de Jonge, A.E.J.M. van den Bogaard, H.M.H. van Eijk, M.A. Janssen, M.C.F. Bost and P.B. Soeters. $y$-Amino butyric acid production in small and large intestine of normal and germ-free wistar rats. Gastroenterology 93 (1987) 472

3) H.M.H. van Eijk, D.R. Rooyakkers and N.E.P. Deutz. Automated determination of polyamines by high-performance liquid chromatography with simple sample preparation. J.Chromatogr. A 730 (1996) 115

\section{Introduction}

The increase in analytical capacity, which resulted from our studies described in the previous section, created the possibility to study marker amino acids present in only a few $\mu$ molar concentrations in blood plasma. 3-Methylhistidine (3-MH) was considered an important marker for increased muscle degradation, while $\gamma$ aminobutyric acid (GABA) was associated with the pathogenesis of hepatic encephalopathy (relevant references are incorporated in the resulting papers). Again, the OPA-derivatization technique to be a powerful tool to enable their quantitation and in the third paper the setup for the determination of plasma 3-MH is described. The procedure for the determination of GABA is included in a metabolic paper, which is beyond the scope of this thesis (21).

However, this paper reported changes in the metabolism of GABA, which in term pointed into the direction of polyamine metabolism, requiring an analytical method to quantitate these components. A scan of the literature for a suitable method revealed that in most papers a laborious extraction procedure was prescribed to remove the interfering free amino acids (22-24). The extraction procedure itself was difficult to control, resulting in a variable extraction recovery. We therefore investigated whether polyamines could be resolved from the bulk of amino acids using an on-column separation, thus making the extraction procedure redundant. Unfortunately, the separation of OPA-polyamine derivatives on a conventional reversed phase column required the use of special solvent formulations to neutralize the interaction with residual silanol groups, present in the packing material of the column. These special formulations prohibited the desired separation. With the introduction of a highly purified packing material this interaction was eliminated, thus allowing us to develop the integrated method that was aimed for. The result of this study is presented in the forth paper. 


\section{3-4lethylhistidine Determined in Plasma by "High-Performance" Liquid Chromatography}

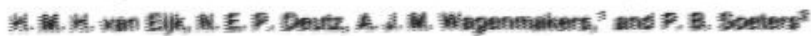

in this fully automated methed for dererraination of 3 -methyl-

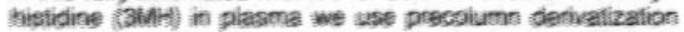
with oghthaldialdehyse and aubseouert separation by HPIC. Jotal anaiysis time is 36 min, and peak areas measursd vary lineaty with the amount of analye injected, over the range of

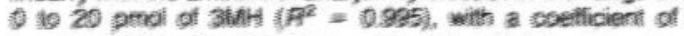
vatiation $(\mathrm{CV})$ of $1.5 \%$. The method is reliatle, accurate. inexpensive, and at least 1000 lald more sersitive than corventional ion-exchange chromatography with ninhydrin. Be-

Departments of Surgery and ${ }^{1}$ Human Biology, University of Limburg, P.O. Box 616, 6200 MD Maastricht, The Netherlands.

${ }^{2}$ Address correspondence to this author, at: University Hospital Maastricht, Department of Surgery, P.O. Box 1918, 6201 BX Maastricht, The Netherlands.

Received October 4, 1989; accepted November 21, 1989.

CLINICAL CHEMISTAY, Vol. 36, No. 3, 1990 cause of its sensitivity, the method pan be used to estimate venous-artetial difterences. in lour humen volumbers the piasme 3Mll concentration varied between 4.97 and 6.08 "umbil L, and the difference between "arterialized" and femoral venous biosd for $3 \mathrm{MH}$ vaned between 0.09 and 0.47 ponoll.

Measureanent of 3-methylhäbtidine (3MF) excreted in 24.h urine has been used as an indicator for the breakdown of myofibrillar protein in muscle, and proved to be useful for long-term studies of muscle protein breakdown $(1-6)$, but not for detecting acute changes. ${ }^{3}$ Measurement of the

\footnotetext{
${ }^{3}$ Nonstandard abbreviations: 3MH, 3-methylhistidine; VA-diff. venous-arterial differences; OPA, $\alpha$-phthaldialdehyde; and THF, tetrahydrofuran.
} 
$3 \mathrm{MH}$ flux across muscle is preferable to measurement of the urinary excretion of $3 \mathrm{MH}$, because small pools of $3 \mathrm{MH}$ in nonskeletal muscle tissues have a sufficiently rapid turnover to contribute to the whole body excretion of $3 \mathrm{MH}$ $(7-10)$. Furthermore, in urine studies, volunteers and patients must be restricted from meat products, which also contain $3 \mathrm{MH}(6,11,12)$.

Although the determination of $3 \mathrm{MH}$ in urine is easy and has been well described (13-17), more difficulties are encountered in assays of $3 \mathrm{MH}$ in plasma. The concentration of $3 \mathrm{MH}$ in plasma is low $(1-20 \mu \mathrm{mol} / \mathrm{L})$ and its peak in a chromatogram may overlap with those for the more concentrated amino acids in plasma. Estimating the $3 \mathrm{MH}$ flux over tissues requires measurement of the $3 \mathrm{MH}$ venousarterial differences (VA-diff). Because these differences are very small, a very sensitive and reproducible assay is necessary. Another important application for such an assay would be the determination of $3 \mathrm{MH}$ in effluent from incubated or perfused muscles (18).

Previously, we described a fully automated, inexpensive, "high-performance" liquid-chromatographic (HPLC) method for determining amino acids in plasma (19). We have adapted this method to completely separate the peak due to $3 \mathrm{MH}$ from those of the more concentrated plasma amino acids. The area of this $3 \mathrm{MH}$ peak could be measured with a $\mathrm{CV}$ of $1.6 \%$ in human plasma, enabling accurate determination of a VA-diff of $0.05 \mu \mathrm{mol} / \mathrm{L}$ or more.

\section{Materials and Methods}

Equipment. The HPLC system consists of two Model 2152 pumps, a Model 2152 controller, a Model 2156 solvent conditioner, and a Model 2155 column oven, all from Pharmacia/LKB, Woerden, The Netherlands. The $25 \mathrm{~cm} \times$ $4.6 \mathrm{~mm}$ (i.d.) separation-column is a Bisschoff Sperisorb ODS II (3- $\mu \mathrm{m}$ particles), equipped with a $10 \mathrm{~mm} \times 4.6 \mathrm{~mm}$ (i.d.) guard column filled with the same packing material (Salm \& Kipp, Breukelen, The Netherlands). For automated precolumn derivatization, we used a WISP 712 B sample processor (Millipore/Waters, Etten Leur, The Netherlands), equipped with a cooled sample compartment. To monitor fluorescence, we used a Model F1000 fluorescence detector equipped with a $12-\mu \mathrm{L}$ flow cell (Merck/Hitachi, Amsterdam, The Netherlands). Measurements were made at an excitation wavelength of $330 \mathrm{~nm}$ and an emission wavelength of $445 \mathrm{~nm}$. Data were collected on-line by a Model 763 SB $192 \mathrm{~K}$ interface (Nelson Analytical, CLI, Schijndel, The Netherlands) and processed by an Olivetti M24SP personal computer with use of Nelson Analytical software.

Reagents and solvents. We use "ultra-pure" water as processed with a Milli Q system (Millipore/Waters). All chemicals were of analytical grade or better (primarily from Pierce Chemical Co., Oud Beijerland, The Netherlands). Solvents were of chromatographic grade (mostly from Merck).

The derivatization reagent is prepared by dissolving 12.5 mg of $o$-phthaldialdehyde (OPA) in $0.25 \mathrm{~mL}$ of methanol, then adding $2.25 \mathrm{~mL}$ of potassium borate buffer $(1.0 \mathrm{~mol} / \mathrm{L}$, $\mathrm{pH} \mathrm{10.4)} \mathrm{and} 10 \mu \mathrm{L}$ of 3-mercaptopropionic acid.

Solvent $\mathrm{A}$ is a $12.5 \mathrm{mmol} / \mathrm{L}$ phosphate buffer, $\mathrm{pH} 7.0$, containing $5 \mathrm{~mL}$ of tetrahydrofuran (THF) per liter. Solvent $B$ consists of the phosphate buffer, acetonitrile, and THF ( $53 / 40 / 7$ by vol).

Calibration standards for $3 \mathrm{MH}$ are prepared by mixing a $25 \mu \mathrm{mol} / \mathrm{L} 3 \mathrm{MH}$ standard with a $250 \mu \mathrm{mol} / \mathrm{L}$ plasma-based standard containing 30 common plasma amino acids.

Sample preparation. Immediately after collection, heparinized blood samples were centrifuged at $1500 \times g$ in a Sorvall GLC-2 centrifuge for $10 \mathrm{~min}$ at $4{ }^{\circ} \mathrm{C}$. The plasma was deproteinized with sulfosalicylic acid, $4 \mathrm{mg}$ per $100 \mu \mathrm{L}$ of plasma, and centrifuged for $10 \mathrm{~min}$ at $10000 \times \mathrm{g}$ in an Eppendorf 5414 centrifuge at $4{ }^{\circ} \mathrm{C}$. Samples and standards were stored at $-70^{\circ} \mathrm{C}$; before analysis, the samples (fourfold) and the standards (12.5-fold) were diluted with water.

Chromatographic conditions. During the first $4.6 \mathrm{~min}$ of the run, the sample processor executes the automated precolumn derivatization. First, $5 \mu \mathrm{L}$ of OPA reagent is injected into the sample loop at zero flow rate. After $1 \mathrm{~min}$, the sampler injects $5 \mu \mathrm{L}$ of sample into the loop; the flow rate is slowly increased from 0 to $1.2 \mathrm{~mL} / \mathrm{min}$, thus allowing sample and reagent to $\mathrm{mix}$ and react for $2 \mathrm{~min}$ before the gradient elution starts. The gradient program is shown in Table 1 . The pressure is $2.2 \mathrm{MPa}$ at the start of the gradient, increases to a maximum of $2.6 \mathrm{MPa}$ during the run, and returns to $2.2 \mathrm{MPa}$ after initial conditions are restored at the end of the analysis. Between 22.0 and 36.0 min after injection, the column is re-equilibrated. After $36.0 \mathrm{~min}$, the flow is stopped for $1 \mathrm{~min}$ to let the pressure drop to zero, after which the sampler proceeds with the next sample.

Data processing. The analog signal produced by the fluorescence monitor is digitalized and sent to a disk file, from which the software produces a report. The retention times and response factors used for the detection and calibration are corrected after every four samples by an external standard method. Results are directly entered into a spreadsheet program, thus simplifying and accelerating data management.

\section{Results}

Compared with the method used previously to establish the amino acid profile in plasma (19), the percentage of THF in solvent $A$ was decreased from $0.9 \%$ to $0.5 \%$ and the gradient program (Table 1) was simplified, resulting in a clearly resolved $3 \mathrm{MH}$ peak in the chromatogram (Figure 1). Quantification of the area of the $3 \mathrm{MH}$ peak was improved by diluting the samples only fourfold instead of the 100 -fold

Table 1. Gradient Conditions

\begin{tabular}{ccc}
$\begin{array}{c}\text { Time since } \\
\text { injection, } \\
\text { min }\end{array}$ & $\begin{array}{c}\text { Flow rate, } \\
\text { mLmin }\end{array}$ & $\begin{array}{c}\text { Percent } \\
\text { solvent B }\end{array}$ \\
0 & 0 & 5 \\
2.5 & 0.02 & 5 \\
2.7 & 0.04 & 5 \\
3.0 & 0.05 & 5 \\
3.5 & 0.10 & 5 \\
4.5 & 0.60 & 5 \\
4.6 & 1.20 & 5 \\
8.0 & 1.20 & 8 \\
9.0 & 1.20 & 8 \\
12.0 & 1.20 & 10 \\
17.0 & 1.20 & 15 \\
22.0 & 1.20 & 100 \\
23.0 & 1.20 & 100 \\
26.0 & 1.20 & 5 \\
35.0 & 0.60 & 5 \\
36.0 & 0 & 5 \\
\hline
\end{tabular}




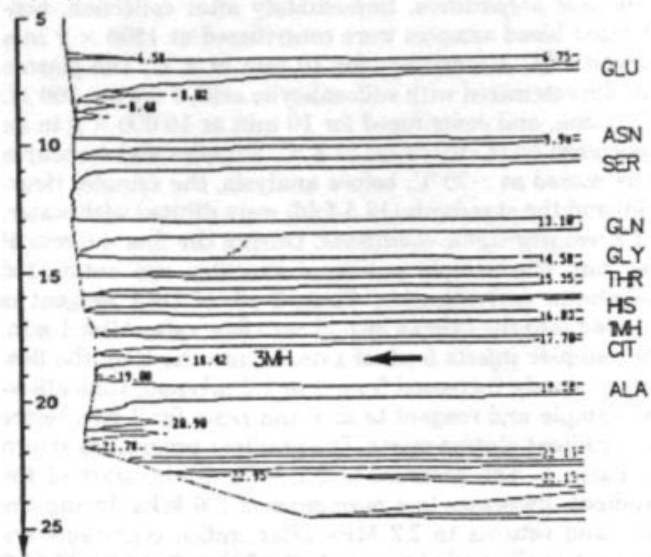

Fig. 1. HPLC detection of 3MH in plasma: chromatogram for $1 \mu \mathrm{L}$ of deproteinized human plasma

dilution used in the previous method (19). Identification of the $3 \mathrm{MH}$ peak was checked by supplementing a plasma sample with $3 \mathrm{MH}$ standard (not shown). Total analysis time, including the automated precolumn derivatization and re-equilibration of the column, was $36 \mathrm{~min}$. The area of the $3 \mathrm{MH}$ peak varied linearly with the amount of analyte injected over the range of 0 to $20 \mathrm{pmol}$ of $3 \mathrm{MH}\left(R^{2}=0.995\right.$, Figure 2). The coefficient of variation (CV) was $1.1 \%$ for a standard containing $50 \mathrm{pmol}$ for each of 30 common plasma amino acids and $5 \mathrm{pmol}$ of $3 \mathrm{MH}$, and $1.6 \%$ for human plasma (10 injections each).

To show that the method can be used to estimate the VA-diff of $3 \mathrm{MH}$, we measured the $3 \mathrm{MH}$ concentrations in the plasma of four human volunteers. After their informed consent had been obtained, arterialized blood was drawn from a heated superficial vein in the back of a hand. This method $(20)$ provides a relatively simple and safe technique for sampling arterial blood. Femoral venous blood was drawn to estimate the VA-diff of $3 \mathrm{MH}$. The plasma $3 \mathrm{MH}$ concentrations varied between 4.97 and $6.08 \mu \mathrm{mol} / \mathrm{L}$ and the VA-diff between 0.09 and $0.47 \mu \mathrm{mol} / \mathrm{L}$.

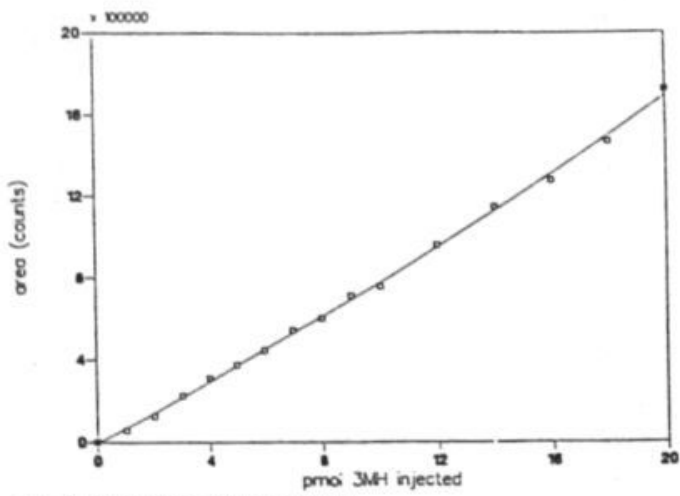

Fig. 2. Calibration curve for $3 \mathrm{MH}$

Peak areas are expressed as arbitrary units (counts) calculated by the chromatographic software

\section{Discussion}

In previous estimations of the 3MH VA-diff $(21,22)$, a traditional ion-exchange amino acid analyzer was used, with postcolumn OPA-derivatization and fluorescence detection. Quantification of the plasma $3 \mathrm{MH}$ concentration was difficult, because a large peak representing histidine eluted very near to the peak for $3 \mathrm{MH}$. However, the selectivity could be improved by the addition of formaldehyde $(10 \mathrm{~mL} / \mathrm{L})$ to the OPA reagent, because this compound markedly decreases the high and otherwise interfering histidine peak in the chromatogram. Despite this complicated sample processing, the reported values for the VA-diff for $3 \mathrm{MH}(21,22)$ agree well with ours.

In the present method, the problem of overlapping peaks has been solved. The $3 \mathrm{MH}$ peak is completely separated from the neighboring peaks representing citrulline, 1 methylhistidine, and alanine. In human plasma, the $3 \mathrm{MH}$ peak area was measured with a CV of $1.6 \%$, enabling accurate determination of a VA-diff of $0.05 \mu \mathrm{mol} / \mathrm{L}$ or more. Compared with other methods (21-24), the present method is more sensitive, is fully automated, and is less expensive.

In conclusion, this automated, inexpensive HPLC method allows the correct measurement of plasma VA-diff in $3 \mathrm{MH}$, thus enabling the estimation of acute changes in myofibrillar protein breakdown.

\section{References}

1. Young VR, Munro HN. $N^{*}$-Methylhistidine (3-methylhistidine) and muscle protein turnover: an overview [Review]. Fed Proc Fed Am Soc Exp Biol 1978; 37:2291-300.

2. Ballard FJ, Tomas FA. 3-Methylhistidine as a measure of skeletal muscle protein breakdown in human subjects: the case for its continued use. Clin Sci 1983;65:209-15.

3. Finley RJ, Inculet RI, Pace R, et al. Major operative trauma increases peripheral amino acid release during the steady-state infusion of total parenteral nutrition in man. Surgery 1986; 99:491-9.

4. Leverve X, Guignier M, Carpentier F, Serre JC, Caravel JP. Effect of parenteral nutrition on muscle amino acid output and 3-methylhistidine excretion in septic patients. Metabolism 1984; 33:471-7.

5. Grecos GP, Abbott WC, Schiller WR, Long CL, Brinkhahn RH, Blakemore WS. The effect of major thermal injury and carbohy. drate-free intake on serum triglycerides, insulin, and 3-methylhistidine excretion. Ann Surg 1984;200:632-7.

6. Sjölin J, Stjernström H, Henneberg L, Hambraeus L, Friman G. Evaluation of urinary 3-methylhistidine excretion in infection by measurements of 1-methylhistidine and the creatinine ratios. Am J Clin Nutr 1989;49:62-70.

7. Marchesini G, Forlani G, Zoli M, Vannini P, Pisi E. Muscle protein breakdown in uncontrolled diabetes as assessed by urinary 3-methylhistidine excretion. Diabetologia 1982;23:456-8.

8. Rennie MJ, Willward DJ. 3-Methylhistidine excretion and the urinary 3-methylhistidine/creatinine ratio are poor indicators of skeletal muscle protein breakdown. Clin Sci 1983;65:217-25.

9. Afting EG, Bernhardt W, Janzen RWC, Rōthig HJ. Quantitative importance of non-skeletal-muscle $N^{\top}$-methylhistidine and creatinine in human urine. Biochem J 1981;200:449-52.

10. Wassner SJ, Li JB. $N^{*}$-Methylhistidine release: contributions of rat skeletal muscle, GI tract, and skin. Am J Physiol 1982;243:E293-7.

11. Rangeley WRD, Lawrie RA. Methylamino acids as indices in meat products. I. The development and validity of an analytical procedure. J Food Technol 1976;11:143-59.

12. Elia M, Carter A, Bacon S, Smith R. The effect of 3-methylhistidine in food on its urinary excretion in man. Clin Sci 1980;59:509-11.

13. Wassner SJ, Schlitzer JL, Li JB. A rapid, sensitive method for the determination of 3-methylhistidine levels in urine and plasma 
using high-pressure liquid chromatography. Anal Biochem 1980; 104:284-9.

14. Neuhauuser M, Fürst $P$. An automatic method for determination of urinary 3-methylhistidine: normal values. Anal Biochem 1979;92:294-304.

15. Turnell DC, Cooper DH. Rapid assay for amino acids in serum or urine by pre-column derivatization and reversed-phase liquid chromatography. Clin Chem 1982;28:527-31.

16. Godel H, Graser T, Földi P, Pfaender P, Fürst P. Measurement of free amino acids in human biological fluids by high-performance liquid chromatography. J Chromatogr 1984;297:49-61.

17. Vielma H, Mendez J, Druckenmiller M, Lukaski H. A practi$\mathrm{cal}$ and reliable method for determination of urinary 3-methylhistidine. J Biochem Biophys Methods 1981;5:75-82.

18. Goodman MN. Differential effects of acute changes in cell $\mathrm{Ca}^{2+}$ concentration on myofibrillar and non-myofibrillar protein breakdown in the rat extensor digitorum longus muscle in vitro. Assessment by production of tyrosine and $N^{\top}$-methylhistidine. Biochem J 1987;241:121-7.

19. Van Eijk HMH, Van der Heijden MAH, Van Berlo CLH,
Soeters PB. Fully automated liquid-chromatographic determination of amino acids. Clin Chem 1988;34:2510-3.

20. Brooks DC, Black PR, Arcangeli MA, Aoki TT, Wilmore DW. The heated dorsal hand vein: an alternative arterial sampling site. J Parenteral Enteral Nutr 1989:13+402-5.

21. Lundholm K, Bennegàrd K. Edèn E, Svaninger G, Emery PW, Rennie MJ. Efflux of 3-methylhistidine from the leg in cancer patients who experience weight loss. Cancer Res 1982:42:4807-11. 22. Emery PW, Rennie MJ. Elimination by formaldehyde of interference with 3-methylhistidine determination: application of the method to the study of muscle protein degradation. Anal Biochem 1982;126:62-73.

23. Larsen TW, Thornton RF. Analysis of the amino acid 3 . methylhistidine by gas-liquid chromatography. Anal Biochem 1980;109:137-41.

24. Hancock WS, Harding DRK. Rapid analysis of 3-methylhistidine in urine, plasma, muscle and amniotic fluid with a single high-performance liquid chromatographic system but with different ion-pairing reagents. J Chromatogr 1982;228:273-8. 


\title{
Automated determination of polyamines by high-performance liquid chromatography with simple sample preparation
}

\author{
Hans M.H. van Eijk, Dennis R. Rooyakkers, Nicolaas E.P. Deutz* \\ Department of Surgery, Biomedical Center, University of Limburg, P.O. Box 616, NL-6200 MD Maastricht. Netherlands
}

\begin{abstract}
Recently, a new fully endcapped reversed-phase packing material, Inertsil, was introduced, especially suitable for the determination of basic compounds. We used this packing material to separate $o$-phthaldialdehyde (OPA) derivatives of amino acid derivatives completely from the OPA derivatives of spermine (SPM), spermidine (SPD), putrescine (PUT) and cadaverine (CAD). The obtained separation made the commonly used off-line extraction procedure redundant and thus an on-line sample clean-up was introduced. This enabled automation of the procedure resulting in a better reproducibility and a more efficient use of equipment. Furthermore, no studies are required to determine the extraction recovery.

The present method has a cycle time of $30 \mathrm{~min}$. A linear response for each polyamine was found up to $250 \mathrm{pmol}$, with an $R^{2}$ ranging from 0.9981 (SPM) to 0.9998 (CAD). The limit of detection, calculated at a signal-to-noise ratio of 3, was 0.1 pmol, corresponding to a plasma concentration of $0.1 \mu \mathrm{mol} / \mathrm{l}$. The coefficient of variation (C.V.) for the peak area was below $3 \%$ and for retention times below $0.5 \%(n=15)$.

In order to evaluate the applicability of the method, three different types of sample were chromatographed, e.g. urine (obtained from healthy human volunteers), pig plasma and sulfosalicylic acid homogenates of pig intestine biopsies. Tissue homogenates and urine-specimen could easily be quantitated, while plasma concentrations were just above the limit of detection, resulting in a plasma C.V. ranging from $4.8 \%$ (SPM) to $13.6 \%$ (SPD) and a tissue C.V. ranging from $2.1 \%$ (SPM) to $8.5 \%$ (CAD), The urinary C.V.s were not determined.
\end{abstract}

In conclusion, the present method provides an easy way to measure polyamine concentrations for most applications.

Keywords: Automation: Polyamines; Amino acids

\section{Introduction}

Polyamines are essential for normal growth and cellular differentiation. Several methods have been described for their determination [1-12], but most of these methods require an extraction procedure to remove interfering amino acid derivatives or reagent excess $[1-3,5,6,8-10,12]$. These features disable

\footnotetext{
"Corresponding author.
}

automatization of the derivatization procedure and decrease reproducibility. Other methods employ ionexchange chromatography and post-column derivatization, but they lack sensitivity $[4,7,11]$.

Using reversed-phase chromatography, the complete separation of $o$-phthaldialdehyde (OPA)-polyamine derivatives from OPA-amino acid derivatives has not been accomplished before. The interaction of OPA-polyamine derivatives with residuing free silanol groups of most common reversed-phase packing materials, resulting in broad tailing peaks, prohibited this. 
Recently a new ultra-pure fully endcapped packing material, Inertsil, was introduced. This material has a high $\mathrm{pH}$ resistance, due to minimal silanol and trace metal interactions and is therefore ideal for the analysis of basic compounds. Using this new packing material, the complete separation of OPA-polyamine derivatives was obtained from the interfering OPAamino acid derivatives of a physiological standard. Although in urine and plasma some interference of other unknown components still remains, the resulting separation is sufficient even in these complex samples. As a result, automatization of the derivatization procedure could be enabled, thereby decreasing the work load for analytical staff, increasing the reproducibility and resulting in a more effective use of equipment.

\section{Experimental}

\subsection{Equipment}

In the first set of experiments, a $250 \times 3.2 \mathrm{~mm}$ I.D. Inertsil 5- $\mu \mathrm{m}$ column (Phenomenex, Bester, Amstelveen, Netherlands) was used. The results of these experiments indicated that a shorter column with a larger I.D. would be more suitable. Therefore, the column was replaced later by a $200 \times 4.6 \mathrm{~mm}$ I.D. column, equipped with a $10 \times 4.6 \mathrm{~mm}$ I.D. pre-column. These other dimensions required delivery by another supplier (Applikon, Schiedam, Netherlands). The column was placed in a thermostatted Spark Mistral oven (Emmen, Netherlands) set at $10^{\circ} \mathrm{C}$.

Our HPLC system consisted of a Model 2248 pump, a Model 2252 controller, a Model 2256 solvent conditioner, a Model 2248-201 low-pressure binary mixing panel (all from Pharmacia, Woerden, Netherlands). The automated pre-column derivatization was executed using a WISP 715 sample processor (Waters, Etten-Leur, Netherlands), equipped with a cooled sample storage compartment and a 48-position sample tray. Fluorescence was-monitored using a Jasco Model 820FP fluorescence detector (B\&L systems, Zoetermeer, Netherlands) equipped with a xenon lamp and a 12- $\mu 1$ flow-cell. Measurements were made at an excitation wavelength of 330 $\mathrm{nm}$ and an emission wavelength of $445 \mathrm{~nm}$. Data were collected on-line by a Model 900 interface (Perkin Elmer/Nelson, Gouda, Netherlands) and processed by a Tandon Model MCS $486 / 50$ personal computer (Amsterdam, Netherlands) running Model 2700 (Turbochrom: version 3.2) software (Perkin Elmer/Nelson) under Microsoft Windows, version 3.1 .

\subsection{Reagents and solvents}

All solutions were prepared with ultra-pure water, generated by a Super-Q system (Millipore, EttenLeur, Netherlands). All chemicals used were of analytical grade (Pierce, Oud Beijerland, Netherlands), solvents of chromatographic grade (Janssen Chimica, Amsterdam, Netherlands).

The $o$-phthaldialdehyde (OPA) reagent was prepared by dissolving $15 \mathrm{mg}$ OPA in $0.25 \mathrm{ml}$ of methanol, adding $2.25 \mathrm{ml}$ of potassium borate buffer (Fluoraldehyde reagent solution: $1.0 \mathrm{~mol} / 1, \mathrm{pH} 10.4$ : Pierce, Brunschwig. Amsterdam, Netherlands) and $15 \mu$ l of 3-mercaptopropionic acid (3-MPA). This reagent was placed in a $4.0-\mathrm{ml}$ WISP vial with a self-sealing silicone rubber, Teflon-coated stopper (Waters).

Solvent A was a $125 \mathrm{mmol} / 1$ sodium citrate buffer, $\mathrm{pH} 6.50$, containing $50 \mathrm{ml}$ of tetrahydrofuran (THF) per litre. Solvent B consisted of the citrate buffer, acetonitrile and THF (45:40:15, v/v/v).

Polyamine standards were prepared by dissolving pure chemicals (Sigma, Amsterdam, Netherlands) in water to a final concentration of $250 \mu \mathrm{mol} / 1$ each. These standards were divided into $1-\mathrm{ml}$ portions and stored at $-80^{\circ} \mathrm{C}$.

\subsection{Sample preparation}

\section{Plasma}

Heparinized pig blood samples were obtained from pre-implanted catheters and collected on ice. followed by immediate centrifugation $\left(5 \mathrm{~min}\right.$ at $4^{\circ} \mathrm{C}$ ). The obtained plasma was deproteinized with solid 5-sulfosalicylic acid (SSA) $(4 \mathrm{mg} / 100 \mu \mathrm{l})$ plasma, frozen immediately in liquid nitrogen and stored at $-80^{\circ} \mathrm{C}$. Before analysis, samples were thawed at $4^{\circ} \mathrm{C}$, vortex-mixed vigorously and centrifuged at 
$11000 \mathrm{~g}$ in a Hereaus Model Biofuge for $10 \mathrm{~min}$ at $4^{\circ} \mathrm{C}$. From the clear supernatant $40 \mu \mathrm{l}$ was mixed with $80 \mu \mathrm{l}$ water and $80 \mu \mathrm{l}$ Fluoraldehyde reagent buffer (end concentrations: $0.5 \mathrm{~mol} / \mathrm{l}$ potassium borate, $\mathrm{pH} \mathrm{10.4)}$ and stored in the cooled $\left(7^{\circ} \mathrm{C}\right)$ sample compartment of the autosampler until analysis.

\section{Tissue}

Pig jejunal mucosa samples were obtained by biopsy and immediately frozen in liquid nitrogen and stored at $-80^{\circ} \mathrm{C}$. Before analysis, they were transferred to a preweighed 1.5-ml eppendorf vial, containing $0.1 \mathrm{~g}$ of glass beads (1.0-mm diameter) and $100 \mu \mathrm{l}$ of an ice-cold $5 \%$ sulfosalicylic acid (SSA) solution. The vials were weighed again, whereafter the tissue was homogenized in a mini-bead beater (Cole Parmer/Applikon, Schiedam, Netherlands), set at high speed for $1 \mathrm{~min}$. Next, the vials were centrifuged and processed as described before.

\section{Urine}

After an overnight fast, urine was collected from healthy male human volunteers. Aliquots were centrifuged $5 \mathrm{~min}$ at $4^{\circ} \mathrm{C}$ and processed in the same way as plasma.

\subsection{Automated pre-column derivatization and gradient elution}

This automated pre-column derivatization procedure has been extensively tested for amino acid analysis [13,14]. In short, employing the WISP 715 'auto-standards' method with the OPA-reagent placed at position 1 of the tray, the automated precolumn derivatization was executed during the first $4.5 \mathrm{~min}$ of the run. First, $5 \mu \mathrm{l}$ of the OPA reagent is injected at zero flow, thus the reagent remains in the sample loop. One minute later (the minimum delay time of the sampler) $5 \mu \mathrm{l}$ of a sample is injected also into the loop. In the next $2.5 \mathrm{~min}$ the pump is activated and the flow is slowly increased to 0.1 $\mathrm{ml} / \mathrm{min}$, thus allowing sample and reagent to $\mathrm{mix}$ and react in the sample loop and the supplying capillaries of the column, after which the gradient elution starts. In the first $10 \mathrm{~min}$ of the gradient all
Tabie 1

Gradient conditions

\begin{tabular}{llcr}
\hline Time (min) & Flow-rate $(\mathrm{ml} / \mathrm{min})$ & \% A & \% B \\
\hline 0 & 0 & 65 & 35 \\
2.5 & 0.020 & 65 & 35 \\
2.7 & 0.040 & 65 & 35 \\
3.5 & 0.100 & 65 & 35 \\
4.5 & 0.600 & 65 & 35 \\
4.6 & 1.200 & 65 & 35 \\
10.0 & 1.200 & 45 & 55 \\
13.0 & 1.200 & 43 & 57 \\
18.0 & 1.200 & 35 & 65 \\
21.0 & 1.200 & 0 & 100 \\
22.0 & 1.200 & 0 & 100 \\
24.0 & 1.200 & 65 & 35 \\
30.0 & 0.600 & 65 & 35 \\
31.0 & 0.000 & 65 & 35 \\
\hline
\end{tabular}

amino acid adducts elute. In the next $10 \mathrm{~min}$ polyamine derivatives elute, after which regeneration and equilibration of the column takes place. Gradient profile is described in Table 1.

\section{Results}

Pilot experiments had revealed that the last-eluting amino acid of a physiological standard elutes before the first polyamine OPA derivative, if the solvent $\mathrm{pH}$ is set above $\mathrm{pH}$ 6. To study the influence of the solvent buffer molarity under these circumstances, a citric acid buffer system, set to $\mathrm{pH} 6.4$ for maximum buffer capacity, was used in an isocratic solvent system with $35 \%$ acetonitrile on a $250 \times 3.2 \mathrm{~mm}$ I.D. Inertsil 5- $\mu \mathrm{m}$ ODS 2 column (Phenomenex). Within the range of 25 to $200 \mathrm{mmol} / 1$, the best separation was found at $125 \mathrm{mmol} / \mathrm{l}$.

Next, the influence of the solvent $\mathrm{pH}$ on the separation was studied in the range between 6 and 8 , using a standard mixture containing all major physiological amino acids (Pierce) and the polyamines spermine (SPM), spermidine (SPD), putrescine (PUT) and cadaverine (CAD). At pH 6, the separation between the first-eluting polyamine (SPM) and the last-eluting amino acid, lysine (LYS), was not complete. Above pH 7, an unknown component (probably an OPA degradation product) coeluted 


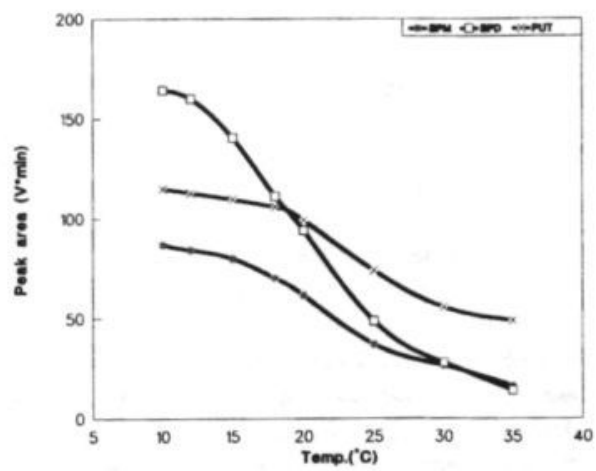

Fig. 1. Influence of the temperature on the on-column degradation of OPA-polyamine derivatives.

with PUT. Therefore, pH 6.5 was considered optimal.

Although the separation was now optimal, the fluorescence response of especially the SPD derivative was low and variable, compared to amino acid derivatives. As it is known that OPA-polyamine derivatives degrade rapidly after their formation $[1,3]$, the influence of the temperature on the oncolumn degradation rate was studied between $10^{\circ} \mathrm{C}$ and $35^{\circ} \mathrm{C}$. With a decreasing column temperature, the fluorescence response increased, reaching a maximum at $10^{\circ} \mathrm{C}$ (Fig. 1). At this temperature, the column back-pressure was too high (30 MPa). For routine measurements a decrease in flow-rate or column length was thus required. As the obtained baseline separation in the standard allowed a decrease in column length, from this point the $200 \times 4.6$ $\mathrm{mm}$ column (Bischoff, Applikon, Schiedam, Netherlands) was applied for all further experiments. The decrease in back-pressure allowed application of a $10 \times 4.6 \mathrm{~mm}$ pre-column, filled with the same packing material (resulting back-pressure $25 \mathrm{MPa}$ ), thus ensuring a longer column life time. For this column, an optimal gradient profile was developed (Table 1), resulting in an adequate separation (Fig. 2A) from all amino acids present in a physiological standard.

The linearity of the method was checked by injecting 5- $\mu \mathrm{l}$ aliquots of polyamine standards with increasing concentrations. A linear response was

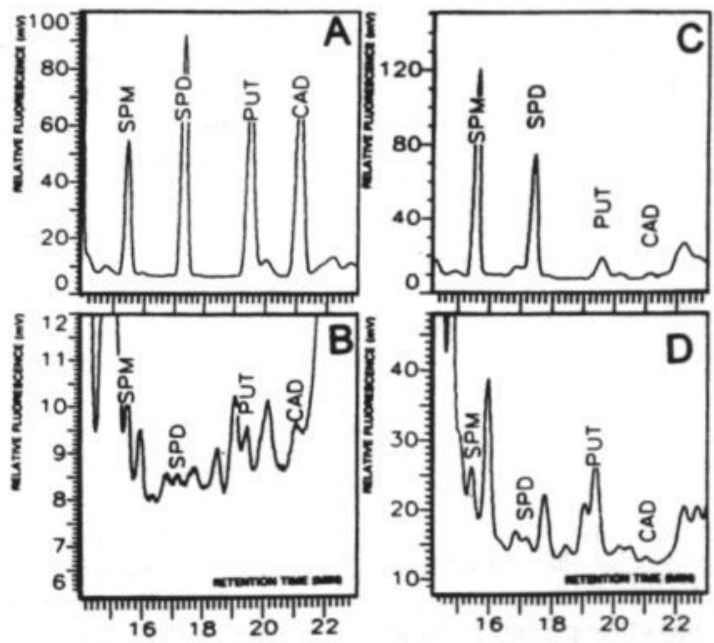

Fig. 2. Separation of polyamines in different sample matrices. Chromatographic conditions are discussed in the text. (A) Separation of a polyamine standard showing no interference by the presence of a physiological amino acid standard ( 25 pmol injected into each component). (B) Pig plasma ( $1 \mu 1$ pure plasma injected). (C) Pig intestine biopsy homogenate (sample amount equivalent to $0.5 \mathrm{mg}$ wet weight). (D) Human urine ( $1 \mu \mathrm{l}$ pure urine injected). 
Table 2

Reproducibility of the method

\begin{tabular}{|c|c|c|c|c|c|c|c|c|}
\hline & \multicolumn{2}{|c|}{$\begin{array}{l}\text { Standard } \\
(n=15, \mu \mathrm{mol} / 1)\end{array}$} & \multicolumn{2}{|c|}{$\begin{array}{l}\text { Pig mucosa homogenate } \\
\text { ( } n=10, \mu \mathrm{mol} / \mathrm{kg} \\
\text { wet weight) }\end{array}$} & \multicolumn{2}{|c|}{$\begin{array}{l}\text { Pig plasma } \\
(n=10 . \mu \mathrm{mol} / 1)\end{array}$} & \multicolumn{2}{|c|}{$\begin{array}{l}\text { Human serum [2] } \\
(n=30, \mu \mathrm{mol} / 1)\end{array}$} \\
\hline & Mean $\pm S . D$. & C.V. (\%) & Mean $\pm S . D$. & C.V. $(\%)$ & Mean $\pm S . D$. & C.V. (\%) & Mean $\pm S . D$. & C.V.(\%) \\
\hline SPM & $125 \pm 3.5$ & 2.8 & $2140 \pm 45$ & 2.1 & $0.56 \pm 0.03$ & 4.8 & $0.18 \pm 0.05$ & 28.6 \\
\hline SPD & $125 \pm 3.3$ & 2.6 & $1210 \pm 43$ & 3.6 & $0.15 \pm 0.02$ & 13.6 & $0.29 \pm 0.06$ & 21.0 \\
\hline PUT & $125 \pm 2.6$ & 2.1 & $360 \pm 18$ & 5.2 & $0.34 \pm 0.04$ & 11.8 & $0.49 \pm 0.13$ & 26.6 \\
\hline CAD & $125 \pm 4.7$ & 3.7 & $40 \pm 5$ & 8.5 & $0.26 \pm 0.03$ & 12.1 & $0.05 \pm 0.02$ & 38.5 \\
\hline
\end{tabular}

found up to 250 pmol per injection, with a $R^{2}$ ranging from 0.9981 (SPM) to 0.9998 (CAD). The limit of detection, calculated at a signal-to-noise ratio of 3 , was 0.1 pmol. Considering a five-fold dilution factor for plasma (see Section 2.3) and an injection volume of $5 \mu \mathrm{l}$, this limit corresponds to a plasma concentration of $0.1 \mu \mathrm{mol} / 1$.

The applicability of the method was evaluated by chromatographing three different types of sample. pig plasma and homogenates of pig intestine biopsies (both obtained from conscious unrestrained pigs recovering from a partial enterectomy or SHAM operation) and human urine (obtained from healthy human volunteers) (Fig. 2B, C, D). To exclude inter-experiment variations all samples were pooled from ten specimen each. An adequate separation and sufficient sensitivity was found to measure polyamine concentrations in all three matrices (Fig. 2).

The coefficient of variation (C.V.) was determined by injecting standards $(n=15)$ and pooled samples $(n=10)$ (Table 2). The variation in retention time was below $0.5 \%$ (not shown). For standards, the peak-area C.V. ranged from 2.1 to $3.7 \%$, in tissue, it ranged from 2.1 to $8.5 \%$ and in plasma, the C.V. ranged from 4.8 to $13.6 \%$. For urine, the C.V. was not determined.

\section{Discussion}

The liquid chromatographic separation of basic compounds and thus of polyamines has always been difficult. This was mainly due to their interaction with residuing silanol groups of the packing material, resulting in broad tailing peaks. To solve this problem, special solvent systems have been used, containing high salt concentrations and/or amines and low $\mathrm{pH}$ values $[1,9,11]$. These systems, however, do not allow the on-line separation of OPA polyamine derivatives from OPA amino acids. Therefore, it has become common practice to extract the interfering amino acid derivatives before injecting the sample [1-4]. Not only does this make the method more laborious, it also introduces two problems.

The recovery of the extraction procedure has to be established and monitored constantly by the addition of an internal standard to the samples.

The use of the OPA label in this application introduces another problem. It is known that OPApolyamine derivatives degrade quickly after their formation [1,3]. Stabilization of the formed derivatives was only partially successful, resulting in recoveries ranging from $31 \%$ to $93 \%$ after a $30 \mathrm{~min}$ delay time, as compared to immediate injection [3]. Direct injection after derivatization was impossible to automate as the reaction had to be proceeded by the extraction procedure. Thus, the coefficients of variations resulting from the whole process were relatively large (plasma C.V. ranged from $21 \%$ to $38.5 \%)$ [2].

The recent introduction of a new generation of ultra-pure silica, has enabled the production of reversed-phase packing materials, which allow the application of a much higher solvent $\mathrm{pH}$ (without degradation) and which exhibit minimal silanol interactions. These new features enabled the complete on-column separation of OPA amino acid derivatives from those of polyamines. As a result, the extraction procedure was no longer required, enabling the utilization of the proven automated precolumn derivatization procedure developed for amino acid measurements [13,14]. Despite the fact that samples now were injected immediately, the fluorescence response of especially the SPD deriva- 
tive was low and variable. We suspected this to be caused by on-column degradation, and therefore attempted to increase derivative stability during the run, by decreasing the column temperature. This resulted in a large increase of the fluorescence response, reaching a maximum (3-4 fold) at about $10^{\circ} \mathrm{C}$ (Fig. 1) and a better reproducibility (Table 2).

The applicability of the resulting method was investigated, using three different types of sample. Plasma polyamine concentrations are low (Fig. 2B), almost reaching the limit of detection, as a result of which the C.V.s are rather large (Table 2). Homogenates from pig intestine biopsies showed a high concentration for SPM and SPD and a much lower concentration of PUT and CAD (Fig. 2C, Table 2). Urinary concentrations are sufficiently high, ensuring that there are no sensitivity problems, but the complexity of the matrix introduces a number of unknown peaks near the polyamine peaks, complicating the interpretation of the chromatogram (Fig. 2D). However, the separation is still adequate to allow a correct measurement.

The limit of detection of our method $(0.1 \mathrm{pmol})$ and its C.V.-values (Table 2) are better as is described for most other OPA-applications [1-4]. Comparing our concentrations with literature values is difficult, as we study polyamine metabolism in pigs. while most references describe only human data. Nevertheless, the pig plasma polyamine concentrations we found, are in the same order of magnitude as reported human concentrations (Table 2).

The better chromatography shown in literature methods, results from the applied extraction procedures, removing all interferences and producing a more concentrated sample. However, it must be considered that, in contrast to the present application, these methods also require validation of the extraction recovery and a correction for the rapid degradation of formed OPA derivatives.

In conclusion, the present method enables an easy and sensitive determination of polyamines in different types of sample, with minimal operator interference.

\section{References}

[1] R.L. Heideman, K.B. Fickling and L.J. Walker, Clin. Chem., $30 / 7$ (1984) 1243.

[2] C. Löser, U. Wunderlich and U.R. Fölsch, J. Chromatogr., 430 (1988) 249.

[3] T. Skaaden and T. Greibrokk. J. Chromatogr., 247 (1982) 111.

[4] M. Jeevanandam, N.J. Holaday and M.R. Ali. Metabolism. 41 (1992) 1204.

[5] R.F. Minchin and G.R. Hanau, J. Liq. Chromatogr., 7(13) (1984) 2605.

[6] J. Bontemps, J. Laschet and G. Dandrifosse, J. Chromatogr.. 311 (1984) 59.

[7] R.B.H. Wills, J. Silalahi and M. Wootton, J. Liq. Chromatogr.. 10 (14) (1987) 3183.

[8] R.C. Simpson, H.Y. Mohammed and H. Veening. J. Liq. Chromatogr., 5(2) (1982) 245.

[9] H. Ohta, Y. Takeda, K.I. Yoza and Y. Nogata, J. Chromatogr.. 628 (1993) 199.

[10] G. Taibi and M.R. Schiavo, J. Chromatogr., 614 (1993) 153.

[II] R.S. Gilber, G.G. Gonzalez, L. Hawel III and C.V. Byrus, Anal. Biochem., 199 (1991) 86.

[12] J. Kirschbaum, B. Luckas and W.-D. Beinert, J. Chromatogr. A. 661 (1994) 193.

[13] H.M.H. van Eijk, M.A.H. van der Heijden, C.L.H. van Berio and P.B. Soeters, Clin. Chem., 34/12 (1988) 2510.

[14] H.M.H. van Eijk. D.R. Rooijakkers and N.E.P. Deutz, J. Chromatogr., 620 (1993) 143. 


\section{Sample preparation and interpretation}

Published as:

1) H.M.H. van Eijk, C.H.C. DeJong. N.E.P. Deutz and P.B. Soeters. Influence of storage conditions on normal plasma amino acid concentrations. Clin. Nutr. 13 (1994) 374

2) H.M.H. van Eijk, M.A.H. van der Heijden, C.L.H. van Berlo and P.B. Soeters. Fully automated liquid-chromatographic determination of amino acids. Clin.Chem. $34 / 12$ (1988) 2510

3) J.P. Vente, M.F. von Meyenfeldt, H.M.H. van Eijk, C.H.L. van Berlo, D.J. Gouma, C.J. van der Linden and P.B. Soeters. Plasma amino acid profiles in sepsis and stress. Ann.Surg. 209 (1989) 57

4) J.P. Vente, M.F. von Meyenfeldt, H.M.H. van Eijk, C.H.L. van Berlo, D.J. Gouma, C.J. van der Linden and P.B. Soeters. Effects of infusion of branched chain amino acid profiles in sepsis and trauma

\section{Introduction}

As has been shown in the previous chapter, the techniques are available to ensure an accurate measurement of amino acid concentrations in a physiological sample. However, the obtained analytical result reflects only the actual concentrations in a given sample, but prior to analysis these concentrations may already have changed due to sampling, processing and storage handling and other procedures. Therefore, even if the analytical method itself is accurate, it does not necessarily reflect the true amino acid concentrations present in blood or tissue of a patient or laboratory animal. A typical example of how large the influence of (inaccurate) pre-analysis treatment can be, is the rapid degradation of catecholamines (1). The blood concentrations of these metabolites change drastically within minutes or even seconds after withdrawal of the sample, when no proper precautions are taken. For amino acid analysis, these changes are usually not so dramatic. Still, several factors have been described that influence the analytical result, but the literature is contradiction regarding how to cope with them to obtain true plasma or tissue concentrations (2-8).

The intention of this study was therefore to investigate the significance of these factors, to determine their (potential) influence on the outcome of the total test procedure. The procedure, which a sample has to pass true, is discussed step by step. The major part of the study resulted in a publication, which is incorporated in this section. Other parts, especially the control data with respect to feeding are shown in a publication incorporated in the first section of this thesis [ ] and in several other publications resulting from clinical studies [ ]. Because these publications are not within the scope of this thesis, they are referred to only.

Finally, one has to consider that the nature of the sample matrix and the analytical method one intends to apply, determine which sample preparation method is best. An extensive discussion with respect to this subject is going on in the literature, but again it would be beyond the scope of this thesis to go into details. Nevertheless, we like to emphasize some important aspects, which will therefore be given in an addendum at the end of this thesis. 


\title{
Influence of storage conditions on normal plasma amino-acid concentrations
}

\author{
H. M. H. VAN EIJK, C. H. C. DEJONG, N. E. P. DEUTZ and P. B. SOETERS \\ Department of Surgery, Biomedical Center, University of Limburg, P.O. Box 616, NL-6200 MD \\ Maastricht, The Netherlands. (Correspondence to: NEPD)
}

ABSTRACT-Conflicting information in the literature is given concerning the optimal preparation and storage conditions of plasma samples for amino-acid analysis. To assess the optimal pre-storage treatment, we compared several methods and studied their influence on plasma amino-acid levels of rats and humans, stored at different temperatures.

In rat plasma, the frequently reported degradation of glutamine was not measurable at a storage temperature of $-70^{\circ} \mathrm{C}$. However, storage of native, not deproteinised plasma at this temperature, resulted in a $32 \%$ decrease of arginine and a $30 \%$ increase in ornithine after 24 weeks. Deproteinisation prohibited this arginine decay. At $-20^{\circ} \mathrm{C}$, arginine decay was even more pronounced, whereas glutamine decreased by $14 \%$ in untreated plasma, by $10 \%$ in sulfosalicylic acid deproteinised plasma and by $3 \%$ if the deproteinisation was followed by removal of the protein pellet and subsequent neutralisation.

To confirm these unexpected results in humans, we repeated this experiment with plasma of 6 volunteers. In contrast to rat plasma, we did not observe any changes in arginine and ornithine concentrations in human plasma stored at $-70^{\circ} \mathrm{C}$. At $-20^{\circ} \mathrm{C}$ the reduction in glutamine was only $4-5 \%$. These results suggest that interspecies differences in enzymatic activity exist in plasma.

Finally, having assessed the optimal treatment and storage conditions (deproteinisation followed by storage at $-70^{\circ} \mathrm{C}$ ), samples were obtained from a total of 112 human volunteers, stratified for age and sex, and amino-acids were measured. In the female group, we found a tendency to a gradual increase in most amino-acid concentrations with advancing age, which however only reached significance for histidine, citrulline, alanine and leucine.

These observations demonstrate that plasma samples for amino-acid analysis should be deproteinised and stored at $-70^{\circ} \mathrm{C}$. Also important interspecies differences appear to exist in plasma enzymatic activity. Finally, control samples should be taken from an age and sex matched control group.

\section{Introduction}

The large numbers of plasma samples collected for amino-acid analysis in our research laboratory (1-3) and the limited capacity for immediate determination makes sample storage inevitable. Because it is well known that sample storage may affect the concentrations of free amino-acids, we scanned the literature for the effects of pre-storage treatment, storageduration and storage temperature. For a relatively mild storage temperature $\left(-20^{\circ} \mathrm{C}\right)$, these influences are well documented (4-14). However, the mostly recommended method, i.e. acid deproteinisation prior to storage below $=70^{\circ} \mathrm{C}(11-16)$, may not be optimal for the preservation of glutamine, an amino-acid which is the subject of intensive investigations, because a low storage $\mathrm{pH}$ accelerates the spontaneous degradation of glutamine to pyroglutamate $(4-5,8$, 11-16). It has therefore repeatedly been suggested, that it may be beneficial not to deproteinise plasma prior to storage $(10,12,17)$ or to use organic solvent deproteinisation (5). On the other hand, it is questionable whether freezing alone completely inhibits all enzymatic activity. Because of these apparently contradictory recommendations we studied the aminoacid concentrations of native, deproteinised plasma and neutralised deproteinised plasma in time at different storage temperatures in rats as well as in humans. 
It is well known that nutritional status influences the concentrations of free amino-acids (18). However, the effects of age and sex are not well known. Therefore, after having established the optimal sample processing and storage conditions, we studied these effects in a group of 112 healthy human volunteers, hospitalised for minor elective surgery.

\section{Materials and methods}

\section{Rat-studies}

Heparinised blood from 4 overnight fasted, ether anesthetised male Wistar rats $( \pm 300 \mathrm{~g}$ ) was obtained by aortic puncture and collected on ice. Plasma was obtained by centrifugation and pooled to rule out inter individual variation. Samples were further treated as described below.

\section{Human studies}

Heparinised blood samples from overnight fasted healthy human volunteers $(n=112)$ were collected by venepuncture from an antecubital vein using a vacuum system (Venaject-system) after informed consent had been obtained. Samples were immediately put on ice. Volunteers were hospitalised for minor elective surgery such as hernia surgery, treatment of varices, plastic surgical minor corrections, removal of osteosynthetic material, arthroscopies, cataract extirpation and minor orthopaedic corrections (e.g. hallux valgus). Patients on chronic medication, those on a specific diet, and those, with recent large weight changes or pre-existent chronic disease were excluded. Patients on sleep medication were also excluded. Samples were obtained between 08:00$08: 45 \mathrm{~h}$ before any anaesthetic or antibiotic had been administered. The effects of sample treatment and conditions and duration of storage were studied in 6 patients. Having assessed the optimal conditions, the remaining 106 elective surgical patients (age 20-90) were studied in order to obtain a total set of 112 ageand sex-stratified human amino-acid data, to function as a control group for future clinical studies.

\section{Sample Preparation}

Plasma was prepared by centrifugation for $5 \mathrm{~min}$ at $11000 \mathrm{~g}$ in a Hereaus Biofuge (Dijkstra Vereenigde, Amsterdam, The Netherlands) at $4^{\circ} \mathrm{C}$. To determine the effects of sample preparation, storage temperature and storage duration, $100 \mu \mathrm{l}$ aliquots of (pooled) rat plasma or human plasma from 6 volunteers were either frozen immediately in liquid nitrogen, deproteinised with $4 \mathrm{mg}$ of solid 5-sulfosalicylic acid (5-SSA: British Drug Houses, Amsterdam, The Netherlands) to stop enzymatic activity and frozen in liquid nitrogen, or deproteinised with 5-SSA followed by centrifugation (as described above) to remove the protein. The resulting supernatant was then neutralized with $2 \mathrm{~N} \mathrm{KHCO}_{3}$ before freezing in liquid nitrogen. Aliquots of each sample treatment were subsequently stored at $4^{\circ} \mathrm{C},-20^{\circ} \mathrm{C}$ or $-70^{\circ} \mathrm{C}$. Free amino-acids were determined in duplicate, immediately and after $1,2,4,6,12$ or 24 weeks storage at $4^{\circ} \mathrm{C}$, and after $4,8,12,16,20$ or 24 weeks storage at $-20^{\circ} \mathrm{C}$ or $-70^{\circ} \mathrm{C}$, using a fully automated HPLC method as described previously (18), with a coefficient of variation (inter- and intra-assay) below $4 \%$. Having assessed the optimal storage conditions, the plasma samples of the remaining 106 elective surgical patients were deproteinised with 5-SSA, immediately frozen in liquid nitrogen and stored for a maximum of 1 month at $-70^{\circ} \mathrm{C}$ before analysis.

\section{Statistics}

Statistics were performed with a standard statistical software package (SPSS-PC*) using the non-parametric Mann-Whitney $U$ test and one-way ANOVA test. $\mathrm{P}<0.05$ was considered to signify significance.

\section{Results}

\section{Rat studies}

The main changes in rat plasma induced by prestorage treatment, storage temperature and duration of storage on rat plasma are summarized in Table 1 and Figure 1 . In short, 24 weeks of storage at $-70^{\circ} \mathrm{C}$ caused a $32 \%$ decrease of arginine and a $30 \%$ increase of ornithine in rat plasma which had not been treated prior to storage. Deproteinisation prohibited these changes. No changes were found in the concentrations of glutamine and glutamate after storage at $-70^{\circ} \mathrm{C}$, irrespective of the prestorage treatment. At $-20^{\circ} \mathrm{C}$, the decrease in arginine and the increase in ornithine were even more pronounced in untreated samples. At this temperature, glutamine in untreated plasma decreased more $(14 \%)$ than in 5-SSA deproteinised plasma $(10 \%)$, while in neutralised deproteinised plasma degradation was negligible $(3 \%)$. Simultaneously, the concentrations of glutamate rose both in untreated plasma and in deproteinised plasma, but the glutamate rise was not stoichiometric to the glutamine decrease. No changes in glutamate were found in neutralised 
Table 1 Influence of storage temperature and sample deproteinisation, with or without subsequent neutralisation, on rat plasma glutamine (GLN) and glutamate (GLU) concentrations $(\mu \mathrm{mol} / \mathrm{L})$

\begin{tabular}{|c|c|c|c|c|c|c|c|}
\hline \multirow{2}{*}{$\begin{array}{l}\text { Storage } \\
\text { Temp }\left({ }^{\circ} \mathrm{C}\right)\end{array}$} & \multirow[b]{2}{*}{$\begin{array}{l}\text { Time } \\
\text { (weeks) }\end{array}$} & \multicolumn{2}{|c|}{ Untreated } & \multicolumn{2}{|c|}{ Deproteinised } & \multicolumn{2}{|c|}{ Neutralised } \\
\hline & & GLU & GLN & GLU & GLN & GLU & GLN \\
\hline 4 & 0 & 44 & 629 & 44 & 629 & 44 & 629 \\
\hline 4 & 1 & 50 & 634 & 51 & 540 & 44 & 618 \\
\hline 4 & 2 & 59 & 626 & 80 & 476 & 66 & 587 \\
\hline 4 & 4 & 65 & 539 & 77 & 360 & 47 & 530 \\
\hline 4 & 6 & 99 & 527 & 88 & 204 & 40 & 459 \\
\hline 4 & 12 & 112 & 364 & 93 & 108 & 45 & 168 \\
\hline 4 & 24 & 199 & 210 & 116 & 19 & 53 & 15 \\
\hline-20 & 0 & 44 & 631 & 44 & 631 & 44 & 631 \\
\hline-20 & 4 & 47 & 621 & 48 & 617 & 41 & 641 \\
\hline-20 & 8 & 40 & 588 & 59 & 600 & 53 & 608 \\
\hline-20 & 12 & 53 & 563 & 67 & 585 & 38 & 617 \\
\hline-20 & 16 & 59 & 570 & 68 & 573 & 38 & 634 \\
\hline-20 & 20 & 58 & 550 & 66 & 573 & 55 & 632 \\
\hline-20 & 24 & 60 & 545 & 50 & 569 & 54 & 613 \\
\hline-70 & 0 & 44 & 640 & 44 & 640 & 44 & 640 \\
\hline-70 & 4 & 40 & 637 & 41 & 645 & 39 & 654 \\
\hline-70 & 8 & 36 & 645 & 36 & 640 & 46 & 637 \\
\hline-70 & 12 & 48 & 623 & 47 & 647 & 36 & 641 \\
\hline-70 & 16 & 40 & 654 & 40 & 644 & 38 & 656 \\
\hline-70 & 20 & 52 & 626 & 49 & 644 & 50 & 659 \\
\hline-70 & 24 & 41 & 626 & 43 & 641 & 53 & 652 \\
\hline
\end{tabular}

\begin{tabular}{ll}
\hline Untreated: & $\begin{array}{l}\text { Native, not deproteinised plasma, frozen } \\
\text { immediately in liquid nitrogen }\end{array}$ \\
Deproteinised: & $\begin{array}{l}\text { Plasma mixed with sulfosalicylic acid }(4 \mathrm{mg} / \\
100 \mu \mathrm{L}) \text { and frozen immediately in liquid } \\
\text { nitrogen }\end{array}$ \\
Neutralised: & $\begin{array}{l}\text { Plasma mixed with sulfosalicylic acid, } \\
\text { centrifuged }\left(5 \mathrm{~min}, 11000 \mathrm{~g} .4^{\circ} \mathrm{C}\right), \text { and the } \\
\text { prepared supernatant neutralised with } 2 \mathrm{~N} \mathrm{KHCO}, \\
\text { and frozen immediately in liquid nitrogen }\end{array}$
\end{tabular}

deproteinised plasma. At $4^{\circ} \mathrm{C}$, arginine decreased to almost zero within 4 weeks, while ornithine increased by $500 \%$ during this period in untreated plasma. Glutamine and glutamate concentrations of untreated plasma and neutralised deproteinised plasma remained only stable during the first week, but in deproteinised plasma, glutamine decreased by $14 \%$. For all other amino-acids (not shown), no changes in the concentrations were found, with the exception of untreated plasma stored at $4^{\circ} \mathrm{C}$, in which a gradual increase of all other amino-acid concentrations was observed.

\section{Human studies}

The influences of storage on human plasma, studied for only 12 weeks, are described in Table 2 . At $-70^{\circ} \mathrm{C}$, threonine and methionine were significantly higher than the prestorage concentrations. No other changes
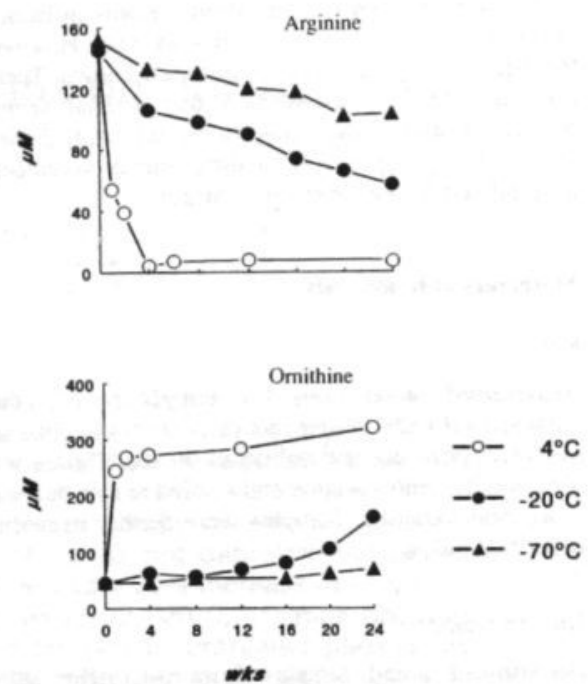

Fig. 1. Influence of storage temperature on untreated rat plasma: Arginine (ARG) and Omithine (ORN) concentrations $(\mu \mathrm{mol} / \mathrm{L})$.

were found for any amino-acid including glutamine, arginine and ornithine, irrespective of sample treatment. At $-20^{\circ} \mathrm{C}$, glutamine decreased by $4 \%$ in this period both in untreated and deproteinised plasma, but this was not statistically significant. In rat plasma, this decrease was $11 \%$ and $7 \%$ respectively. Again, threonine was significantly higher than the prestorage concentration. However, this value was not different from the $-70^{\circ} \mathrm{C}$ value, suggesting that the apparent rise may be an artefact due to a too low starting value. Glutamate, arginine and ornithine did not change. From these results, we concluded that storage at $-70^{\circ} \mathrm{C}$ after deproteinisation with 5-SSA, without neutralisation was the most convenient and reliable sample processing technique.

Using this sample preparation and storage technique, in addition to the already collected data from the 6 volunteers, samples from 106 healthy human volunteers, stratified for age and sex, were determined within 1 month after collection. The results (Table 3) suggest an increasing amino-acid concentration with increasing age in the female group, although only the change in citrulline reached significance $(p<0.05$. oneway ANOVA procedure). In the male group this relation seemed to be reversed. With increasing age, asparagine, histidine, valine, methionine, isoleucine and leucine decreased significantly. The value for 
Table 2 Influence of storage temperature and sample deproteinisation on human plasma amino-acids after a storage period of 12 weeks. Samples were taken from 6 healthy elective surgical patients. Data are means \pm S.E.M. Effect of storage: $p<0.05$ *

\begin{tabular}{|c|c|c|c|c|c|}
\hline Amino-acid & Before-storage & $\begin{array}{l}-20^{\circ} \mathrm{C} \\
\text { Plasma }\end{array}$ & $\begin{array}{l}-20^{\circ} \mathrm{C} \\
\text { Deproteinised }\end{array}$ & $\begin{array}{l}-70^{\circ} \mathrm{C} \\
\text { Plasma }\end{array}$ & $\begin{array}{l}-70^{\circ} \mathrm{C} \\
\text { Deproteinised }\end{array}$ \\
\hline Glutamic acid & $51 \pm 6$ & $59 \pm 6$ & $53 \pm 5$ & $48 \pm 6$ & $48 \pm 5$ \\
\hline Asparagine & $49 \pm 2$ & $51 \pm 2$ & $51 \pm 2$ & $52 \pm 3$ & $56 \pm 5$ \\
\hline Serine & $112 \pm 5$ & $123 \pm 5$ & $122 \pm 5$ & $126 \pm 6$ & $124 \pm 5$ \\
\hline Glutamine & $615 \pm 27$ & $588 \pm 30$ & $583 \pm 21$ & $626 \pm 23$ & $614 \pm 26$ \\
\hline Glycine & $209 \pm 13$ & $216 \pm 13$ & $212 \pm 10$ & $226 \pm 12$ & $221 \pm 11$ \\
\hline Threonine & $112 \pm 14$ & $127 \pm 13^{*}$ & $130 \pm 14^{*}$ & $133 \pm 16^{*}$ & $129 \pm 14^{\circ}$ \\
\hline Histidine & $81 \pm 2$ & $83 \pm 2$ & $83 \pm 1$ & $88 \pm 3$ & $86 \pm 2$ \\
\hline Citrulline & $29 \pm 4$ & $35 \pm 4$ & $33 \pm 4$ & $36 \pm 4$ & $35 \pm 4$ \\
\hline Alanine & $332 \pm 21$ & $346 \pm 22$ & $337 \pm 18$ & $357 \pm 20$ & $350 \pm 21$ \\
\hline Taurine & $39 \pm 2$ & $40 \pm 1$ & $39 \pm 1$ & $45 \pm 2$ & $43 \pm 2$ \\
\hline Arginine & $115 \pm 3$ & $107 \pm 4$ & $105 \pm 3$ & $110 \pm 4$ & $107 \pm 4$ \\
\hline$\alpha$ amino butyric acid & $22 \pm 3$ & $24 \pm 3$ & $24 \pm 2$ & $24 \pm 3$ & $24 \pm 3$ \\
\hline Tyrosine & $52 \pm 7$ & $56 \pm 8$ & $55 \pm 8$ & $58 \pm 8$ & $56 \pm 8$ \\
\hline Valine & $213 \pm 16$ & $193 \pm 15$ & $191 \pm 14$ & $200 \pm 14$ & $196 \pm 15$ \\
\hline Methionine & $25 \pm 1$ & $26 \pm 1$ & $24 \pm 1$ & $29 \pm 1^{*}$ & $29 \pm 1^{*}$ \\
\hline Isoleucine & $60 \pm 4$ & $57 \pm 4$ & $57 \pm 4$ & $59 \pm 4$ & $58 \pm 4$ \\
\hline Phenylalanine & $58 \pm 5$ & $56 \pm 5$ & $56 \pm 5$ & $58 \pm 5$ & $57 \pm 5$ \\
\hline Tryptophan & $38 \pm 2$ & $38 \pm 3$ & $38 \pm 3$ & $39 \pm 2$ & $38 \pm 2$ \\
\hline Leucine & $109 \pm 8$ & $97 \pm 8$ & $96 \pm 8$ & $100 \pm 7$ & $98 \pm 8$ \\
\hline Omithine & $57 \pm 4$ & $53 \pm 3$ & $56 \pm 3$ & $50 \pm 3$ & $49 \pm 3$ \\
\hline Lysine & $169 \pm 6$ & $161 \pm 13$ & $160 \pm 12$ & $157 \pm 13$ & $155 \pm 13$ \\
\hline
\end{tabular}

valine, methionine, isoleucine, phenylalanine, tryptophan and leucine in women aged $20-50$ years were significantly lower than the corresponding values in men of a similar age (Mann Whitney U non-parametric test). Studying the effect of age on the whole group (man and woman together), only histidine, citrulline, alanine and leucine reached statistical significance (one way ANOVA, not shown). An interesting observation was the gradual increase in branched-chain amino-acids (BCAA) in women, especially beyond the age of 40 (Fig. 2). Although this increase did not attain statistical significance (one way ANOVA), such a change was not observed in males. As a result, there was a marked and statistically significant difference in BCAA concentrations between men and women in the age groups 20-29, 30-39 and 40-49. Thereafter, the difference disappeared (Mann Whitney $\mathrm{U}$ non parametric test, men versus women).

\section{Discussion}

Clinical studies require a great effort from the attending staff and from the investigators to obtain valuable samples and data. The reliability of the collected data depends on a correct storage and processing procedure. Because of the duration of these studies and the often limited capacity to process the samples immediately, sample treatment and storage conditions are crucial (4-21). Although the effects of storage, especially at $-20^{\circ} \mathrm{C}$, have repeatedly been described, the data are conflicting. It has been suggested that storage of native, not deproteinised plasma may yield more reliable concentrations of glutamine, because the low storage $\mathrm{pH}$, induced by acid deproteinisation, may result in an accelerated non-enzymatic degradation to pyroglutamate $(4-5,8,11-16)$. However, it is questionable whether freezing alone prohibits all enzymatic activity. Because we perform both clinical studies (1), and experimental animal studies (2-3), we also wondered if differences in species require different sample processing techniques. The present study was therefore designed to investigate the influence of sample treatment and storage conditions on the amino-acid concentrations of rat and human plasma.

As expected, no changes were observed in glutamine concentrations in samples stored at $-70^{\circ} \mathrm{C}$, regardless of species and treatment prior to storage. However, in untreated rat plasma, arginine decreased and ornithine increased, suggesting a substantial arginase activity, even at this low storage temperature. Although we did not find this effect in human plasma, relatively low arginine levels have been reported in untreated human plasma stored at $-80^{\circ} \mathrm{C}(21)$. This suggests that arginase activity, which was believed to be only measurable in hemolytic plasma $(17,19-20)$, 
Table 3 Normal human plasma amino-acid concentrations. Data are means \pm S.E.M. Effect of age (one way ANOVA): $p<0.05 *$; $p<0.01^{* *}$. Effect of gender-men versus women (Mann Whitney U non parametric): $p<0.05^{t} ; p^{\prime}<0.01^{t+}: p<0.001^{t+1}$

\begin{tabular}{|c|c|c|c|c|c|c|}
\hline \multirow[b]{2}{*}{ Age } & \multicolumn{6}{|c|}{ FEMALE GROUP } \\
\hline & $\begin{array}{l}20-29 \\
n=7\end{array}$ & $\begin{array}{l}30-39 \\
n=7\end{array}$ & $\begin{array}{l}40-49 \\
n=10\end{array}$ & $\begin{array}{l}50-59 \\
n=7\end{array}$ & $\begin{array}{l}60-69 \\
n=11\end{array}$ & $\begin{array}{l}70-89 \\
n=10\end{array}$ \\
\hline Glutamic acid & $39 \pm 8$ & $51 \pm 8$ & $43 \pm 4$ & $55 \pm 8$ & $52 \pm 5$ & $49 \pm 7$ \\
\hline Asparagine & $51 \pm 4$ & $48 \pm 4$ & $48 \pm 2$ & $44 \pm 3$ & $47 \pm 2$ & $45 \pm 4$ \\
\hline Serine & $104 \pm 14$ & $112 \pm 13$ & $97 \pm 10$ & $89 \pm 9$ & $107 \pm 11$ & $95 \pm 9$ \\
\hline Glutamine & $568 \pm 43$ & $629 \pm 28$ & $650 \pm 29$ & $605 \pm 33$ & $689 \pm 28$ & $689 \pm 32$ \\
\hline Glycine & $207 \pm 54$ & $231 \pm 13$ & $299 \pm 44$ & $307 \pm 67$ & $238 \pm 27$ & $236 \pm 39$ \\
\hline Threonine & $144 \pm 11$ & $149 \pm 17$ & $128 \pm 12$ & $114 \pm 8$ & $124 \pm 5$ & $122 \pm 15$ \\
\hline Histidine & $80 \pm 4$ & $84 \pm 5$ & $78 \pm 3$ & $81 \pm 4$ & $86 \pm 4$ & $76 \pm 9$ \\
\hline Citrulline & $24 \pm 4$ & $29 \pm 2$ & $34 \pm 3$ & $34 \pm 5$ & $35 \pm 2$ & $40 \pm 4^{*}$ \\
\hline Alanine & $330 \pm 50$ & $296 \pm 38$ & $338 \pm 33$ & $351 \pm 21$ & $400 \pm 65$ & $399 \pm 53$ \\
\hline Taurine & $36 \pm 3$ & $44 \pm 2$ & $38 \pm 3$ & $45 \pm 4$ & $47 \pm 2$ & $40 \pm 4$ \\
\hline Arginine & $86 \pm 12$ & $88 \pm 9$ & $99 \pm 6$ & $105 \pm 13$ & $105 \pm 7$ & $101 \pm 8$ \\
\hline$\alpha$ amino butyric acid & $13 \pm 2$ & $16 \pm 1$ & $18 \pm 1$ & $15 \pm 1$ & $22 \pm 3$ & $22 \pm 2$ \\
\hline Tyrosine & $39 \pm 7$ & $50 \pm 6$ & $53 \pm 3$ & $63 \pm 3$ & $64 \pm 5$ & $66 \pm 6$ \\
\hline Valine & $183 \pm 8$ & $173 \pm 5$ & $216 \pm 8$ & $222 \pm 12$ & $228 \pm 16$ & $251 \pm 17$ \\
\hline Methionine & $22 \pm 2$ & $19 \pm 2$ & $21 \pm 1$ & $21 \pm 2$ & $24 \pm 2$ & $25 \pm 2$ \\
\hline Isoleucine & $55 \pm 6$ & $48 \pm 2$ & $57 \pm 3$ & $59 \pm 5$ & $58 \pm 5$ & $68 \pm 7$ \\
\hline Phenylalanine & $48 \pm 5$ & $43 \pm 3$ & $56 \pm 2$ & $59 \pm 2$ & $58 \pm 3$ & $61 \pm 5$ \\
\hline Tryptophan & $47 \pm 4$ & $38 \pm 6$ & $49 \pm 2$ & $55 \pm 2$ & $49 \pm 3$ & $50 \pm 3$ \\
\hline Leucine & $100 \pm 9$ & $95 \pm 4$ & $121 \pm 4$ & $124 \pm 7$ & $117 \pm 7$ & $128 \pm 9$ \\
\hline Lysine & $139 \pm 16$ & $122 \pm 7$ & $156 \pm 8$ & $162 \pm 8$ & $163 \pm 26$ & $170 \pm 19$ \\
\hline BCAA & $338 \pm 18$ & $271 \pm 49$ & $393 \pm 14$ & $405 \pm 22$ & $403 \pm 27$ & $403 \pm 73$ \\
\hline \multirow{3}{*}{ Age } & \multicolumn{6}{|c|}{ MALE GROUP } \\
\hline & $20-29$ & $30-39$ & $40-49$ & $50-59$ & $60-69$ & $70-89$ \\
\hline & $\mathrm{n}=8$ & $\mathrm{n}=8$ & $n=11$ & $\mathbf{n}=9$ & $n=10$ & $n=14$ \\
\hline Glutamic acid & $55 \pm 7$ & $53 \pm 5$ & $50 \pm 6$ & $59 \pm 6$ & $49 \pm 6$ & $62 \pm 11$ \\
\hline Asparagine & $51 \pm 3$ & $54 \pm 3$ & $47 \pm 3$ & $49 \pm 4$ & $45 \pm 3$ & $41 \pm 2^{*}$ \\
\hline Serine & $109 \pm 5$ & $95 \pm 7$ & $96 \pm 7$ & $93 \pm 9$ & $95 \pm 9$ & $85 \pm 4$ \\
\hline Glutamine & $686 \pm 56$ & $676 \pm 39$ & $693 \pm 32$ & $663 \pm 31$ & $658 \pm 30$ & $665 \pm 32$ \\
\hline Glycine & $236 \pm 20$ & $223 \pm 16$ & $228 \pm 13$ & $198 \pm 12$ & $197 \pm 15$ & $173 \pm 14^{t}$ \\
\hline Threonine & $141 \pm 11$ & $123 \pm 7$ & $124 \pm 13$ & $114 \pm 7$ & $120 \pm 14$ & $106 \pm 9$ \\
\hline Histidine & $93 \pm 9$ & $87 \pm 5$ & $87 \pm 4^{11}$ & $83 \pm 4$ & $81 \pm 3$ & $72 \pm 5 * *$ \\
\hline Citrulline & $32 \pm 4$ & $31 \pm 2$ & $34 \pm 5$ & $35 \pm 3$ & $39 \pm 6$ & $41 \pm 5$ \\
\hline Alanine & $319 \pm 46$ & $393 \pm 51$ & $335 \pm 39$ & $353 \pm 39$ & $345 \pm 41$ & $313 \pm 24$ \\
\hline Taurine & $43 \pm 4$ & $40 \pm 3$ & $43 \pm 3$ & $43 \pm 3$ & $35 \pm 3^{t+1}$ & $37 \pm 2$ \\
\hline Arginine & $92 \pm 9$ & $86 \pm 8$ & $95 \pm 8$ & $99 \pm 6$ & $98 \pm 9$ & $91 \pm 9$ \\
\hline$\alpha$ amino butyric acid & $16 \pm 3$ & $19 \pm 3$ & $23 \pm 2^{\dagger}$ & $19 \pm 2$ & $23 \pm 3$ & $17 \pm 1 *$ \\
\hline Tyrosine & $62 \pm 3$ & $63 \pm 4$ & $61 \pm 4$ & $62 \pm 3$ & $54 \pm 6$ & $60 \pm 4$ \\
\hline Valine & $251 \pm 15^{t+1}$ & $247 \pm 13^{t 1}$ & $253 \pm 18$ & $249 \pm 18$ & $251 \pm 17$ & $237 \pm 14^{*}$ \\
\hline Methionine & $26 \pm 1^{t}$ & $26 \pm 2^{\dagger}$ & $25 \pm 1^{\dagger}$ & $26 \pm 2^{\dagger}$ & $23 \pm 2$ & $24 \pm 2$ \\
\hline Isoleucine & $69 \pm 5^{t+1}$ & $73 \pm 4^{t+}$ & $67 \pm 5$ & $72 \pm 6$ & $66 \pm 5$ & $61 \pm 4^{*}$ \\
\hline Phenylalanine & $63 \pm 5^{t+1}$ & $61 \pm 2^{t 1}$ & $63 \pm 4^{t}$ & $63 \pm 4$ & $55 \pm 3$ & $65 \pm 4$ \\
\hline Tryptophan & $55 \pm 4^{t}$ & $59 \pm 4^{\prime \prime}$ & $56 \pm 2$ & $59 \pm 5$ & $50 \pm 3$ & $54 \pm 4$ \\
\hline Leucine & $140 \pm 14^{t+1}$ & $147 \pm 9^{t t}$ & $142 \pm 8^{\dagger}$ & $147 \pm 16$ & $134 \pm 9$ & $125 \pm 8^{\circ}$ \\
\hline Lysine & $157 \pm 10$ & $164 \pm 10^{t t}$ & $171 \pm 10$ & $154 \pm 14$ & $161 \pm 14$ & $153 \pm 10$ \\
\hline BCAA & $460 \pm 34^{t+1}$ & $467 \pm 25^{11}$ & $462 \pm 30^{t}$ & $467 \pm 38$ & $451 \pm 26$ & $381 \pm 43^{\circ}$ \\
\hline
\end{tabular}

may also be present in non hemolytic human plasma. This is supported by a recent publication (22), in which a relation is suggested between enhanced human plasma arginase activity and disease, and, in the female population, with increasing age. As the influences of storage and pre-storage treatment were mostly studied using healthy and relatively young volunteers, this may explain why as far as we are aware the effect has not been reported before. The above findings point out the necessity for immediate deproteinisation of plasma prior to storage, even if the sample is not haemolysed and stored below $-70^{\circ} \mathrm{C}$. 


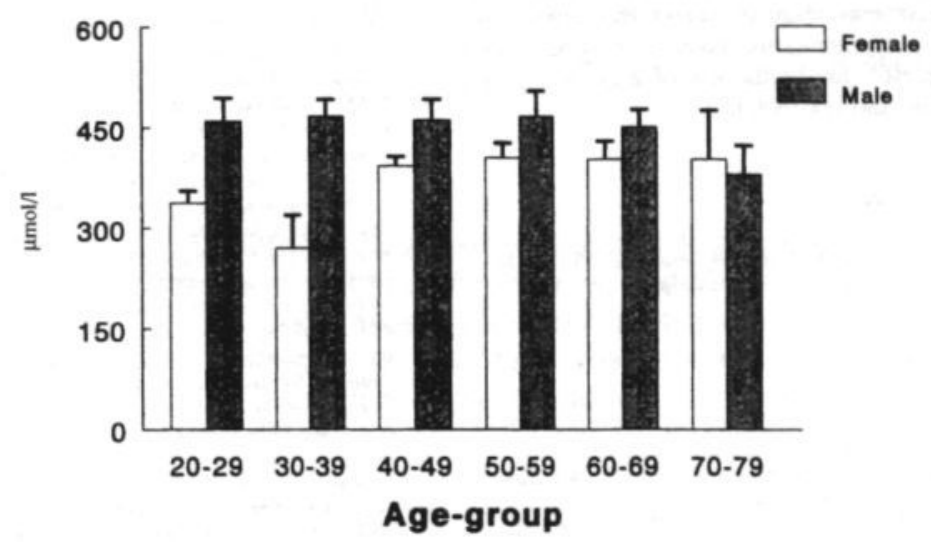

Fig. 2. Influence of age on human plasma branched chain amino acid concentrations (BCAA) in females and males.

Removal of the denatured protein followed by neutralisation of the clear plasma supernatant did not give any additional beneficial effect to addition of 5-SSA to plasma alone, when samples were stored at $-70^{\circ} \mathrm{C}$.

At $-20^{\circ} \mathrm{C}$, glutamine in untreated rat plasma decreased more rapidly than in human plasma (Table 1 and 2), suggesting a greater glutaminase activity in rat plasma. Glutamine concentrations were reduced less in deproteinised rat plasma, than in untreated plasma. Glutamate concentrations increased in both groups (rat and human), but not in direct proportion to the loss of glutamine. We therefore conclude that glutamine degradation is predominantly caused by non enzymatic hydrolysis leading to the formation of pyroglutamate. Consequently, the sum of the GLU and GLN concentrations (10) is not a good estimation to correct for possible degradation of glutamine. Although neutralisation of deproteinised plasma supernatant before storage minimised glutamine degradation, it is laborious, can cause dilution errors and takes time, in which further degradation can take place. At $4^{\circ} \mathrm{C}$, neutralisation of deproteinised plasma supernatant stabilised all amino-acid concentrations including glutamine for about 1 week.

As a result, we conclude that inactivation of enzymatic activity by acid deproteinisation, followed by immediate freezing in liquid nitrogen prior to storage at $-70^{\circ} \mathrm{C}$ is the most convenient and reliable sample processing and storage technique. If storage at $-70^{\circ} \mathrm{C}$ is not possible, $-20^{\circ} \mathrm{C}$ may also be appropriate if the supernatant of deproteinised samples is neutralised prior to storage. Storage of untreated plasma should be avoided.

Control amino-acid concentrations are often obtained by measuring the plasma concentrations of personnel, thus reflecting a relatively young group of people. Even if these samples are correctly treated and stored, such a control group might not be valid, because the patient population is often much older. As a result. discrepancies may be missed, or misinterpreted. Therefore, we studied the influence of age and sex on the concentration of plasma free amino-acids. Although age dependent changes were observed, especially in the female group, only a few of these changes reached statistical significance due to the large standard errors (Table 3). It is noteworthy that the differences in amino-acid concentrations between man and woman exist especially between the age of 20-50. Although the cause of these changes is not clear, it may be related to hormonal status differences. The differences and alterations in BCAA concentrations appear to be of particular importance in studies during liver disease, when BCAA levels are known to be decreased.

The implications of our conclusions are evident. Glutamine and arginine are considered important aminoacids in clinical and metabolic research (23-25). Our results show that incorrect storage of plasma samples can cause a considerable change in the concentrations of especially these amino-acids. The existence of interspecies variations in enzymatic activity may also 
cause experimental artifacts and care must therefore be taken in interpreting the results of an experiment to another species. Even if the data are collected following correct prestorage treatment and sufficiently low storage temperature, discrepancies may be missed or misinterpreted due to the use of a control group that is not age- and sex-matched.

\section{Acknowledgement}

The authors wish to thank W. J. H. J. Meijerink MD, PhD for his crucial help in collecting patient plasma samples.

\section{References}

1. Vente J P, von Meyenfeldt M F, van Eijk H M H et al. Effects of infusion of branched chain amino acids enriched TPN solutions on plasma amino acid profiles in sepsis and trauma patients. Clin Nutr 1990; 9: 241-245.

2. Dejong C H C. Kampman M T. Deutz N E P. Soeters P B. Altered glutamine metabolism in rat portal drained viscera and hindquarter during hyperammonemia. Gastroenterology 1992; 102: 936-948.

3. Deutz N E P, Reijven P L M, Bost M C F, van Berlo C L H Soeters P B. Modification of the effects of blood on amino acid metabolism by intravenous isoleucine. Gastroenterology 1991: 101: 1602-1613.

4. Tritsch G I. Moore G E. Spontaneous decomposition of glutarnine in cell culture media. Exp Cell Res 1962; 28: $360-364$.

5. Alfredsson G, Wiesel F A, Lindberg M. Glutamate and glutamine in cerebrospinal fluid and serum from healthy volunteers - analytical aspects. J Chromatogr 1988; 424: 378-384.

6. Khan K. Hardy G, McElroy B, Elia M. The stability of L-glutamine in total parenteral solutions. Clin Nutr 1991; 10: 193-198.

7. Khan K. Elia M. Factors affecting the stability of L-glutamine in solution. Clin Nutr 1991: 10: 186-192.

8. Khan K. Blaak E, Elia M. Quantifying intermediary metabolites in whole blood after a simple deproteinization step with sulfosalicylic acid. Clin Chem 1991; 37/5: 728-733.

9. Hubbard R W. Chambers J G. Sanchez A, Slocum R, Lee P. Amino acid analysis of plasma: studies in sample preparation. J Chrom 1988; 431: 163-169.

10. Schaefer A, Piquard F, Haberey P. Plasma amino-acids analysis: Effects of delayed samples preparation and of storage. Clin Chim Acta 1987: 164: 163-169.
11. Vaidyanath N, Brikhahn R, Border J R et al. A method for determining amino acid concentrations and specific activities of amino acids and some other compounds in biological fluids. Anal Biochem 1976; 70: 479-488.

12. Ukida M, Schäfer K, Bode J C. Effect of storage at $-20^{\circ} \mathrm{C}$ on the concentration of amino acids in plasma. J Clin Chem Clin Biochem 1981: 19: 1193-1195.

13. Sahai $S$, Uhlhaas $S$. Stability of amino acids in human plasma. Clin Chim Acta 1985; 148: 255-259.

14. Slocum R H, Cummings J G. Amino acid analysis of physiological samples. In: Techniques in diagnostic human biochemical genetics: A laboratory manual. Frits A Hommes (Ed), Wiley-Liss, New York, 1991: 87-126.

15. Bruce Grossie Jr V. Yick J, Alpeter M. Welbourne T C, Ota D M. Glutamine stability in biological samples evaluated by fluorometric analysis. Clin Chem 1993: 39: 1059-1063.

16. da Fonseca-Wolheim F. Deaminidation of glutamine by increased plasma $\tau$-glutamyltransferase is a source of rapid ammonia formation in blood and plasma specimens. Clin Chem 1990; 36: 1479-1482.

17. Armstrong M D. Stave U. A study of plasma free amino acid levels. I. Study of factors affecting validity of amino acid analysis. Metabolism 1973: 22: 549-560.

18. van Eijk $\mathrm{H} \mathrm{M} \mathrm{H}$, van der Heijden $\mathrm{MA} \mathrm{H}$, van Berlo $\mathrm{CL} \mathrm{H}$, Soeters P B. Fully automated liquid-chromatographic determination of amino acids. Clin Chem 1988; 34: 2510-2513.

19. Perry T L, Hansen S. Technical pitfalls leading to errors in the quantitation of plasma amino acids. Clin Chim Acta 1969; 25: 53-58.

20. Bremer H J, Duran M, Kamerling J P, Przyrembel H, Wadman S K. In: Disturbances of amino acid metabolism: Clinical chemistry and diagnosis. Urban \& Schwartzenberg, München 1981: 502-504.

21. Uhe A M, Collier G R, McLennan, Tucker D J, O'Dea K. Quantification of tryptophan and other plasma amino acids by automated pre-column o-phthaldialdehyde derivatization highperformance liquid chromatography: improved sample preparation. J Chromatogr 1991: 564: 81-91.

22. Wang $S$ R, Chen M L, Huang M H. Lin H Y, Tsai J J, Kuo B I T. Plasma arginase concentration measured by an enzyme-linked immunosorbent assay (ELISA) in normal adult population. Clin Biochem 1993; 26: 455-460.

23. Dudrick $P$ S. Souba $W W$. The role of glutamine in nutrition. Cur Op Gastroent 1991: 7: 299-305.

24. Ziegler T R, Young L S. Benfell K et al. Clinical and metabolic efficacy of glutamine-supplemented parenteral nutrition after bone marrow transplantation. A randomized, double-blind, controlled study. Ann Int Med 1992: 116: $821-828$.

25. Daly J M. Lierberman M D. Goldfine J et al. Enteral nutrition with supplemental arginine, RNA, and omega- 3 fatty acids in patients after operation: Immunologic, metabolic, and clinical outcome. Surgery 1992; 112: 56-67. 


\section{Isolation and quantitation of isotopically labelled amino acids from biological samples}

Published as:

1) H.M.H. van Eijk, M.P.L. Huinck, D.R. Rooyakkers and N.E.P. Deutz. Automated simultaneous isolation and quantitation of labeld amino acid fractions from plasma and tissue by ion-exchange chromatography. J.Chromatogr.B 660 (1994) 251

2) H.M.H. van Eijk, D.R. Rooyakkers, A.J.M. Wagenmakers, P.B. Soeters and N.E.P. Deutz. Isolation and quantitation of isotopically labeled amino acids from biological samples. J.Chromatogr.B 691 (1997) 287

Introduction

In recent decennia, methods have become available allowing the quantitation of degradation and synthesis of whole body proteins, and also of specific proteins in tissue and plasma (1-4). To make these calculations possible, it is necessary to measure the enrichment or specific activity of selected labeled amino acids in blood or tissue, resulting from the isolation of these amino acids and determination of the total concentration and its labeled part.

Formerly, the isolation of only a single amino acid required a laborious procedure and a separate analysis was needed to determine the isolated amount ( 5 , 6). However, metabolic and/or intervention studies do usually not result in large differences between the concentrations of target metabolites of the study groups. More likely are differences ranging from a few percent to a factor of two. Therefore, a relative large number of samples is required to prove statistical significance. Using the traditional methods, this becomes a problem. It was therefore the intention of this study to develop an automated system, capable of isolating any major plasma or tissue amino acid of interest and determining its concentration at the same time.

To enable this approach, three problems had to be solved:

- A method had to be developed to purify the target amino acids

- The concentration of the isolated compounds had to be established

- Measurement of the radioactive or enriched part had to be performed

\section{Amino acid isolation}

A logical procedure to isolate and quantitate target amino acids is chromatography. The main problem encountered, was that the procedures available in our laboratory in the beginning of the 1990's, required $\mu$ mol amounts of pure, underivatized amino acids to determine the enriched part or specific activity of the isolated fraction. At that time, it was not clear if and to what extent a UV absorbing or fluorescent probe attached to the isolated amino acid, would interfere with the specific activity measurement. Furthermore, we did already know that the presence of a probe prohibited ninhydrin decarboxylation (7), a procedure required to measure enrichment by means of isotope ratio mass spectrometry (IRMS).

Initially, we therefore used ion-exchange chromatography to isolate the target amino acids (8). This method allowed the isolation of pure, non-derivatized amino acids, while, compared to a reversed phase column of the same dimensions, a much larger sample load is allowed without a notable effect on the separation. This made measurement of a low enrichment or a low specific activity possible. 
The success of the method resulted in a similar increase in demand for a larger capacity as was observed for the analytical method described in the first section. We therefore initially developed short runs, optimized to isolate and quantitate only the isotopically labeled components. The remaining amino acids concentrations were determined in a separate analysis (9). However, soon this approach also became insufficient and thus the possibilities of (semi-)preparative reversed phase chromatography were explored. It had been indicated already that this technique can also be used to isolate underivatized amino acids $(5,10)$.

Unfortunately, the selectivity with respect to pure amino acids was mediocre. At the same time, OPA-derivatization was applied for a semi-preparative isolation of labeled glutamine from plasma (11). However, the OPA label was suspected to interfere with liquid scintilation counting and the large sample load on the (analytical) column prohibited baseline separations for most amino acids. By scaling up the analytical separation achieved before, we were able to isolate $\mu$ mol quantities of all major plasma amino acids (12).

\section{Determination of the radioactive part}

The application of radioactively labeled amino acid tracers requires not only the chromatographic isolation of the desired component peak, but also the correct determination of the amount of radioactivity accumulated in the fraction. The complexity of the latter aspect is often underestimated.

Quenching effects the accuracy of scintillation counting, and especially of the low energy isotope tritium. Quenching is the process of energy absorption released from radioactive decay by the solvent in which the radioisotope is dissolved. Thus, the isotope's energy spectrum shifts to a lower level, resulting in an underestimation of the activity. To correct for this phenomenon, radioactivity counters are equipped with a quenching indicator (QIP), enabling a mathematical correction (13). Unfortunately, QIP's can only estimate the required correction for the spectral shift and correctness of this estimation is variable and dependent on the technique used.

In our application, the radioactively labeled amino acids are collected in a $6 \mathrm{ml}$ fraction volume. In view of the fact that most scintillation counters accept only 6 or 20 $\mathrm{ml}$ vials, only a two-fold dilution with scintillation cocktail could be maximally applied. In view of the fact that the number of collected fractions was expected to be large, some form of removal of the solvent like freeze-drying would become very laborious. Alternatively we searched for a scintillation cocktail, which accepts a high amount of solvent, still giving an acceptable efficiency and a low degree of quenching. Because the results of this study are of major importance to obtain maximal accuracy, they are added as an addendum at the end of this thesis.

\section{Determination of the enriched part}

The determination of a substrate enriched with a stable isotope requires a different approach compared to radioactive labeled amino acids. In contrast to radioisotopes the occurrence of stable isotopes is relatively large. ${ }^{[13]} \mathrm{C}$ for instance, has a natural abundance of about $1 \%$, while ${ }^{[14]} \mathrm{C}$ has a natural abundance of less then $10^{-10} \%$. Also, stable isotopes do not posses a physical property, which allows an easy quantification of their occurrence. The only techniques available are mass spectrometry (MS) and nuclear magnetic resonance (NMR), both complicated and expensive techniques, while MS is the most sensitive.

In metabolic studies, the amino acid carboxylic carbon atom is often the target for label enrichment. Given the high costs of stable isotopic tracers, only low infusion 
rates are applied and thus only a maximal enrichment of a few promille above the natural abundance is obtained. Combustion of an average amino acid, containing 5 carbon atoms, for mass spectrometric analysis results in a fivefold dilution of this enrichment. Furthermore, the chromatographic separation from other amino acids and the detection of their presence, requires derivatization using a fluorescent or UVabsorbing probe. Attachment of the probe will increase the dilution of the target carbon atom even more with an additional number of carbon atoms. The isotope ratio measurement itself must therefore distinguish a (very) small increase in enrichment from a large background.

To improve the enrichment ratio, it would therefore be more beneficial to use underivatized amino acids as can be obtained by means of the ion-exchange method. Using the $\left[1-{ }^{13} \mathrm{C}\right]$ label, the enrichment can be increased even more through liberation of this carbon atom from the amino acid backbone using a decarboxylation reaction with ninhydrin at low $\mathrm{pH}$. Unfortunately, this reaction requires a free amino group and this group is occupied after derivatization with the probes used to enable a reversed phase separation. To solve this problem, we separated the amino acids after derivatization with 9-fluorenylmethylchloroformate (FMOC). The probe was then removed from the isolated derivative by acid hydrolysis as is discussed in the second publication of this section. In view of the effort which is required to isolate a sufficient amount of target amino acid, it may be clear that we also tried to develop a more efficient introduction of the sample $\mathrm{CO}_{2}$ into the mass spectrometer.

The decarboxylation reaction is usually performed in a capped glass vial and only a limited amount is injected from the vial to prevent air contamination $(7,14)$. In this respect, it must be noted that not only air $\mathrm{CO}_{2}$ contamination will reduce the actual enrichment. Nitrogen contamination also influences the measurement as it can recombine to $\mathrm{N}_{2} \mathrm{O}$ in the ion-source of the mass spectrometer possessing the same mass as $\mathrm{CO}_{2}$. Therefore, the $\mathrm{CO}_{2}$ sample introduction into the MS-system is usually preceded by a gas chromatographic separation. The relative large gas-flow applied for this separation would break the vacuum of the mass spectrometer and thus a large part of the gas-stream has to be discarded through "splitting", and thus also a large part of the sample $\mathrm{CO}_{2}$. As a result of these considerations, only a very small part of $\mathrm{CO}_{2}$ produced from the isolated amino acid actually reaches the mass spectrometer.

Therefore, attempts were made to direct a larger part of the sample into the mass spectrometer. The results of these studies are discussed also in the addendum at the end of this thesis. 


\title{
Automated simultaneous isolation and quantitation of labeled amino acid fractions from plasma and tissue by ion-exchange chromatography
}

\author{
Hans M.H. van Eijk, Marc P.L. Huinck, Dennis R. Rooyakkers, \\ Nicolaas E.P. Deutz* \\ Department of Surgery, Biomedical Center, University of Limburg, P.O. Box 616, NL-6200 MD Maastricht, Netherlands
}

First received 26 April 1994; revised manuscript received 14 June 1994

\begin{abstract}
In order to trace metabolic pathways of amino acids in the body, a known labeled amount of an amino acid is infused. Dilution in the body pool is measured, using the specific activity and calculated by dividing the labeled amount of an amino acid (tracer) by its total pool (tracer + tracee). This paper describes a method, which combines fractionation and quantitation of multiple amino acids in one chromatographic run. To achieve this, we performed a classical amino acid ion-exchange separation on standard HPLC equipment. The column effluent was divided continuously into two solvent streams using a rapidly switching, pump controlled "split-valve". The main part $(90 \%)$ was directed to a computer controlled fraction collector, while the remaining $10 \%$ was mixed with $o$-phthaldialdehyde reagent after which fluorescence was measured. Using this system, 10-1000 $\mu$ l of deproteinized plasma, representing a maximum of $50 \mathrm{nmol}$ of each amino acid, could be fractionated and quantitated in the same chromatographic run. In addition to optimal counting efficiency of an off-line radioactivity counter, it enabled easy measurement of the specific activity of multiple amino acid tracers.
\end{abstract}

\section{Introduction}

Labeled amino acids are widely used to determine protein synthesis or degradation rates of the body or of a specific organ. To enable this, it is necessary to isolate each amino acid and to measure the total and the labeled amounts in the collected fractions. For metabolic studies, the standard procedures for individual amino acids are too laborious and require too much sample and/or radioactivity [1-11]. Therefore, there is a need for a universal method for the isolation and

\footnotetext{
- Corresponding author.
}

quantitation of amino acids in one chromatographic run.

Usually, amino acids are quantitated by ionexchange or reversed-phase chromatography. As we wanted to isolate large amounts of pure, underivatized amino acids, ion-exchange chromatography is the separation technique of choice for this application. However, detection of the separated amino acids requires a post-column reaction, thereby converting the isolated pure amino acids into a derivative, diluting the resulting fraction and complicating counting of the radioactive part, due to quenching and/or chemiluminescence. 
To avoid these problems, we developed a split-flow technique which divides the column effluent dynamically into two liquid flows by a pump-controlled "split-valve". The main part $(90 \%)$ is directed to a computer-controlled fraction-collector, while the remaining part $(10 \%)$ is used for quantitation by mixing it on-line with $o$-phthaldialdehyde reagent and fluorescence monitoring. Because flow-rates, split-percentage and collection-windows are known, the amount of each collected amino acid can be calculated from the obtained chromatogram.

\section{Experimental}

\subsection{Equipment}

The HPLC system used (Fig. 1) consisted of a Model 2248 reagent pump, a Model 2249 gradient pump controlling a Model 2248-201 low pressure ternary mixing panel and a Model 2256

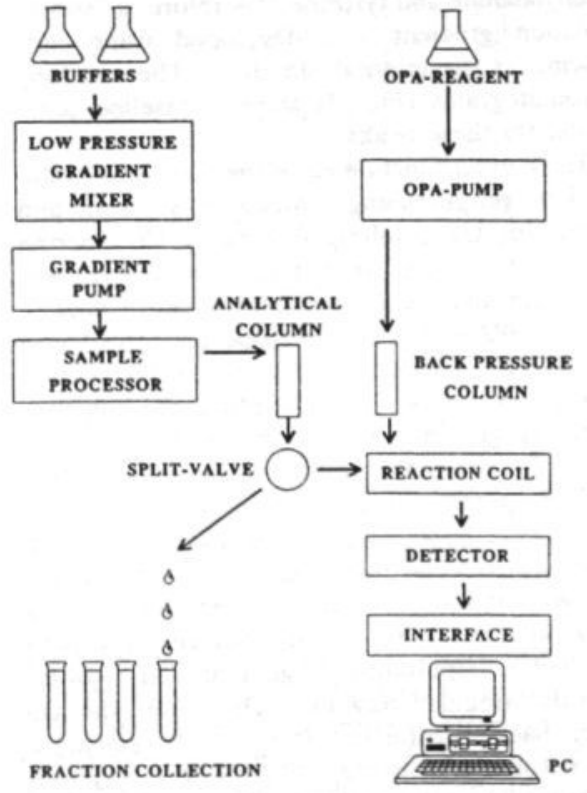

Fig. 1. Schematic system description. solvent conditioner, all from Pharmacia (Woerden, Netherlands).

The analytical column was a $200 \times 4.6 \mathrm{~mm}$ I.D. ion-exchange column filled with Ultropac 8 $(8 \mu \mathrm{m})$ (Pharmacia). The column was placed in a programmable Mistral column oven (Spark, Emmen, Netherlands). The column effluent was divided dynamically into two solvent streams using a 24 VDC three-way PTFE split-valve (Cole-Parmer, Applikon, Schiedam, Netherlands) controlled by the Pharmacia Model 2248 reagent pump. The switching time was set to $1400 \mathrm{~ms}$ and the switching volume to $1 \mu \mathrm{l}$ at a split-percentage of $10 \%$.

For the automated sample injection a WISP 715 sample processor (Millipore/Waters, EttenLeur, Netherlands) was used, equipped with a cooled sample storage compartment and a 48position sample tray.

Amino acid fractions were collected, using a Helifrac fraction collector (Pharmacia) equipped with a 76-position tray. For a more efficient use, it was controlled externally by a Model 900 interface (Perkin-Elmer/Nelson, Gouda, Netherlands). The interface was programmed from a Tandon 486 personal computer, running Model 2700 "Turbochrom" software (Version 3.2: Perkin-Elmer/Nelson) under Microsoft Windows (Version 3.1). This interface was also used for the collection and processing of data produced by the fluorescence detector.

Fluorescence was monitored with a Jasco Model 821FP detector (B and L systems, Zoetermeer, Netherlands) equipped with a xenon lamp and a $12-\mu$ l flow-cell. Measurements were made at an excitation wavelength of 330 $\mathrm{nm}$ and an emission wavelength of $445 \mathrm{~nm}$.

\subsection{Reagents and solvents}

All solutions were prepared with ultra-pure water, generated by a super-Q system (Millipore/Waters). All chemicals used were of analytical grade (Merck, Amsterdam, Netherlands), solvents of chromatographic grade (Janssen Chimica, Amsterdam, Netherlands).

The derivatization reagent was prepared by dissolving $0.5 \mathrm{~g}$ of $o$-phthaldialdehyde (OPA) in 
$12.5 \mathrm{ml}$ of methanol, adding $500 \mathrm{ml}$ of potassium borate buffer $(0.5 \mathrm{~mol} / \mathrm{l}, \mathrm{pH} \mathrm{10.4)}$ and $0.5 \mathrm{ml}$ of 3-mercaptopropionic acid (3-MPA). This reagent was placed in a $500-\mathrm{ml}$ PTFE-coated brown Duran glass bottle. The bottle was kept under $0.02 \mathrm{MPa}$ helium pressure using a Pharmacia solvent degassing cap.

A "short" gradient profile with a binary solvent system was used to isolate isoleucine, leucine, tyrosine, phenylalanine and norleucine (as an internal standard). Solvent A was a 0.3 mol/1 lithium citrate buffer $\mathrm{pH} 3.00$, containing $15 \mathrm{ml}$ iso-propanol, while solvent $\mathrm{B}$ was 0.3 mol/1 lithiumhydroxide. Gradient conditions are described in Table 1.

Amino acid standards were prepared by dissolving pure amino acids in water to a final concentration of $25 \mu \mathrm{mol} / \mathrm{l}$ each, and calibrated against a physiological standard (Sigma, Amsterdam, Netherlands), using a standard HPLC technique [12]. The calibrated standard was divided in $1-\mathrm{ml}$ portions and stored at $-80^{\circ} \mathrm{C}$.

\subsection{Sample preparation}

Heparinized arterial blood samples were obtained from rats and collected on ice, followed by immediate centrifugation at $11000 \mathrm{~g}$ in a Hereaus biofuge (Dijkstra, Amsterdam, Netherlands) for $10 \mathrm{~min}$ at $4^{\circ} \mathrm{C}$. Next, plasma was deproteinized with 5-sulfosalicylic acid (5-SSA), $8 \mathrm{mg} / 200 \mu \mathrm{l}$ plasma, frozen immediately in liquid nitrogen and stored at $-80^{\circ} \mathrm{C}$. Before analysis, samples were thawed at $4^{\circ} \mathrm{C}$, vortexmixed vigorously and centrifuged as described before. A $50-\mu 1$ volume of the clear supernatant was then mixed with $50 \mu \mathrm{l}$ of an ice-cold 0.2

Table 1

Gradient conditions

\begin{tabular}{rrrl}
\hline $\begin{array}{l}\text { Time } \\
(\mathrm{min})\end{array}$ & $\begin{array}{l}\text { Solvent A } \\
(\%)\end{array}$ & $\begin{array}{l}\text { Solvent B } \\
(\%)\end{array}$ & $\begin{array}{l}\text { Temperature } \\
\left({ }^{\circ} \mathrm{C}\right)\end{array}$ \\
\hline $0-35$ & 100 & 0 & 45 \\
$35-50$ & 100 & 0 & 60 \\
$50-55$ & 0 & 100 & 60 \\
$55-80$ & 100 & 0 & 45 \\
\hline
\end{tabular}

mol/1 lithium citrate "loading buffer" $\mathrm{pH} 2.20$ (containing $60 \mu \mathrm{mol} / \mathrm{l}$ norleucine as internal standard) in a $300-\mu \mathrm{l}$ insert and placed in a 4-ml WISP vial, and sealed with a PTFE seal.

\section{Results}

Three different three-way valves were tested to serve as a split-valve: the Lee LFYA 1 bar ministac valve, the Lee LFYA 4 bar ministac valve (both Dennis de Ploeg, Valkenburg, Netherlands) and the 24 VDC Cole Parmer Teflon PTFE solenoid valve (Applikon, Schiedam, Netherlands). From these, the Cole Parmer valve was the cheapest and most reliable valve. Although its internal volume was higher compared to the Lee-valves $(32 \mu \mathrm{l}$ versus $18 \mu \mathrm{l})$, this proved not to be a disadvantage in practice. Therefore, the Cole Parmer valve was used throughout our experiments.

Our primary goal was the isolation of phenylalanine and tyrosine. Therefore, a "short" isolation gradient was developed using norleucine as an internal standard. The resulting chromatograms (Fig. 2) show a baseline separation for these peaks.

The correct functioning of the valve was evaluated by programming a value of $8 \%$ split and measuring the resulting flow-rates. Considering the low back-pressure generated by the reagent flow-path and the helium over-pressure present on the OPA reservoir, we suspected this flow to be too high. Therefore, we measured the splitted solvent flow-rates with and without the influence of the reagent flow (direct and indirect method, Table 2). From the results, we concluded that the split-percentage was correct and stable, but the reagent flow was too high and irregular. In order to stabilize this reagent flow, the backpressure had to be increased. Placement of a back-pressure valve in the reagent flow-path resulted in a pulsating reagent flow and consequently irregular baseline. Therefore, the reagent back-pressure was increased by placing a $150 \times 3 \mathrm{~mm}$ I.D. column filled with the cationexchange resin Durrum DC-6A in the reagent flow-path, enabling a stable reagent flow down to 

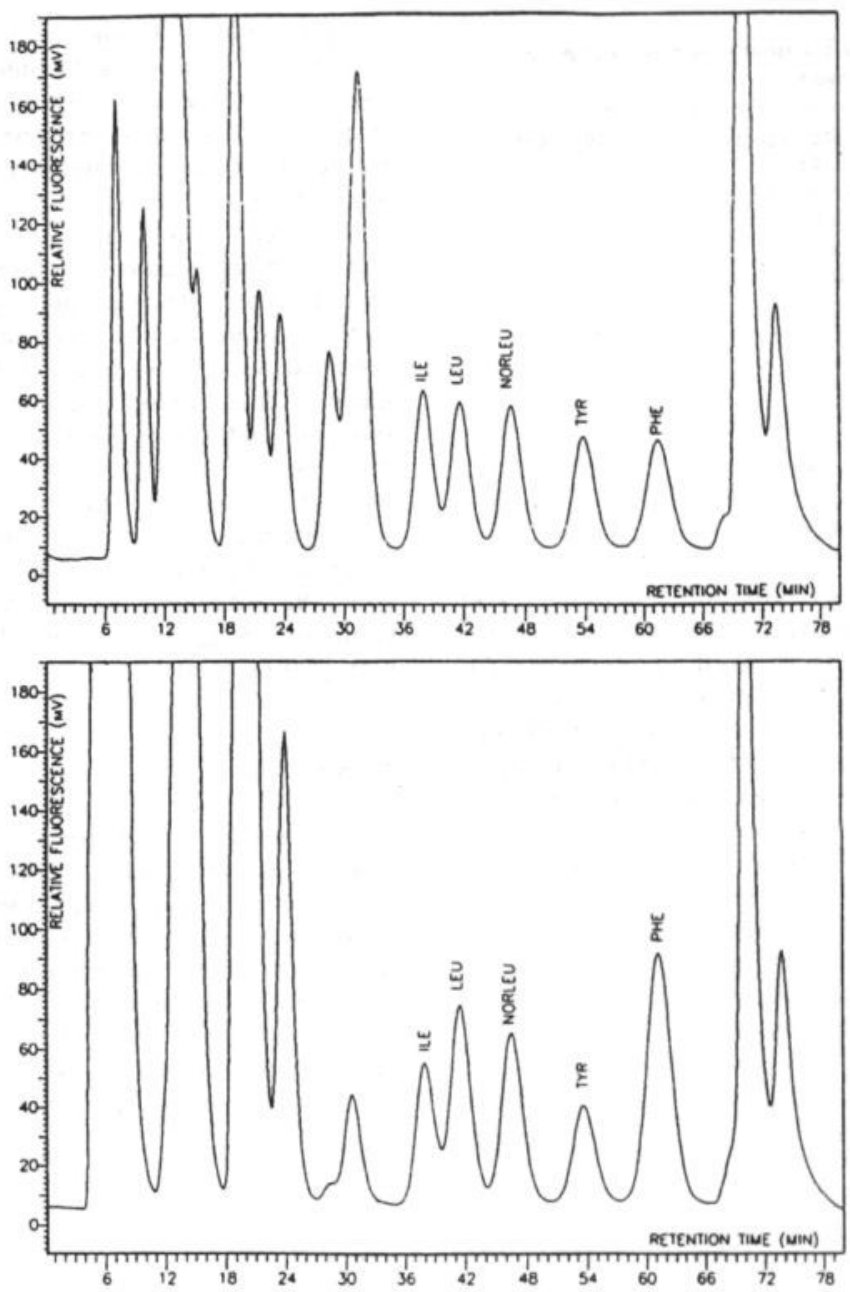

Fig. 2. Separation of tyrosine and phenylalanine in a $100 \mu \mathrm{mol} / \mathrm{l}$ physiological standard containing all major plasma amino acids (upper panel) and in plasma (lower panel). Injection volume was $75 \mu \mathrm{l}$ for each sample.

$0.035 \mathrm{ml} / \mathrm{min}$ (not shown) and resulting in a back-pressure of $0.2 \mathrm{MPa}$. Using this minimal OPA flow, an optimal chromatogram was obtained with a solvent flow of $0.050 \mathrm{ml} / \mathrm{min}$. This limited the minimal applicable split-percentage in this application to $10 \%$ at a total eluent flow of $0.5 \mathrm{ml} / \mathrm{min}$. So, $90 \%$ of the column effluent could be used for radioactivity counting.

As an optimal reaction time of amino acids with OPA reagent is reported to be $2-3 \mathrm{~min} \mathrm{[13],}$ the present flow-rates required a reactioncoil of ca. $1.5 \mathrm{~m} \times 0.3 \mathrm{~mm} \mathrm{I.D.} \mathrm{The} \mathrm{resulting} \mathrm{calculated}$ 
Table 2

Determination of the variation in split-percentage by direct and indirect measurement

\begin{tabular}{lll}
\hline Measurement & $\begin{array}{l}\text { Direct method } \\
(\%)\end{array}$ & $\begin{array}{l}\text { Indirect method } \\
(\%)\end{array}$ \\
\hline 1 & 9.87 & 7.97 \\
2 & 9.57 & 7.96 \\
3 & 9.13 & 7.97 \\
4 & 9.26 & 7.96 \\
5 & 8.35 & 7.92 \\
6 & 9.01 & 7.92 \\
Mean & 9.20 & 7.95 \\
S.D. & 0.52 & 0.02 \\
C.V. $(\%)$ & 5.66 & 0.30 \\
\hline
\end{tabular}

Both methods are discussed in the text.

difference in delay time of the amino acid fractions before arrival in the fraction collector or the detector was checked by measuring the fraction recoveries of isoleucine, leucine, norleucine, tyrosine and phenylalanine of 10 consecutive runs of a $25-\mu M$ physiological amino acid standard with the described standard HPLC technique [12]. A nearly $100 \%$ recovery was obtained, confirming the correctness of the settings (Table 3). The somewhat higher results may be explained by minor contaminations in buffers and reagents, playing a significant role at the low levels in the collected fractions,

Operation of the system with fluorescence detection, limitates the maximum amount which can be isolated and quantitated at the same time to $50 \mathrm{nmol}$ per amino acid, above which detector overload occurs. Using the less sensitive UVdetection at $330 \mathrm{~nm}$, a 10 times higher amount can be fractionated. Above this amount, the reagent concentration becomes limiting, while the resolution deteriorates due to column overload effects (not shown).

In order to determine the accuracy of the method, 51 rat plasma samples were fractionated and the concentrations obtained from the resulting chromatogram, were compared to those obtained with the standard technique [12]. The mean values found for isoleucine, leucine, tyrosine and phenylalanine were respectively $96 \%, 96 \%, 104 \%$ and $97 \%$ of the standard method. Considering the coefficients of variation, which are about $3 \%$ for both methods, no significant difference at the $95 \%$ confidence level could be established when these results were compared using the method of Bland and Altman [14] (Fig. 3).

\section{Discussion}

Until now it was laborious to perform metabolic studies with multiple amino acid tracers as numerous specialized techniques were required to isolate and quantitate these tracers and their tracees [11]. An universal technique for the isolation and quantitation of all amino acids was therefore desired. To enable this, we combined the reliable chromatographic separation of an amino acid analyzer with modern HPLC techniques.

Table 3

Determination of recovery percentages and reproducibility

\begin{tabular}{|c|c|c|c|c|c|c|c|c|c|}
\hline \multirow{3}{*}{$\begin{array}{l}\text { Amino } \\
\text { acid }\end{array}$} & \multicolumn{3}{|c|}{ Recovery (\%) } & \multicolumn{6}{|c|}{ On-line chromatography } \\
\hline & \multirow[b]{2}{*}{ Mean } & \multirow[b]{2}{*}{ S.D. } & \multirow[b]{2}{*}{ C.V. $(\%)$} & \multicolumn{3}{|c|}{ Area (mV min) } & \multicolumn{3}{|c|}{$t_{\mathrm{R}}(\min )$} \\
\hline & & & & Mean & S.D. & C.V. $(\%)$ & Mean & S.D. & C.V. $(\%)$ \\
\hline ILE & 102.2 & 3.31 & 3.24 & 169.2 & 7.28 & 4.30 & 70.93 & 0.20 & 0.28 \\
\hline LEU & 107.3 & 6.80 & 6.34 & 170.6 & 4.73 & 2.77 & 74.90 & 0.12 & 0.16 \\
\hline NORLEU & 94.8 & 2.64 & 2.78 & 166.6 & 2.57 & 1.54 & 80.22 & 0.10 & 0.13 \\
\hline TYR & 107.3 & 3.20 & 2.99 & 147.6 & 4.10 & 2.78 & 87.97 & 0.22 & 0.25 \\
\hline PHE & 105.8 & 5.91 & 5.59 & 165.2 & 4.27 & 2.59 & 96.73 & 0.17 & 0.18 \\
\hline
\end{tabular}



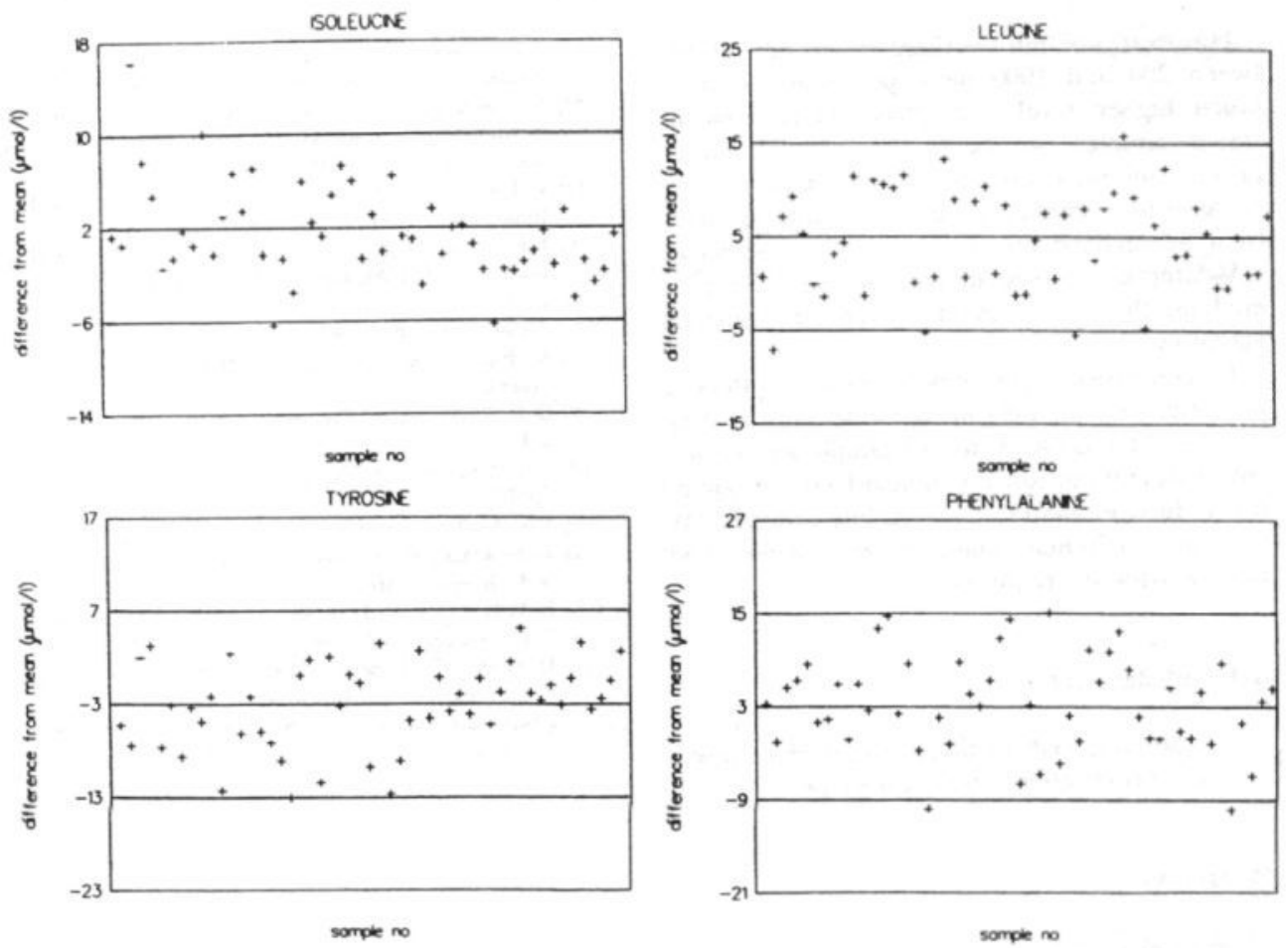

Fig. 3. Comparison of results obtained by the standard HPLC technique and the present isolation technique using the method of Bland and Altman [14]. The results $(\mu \mathrm{mol} / \mathrm{I})$ are plotted as the difference from the mean (center line) with the 2 S.D. levels at 95\% confidence level (upper and lower lines).

The present method was designed to obtain maximal recovery of radioactivity with a minimal amount of sample. We therefore chose to determine radioactivity off-line and not on-line. On-line counting requires at least $10-15$ times more activity, because the solvent flow passes through the flow cell of the detector in a short time, resulting in a lower signal-to-noise ratio and thus a high background. Using an off-line determination, the counting time can be much longer. For tritium, this reduces the required activity for each desired amino acid to only 50$100 \mathrm{dpm}$ for an accurate measurement. Because each amino acid can be isolated within the same chromatographic run, the total sample amount and the total amount of activity can be minimal.

Fluorescence detection was chosen for the same reason. The maximum amount which can be quantitated fluorimetrically is $50 \mathrm{nmol}$. Above this value the detector signal goes off-scale. This amount represents a maximum of $100-1000 \mu \mathrm{l}$ of deproteinized plasma, depending on the amino acid in question. These volumes are well within the range of amounts that can be obtained from small laboratory animals. Also, it is within the maximum volume range that can be injected directly onto the column without a negative effect on the separation. 
However, column overload effects appear between 200 and $1000 \mathrm{nmol}$ per amino acid, a much higher level. Therefore, more concentrated samples can be fractionated, or larger plasma amounts after lyophilization and resuspension in a smaller volume. Quantitation may then be realized by applying the less sensitive UV-detection instead of fluorescence detection, enabling the measurement of even lower specific activities.

In conclusion, the present method offers a powerful tool for measuring the specific activity of several amino acids in one sample and in one chromatographic run on standard HPLC equipment. In combination with off-line radioactivity counting, minimal amounts of sample and radioactivity are required.

\section{Acknowledgement}

The authors wish to thank Mr. R.H.P. Oderkerk for his excellent analytical support.

\section{References}

[1] R.R. Wolfe, Radioactive and Stable Isotope Tracers in Biomedicine, Wiley-Liss, New York, NY, 1992, p. 357.
[2] E.P. Donahue, L.L. Brown, P.J. Flakoll and N.N. Abumrad, J. Chromatogr., 571 (1991) 29.

[3] N. Vaidyanath, R. Birkhahn, J.R. Border, R. McMenamy, G. Oswald, G. Trietley and T.F. Yuan, Anal. Biochem., 70 (1976) 479.

[4] P. Tessari, S. Inchiostro, M. Vettore, L. Sabadin and G. Biolo, Clin. Biochem., 24 (1991) 425.

[5] F.F. Horber, J. Kahl, L. Lecavalier, B. Krom and M.W. Haymond, J. Chromatogr., 495 (1989) 81.

[6] L. Lecavalier, F.F. Horber and M.W. Haymond, J. Chromatogr., 491 (1989) 410.

[7] K. Bartlett and A.G. Causey, Methods Enzymol., 166 (1988) 79.

[8] D.R. Reeve and A. Crozier, J. Chromatogr., 137 (1977) 271.

[9] J.A. Grunau and J.M. Swiader, J. Chromatogr., 594 (1992) 165

[10] S.E. Møller, J. Chromatogr., 613 (1993) 223.

[11] E. Newman, M.J. Heslin, R.F. Wolf, P.W.T. Pisters and M.F. Brennan, Metabolism, 43 (1994) 70.

[12] H.M.H. van Eijk, D.R. Rooyakkers and N.E.P. Deutz, J. Chromatogr., 620 (1993) 143.

[13] H. Godel, T. Graser, P. Foldi, P. Pfaeder and P. Furst, J. Chromatogr., 297 (1984) 49.

[14] J.M. Bland and D.G. Altman, Lancet, 8 (1986) 307. 


\title{
Isolation and quantitation of isotopically labeled amino acids from biological samples
}

\author{
Hans M.H. van Eijk ${ }^{a}$, Dennis R. Rooyakkers ${ }^{a}$, Anton J.M. Wagenmakers ${ }^{\text {, }}$, \\ Peter B. Soeters ${ }^{a}$, Nicolaas E.P. Deutz ${ }^{a, *}$ \\ 'Department of Surgery, Maastricht University, P.O. Box 616, NL-6200 MD Maastricht, Netherlands \\ 'Department of Human Biology, Maastricht University, P.O. Box 616, NL-6200 MD Maastricht, Netherlands
}

Received 29 August 1996; revised 3 October 1996; accepted 15 October 1996

\begin{abstract}
To face the problem of simultaneous isolation and quantitation of isotopically labeled amino acids in biological samples, two semi-preparative chromatographic methods were developed. One method was especially designed to isolate radioactively labeled amino acids for which we used derivatization with the fluorophore $o$-phthaldialdehyde (OPA), which is known to be easy and reliable. Isolation of amino acids labeled with stable isotopes required another approach as we wanted to use isotope ratio mass spectroscopy (IRMS), which can only be performed on pure, non-derivatized amino acids. Because the OPA probe cannot be removed after isolation of the derivative, we used 9-fluorenylmethylchloroformate (FMOC) instead. This probe is linked to an amino acid via a peptide bond which can easily be broken by gas-phase acid hydrolysis (103\% recovery after $5 \mathrm{~h}$ at $150^{\circ} \mathrm{C}: \mathrm{S} . \mathrm{D}=3.5 \%, n=14$ ). Run time (injection to injection) was 60 min for the OPA method and 75 min for the FMOC method. Both fluorescence and UV absorbance detection can be employed. The coefficient of variation (C.V.) for peak area measurement was below $2 \%$ for most OPA amino acids and below $3 \%$ for most FMOC amino acids. At maximum, a total of $1000 \mu \mathrm{l}$ could be injected, representing approximately $200 \mu \mathrm{l}$ of deproteinized plasma. The methods were linear up to injection of $0.5 \mu \mathrm{mol}$ of all amino acids (OPA: $r^{2}=0.995-0.999$; FMOC: $r^{2}=0.992-0.999$ ). The C.V. of the IRMS measurement within the range which can be isolated maximally in one chromatographic run ( $50-500 \mathrm{nmol}$ ), was less than $3 \%$ above $100 \mathrm{nmol}$, indicating that chromatographic isolation fulfils the needs of the IRMS determination. The resulting methods are suitable for the isolation and quantitation of micromolar amounts of labeled amino acids from biological samples.
\end{abstract}

Keywords: Derivatization, LC: Amino acids

\section{Introduction}

A powerful tool in studying protein synthesis and/ or degradation in laboratory animals is quantitation

"Corresponding author. of the change in specific activity of selected radioactively labeled amino acids in blood or tissue. For this purpose, isolation of these amino acids and determination of their labeled and total amounts is required. This was formerly performed through ionexchange chromatography [1]. However, as this 
technique requires several hours to separate all major plasma amino acids, short runs were optimized and used to isolate and quantitate only the isotopically labeled components. The remaining amino acids concentrations had to be determined in a separate analysis [2].

Alternatively, amino acids can be separated by reversed-phase chromatography. Although this technique may also be used to isolate non-derivatised amino acids [3,4], the selectivity of a reversed-phase system with regard to pure amino acids is mediocre. For analytical applications, selectivity and sensitivity were therefore commonly improved by derivatization with $o$-phthaldialdehyde (OPA) [2,5] or 9-fluorenylmethylchloroformiate (FMOC) [5-7]. Recently, OPA was also applied for a semi-preparative isolation of glutamine from plasma [8].

To study metabolism of slowly turning-over proteins in humans, the $\left[1-{ }^{13} \mathrm{C}\right]$ leucine method is frequently used [9]. In this method purified proteins are hydrolyzed and the leucine fraction is isolated, mostly by preparative gas chromatography (GC) and then decarboxylated by heating with ninhydrin at low $\mathrm{pH}$. The ${ }^{13} \mathrm{C}$ enrichment in the liberated $\mathrm{CO}_{2}$ is then measured by isotope ratio mass spectroscopy (IRMS) [10]. Unfortunately, the amounts and purity of leucine, isolated by preparative GC were variable in our hands. We therefore investigated whether liquid chromatography would be a suitable alternative. We first used ion-exchange chromatography [1] as, in contrast to most reversed-phase techniques, it allows direct isolation of pure amino acids needed for the ninhydrin decarboxylation procedure which is required for the IRMS measurement. However, the separation of leucine from isoleucine is difficult and analysis times are long. An alternative possibility could be the isolation of FMOC-derived amino acids, from which the FMOC probe can be removed after isolation as it couples to the amino acid via a peptide bond that can easily be broken [11]. Unfortunately, the FMOC derivatization procedure is more difficult than the OPA method due to excess reagent interference and problems with the recovery of the derived product $[12,13]$ and this application therefore needed further development.

Therefore, two new applications were designed. One, for the isolation of radioactive tracers using the
OPA-probe and another for the isolation of stable isotope tracers using the FMOC-probe.

\section{Experimental}

\subsection{Equipment}

Our HPLC system consisted of a Model 2248 reagent pump, a Model 2249 gradient pump controlling a Model 2248-201 low pressure ternary mixing panel and a Model 2256 solvent conditioner, all from Pharmacia (Woerden, Netherlands). The analytical column for the OPA application was a $250 \times 10 \mathrm{~mm}$ I.D. column filled with Spherisorb ODS II $5 \mu \mathrm{m}$, while for the FMOC application the same column dimensions were used, but filled with Inertsil $5 \mu \mathrm{m}$ (both columns: Chrompack, Bergen op Zoom, Netherlands). Both columns were placed in a programmable Mistral column oven (Spark, Emmen, Netherlands). The Spherisorb column was operated at $25^{\circ} \mathrm{C}$ and the Inertsil column at $30^{\circ} \mathrm{C}$. For the automated sample processing a WISP Model 715 or Model 717 sample processor (Waters, Etten-Leur, Netherlands) was used, equipped with a cooled sample storage compartment and a 48 position sample tray. Amino acid fractions were collected, using a Helifrac fraction collector (Pharmacia) equipped with a 43 position tray for $18 \mathrm{ml}$ scintillation vials. For a more efficient use, it was controlled externally by a Model 900 interface (Perkin-Elmer/ Nelson, Gouda, Netherlands). The interface was programmed from a Tandon 486 personal computer, running Model 2700 TURBochrom software (version 3.2: Perkin-Elmer/Nelson) under Microsoft Windows 95. The interface was also used for the collection and processing of data produced by the fluorescence detector. Fluorescence was monitored with a Jasco Model 821FP detector (B \& L systems, Maarssen, Netherlands) equipped with a xenon lamp and a $16 \mu$ l flow-cell. Measurements were made at the excitation wavelengths of 330 and $260 \mathrm{~nm}$ and at the emission wavelengths of 550 and $360 \mathrm{~nm}$ for OPA and FMOC, respectively. Radioactivity was determined using a Beckman Model LS 3801 Liquid scintillation counter. The ${ }^{13} \mathrm{C}$ enrichment of $\mathrm{CO}_{2}$ 
was measured on a Model MAT-252 isotope ratio mass spectrometer (IRMS) (Finnigan, Veenendaal, Netherlands).

\subsection{Sample preparation}

\subsubsection{Standards}

Amino acid standards were prepared by dissolving pure amino acids in water to a final concentration of $250 \mu \mathrm{mol} \mathrm{I}^{-1}$ each, and calibrated against a physiological standard (Sigma, Amsterdam, Netherlands), using HPLC [2]. The calibrated standard was divided in $1 \mathrm{ml}$ portions and stored at $-80^{\circ} \mathrm{C}$.

\subsubsection{Plasma}

Heparinized blood samples were obtained from laboratory animals and humans and collected on ice, followed by immediate centrifugation ( $5 \mathrm{~min}, 11000$ $\mathrm{g}, 4^{\circ} \mathrm{C}$ ) in a Hereaus biofuge (Dijkstra, Amsterdam, Netherlands). Next, plasma was deproteinized with 5 -sulfosalicylic acid (SSA), $8 \mathrm{mg} / 200 \mu \mathrm{l}$ plasma, frozen immediately in liquid nitrogen and stored at $-80^{\circ} \mathrm{C}$. Before analysis, samples were thawed at $4^{\circ} \mathrm{C}$, vortex-mixed vigorously and centrifuged as described before.

\subsection{Reagents and solvents}

All solutions were prepared with ultra-pure water, generated by a Super-Q system (Millipore/Waters). All chemicals used were of analytical grade (Brunschwig, Amsterdam, Netherlands), solvents of chromatographic grade (Across Chimica, 's-Hertogenbosch, Netherlands).

\subsection{OPA system}

\subsubsection{OPA reagent}

The OPA reagent was prepared daily by dissolving $10 \mathrm{mg}$ of OPA (Fluoraldehyde, Pierce, Brunschwig, Amsterdam, Netherlands) in $0.50 \mathrm{ml}$ of methanol, adding $3.00 \mathrm{ml}$ of potassium borate buffer $(1.0 \mathrm{~mol} /$ $1, \mathrm{pH} \mathrm{10.4)} \mathrm{and} 12.5 \mu \mathrm{l}$ of 3-mercaptopropionic acid (3-MPA).

\subsubsection{Derivatization}

The OPA-reagent $(400 \mu \mathrm{l})$ was added by the WISP autosampler to a vial pre-filled with $200 \mu \mathrm{l}$ of deproteinized plasma and mixed once. After $2 \mathrm{~min}$, $55 \mu \mathrm{l}$ of citric acid $(1 M)$ was added to adjust the $\mathrm{pH}$ of the reaction mixture to the $\mathrm{pH}$ of the eluent. Next, $600 \mu \mathrm{l}$ was injected into the chromatograph, corresponding to $183 \mu \mathrm{l}$ of pure sample.

\subsubsection{Solvents}

Solvent A was $25 \mathrm{mmol}^{-1}$ citrate buffer, $\mathrm{pH} 6.8$ containing $2 \%(\mathrm{v} / \mathrm{v})$ tetrahydrofuran (THF). Solvent $B$ was citrate buffer mixed with acetonitrile and THF $(50: 40: 10, v / v / v)$. Gradient conditions are given in Table 1.

\subsection{FMOC system}

\subsubsection{FMOC reagent}

The FMOC solution was prepared daily by dissolving $20 \mathrm{mg}$ of FMOC in $4.0 \mathrm{ml}$ of acetonitrile. Potassium borate $(0.75 M, \mathrm{pH} 8.75)$ served as reagent buffer.

\subsubsection{Derivatization}

Deproteinized plasma (see above) $(200 \mu \mathrm{l})$ was added to a $3 \mathrm{ml}$ WISP vial, containing $400 \mu \mathrm{l}$ of reagent buffer and mixed thoroughly. Samples were placed in the WISP sample processor and derivatization was initiated by the addition of $400 \mu \mathrm{l}$ of FMOC reagent solution. After $90 \mathrm{~s}, 200 \mu \mathrm{l}$ of a $50 \mathrm{mM}$ 1 -aminoadamantane (ADAM) in ethanol was added to neutralize the FMOC excess, after which $1000 \mu \mathrm{l}$ was injected into the chromatograph, corresponding to about $183 \mu \mathrm{l}$ of pure sample.

\subsubsection{Solvents}

Solvent A was a $50 \mathrm{mmol}^{-1}$ sodium acetate buffer, $\mathrm{pH} 4.2$ acetonitrile solution $(70: 30, \mathrm{v} / \mathrm{v})$. Solvent B was acetonitrile-water $(75: 25$, v/v). Gradient conditions are given in Table 1.

\subsection{Liquid scintillation counting}

Amino acid fractions $(6 \mathrm{ml})$ were collected in 18 $\mathrm{ml}$ plastic scintillation vials and mixed with $12 \mathrm{ml}$ Ultima Gold XR (Packard, Groningen, Netherlands). 
Table I

\begin{tabular}{|c|c|c|c|c|c|c|c|}
\hline \multicolumn{4}{|c|}{ OPA method } & \multicolumn{4}{|c|}{ FMOC method } \\
\hline $\begin{array}{l}\text { Time } \\
\text { (min) }\end{array}$ & $\begin{array}{l}\text { Flow } \\
(\mathrm{ml} / \mathrm{min})\end{array}$ & $A(\%)$ & B (\%) & $\begin{array}{l}\text { Time } \\
(\mathrm{min})\end{array}$ & $\begin{array}{l}\text { Flow } \\
\text { (ml/min) }\end{array}$ & $A(\%)$ & B (\%) \\
\hline 0 & 0 & 100 & 0 & 0 & 0 & 100 & 0 \\
\hline 0.1 & 2.00 & 100 & $\mathbf{0}$ & 0.1 & 2.00 & 100 & 0 \\
\hline 0.2 & 4.00 & 100 & 0 & 0.2 & 4.00 & 100 & 0 \\
\hline 44.0 & 4.00 & 55 & 45 & 5.0 & 4.00 & 100 & 0 \\
\hline 45.0 & 4.00 & 0 & 100 & 10.0 & 4.00 & 98 & 2 \\
\hline 49.0 & 4.00 & 0 & 100 & 45.0 & 4.00 & 60 & 40 \\
\hline 50.0 & 4.00 & 100 & 0 & 50.0 & 4.00 & 59 & 41 \\
\hline \multirow[t]{5}{*}{60.0} & 0 & 100 & 0 & 53.0 & 4.00 & 55 & 45 \\
\hline & & & & 55.0 & 4.00 & 0 & 100 \\
\hline & & & & 60.0 & 4.00 & 0 & 100 \\
\hline & & & & 65.0 & 4.00 & 100 & 0 \\
\hline & & & & 75.0 & 0.00 & 100 & 0 \\
\hline
\end{tabular}

To eliminate chemoluminescence, samples were rested overnight at room temperature and ${ }^{3} \mathrm{H}$ and/or ${ }^{14} \mathrm{C}$ activity was determined using a Beckman Model LS 3801 liquid scintillation counter, preset to $20 \mathrm{~min}$ counting time.

\subsection{Stable isotope determination}

\subsubsection{Hydrolysis}

After isolation of the FMOC amino acid fractions in $6 \mathrm{ml}$ glass scintillation vials, the samples were lyophilized after which they were put in a hydrolysis container of our own design (Fig. 1). The container consisted of a stainless steel outer vial and a Tefion inner vial and contained a support rack for seven 6 $\mathrm{ml}$ vials. A 20-ml portion of $6 \mathrm{M} \mathrm{HCl}$ was put on the bottom and the rack was filled with the dried samples. The container was closed and placed in an oven for $5 \mathrm{~h}$ at $150^{\circ} \mathrm{C}$. Hereafter, samples were redissolved in $250 \mu \mathrm{l}$ of water, transferred to a $2-\mathrm{ml}$ crimp cap vial and lyophilized again.

\subsubsection{Decarboxylation}

A 20-mg portion of ninhydrin, together with 100 $\mu l$ of helium-degassed $0.1 M$ citric acid solution was added to the lyophilized samples in a $2-\mathrm{ml}$ vial. which was flushed with helium and closed with a crimp cap. Decarboxylation was initiated by heating to $100^{\circ} \mathrm{C}$ for $30 \mathrm{~min}$. Next, a $500-\mu \mathrm{l}$ portion of helium was injected into the vial using a $1-\mathrm{ml}$ gastight syringe equipped with a gas-tight valve (SGE Bester, Amstelveen, Netherlands), then the water in the vial was frozen by holding the vial in solid carbon dioxide. ${ }^{13} \mathrm{C}$ enrichment of the liberated $\mathrm{CO}_{2}$ was then measured by a head-space injection of $500 \mu \mathrm{l}$ into the injector of a GC (Hewlett Packard, Amstelveen, Netherlands: containing a Poroplot column operated at room-temperature) which was connected on-line to the IRMS via a water trap.

\section{Results}

Our goal was to process $200 \mu \mathrm{l}$ of deproteinized plasma or tissue homogenate, requiring an injection volume (of derivatization mix) of $600-800 \mu$ l. This volume was too large to apply to an analytical column. Therefore we used a semi-preparative column $(250 \times 10 \mathrm{~mm}$ I.D.), which was equipped with a $10 \times 4.6 \mathrm{~mm}$ (I.D.) guard column, filled with the same packing material. For the OPA application we used Spherisorb ODS II $5 \mu \mathrm{m}$ packing, while for the FMOC application we used Inertsil $5 \mu \mathrm{m}$ packing. On both columns, a maximum of about $1000 \mu \mathrm{l}$ could be injected without significant loss of resolution. The flow-rate for both methods was $4 \mathrm{ml} /$ min, resulting in a back-pressure of $16 \mathrm{MPa}$ at the start of the gradient.

\section{I. OPA method}

Derivatization with OPA is performed at high $\mathrm{pH}$ (10.5). As large sample volumes are applied to the column, the stability of the Spherisorb packing 
material is challenged with each injection. This effect was amplified if peroxide is present in the tetrahydrofuran (THF), used for the solvents. Taking no precautions, these effects caused a rapid decrease in the carbon load of the column ( $12 \%$ to $10.5 \%$, within 100 injections), resulting in a $k^{\prime}$ change of fluroanthene from 8.5 to 6.3 in a mixture of acetonitrile-water $(70: 30, v / v)$ (determined courteously by Chrompack, Middelburg, Netherlands). This degradation could be minimized by neutralization of the reaction-mixture prior to injection and the use of peroxide free THF (Across Chimica). The use of butylated hydroxytoluene (BHT) stabilized THF also slowed down the column degradation but introduced "ghost"-peaks. Neutralization of the reaction-mixture was performed by the addition of $55 \mu \mathrm{l} 1 \mathrm{M}$ citric acid, prior to injection by the autosampler. This addition resulted in the formation of a buffer with a $\mathrm{pH}$ of about 7, also compensating for small differences in the acidity of samples, due to differences in their protein content. A beneficial side effect of this method was that the retention times of especially the first eluting peaks were stabilized and baseline separation for most amino acids could be obtained (Fig. 2A and B). Column performance could thus be improved to about 500-1000 runs.

Although UV absorbance detection at $330 \mathrm{~nm}$ can also be used, we choose fluorescence detection to get a better baseline-stability. Response overflow was prohibited by selecting the optimal excitation wavelength $(330 \mathrm{~nm})$ but a sub-optimal emission wavelength $(550 \mathrm{~nm})$. Linearity of the method was checked in the range from $50 \mathrm{nmol}$ to $0.5 \mu \mathrm{mol}$ resulting in an $r^{2}$ of 0.992 or better for all amino acids. The coefficient of variation (C.V.) was determined for peak area measurement by injection of 10 standards. The C.V. for most peak areas was below $2 \%$ (Table 2 ).

\subsection{FMOC method}

The FMOC-method was primarily designed to isolate amino acids enriched with stable isotopes in

Table 2

\begin{tabular}{|c|c|c|c|c|c|c|}
\hline \multirow[t]{2}{*}{ Amino acid } & \multicolumn{3}{|c|}{ OPA method } & \multicolumn{3}{|c|}{ FMOC method } \\
\hline & $\begin{array}{l}\text { Area mean } \\
\left(\mu V^{*} s\right)\end{array}$ & $\begin{array}{l}\text { Area S.D. } \\
(\mu V * s)\end{array}$ & $\begin{array}{l}\text { Area C.V. } \\
(\%)\end{array}$ & $\begin{array}{l}\text { Area mean } \\
(\mu V * s)\end{array}$ & $\begin{array}{l}\text { Area S.D. } \\
(\mu \mathrm{V} \cdot s)\end{array}$ & $\begin{array}{l}\text { Area C.V. } \\
(\%)\end{array}$ \\
\hline Asp & $3082 \quad 141$ & 23203 & 0.75 & 4489578 & 111145 & 2.48 \\
\hline Glu & 2830136 & 20572 & 0.73 & 6969069 & 164922 & 2.37 \\
\hline Asn & 2987576 & 25506 & 0.85 & 7775923 & 118187 & 1.52 \\
\hline Ser & 3403090 & 27335 & 0.80 & 11004208 & 175407 & 1.59 \\
\hline Gln & 3338218 & 29880 & 0.90 & 9734687 & 114425 & 1.18 \\
\hline His & 2502723 & 31780 & 1.27 & 2183421 & 69615 & 3.19 \\
\hline Gly & 3078663 & 45799 & 1.49 & 11403174 & 105144 & 0.92 \\
\hline Thr & 3208384 & 30343 & 0.95 & 8165493 & 128707 & 1.58 \\
\hline Cit & 2719669 & 24130 & 0.89 & 7451300 & 97202 & 1.30 \\
\hline Ala & 3154292 & 23811 & 0.75 & 8099607 & 117904 & 1.46 \\
\hline Arg & 3156594 & 51952 & 1.65 & 9375717 & 97925 & 1.04 \\
\hline Tau & 3285553 & 39536 & 1.20 & 10368836 & 82198 & 0.79 \\
\hline aab & 3968403 & 78705 & 1.98 & 9014150 & 102358 & 1.14 \\
\hline Tyr & 2778615 & 52794 & 1.90 & 3350931 & 84984 & 2.54 \\
\hline Val & 3393233 & 27681 & 0.82 & 9605071 & 104577 & 1.09 \\
\hline Met & 3193338 & 50596 & 1.58 & 8906826 & 214798 & 2.41 \\
\hline NVal & 6720479 & 81202 & 1.21 & 17035191 & 17013 & 1.00 \\
\hline Ile & 3251257 & 35474 & 1.09 & 9336035 & 90808 & 0.97 \\
\hline Phe & 3078111 & 32620 & 1.06 & 11621542 & 96535. & 0.83 \\
\hline Trp & 3069970 & 26825 & 0.87 & & & \\
\hline Leu & 3239852 & 29086 & 0.90 & 8810612 & 93213 & 1.06 \\
\hline Orn & 778829 & 14574 & 1.87 & 3071869 & 137232 & 4.47 \\
\hline Lys & 960095 & 18056 & 1.88 & 7283754 & 293197 & 4.03 \\
\hline
\end{tabular}


general and focused more specifically on leucine. The method development regarded two aspects:

(1) Hydrolysis of the derivative to liberate the amino acid, enabling isotope ratio mass spectrometer analysis.

(2) Adaptation of reagent composition

\subsubsection{Ad (I)}

Two types of acid hydrolysis were studied, namely hydrolysis in glass vials sealed under vacuum at $110^{\circ} \mathrm{C}$ and gas-phase hydrolysis at $150^{\circ} \mathrm{C}$ in especially designed containers. Vacuum hydrolysis gave a maximal recovery of $86 \%$ after $34 \mathrm{~h}$ at $110^{\circ} \mathrm{C}$ (not shown). Shorter or longer hydrolysis times resulted in a decrease of recovery. Gas-phase hydrolysis required the development of our own hydrolysis vial as none of the commercially available containers we tried could withstand a leak-test at $150^{\circ} \mathrm{C}$. Our design consisted of a stainless steel outer vial (for structural strength) and an inert Teflon inner vial, containing a Teflon rack to support the glass vials which contained the samples (Fig. 1). Using this vial, the mean hydrolysis recovery of leucine-FMOC was $103 \%(\mathrm{C} . \mathrm{V} .=3.5 \%, n=14)$, after $5-6 \mathrm{~h}$ at $150^{\circ} \mathrm{C}$.

\subsubsection{Ad (2)}

For a preparative application, the commonly used reagent prescription [5-7] was not suitable, because only minimal amounts of amino acids could be derivatized. Instead of acetone, we therefore used acetonitrile, thus enabling the preparation of more concentrated FMOC solutions. For the analysis of deproteinized plasma, a 7.5-10.0 $\mathrm{mmol}^{-1}$ FMOC reagent solution was sufficient. Protein hydrolysates, which are more concentrated (mmol of each amino acid), required a more concentrated $50 \mathrm{mmol} \mathrm{I}^{-1}$ FMOC solution, to guarantee a sufficient reagent excess. However, the solubility of FMOC derivatives

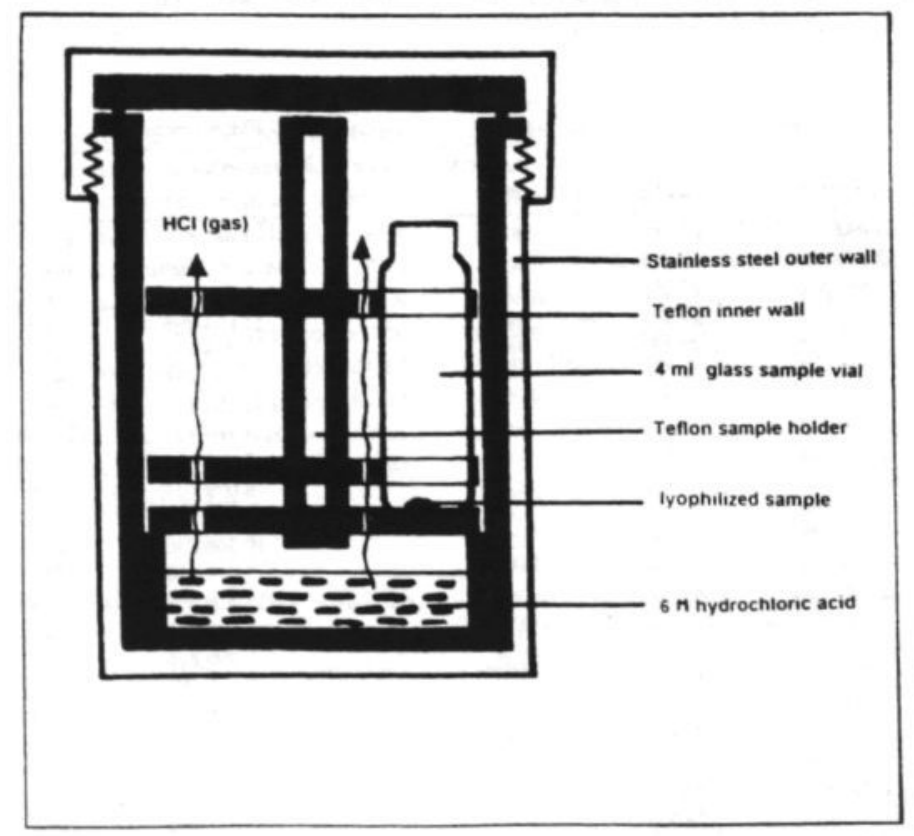

Fig. 1. Hydrolysis vial for gas-phase hydrolysis. 
is limiting. Thus, a maximal total amount of 5-10 $\mu \mathrm{mol}$ of amino acid (250-500 nmol each amino acid) can be processed in one run. The reagent solution was stable for at least one week, if stored in the dark at $4^{\circ} \mathrm{C}$ in an amber $4 \mathrm{ml}$ WISP vial, equipped with self-sealing Teflon stopper. After $90 \mathrm{~s}$ reaction time, the excess FMOC was neutralized with $200 \mu \mathrm{l}$ 1-amino adamantane (ADAM, $50 \mathrm{mmol} /$ 1) dissolved in ethanol, thus preventing the formation of a large FMOC hydroxide peak.

A second factor influencing the response is the reaction $\mathrm{pH}$. It is known that maximal fluorescence is obtained at $\mathrm{pH} 7.7$ [7]. However, the $\mathrm{pH}$ range for maximal fluorescence is very narrow $(\mathrm{pH} 7.4-7.8)$, while above $\mathrm{pH} 8.0$ most amino acids have a stable (although some $30 \%$ lower) response curve up to $\mathrm{pH}$ 10.4. We therefore increased the reaction $\mathrm{pH}$ to 8.75 , thus also increasing the capacity of the borate buffer and ensuring better reproducibility. A three-fold dilution of acid deproteinized plasma with $0.75 \mathrm{M}$ borate buffer $(\mathrm{pH} 8.75)$ was sufficient to maintain this reaction $\mathrm{pH}$. As a result of these adaptations, the total process volume of a $200 \mu \mathrm{l}$ deproteinized plasma sample (or 50-100 $\mu \mathrm{l}$ protein hydrolysate) was now $1200 \mu \mathrm{l}$. From this, we injected $1000 \mu \mathrm{l}$ which enabled good chromatography (Fig. 2C and D).

The linearity and C.V. of the method was checked up to $0.5 \mu \mathrm{mol}$ in the same way as for the OPA method $\left(r^{2}=0.992\right.$ or higher). Above this, linearity was lost due to precipitation of derivatives. The C.V. for peak area measurement was below $3 \%$ for most amino acids (Table 2), which is comparable with the OPA method.

\subsection{IRMS measurement}

According to the literature $[9,10]$ a minimum of $250 \mathrm{nmol}$ of amino acid derived $\mathrm{CO}_{2}$ is required to enable a good IRMS measurement. The present
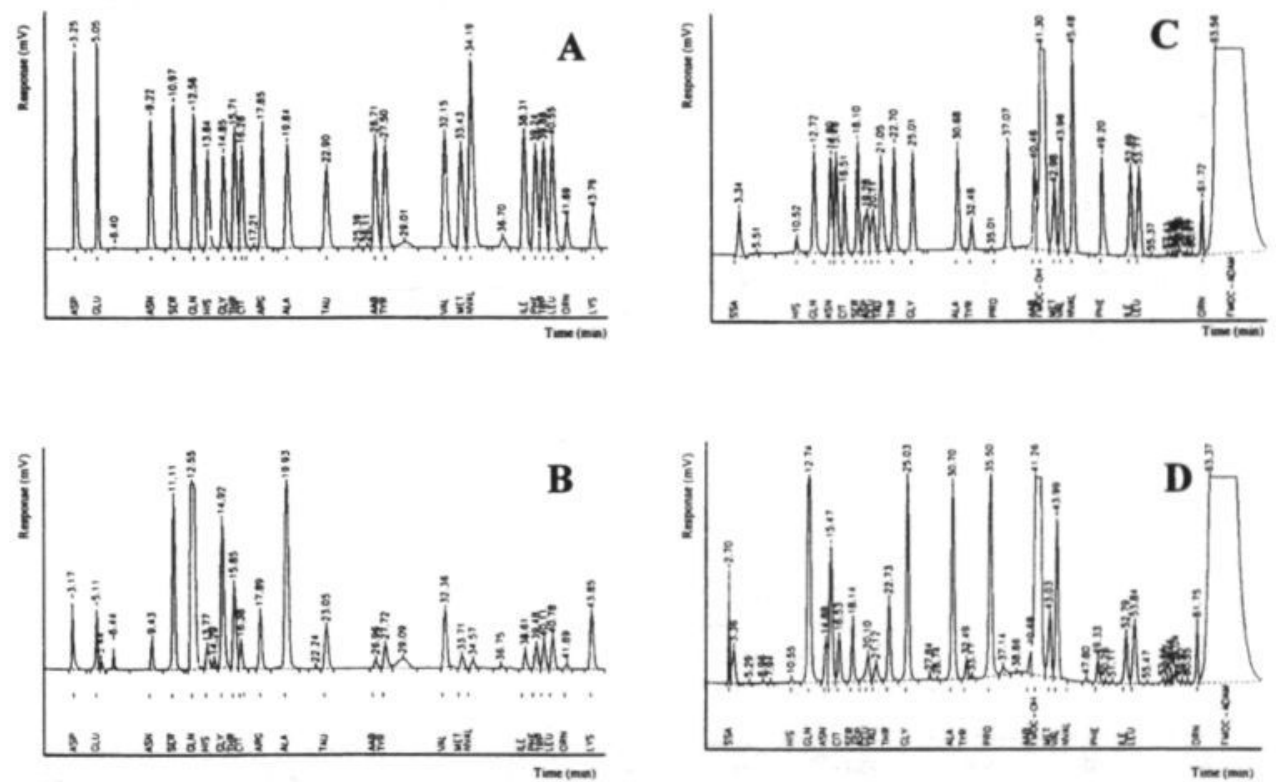

Fig. 2. Panel A: Separation of an OPA-amino acid standard ( $50 \mathrm{nmol}$ injected each amino acid). Panel B: Separation an OPA derived rat plasma sample ( $200 \mu \mathrm{l}$ plasma injected); Panel C: Separation of an FMOC-amino acid standard ( $50 \mathrm{nmol}$ injected each amino acid). Panel D: Separation of an FMOC derived pig plasma sample ( $200 \mu \mathrm{l}$ plasma injected). 
FMOC method allows isolation of maximal $250-500$ nmol of each amino acid. To check if these amounts allow accurate measurements on our IRMS system, we determined $\mathrm{CO}_{2}$ enrichment of naturally enriched leucine in the range $50-500 \mathrm{nmol}(n=4)$. Mean enrichment (expressed as the delta value [9]) was found to be constant, but the C.V. increased rapidly below $50 \mathrm{nmol}$ (Fig. 3). We therefore concluded that the described chromatographic procedure allows the isolation of amounts of amino acid large enough to enable good IRMS measurement.

\subsection{Determination of the enrichment or specific activity of isolated amino acids}

The chromatographic separation of amino acids may result in isotope fractionation of the eluting peak [14], so we also examined this possibility for our reversed-phase methods. Therefore, $2 \mu \mathrm{mol}$ of leucine enriched with $\left[1-{ }^{14} \mathrm{C}\right]$ was injected (OPAmethod, using a linear gradient to $100 \%$ in $60 \mathrm{~min}$ ) and the eluting peak was collected in $0.1 \mathrm{~min}$ fractions. The recorded area of the isolated fractions and their radioactivity were determined. A definite shift in the retention of the heavier isotope (Fig. 4) was observed. As a consequence, for stable isotope measurements it is thus necessary that the peak of interest elutes freely from surrounding peaks and is collected completely. To check for this, we injected a mixture of isoleucine and leucine (both $5 \mathrm{mmol} / \mathrm{l}$ ). Isoleucine and leucine fractions were collected in six-fold and in each fraction, concentrations of both amino acids were determined [2] (after hydrolysis of the FMOC derivatives). We found a leucine contamination ranging from $0.83 \%$ to $1.77 \%$ in the isoleucine fractions (mean $=1.28 \%$ ) and an isoleucine contamination ranging from $0.82 \%$ to $1.00 \%$ in the leucine fractions (mean $=0.86 \%$ ). This contamination was too low to interfere with the interpretation of the leucine enrichment measurement.

The radioactivity measurement efficiency is strongly influenced by the scintillation liquid used.

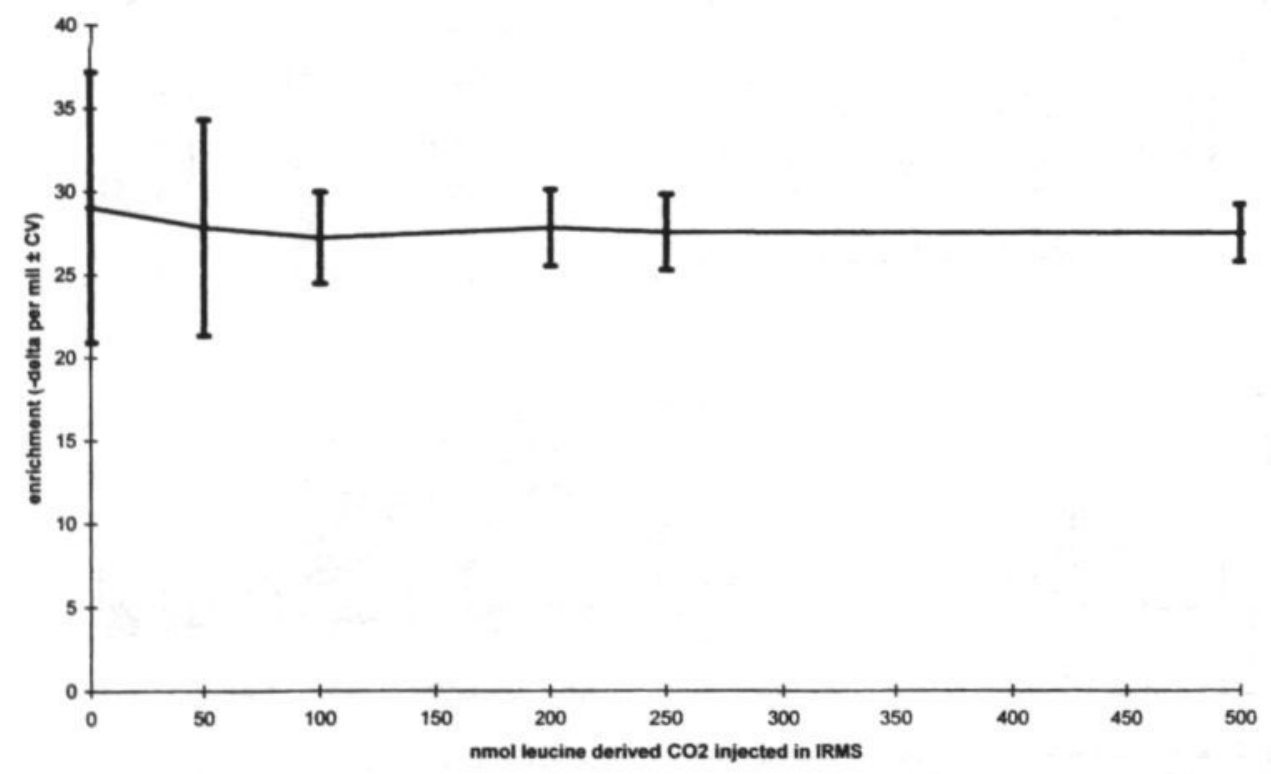

Fig. 3. Precision of IRMS measurement. Relation between the amount of $\mathrm{CO}_{2}$ derived from decarboxylated leucine and its enrichment $(n=4)$. 


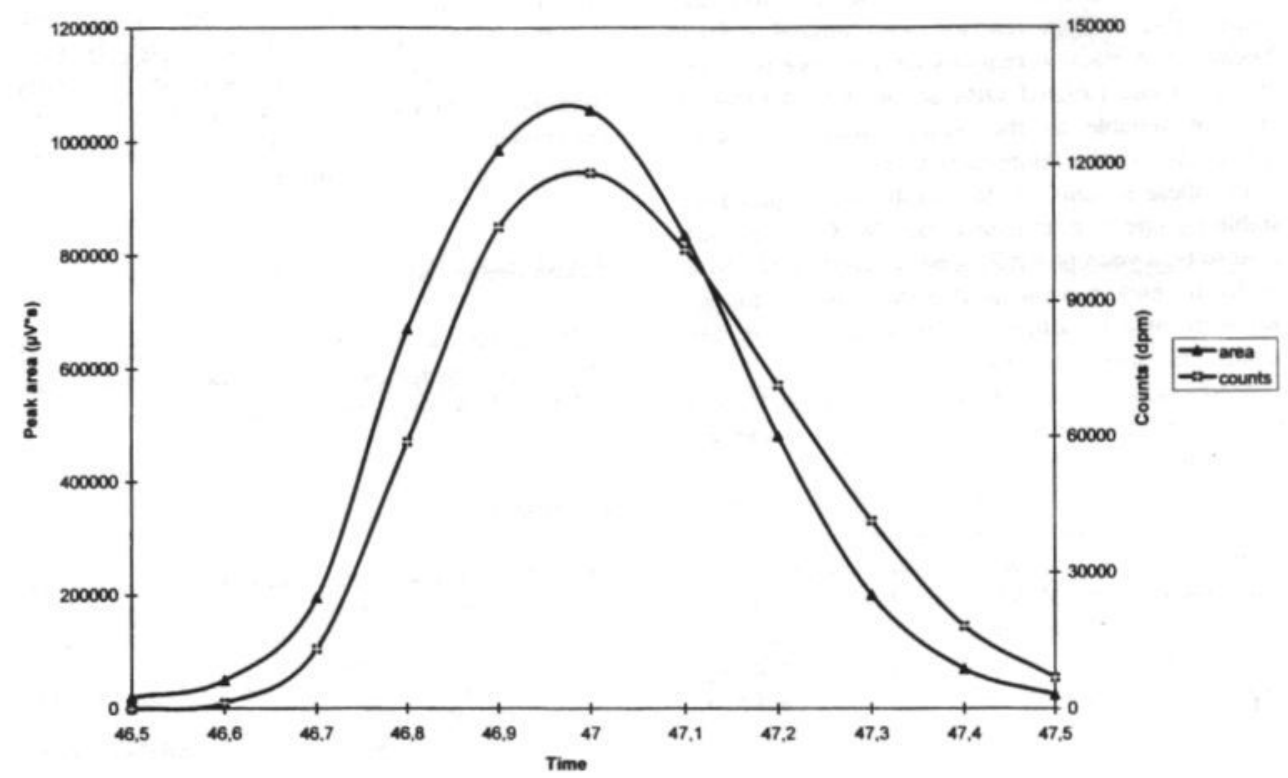

Fig. 4. Influence of isotope incorporation on retention behavior of "4 $\mathrm{C}$-labeled leucine; evidence for isotope fractionation.

High solvent salt concentrations may cause precipitation and thus underestimation of activity, while an organic solvent on the other hand, may cause chemiluminescence and thus overestimation of activity. In search for an optimal cocktail, 5 different products were tested for solubility of the sample, counting efficiency and chemiluminescence activity. Best results were obtained if the 4-6 ml fractions were diluted at least twice with Optima Gold (not shown).

\section{Discussion}

We have described a complex set of techniques and procedures with the purpose of measuring the enrichment of stable isotopes or the specific activity of radioactive amino acids. Our first goal was the isolation of radioactively labeled amino acids and to study the chromatographic limitations of a semipreparative column. Pilot experiments had revealed that an injection volume of $>250 \mu \mathrm{l}$ was required to obtain sufficient material for radioactivity determi- nation of biological samples obtained from laboratory animals. This injection volume is too large to enable good chromatography on an analytical column. Considering the maximal flow-rate which could be delivered by our pumping system, and the required injection volume, we expected a semi-prep column $(250 \times 10 \mathrm{~mm}$ I.D.) to be appropriate. For derivatization, we chose the OPA label as this derivatization reaction can easily be automated and as we have many years experience with it in an analytical approach [2]. The resulting separation enabled simultaneous isolation and quantitation of each major plasma amino acid from 100-200 $\mu$ l quantities, which was sufficient to allow counting of its radioactivity.

Unfortunately, the method could not be employed for an IRMS measurement of the enrichment of $\left[1-{ }^{13} \mathrm{C}\right]$ leucine, because the OPA-probe cannot be removed from the isolated derivatives. Using radioactive tracers, this is of no concern, but to enable IRMS measurements of amino acids with a low degree of ${ }^{13} \mathrm{C}$-enrichment in the carboxylic 
group, the enriched carbon is released from the amino acid through reaction with ninhydrin [10]. Because this reaction requires the presence of a free amino group, isolated OPA-amino acid derivatives are not suitable as the amino group is coupled irreversibly to the fluorescent label.

For these reasons, another probe was required for stable isotope measurements and FMOC was considered to be a good possibility, as the peptide-bond can easily be broken using acid hydrolysis [8]. Indeed, we were able to achieve a $100 \%$ recovery of free amino acid using gas-phase hydrolysis.

Next, the chemistry of the derivatization reaction had to be adapted to enable a semi-preparative application. A major problem in the use of FMOC has always been the interference of the unreacted product and control of the reaction $\mathrm{pH}$, especially when processing acid deproteinized samples $[8,10]$. This may be why FMOC has not become as popular as OPA, despite the capability of the derivatization of imino acids also. We were able to solve most of these problems by using acetonitrile to dissolve the FMOC and by adjusting the $\mathrm{pH}$ of the reagent buffer, thus increasing its buffer capacity. As a result, we are now able to derivatise $200 \mu \mathrm{l}$ plasma to a final volume of $1200 \mu \mathrm{l}$.

The resulting FMOC method can in principle also be used to isolate radioactive amino acids. However, the OPA method has several advantages. First, the final volume after derivatization of $200 \mu \mathrm{l}$ plasma is $655 \mu \mathrm{l}$ using the OPA method, compared to $1200 \mu \mathrm{l}$ for the FMOC method. This enables easier chromatography. Also, the analysis time of the OPA-method is substantially lower than the FMOC-method (60 min compared to $75 \mathrm{~min}$ ). This enables a more efficient sample throughput. Therefore, we use the FMOC method only for stable isotope measurements and the OPA-method to isolate radioactive amino acids.

These new methods open possibilities for multiple tracer studies, because relatively large amounts of amino acid can be isolated and quantitated in one run, thereby requiring infusion of only low amounts of tracer necessary to measure their specific activity (minimum: $100 \mathrm{dpm} / 10 \mathrm{nmol}$ amino acid) or $\left[1-{ }^{13} \mathrm{C}\right]$ enrichment (minimum: $100 \mathrm{nmol}$ amino acid), thus reducing costs of these studies.

\section{Acknowledgments}

The authors wish to thank Mr. F. van de Vegt and Mr. B. Ciocchi for the stable isotope measurements and Mrs. S. Schrijen for her analytical support.

\section{References}

[1] H.M.H. van Eijk, M.P.L. Huinck, D.R. Rooyakkers and N.E.P. Deutz, J. Chromatogr. B, 660 (1994) 251.

[2] H.M.H. van Eijk. D.R. Rooyakkers and N.E.P. Deutz, J. Chromatogr., 620 (1993) 143.

[3] L. Lecavalier, F.F. Horber and M.W. Haymond, J. Chromatogr., 491 (1989) 410.

[4] P. Tessari, S. Inchiostro, M. Vettore, L. Sabadin and G. Biolo, Clin. Biochem., 24 (1991) 425.

[5] P. Fürst, L. Pollack, T.A. Gräser, H. Godel and P.Stehle, J. Chromatogr., 499 (1990) 557.

[6] S. Einarsson, B. Josefsson and S. Lagerkvist, J. Chromatogr., 282 (1983) 609.

[7] H. Godel, in Bestimmung von freien Aminosäuren in biologischenm material mittels HPLC (Thesis), Universität Hohenheim, Germany, 1986.

[8] T. Jenssen, N. Nurihan, G. Perriello, A. Bucci, I. Toft and J. Gerich, J. Liq. Chromatogr., 17 (1994) 1337.

[9] R.R. Wolfe, Radioactive and Stable Isotope Tracers in Biomedicine, Wiley-Liss, New York, NY, 1992, p. 247.

[10] C.M. Scrimgeour, K. Smith and M.J. Rennic, Biomed. Environ. Mass Spectrom., 15 (1988) 369.

[11] L.A. Carpino and G.Y. Han, J. Org. Chem., 37 (1972) 3404.

[12] T. Näsholm, G. Sandberg and A. Ericsson. J. Chromatogr., 396 (1987) 225.

[13] S. Einarsson, B. Josefsson and S. Laferkvist, J. Chromatogr., 282 (1983) 609.

[14] P.Q. Baumann, D.B. Ebenstein, B.D. O'Rourke and K.S. Nair, J. Chromatogr., 573 (1992) 11. 


\title{
Automated isolation of high-purity plasma albumin for isotope ratio measurements
}

\author{
Hans M.H. van Eijk, Dennis R. Rooyakkers, Bernadette A.C. van Acker, Peter B. Soeters, \\ Nicolaas E.P. Deutz ${ }^{*}$
}

Department of Surgery, Maastricht University, P.O. Box 616, NL-6200 MD Maastricht, The Netherlands

Received 6 January 1999; received in revised form 9 April 1999; accepted 11 May 1999

\begin{abstract}
Measurement of the incorporation of labeled amino acids in plasma albumin, isolated from plasma sampled at different time points after infusion start is a well-known technique to study human albumin synthesis. Unfortunately, no chromatographic method has been described yet, enabling the automated isolation of high-purity albumin from large numbers of plasma samples as is required to study the kinetics of this process. Therefore, we developed a fast protein liquid chromatographic method, capable of processing $200 \mu \mathrm{l}$ amounts of plasma in 74 min (injection to injection). The system can run unattended as the FPLC system is connected to a sample processor equipped with a polyether ether ketone (PEEK) sample loop and a cooled sample tray. Albumin isolation was divided into three steps. First, plasma samples were injected onto a 1-ml Blue Sepharose HiTrap affinity column, equilibrated with $50 \mathrm{mmol} / 1$ phosphate buffer (pH 7.0). After elution of non-binding protein, switching the solvent to phosphate buffer with $1.5 \mathrm{~mol} / 1$ sodium chloride eluted albumin. The resulting albumin fraction was desalted on-line by directing it through two consecutive HiTrap 5-ml desalting columns, whereafter it was retained in the system within a 5-ml PTFE loop, connected to a motor valve. After switching this valve, thus bypassing the sample loop, the phosphate buffers were changed automatically to Tris buffers. Final purification involved elution of the captured fraction over a $1-\mathrm{ml}$ ion-exchange Resource $\mathrm{Q}$ column, using a sodium chloride gradient, ranging from 0 to 0.5 $\mathrm{mol} / \mathrm{l}$ in Tris buffer $(20 \mathrm{mmol} / 1, \mathrm{pH} 7.5)$. A more than $99 \%$ purity of the final albumin fraction was confirmed by capillary electrophoresis. (c) 1999 Elsevier Science B.V. All rights reserved.
\end{abstract}

Keywords: Isotope ratio: Albumin

\section{Introduction}

Hypoalbuminaemia is a feature associated with malnutrition and disease [1-4]. Although several efforts have been made to clarify its mechanism, the etiology of hypoalbuminaemia is still not completely

"Corresponding author. Tel: + 31-43-3881-497; fax: +31-43$3882-126$.

E-mail address: nep.deutzeah.unimaas.nl (N.E.P. Deutz) understood. Using the decay-curve of injected $\left[{ }^{131} \mathrm{I}\right]$ labeled albumin $[1,2,5]$, some authors found a decrease in albumin synthesis, while others have observed an increase in albumin breakdown. It has been assumed that this discrepancy can be explained by the fact that this technique facilitates an indirect measurement, which is not a good indicator of the actual situation $[1,3]$.

An alternative method approach to measure albumin synthesis is through continuous infusion of 
labeled leucine and determination of its incorporation rate into albumin [1,6-8]. Accuracy of this method depends largely on the degree of (im-) purity of the isolated albumin fraction. Even a small contamination (a few percent) with a protein possessing a high fractional synthetic rate (FSR) results in an overestimation of the albumin FSR. Traditional methods like cold ethanol purification according to Cohn [9] result in a purity of about $96 \%$ as can be seen from the product guarantee label of chemical suppliers. The remainders are mostly globulins, which may increase drastically in the acute phase response. Alternatively, single-step chromatographic methods are employed $[6,10]$, but these also cannot ensure the desired high degree of purity $[10,11]$. In contrast, multi-step methods, capable of producing the desired purity, usually require a laborious and time costly re-introduction of collected fractions into the next chromatographic step [11,12]. Considering the large number of samples required to reach statistical significance it may not be a surprise that thus less complicated isolation methods [13] are favorably used to measure albumin synthesis rates, which are more sensitive to protein contamination, especially in the acute phase response. This may explain (part of the) discrepancies in albumin synthesis rates described in the literature.

The aim of this study was therefore to develop a fast, automated, low cost, multi-step chromatographic method for the isolation of high-purity plasma albumin.

This was achieved using a fast protein liquid chromatography (FPLC) method based on two consecutive chromatographic principles, affinity chromatography and ion-exchange chromatography. The method enables the purification of $\mathrm{mg}$ amounts of high-purity plasma albumin from a large number of samples. The fraction's purity was certified by capillary electrophoresis (CE).

\section{Experimental}

\subsection{Equipment}

Our FPLC system consisted of a Model LCC 501 controller, two Model P1 pumps, two Model MV8 motor valves, a Model MV7 motor valve, a Model
UVM II UV detector, equipped with a $5 \mathrm{~mm}$ analytical flow cell and a Model Superfrac fraction collector, all from Pharmacia Biotech (Roosendaal, The Netherlands). Three PTFE three-way low-pressure solenoid valves (Cole Parmer, Applikon, Schiedam, The Netherlands) were included in the system to select the solvents and to divide the flow to the fraction collector. The FPLC separation program (Table 1) was written on a personal computer running FPLC-manager.

Chromatographic data were processed on a separate computer running Turbochrom data system (version 4.12; Perkin-Elmer, Gouda, The Netherlands). Samples were introduced using a Model 233 XL Gilson sample processor (Meyvis, Bergen op Zoom, The Netherlands), equipped with a $200 \mu \mathrm{l}$ polyether ether ketone (PEEK) sample loop and cooled $\left(4^{\circ} \mathrm{C}\right)$ sample trays.

\subsection{Solvents and columns}

Two solvent systems were used. The first system contained phosphate buffer and was used to trap and elute albumin from the Blue Sepharose affinity column. Buffer A was $50 \mathrm{mmol} / 1$ phosphate buffer, $\mathrm{pH} 7.0$ and buffer $\mathrm{C}$ was phosphate buffer with 1.5 mol/l sodium chloride. The second solvent system contained Tris buffer and was used for further purification on the ion-exchange column. Buffer B was $20 \mathrm{mmol} / 1$ Tris buffer, $\mathrm{pH} 7.5$ and buffer D was Tris buffer with $0.5 \mathrm{~mol} / 1$ sodium chloride.

Three different columns were used to isolate the albumin fraction. The first column was a $1-\mathrm{ml}$ HiTrap Blue column. Next, two 5-ml HiTrap desalting columns were used in series to remove the buffer salts from the first purification step. The last column was a 1-ml Resource $\mathrm{Q}$ ion-exchange column (all from Pharmacia Biotech).

\subsection{Samples and standards}

Heparinized blood samples from human volunteers, submitted for the resection of a tumor of the large bowel, were obtained (after informed consent) by venapuncture and collected on ice. Samples were collected after an 8 -h period of $\left[1-{ }^{13} \mathrm{C}\right]$ leucine infusion before and after surgery. Plasma was prepared immediately by $10 \mathrm{~min}$ centrifugation at $8500 \mathrm{~g}$ at 
Table I

FPLC program

\begin{tabular}{llllll}
\hline Time $(\mathrm{min})$ & Setting & Code & Time (min) & Setting & Code \\
\hline 0 & Conc\% B & 0 & 22.1 & Valve.pos & 3.1 \\
0 & Port.set & 0.0 & 28 & Conc\% B & Port.set \\
0 & Pport.set & 3.0 & 28.5 & Feed tube & 6.1 \\
0 & Port.set & 4.0 & 28.5 & Port.set & 0.1 \\
0 & Valve.pos & 1.1 & 28.5 & Conc\% B & 35 \\
0 & Valve.pos & 2.2 & 31 & Feed tube & Port.set \\
0 & Valve.pos & 3.1 & 32 & Port.set & 5.1 \\
0.1 & ml/min & 1 & 32 & Conc\% B & 0.0 \\
5 & Conc\% B & 0 & 32 & Conc\% B & 100 \\
5.1 & Conc\% B & 100 & Conc\% B & 100 \\
5.1 & Valve.pos & 1.2 & 37 & Valve.pos & 0 \\
7 & Valve.pos & 1.1 & 40 & Port.set & 1.1 \\
9 & Valve.pos & 2.1 & 40.1 & Port.set & 3.0 \\
16 & Conc\% B & 100 & 50 & Valve.pos & 4.0 \\
16.1 & Port.set & 3.1 & 60 & Wash A.B & 1.2 \\
16.1 & Port.set & 4.1 & 60 & Valve.pos & 1.1 \\
16.1 & Conc\% B & 0 & 60 & Valve.pos & 2.2 \\
16.2 & Wash A.B & 1.1 & 60.1 & Port.set & 1.1 \\
16.3 & Valve.pos & 3.3 & 60.2 & ml/min & 0.1 \\
17 & Valve.pos & 1.3 & 72 & 74 & 0 \\
22 & Conc\% B & 0 & & & \\
\hline
\end{tabular}

$4^{\circ} \mathrm{C}$ and stored at $-80^{\circ} \mathrm{C}$ until analysis. Before analysis samples were centrifuged again for $5 \mathrm{~min}$.

Albumin standards were prepared weekly by dissolving weighed amounts (Sigma, Zwijndrecht, The Netherlands) into $50 \mathrm{mmol} / 1$ phosphate buffer $(\mathrm{pH} 7)$ and stored at $4^{\circ} \mathrm{C}$ until analysis.

\subsection{Procedure}

\subsection{Isolation}

First, $200 \mu \mathrm{l}$ plasma was injected into the FPLC system, equilibrated with phosphate buffer (A). Nonhinding protein was eluted to waste by switching a Model MV8 motor valve. Next, the buffer was switched to phosphate buffer with $1.5 \mathrm{~mol} / 1$ sodium chloride (C). Solvent lines were flushed with the new buffer, whereafter the motor valve was switched and albumin was eluted from the Blue Sepharose column. The passing albumin fraction was directed through the desalting columns and stored temporarily into a 5-ml PTFE loop, mounted to a Model MV7 motor injection valve. Solvents were changed to Tris buffers (B, D) and a motor valve Model MV8 mounted prior to the Blue Sepharose column was switched to bypass this column and the desalting columns. Next, the desalted fraction was eluted in back-flush from the sample loop onto the ion-exchange column, which was equilibrated with 20 $\mathrm{mmol} / 1$ Tris buffer, $\mathrm{pH}$ 7.5. Albumin was then eluted using a gradient between buffer (B) and (D). The purified albumin fractions were collected in 6-ml glass scintillation vials.

\subsubsection{Determination of the purity}

Purity was confirmed by CE, using a Beckman Model P/ACE 5500 system, equipped with an unfused-silica capillary of $27 \mathrm{~cm}$ (effective length of 20 $\mathrm{cm}) \times 50 \mu \mathrm{m}$ I.D. The system was operated with 100 $\mathrm{mmol} / 1$ borate buffer, $\mathrm{pH} 10.2$ and set to a detection wavelength of $200 \mathrm{~nm}$. Samples were introduced using a pressure injection $(34.5 \mathrm{kPa})$, after which a $10 \mathrm{kV}$ voltage was applied for $5 \mathrm{~min}$.

\section{Results and discussion}

The determination of albumin synthesis rate under conditions of metabolic stress has been subject for a number of investigations $[1-6,17,18]$. The results of these studies are not always conclusive, sometimes 
even contradictory. It has been suggested that these differences in the results may be explained by the design of the study (direct or indirect measurement), but also by the analytical method used to isolate albumin. It is known that albumin purified by the commonly used ethanol fractionation according to Cohn, still contains impurities $[10,11]$. In contrast, sedimentation of total plasma proteins, followed by dissolution of albumin in acidified ethanol has been claimed to produce pure albumin [13]. Combined with its ease of use, the latter method has become popular in isotope enrichment studies $[1,7,8]$. However, it cannot be excluded that this single-step approach completely prohibits contamination of proteins, which are elevated during the acute phase response. Furthermore, it has been described that conformational changes resulting from pathology and polymerization influence the ability to re-dissolve in ethanol [11]. Recovery percentages will thus be lower and it is not known what the consequences are considering the determination of turnover rates.

In contrast to this approach, a chromatographic isolation is a much better guarantee of a pure fraction. A single-step chromatographic method has already been described for this purpose [2], but this still does not exclude significant contaminations $[10,11]$. A multi-step chromatographic procedure is more likely to exclude a high degree of these remaining impurities, but usually these procedures are laborious and have a long cycle time (6 to $8 \mathrm{~h}$ ), which therefore do not facilitate efficient processing of studies with large numbers of samples.

In the present method, first isolation step involved affinity chromatography using a Cibacron Blue column, thus enabling the highest clean-up in one step. It was our goal to isolate an amount of $10 \mathrm{mg}$ albumin. Normal human plasma albumin concentration ranges from 40 to $60 \mathrm{~g} / \mathrm{l}$. We therefore expected that the injection and separation of a 200 $\mu \mathrm{l}$-plasma portion best could be performed on a $1-\mathrm{ml}$ Blue Sepharose HiTrap affinity column, possessing a binding capacity of about $40 \mathrm{mg}$ (according to the manufacturer). The first eluting peak consists of non-binding protein eluted with the $50 \mathrm{mmol} / \mathrm{l}$ phosphate buffer, while the second peak mainly consists of albumin (Fig. 1). Although it was recommended to dilute the sample into the starting buffer (for a better recovery), we found that a direct

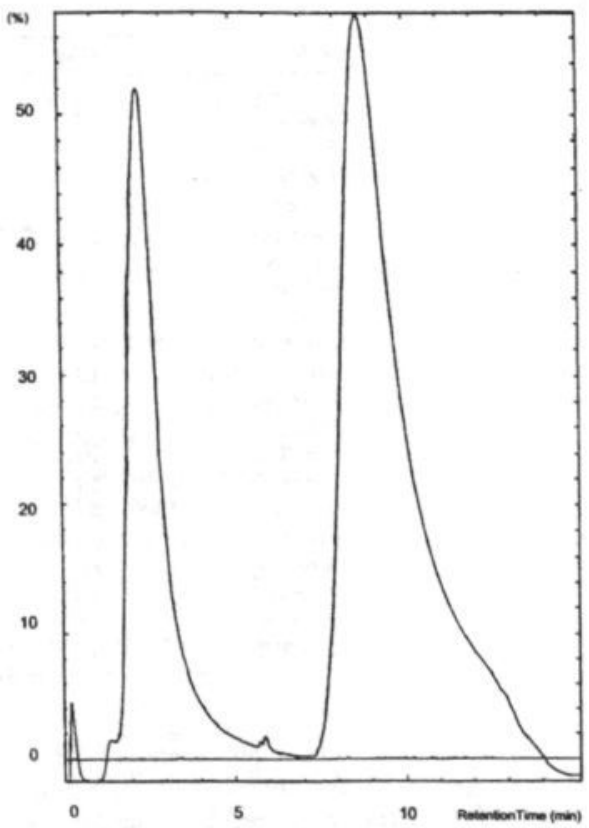

Fig. 1. Separation of plasma proteins on a Blue Sepharose HiTrap column.

injection was also adequate. In this way, up to 100 samples could be injected onto the column, after which its back-pressure increased and the bindingcapacity decreased (notable by a shift in response of a standard from the second peak to the first peak). The albumin fraction, eluting from the column in a high-salt phosphate buffer, still contained impurities.

To remove these impurities, gel-filtration and ionexchange chromatography were considered. Because gel-filtration is known to require long run-times, we chose to use ion-exchange chromatography. This choice induced another problem. The albumin-containing fraction eluting from the affinity chromatography contains high salt concentrations of the collected fractions, which prohibit the efficient application of ion-exchange chromatography. Direct injection of the collected fraction onto the ion-exchange column would therefore result in the unretained elution of all proteins present. Therefore, a desalting 
step of the obtained fractions is required. Furthermore, best resolution on an ion-exchange column is obtained using Tris-based buffers. A change in the buffer system is thus required also.

To automate this step, two consecutive HiTrap 5-ml desalting columns were incorporated into the FPLC system, mounted in series with a 5-ml PTFE loop, attached to a motor driven (Model MV-7) injection valve. This setup prohibited the subjection of the (disposable) desalting columns to a too high back-pressure (above 5 bar). Furthermore, it enabled the on-line storage of the albumin fraction, while the buffer system was changed to Tris buffers and the application of a sharp salt gradient to the ion-exchange column at a relative high flow-rate $(1 \mathrm{ml} /$ $\mathrm{min})$. The desalting columns lasted for about 100 injections after which they were replaced.

To reduce costs, the final purification involved separation on a 1-ml Resource Q column, rather than using the four-times more expensive 1-ml Mono $\mathrm{Q}$ column. The performance of both columns was nearly identical, while the back-pressure of the Resource Q column is only a quarter of the Mono Q column (not shown). The resulting separation allowed the isolation of a high purity albumin fraction (Fig. 2), which are collected into 6-ml glass scintillation vials.

The next problem was how to establish the purity of the isolated albumin fraction. Most biochemical methods are designed to identify proteins on the bases of an activity test. Recovery percentages of each purification step are also based on these tests. Our problem was however to determine the amount of impurities in the isolated fraction, as especially contamination with quickly turning proteins could change the results of the enrichment measurement. Sodium dodecyl sulfate-polyacrylamide gel electrophoresis (SDS-PAGE) was found unsuitable (not shown) as a large amount of sample must be applied to visualize any contamination, which in turn goes at the cost of resolution. The resulting albumin spot could thus easily hide remaining other proteins [10,11]. Alternatively, CE was considered, a fast and sensitive method, requiring only small amounts of sample. Using this technique, we could not detect any contaminants in the isolated fractions (Fig. 3).

After the methodological setup was now completed, performing two pilot studies tested the va-

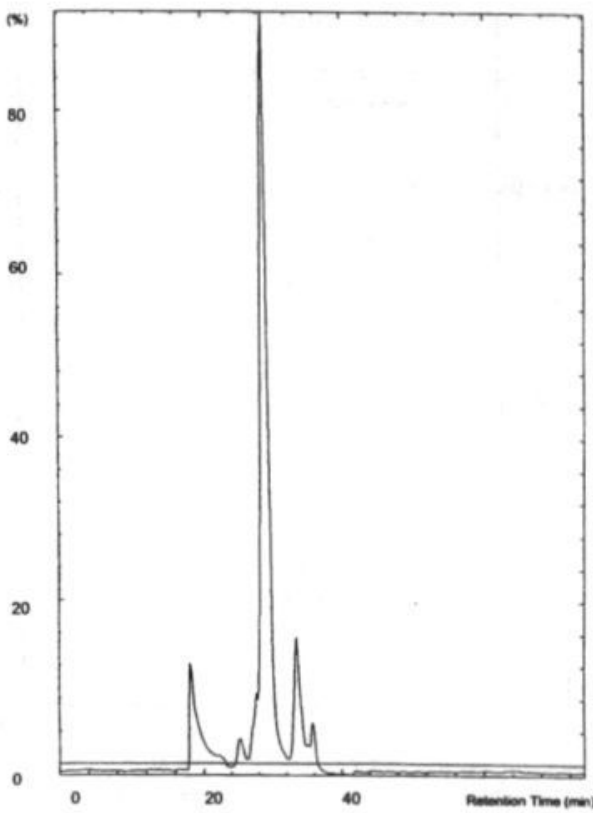

Fig. 2. Ion-exchange separation of the Blue Sepharose fraction (highest peak is albumin; separation conditions as in text).

lidity of the described technique. In the first experiment, a primed continuous infusion of L-[4,5$\left.{ }^{3} \mathrm{H}\right]$ leucine was given to a conscious laboratory pig. operated previously in conformity to our standard protocol as is described elsewhere [14]. At $T=0,1$, $2,3,4,5$ and $6 \mathrm{~h}$ arterial plasma samples were collected on ice. Plasma free and albumin bound leucine specific activity was determined as is described elsewhere [15]. Mean plasma free leucine specific activity was 14030 desintegrations per minute $(\mathrm{dpm}) / \mu \mathrm{mol}$. A mean amount of $11.1 \mathrm{mg}$ purified albumin was isolated from $200 \mu \mathrm{l}$ plasma portions, from which a mean amount of $3.15 \mu \mathrm{mol}$ leucine was isolated after hydrolysis. In these samples, a linear increase $\left(R^{2}=0.99\right)$ in activity was found (Table 2), from which the FSR was calculated as $7.7 \% /$ day.

In the second pilot experiment, a group of five postabsorptive patients, submitted for gastrointestinal diseases, received a primed continuous [1- 

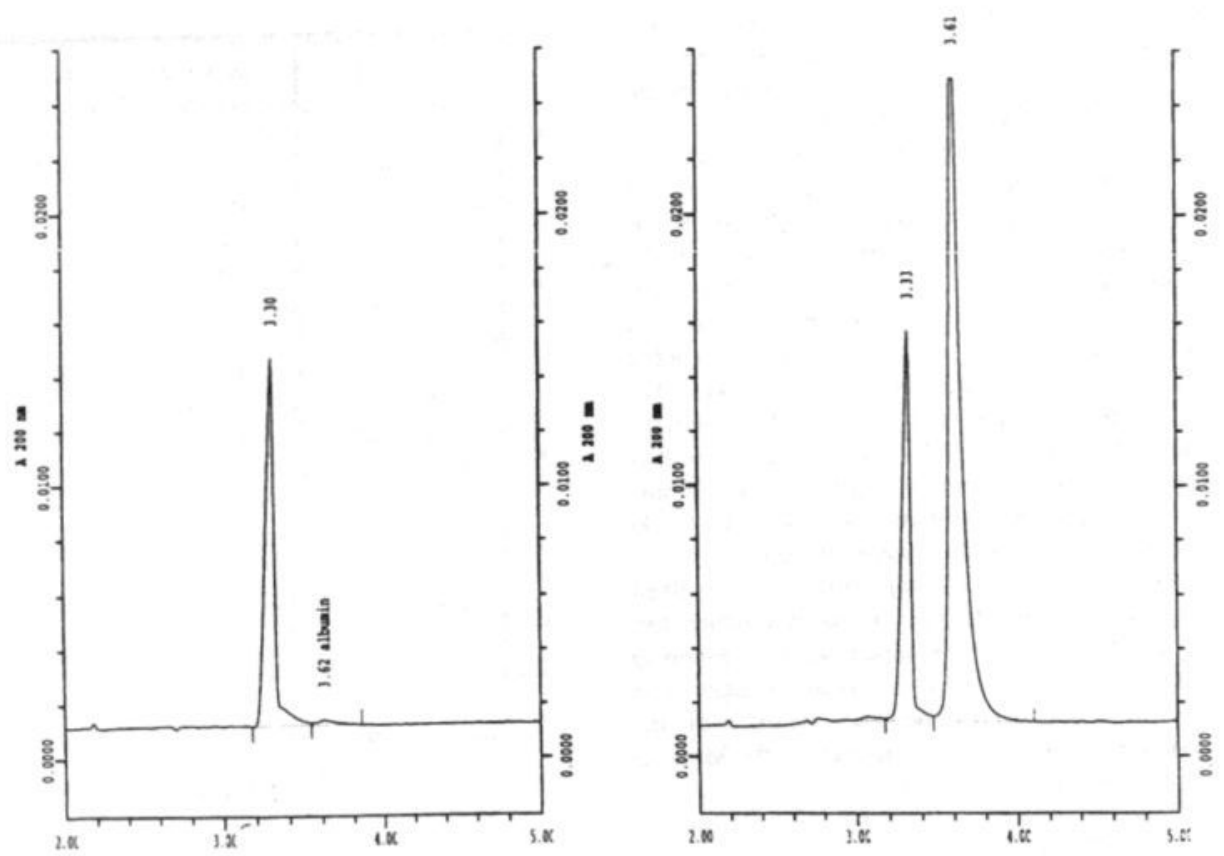

Fig. 3. Purity check of the final albumin fraction by capillary electrophoresis (upper panel: blank Tris buffer, lower panel: purified albumin fraction).

${ }^{13} \mathrm{C}$ lleucine infusion for $8 \mathrm{~h}$ after their informed consent was obtained. Plasma samples were icechilled immediately and collected in time. Albumin fractions were isolated, hydrolyzed and leucine enrichment was determined on a gas chromatograph

Table 2

Deterinination of albumin synthesis rate

\begin{tabular}{|c|c|c|c|}
\hline \multicolumn{2}{|c|}{ Pig pilot $(n=1)$} & \multicolumn{2}{|c|}{ Patient pilot $(n=5)$} \\
\hline $\begin{array}{l}\text { Time } \\
\text { (h) }\end{array}$ & $\begin{array}{l}\text { Increase in activity } \\
\text { (DPM) }\end{array}$ & $\begin{array}{l}\text { Time } \\
\text { (h) }\end{array}$ & $\begin{array}{l}\text { Increase in enrichment } \\
\text { (TTR, \%) }\end{array}$ \\
\hline 1 & 81 & 2 & $0.052( \pm 0.009)$ \\
\hline 2 & 197 & 3 & $0.084( \pm 0.014)$ \\
\hline 3 & 329 & 4 & $0.120( \pm 0.021)$ \\
\hline 4 & 457 & 6 & $0.192( \pm 0.033)$ \\
\hline 5 & 594 & 8 & $0.276( \pm 0.046)$ \\
\hline 6 & 726 & & \\
\hline FSR & $7.7 \% /$ day & FSR & $8.8 \% /$ day \\
\hline
\end{tabular}

combustion isotope ratio mass spectrometer Model MAT 252 (Thermoquest, Veenendaal, The Netherlands) as their tert.-butyldimethylsilyl (TBDMS) derivatives as is described elsewhere [16]. Again, a linear increase in enrichment (expressed as the tracer tracee ratio: TTR) was found $\left(R^{2}=0.99\right)$. Mean plasma precursorpool enrichment (KIC) was $10.2 \%$ TTR (standard error of the mean; S.E.M. $=0.5 \%$ TTR), resulting in an albumin synthesis rate (FSR) of $8.8 \% /$ day $\pm 1.1 \%$ (mean \pm S.E.M.; Table 2$)$, which are well within the range of recent literature $[17,18]$.

In conclusion, in contrast to the traditional methods, the here described method enables the automated isolation of high-purity albumin for isotope incorporation studies. Furthermore, the multi-step character of the present method minimizes the risk of isolating an albumin fraction, contaminated with proteins with a high turnover rate, which would result in an overestimation of the FSR. In traditional 
single-step methods, the risk increases when studying patient populations with an acute phase response, thus possessing elevated concentrations of potential interfering proteins.

Future studies must distinguish if, and to what extent differences in the albumin purification method may explain the described differences in albumin synthesis rate.

\section{Acknowledgements}

The authors wish to thank Mr. A.J.M. Wagenmakers for the mass spectroscopy enrichment measurements, Mr. B. Van Kreel and Mrs. Wijnen for performing the capillary electrophoresis analysis.

\section{References}

[1] J. Morlese, T. Forrester, A. Badaloo, M. Del Rosario, M Frazer, F. Jahoor, Am. J. Clin. Nutr. 64 (1996) 952.

[2] G. Kaysen, P. Schoenfeld, Kidney Int. 25 (1984) 107.

[3] H. Moshage, J. Janssen, J. Hafkenscheid, S. Yap, J. Clin. Invest. 79 (1987) 1635.
[4] G. Kaysen, V. Rathore, G. Shearer, T. Depner, Kidney Int. 48 (1995) 510.

[5] P. Wilkinson, C. Medenhall, Clin. Sci. 25 (1963) 281.

[6] M. Cayol, I. Tauveron, F. Rambourdin, J. Prugnaud, P. Gachon, P. Thieblot, J. Grizard, C. Obled, Clin. Sci. 89 (1995) 389.

[7] F. Jahoor, D. Burrin, P. Reeds, M. Frazer, Am. J. Physiol. 267 (1994) R221.

[8] P. De Feo, F. Horber, W. Haymond, Am. J. Physiol. 263 (1992) E794.

[9] P. Kistler, H. Friedli, in: J. Curling (Ed.), Methods of Plasma Protein Fractionation, Academic Press, London, 1980.

[10] J. Curling, Separation of Plasma Proteins, Pharmacia, Uppsala, 1983.

[11] J. Berglof, S. Eriksson, J. Curling, J. Appl. Biochem. 5 (1983) 282.

[12] I.A. MacLaren, M.L. Petras, Biochim. Biophys. Acta 427 (1976) 238.

[13] A. Korner, J.R. Debro, Nature 4541 (1956) 1067.

[14] G. Ten Have, M. Bost, J. Suyk-Wierts, A. Van den Boogaard, N. Deutz, Lab. Animals 30 (1996) 347.

[15] H.M.H. van Eijk, D.R. Rooyakkers, A.J.M. Wagenmakers, P.B. Soeters, N.E.P. Deutz, J. Chromatogr. B 691 (1997) 287.

[16] F. Pont, L. Duvillard, C. Maugeais, A. Athias, L. Pergesol, P. Gambert, B. Verges, Anal. Biochem. 248 (1997) 277.

[17] P. Essen, M. McNurlan, L. Tjader, A. Sandgren, A.G. Calder, PJ. Garlick, J. Wernerman, Clin. Nutr. 11 (1992) 1. Abstract.

[18] O. Mansoor, M. Cayol, P. Gachon, Y. Boirie, P. Schoeffler, C. Obled, B. Beaufrere, Am. J. Physiol. 273 (1997) E898. 


\title{
Determination of Amino Acid Isotope Enrichment Using Liquid Chromatography-Mass Spectrometry
}

\author{
Hans M. H. van Eijk, Dennis R. Rooyakkers, Peter B. Soeters, and Nicolaas E. P. Deutz ${ }^{1}$ \\ Department of Surgery, Maastricht University, P.O. Box 616, NL-6200 MD Maastricht, The Netherlands
}

Received November 30, 1998

The change in amino acid enrichment, an indicator of a change in protein synthesis and/or degradation, is usually measured using gas chromatography-mass spectrometry and/or (GC-combustion) isotope ratio mass spectrometry. Unfortunately, often a complex and sensitive derivatization procedure and/or a large amount of sample is required. Also, these techniques are less suited to study intermediary metabolism, in which the simultaneous application (and thus measurement) of multiple amino acid tracers is preferred. Alternatively, in this study the possibilities of the coupling of liquid chromatography and mass spectrometry were explored, resulting in the measurement of both the concentration and isotope enrichment of $o$ phthaldialdehyde (OPA)-derivatizated plasma amino acids in one run. This was achieved by the injection of OPA-derivatizated amino acids into an automated HPLC system. After the elution of buffer salts and reagent excess to drain using column switching, the column effluent was directed via a fluorescence detector into a Thermoquest Model LCQ benchtop LC-MS. Mass spectrometric measurements were performed in "zoom-scan" mode, employing multiple scan events if the target components were not baseline separated. Best signal-to-noise ratio's were obtained using the LCQ's electrospray probe in the negative mode. Still, when working under standard conditions the total ion current of OPA-amino acid derivatives eluting at the beginning of the chromatogram (e.g., citrulline, arginine and glyeine) was by a factor of 5 lower, compared to components eluting in the last part of the chromatogram (leucine, valine, and ornithine). These differences could be minimized by increasing the temperature of the heated capillary to $260^{\circ} \mathrm{C}$ and by applying $5 \%$ collision energy (between the skimmer and the first octapole) to the first eluting components. $A$ further improvement could not be obtained by the addition of

\footnotetext{
'To whom correspondence should be addressed. Fax: +31-433882126. E-mail: nep.deutzeah.unimaas.nl.
}

makeup liquids like ammonia, acetic acid, methanol, or acetonitrile (up to $25 \%$ of column effluent flow). Considering these results and the fact that the first eluting amino acid derivatives are the most polar ones, we hypothesized that hydration of these components interferes with the ionization process. A linear calibration curve was obtained for both fluorescent response and total ion current (TIC) for all amino acids in the range from 5 to $1000 \mathrm{pmol}$ per injection. The coefficient of variation of the fluorescent response was typically on the order of 1-4\%, for the TIC this was between 4 and $9 \%$. However, measurement of isotope ratios requires not only the determination of the area of the base peak, but also of the area of the (enriched) isotopomeric peak(s), having a much lower abundance. Therefore, isotope ratio measurements require the injection of at least $25 \mathrm{pmol}$ of the amino acid derivative of interest (except for ARG $50 \mathrm{pmol}$ ) to obtain true ratio's. The accuracy of the isotope enrichment measurement was determined by the injection of a standard containing all major physiological amino acids (400 pmol each) and a standard at physiological concentrations (ranging from 50 pmol (CrT) to 350 pmol (VAL). Standard deviation of the isotopic ratios ranged from 0.1 to $0.5 \%$ for the high $(400 \mathrm{pmol})$ standards and from 0.2 to $0.8 \%$ for the low (physiological) standard, which is comparable with GC-MS. A plot of the results against the theoretical values gave a linear curve for all isotopes studied $\left(R^{2}\right.$ ranged from 0.9984 to $0.9997)$. However, the $\left[1-^{-1} \mathrm{C}\right]$-enriched amino acids measured (LEU, GLY, and VAL) gave a closer agreement to the expected values as was found for [ureido. "C-5,5-" $\mathrm{H}_{2}$ ]-enriched citrulline and [guanidino-" $\mathrm{N}_{2}$ ]enriched arginine. We could not determine whether this was due to the measurement procedure itself or resulting from an instability of the tracers in solution. Nevertheless, the results were reproducible and the theoretical value could be calculated using the tan. gent of the enrichment curves. Considering the easier (and cheaper) derivatization procedure and instrumentation, the simultaneous collection of isotopo- 
meric distribution spectra (enabling the application of multiple labeled components) and concentration data, the method presents an attractive alternative to traditional GC-MS applications. o ine readeale Proes.

The infusion of amino acids enriched with stable isotopes is a powerful tool to study protein metabolism in humans (1). Traditionally, the change in enrichment of these amino acids is measured either by gas chromatography-mass spectroscopy (GC-MS) (2-4) or isotope-ratio mass spectroscopy (IRMS), ${ }^{2}$ after isolation of the target amino acid $(1,5,6)$. GC-MS is mostly used to measure amino acids with a high enrichment, while those having a low enrichment are mostly studied with the more precise IRMS technique. Both methods, however, require either a complex and laborious derivatization procedure (GC-MS) or a large amount of the purified target amino acid (IRMS), which is difficult to obtain (1).

In contrast, liquid chromatography offers a range of procedures through which amino acids can be easily isolated either as pure amino acids or as their derivatives after reacting with a fluorescent or $\mathrm{UV}$ absorption probe (7-10). In this respect, derivatization is preferable because it enables both an easier reversed-phase separation (which is beneficial for LC-MS applications) and a direct way to quantitate the separated amino acids using a traditional UV or fluorescence detector. Application of a mass spectrometer may overrule this argument, but determination of the total ion current (TIC) as a measure for the concentration usually results in a higher standard deviation. Furthermore, the application of mass scan filters enhances precision of isotope ratios of the selected amino acids, but also results in the loss of concentration data of the filtered amino acids, making a separate analysis necessary, thus increasing costs and labor.

However, formerly the coupling of an LC system to a mass spectrometer was a problem. The (relatively) large amounts of buffer salts caused blockages in the MS inlet, while the introduction of a liquid flow generated problems for the vacuum system. Therefore, low flow rates $(\mu \mathrm{l} / \mathrm{min})(11,12)$ or splitting techniques $(13)$ were applied, limiting both chromatography and MS analysis.

With the introduction of fast atom bombardment LC/MS (14), atmospheric pressure ionization chemical ionization (APCI) (15), and electrospray ionization

\footnotetext{
"Abbreviations used: IRMS, isotope-ratio mass spectroscopy, APCI, atmospheric pressure ionization chemical ionization; ESI, electrospray ionization; OPA, o-phthaldialdehyde; 3-MPA, 3-mercaptopropionic acid; atmospheric pressure ionization; AGC, automatic gain control.
}

(ESI) (16), the interfacing with an HPLC system running under normal flow conditions ( $1 \mathrm{mV} / \mathrm{min}$ ) has be come much easier. Furthermore, the introduction of benchtop systems enabled the application of mass spec. trometry also in smaller laboratories.

This paper evaluates the possibilities of the LCQ, a Thermoquest benchtop LC-MS system, equipped with an iontrap, to measure isotopic ratios of plasma amino acids. For this purpose, our previously described HPLC separation and isolation methods for 0 -phthaldialdehyde (OPA)-derived amino acids $(1,10)$ were adapted to enable direct introduction into the mass spectrometer. Optimization of the mass spectrometric measurement was performed with respect to detector sensitivity and precision of the isotopic ratio determination.

To validate the measurement, calibration curves were constructed to determine the linear ranges of the concentration and the isotopic ratios. In addition, suitability of the method was evaluated by measuring the enrichment of plasma samples obtained from animal experiments.

\section{MATERIALS AND METHODS}

\section{System}

The HPLC system consisted of a Gilson Model 233 $\mathrm{XL}$ sample processor equipped with cooled sample and reagent trays and two Rheodyne six-way high-pressure valves (Meyvis, Bergen op Zoom, The Netherlands). Two Model PU980 pumps, equipped with an internal membrane low dead volume damper were connected through a microflow high-pressure mixer (Jasco Benelux, Maarssen, The Netherlands). In this way, a steep high-pressure gradient could be produced with minimal dead volume and pressure pulsation below $1 \%$ throughout the working region, ensuring an optimal signal-to-noise ratio for the mass spectrometer. On-line quantitation was performed, using a Model 970 fluorescence detector, equipped with a high-pressure flow cell (Jasco).

The separation was performed on a $150 \times 3.2-\mathrm{mm}$ (i.d.) Allsphere 3- $\mu \mathrm{m}$ ODS 2 column (Alltech, Breda, The Netherlands) which was mounted in a Spark Mistral column oven (Separations, Hendrik Ido Ambacht, The Netherlands).

The benchtop mass spectrometer was a Thermoquest LCQ (Veenendaal, The Netherlands), equipped with an electrospray (ESI) probe. The system was operated in negative mode employing the "zoom-scan" function for a baseline separation of the isotopomeric peaks and a better signal-to-noise ratio. Maximal sensitivity was obtained if the ion time was set to $1000 \mathrm{~ms}$, using 1 $\mu$ scan only. The heated capillary was kept at $260^{\circ} \mathrm{C}$, while sheath and auxiliary gas were set to 90 and 20 arbitrary units each. The tube lens offset was $-3 \mathrm{~V}$ and the spray voltage was $4.2 \mathrm{kV}$. 


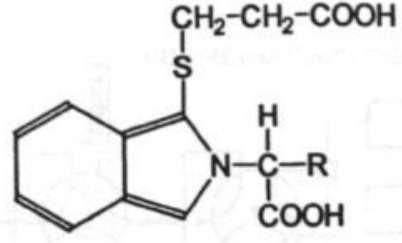

FIG. 1. General structure of OPA amino acid derivatives. $R$ represents the variable side chain of an amino acid.

\section{Chromatographic Procedure}

Precolumn derivatization was performed using a Gilson $233 \mathrm{XL}$ sample processor, equipped with 2 Rheodyne six-port high-pressure valves. This setup facilitated column switching, which had to be applied to prevent a reaction between ammonium acetate of the solvent buffers and the OPA-reagent excess. It was observed that the resulting product of this reaction binds strongly to the column packing material, degrading the separation within a few runs. Attempts to clean the column by flushing it with organic solvents and dimethyl sulfoxide were not successful. To prohibit this, the automatic derivatization procedure of the autosampler was adapted and derivatization and separation were executed on separate columns.

In the adapted procedure, sample and reagent are injected into a 100- $\mu$ l sample loop using the autosamplers syringe. The loop had been preflushed with 25 $\mathrm{mM}$ sodium phosphate buffer. $\mathrm{pH} 6.8$ (Fig. 1). Next, valve 2 is switched and the reaction mixture is pumped onto a two consecutive $7.5 \times 4.6-\mathrm{mm}$ trap columns filled with Allsphere ODS 2 5- $\mu \mathrm{m}$ material (Alltech, Breda, The Netherlands), using the phosphate buffer delivered by pump $\mathrm{C}$. The trap columns retain amino acid derivatives and OPA excess. The reagent borate buffer ( $\mathrm{pH}$ 10.5) can now be replaced by the phosphate buffer lowering the $\mathrm{pH}$ to 6.8 at which OPA excess does not react with the ammonium acetate buffer. The trap column is incorporated into the flow path of the analytical column by switching valve 1 . OPA derivatives and excess are now eluted onto the analytical column and separated using the ammoniumacetate containing solvents (A and B) in a linear gradient from 100 to $37 \%$ $A$ in $28 \mathrm{~min}$. The phosphate buffer front is eluted to waste by switching valve 3 (LCQ bypass valve), whereafter the components are introduced into the LC-MS system.

\section{Determination of Isotopic Ratios}

Isotopic ratio's were obtained by a zoom-scan measurement of each amino acid derivative of interest. This involves the collection of a $10 \mathrm{AMU}$ window in the ion trap around the base peak of the amino acid deriv- ative, followed by a slow scan procedure resulting in a baseline resolution between the isotopomeric peaks. From the spectrum obtained, the abundance was calculated by dividing the area of the isotopomeric peaks by the area of the nonenriched base peak. Enrichment was defined as the calculated sample abundance minus the natural (measured) abundance of a nonenriched standard (or plasma) multiplied (if necessary) by the tangent of the enrichment curve of the isotope of interest.

\section{Animal Experimentation}

Animal infusion experiments were conducted according to our standard research protocol (21). The animal ethical committee of Maastricht University approved the experiments (DEC No. 9531). In short, a constant primed infusion was applied in the vena cava of a $21-\mathrm{kg}$ female pig. The prime was $1 \mathrm{~m} / \mathrm{kg}$ infusion of a tracer cocktail containing $0.96 \mathrm{mM}\left[-{ }^{2} \mathrm{H}_{5}\right] \mathrm{PHE}$ and [ring-3,5 $\left.{ }^{2} \mathrm{H}_{2}\right]$ TYR, $5.28 \mathrm{mM}\left[1-{ }^{13} \mathrm{C}\right]$ VAL, $2.4 \mathrm{mM}\left[1-{ }^{13} \mathrm{C}\right]$ LEU and $\left[5,5,5-{ }^{2} \mathrm{H}_{3}\right]$ LEU, $3.2 \mathrm{mM}$ [guanidino- $\left.{ }^{16} \mathrm{~N}_{2}\right] \mathrm{ARG}, 1.5 \mathrm{mM}$ [ureido $\left.-{ }^{13} \mathrm{C}, 5,5-{ }^{2} \mathrm{H}_{2}\right] \mathrm{CIT}$, and $54 \mathrm{mM}\left[1-{ }^{13} \mathrm{C}\right]$ urea. The prime was followed by a continuous infusion at $3 \mathrm{mV}$ $\mathrm{kg} / \mathrm{h}$ of a tracer cocktail containing the same tracers at a lower concentration (e.g., $0.64 \mathrm{mM}$ PHE, TYR, 1.76 mM VAL, $1.6 \mathrm{mM}$ LEU, $2.1 \mathrm{mM}$ ARG, $0.2 \mathrm{mM}$ CIT, and $2 \mathrm{mM}$ urea). Tracers were obtained from Mass Trace (Woburn, MA)

\section{Reagents and Solvents}

OPA reagent. OPA reagent consisted of $5 \mathrm{mg} \mathrm{o-}$ phthaldialdehyde (fluoraldehyde, Pierce/Omnilabo, Breda, The Netherlands) dissolved in $0.5 \mathrm{ml}$ methanol, buffered with $3.5 \mathrm{ml} 1 \mathrm{M}$ potassium borate buffer, $\mathrm{pH}$ 10.4 , and with the addition of $8 \mu \mathrm{l} 3$-mercaptopropionic acid (3-MPA).

Solvents. Solvent A was $15 \mathrm{mM}$ ammonium acetate buffer, containing $0.5 \%$ (v/v) of tetrahydrofuran. Solvent $B$ was a mixture of $15 \mathrm{mM}$ ammonium acetate buffer, acetonitril, and tetrahydrofuran $(65 / 30 / 5, \mathrm{v} / \mathrm{v} / \mathrm{v})$. Prior to use, helium sparking degassed the solvents. The trap column was flushed constantly with $25 \mathrm{mM}$ sodium phosphate buffer, $\mathrm{pH} 6.8$

\section{RESULTS AND DISCUSSION}

\section{Chromatography}

General. Usually, the concentrations of amino acids in physiological fluids have been determined mainly by liquid chromatography. However, the determination of amino acid isotope enrichment as intended in this study requires an additional mass spectrometric analysis. In the past, the coupling between a mass spectrometer and a LC system was troublesome and so 
gas chromatography was the only real option which could be applied. However, the development of atmospheric pressure ionization techniques (API) enabled the direct introduction of high flow rates (up to $1 \mathrm{mV}$ min as usually applied in LC applications) into the mass spectrometer, thus creating interesting possibilities for new applications.

Isotope enrichment measurements of selected amino acids require a baseline separation of derivatives of interest which possess the same or nearly the same molecular weight (e.g., consider isoleucine, leucine and arginine, citrulline). The separation of nondervatizated amino acids can only be performed using ion-exchange chromatography. However, this separation technique requires the application of solvents with high salt concentrations, which does not combine well with the requirements of a mass spectrometer. For this application, a reversed-phase technique is better suited, but this requires derivatization of the amino acids to improve their chemical properties for the separation. In addition, derivatization also improves the possibilities to detect and thus quantitate the separated amino acid derivatives. To reach this goal, a number of different reagents can be used. From these, OPA was selected because its use is well described and the derivatization procedure is easily automated $(10,17)$.

A disadvantage of OPA is, however, the instability of its derivatives. Immediately after their formation, an intramolecular rearrangement is initiated, resulting in the excision of the thiol's carbon chain from the molecule (18-20). It has been described that the rate at which the degradation process takes place depends on the structure of the thiol. To minimize on-column degradation, we used 3-MPA. The general structure of an OPA-derivatizated amino acid is depicted in Fig. 2.

In view of this degradation process, no good results can be achieved when OPA-amino acid fractions are collected on a separate chromatograph and subsequently introduced into the mass spectrometer as was used previously for radioactively labeled amino acids (1). The progressive derivative decay does not facilitate automated injection of the collected fractions.

Instead, the mass spectrometer is coupled directly to the chromatographic separation system. This setup has the advantage of an easy automatization and a better reproducibility of the whole measurement and the possibility to determine the enrichment of multiple amino acids in one chromatographic run.

Chromatographic optimization. To enable direct introduction of eluting amino acid fractions into the mass spectrometer, the separating method used previously (17) was adjusted. This included the use of volatile solvent buffers and redefinition of the chromatographic system, gradient shape, and solvent composition.

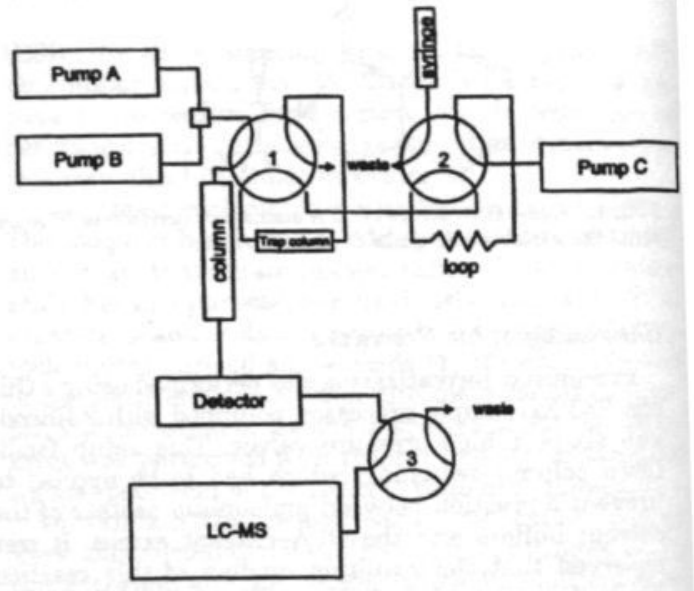

FIG. 2. Schematic setup of the flowpath of the system: Step 1: load sample loop (valve 2, syringe to loop); pump C flushes trap column. Step 2: trapping OPA derivatives, removal of reagent buffer (valve 2 pump $\mathrm{C}$ to trap column via loop). Step 3: elution, valve 1 via trap column to column; pump C via loop and valve 1 to waste. Step 4: selection of amino acid derivatives for MS analysis; valve 3 to MS or waste.

Pilot experiments had shown that the best signal to noise ratio for the mass-spectrometer was obtained by operating the ESI probe in negative mode. The total ion current obtained by APCI was higher. Despite our efforts, it could not be prohibited that a much larger degree of fragmentation occurred, which is not favorable for isotopic ratio measurements of whole molecules.

Optimal analytical conditions were assured by using a $150 \times 3.2$-mm i.d. HPLC column operated at a flow rate of $400 \mu \mathrm{V} / \mathrm{min}$. Because the ESI response is concentration dependent, the application of a smaller column diameter enhances the ESI response even more. It also severely limits the maximal amount of sample, which can be chromatographed. Therefore, the $3.2-\mathrm{mm}$ i.d. column was considered optimal for this application.

After implementation of these modifications and optimizing gradient conditions, a baseline separation for most of the major plasma-free amino acids was obtained (Figs. 3A and 3B).

Alternatively to the previous reaction sequence, a preprogrammed autosampler program can be used in which the reagent is transferred to the sample vial and neutralized with acid. However, this method is less favorable than the previous method. We found that the components of a standard reacted in this way gave only $80 \%$ response compared to the previous method. Furthermore, the chemical noise monitored by the LC-MS increased and a much more rapid decay of the chro 

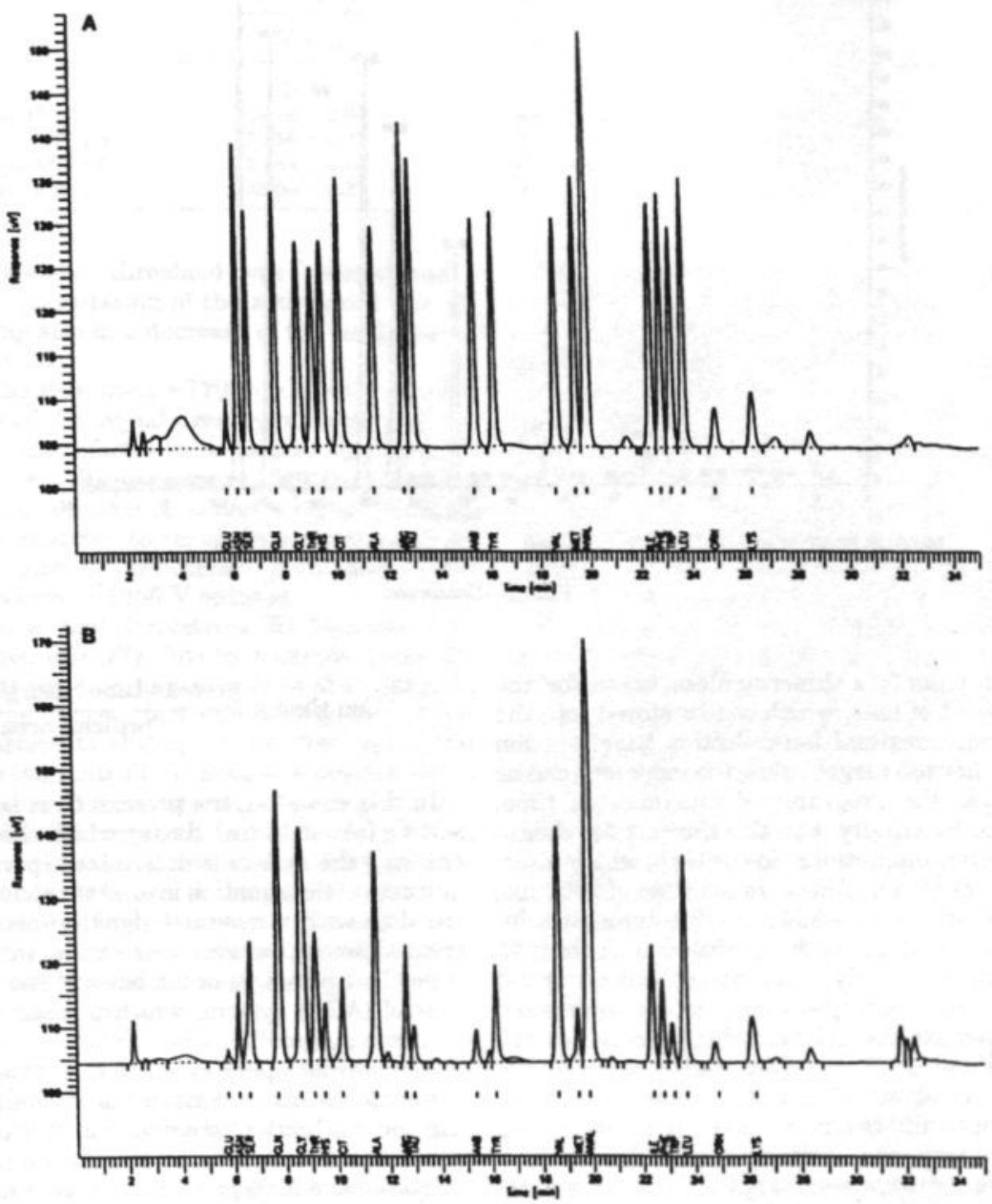

FIG. 3. (A) Fluorescence trace of the separation of a physiological standard ( 400 pmol each component); separation conditions in the text. (B) Fluorescence trace of the separation of a pig plasma sample. (C) Total ion current of selected amino acids derived from the plasma sample shown in B. Each component peak is determined in a "zoom-scan" window.

matographic separation occurred. We suspected the air contact during mixing-steps to cause an increased degradation compared to the first method.

Optimization of the mass spectrometer. After adaptation of the amino acid separation, described in the previous section, optimization of the mass spectrometer settings was required. To fine-tune the instrument, OPA-derived amino acid fractions were collected using the preparative HPLC system described previously (1). Immediately after collection, these fractions were introduced into the LCQ using its syringe pump, set at 10 $\mu \mathrm{V} / \mathrm{min}$. The syringe was connected to a PEEK T-piece to enable mixing with the HPLC effluent, which was pumped at $0.4 \mathrm{ml} / \mathrm{min}$.

After tuning was performed, the ion-trap settings were adjusted. The default settings of the instrument are designed to prohibit space charging (resulting in molecular rearrangements) and detector overflow. Isotopic ratio measurements, however, require the collection of a sufficient large amount of ions for all isotopic peaks of interest to determine correct statistics. Using the LCQ, this can be achieved by increasing the ion- 


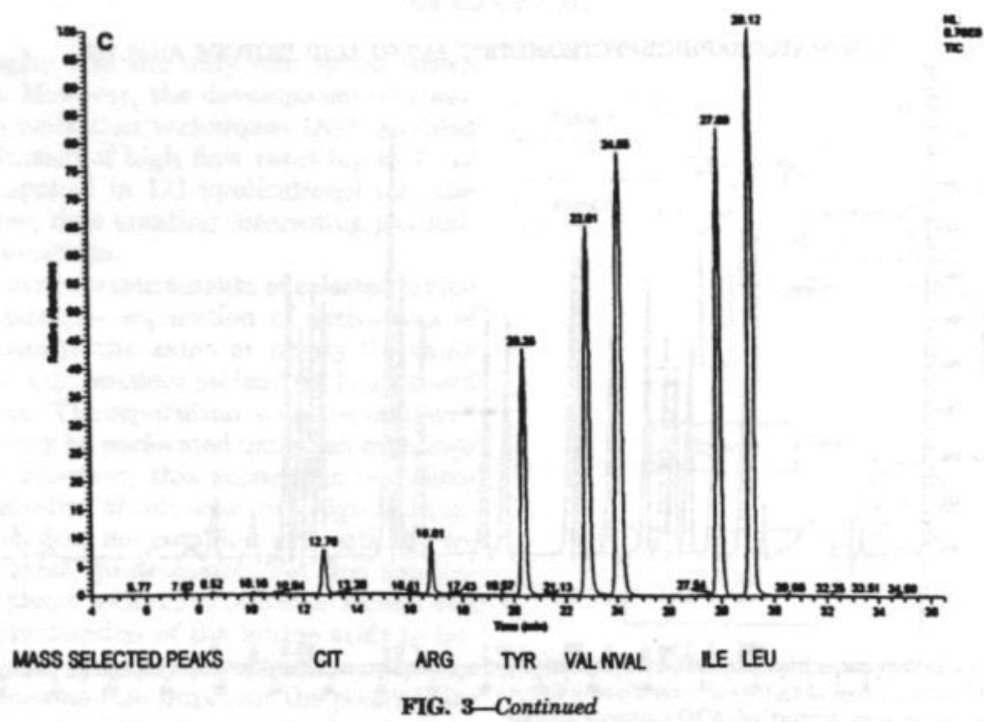

trap's "target value" (a dimensionless value for the maximal amount of ions, which can be stored into the trap) at a given maximal ion collection time (the ion time). The higher the target value, the more ions can be collected within the programmed maximal ion time. This increases sensitivity, but also the risk for chemical reactions (recombinations) in the trap, which interferes with the accuracy. Above an ion time of $2000 \mathrm{~ms}$, the abundance found for a $500 \mu \mathrm{M}$ OPA-tyrosine solution (used as a model derivative), infused at a rate of 25 $\mu \mathrm{V} / \mathrm{min}$, decreased rapidly if the target value was set above $5 \times 10^{7}$. At this target value, the ion time found for the chromatographic solvents alone pumped at $\mathbf{4 0 0}$ $\mu \mathrm{V} / \mathrm{min}$ was about $1000 \mathrm{~ms}$. Considering a chromatographic peak is about $25 \mathrm{~s}$ wide in our separation, sufficient data points can be collected to integrate the isotopomeric peaks (at a setting of $1 \mu \mathrm{scan}$ ).

When these settings were applied in a chromatographic run, a very low natural abundance was found for most OPA-amino acids together with a large coefficient of variation. Apparently, the area of the isotopomeric peaks was underestimated. To enable a better quantitation of these peaks, an increase of these signals was required. This could not be achieved through an increase in the injected amount because this would result in poor chromatography nor by an increase in the target value which would result in a too high concentration of ions in the trap (space charging). Increasing both target value and the detector gain solved the dilemma. This can be explained through the following equation:

$$
\text { ion time }=\frac{\text { prescan time } \times \text { target value }}{\text { prescan area }}
$$

In this equation, the prescan time is a fixed system setting (about $10 \mathrm{~ms}$ ), during which the amount of ions entering the system is determined (prescan area). The outcome of the equation is used to calculate the optimal ion time with a maximal signal-to-noise ratio. An increased amount of ions thus results in a decreased ion time. This principle is the basis of the automatic gain control (AGC) system, which is used to enhance the dynamic range.

For normal operation this is a favorable solution. However, for isotope ratio measurements it is not. During the calibration procedure of the instrument, the detector gain is optimized to obtain a maximal signalto-noise ratio for a given base peak. But this setting is not optimal for the much lower concentrated isotopomeric peaks, resulting in an underestimation of their appearance. By increasing the detector gain, the presence of a small amount of isotopomeric ions is detected earlier. Normally, the increase in signal would be compensated by a decrease in ion time because both the target value and the prescan times are constant. This would result in a reduced number of ions in the trap and thus a lower percentage of the lower concentrated isotopomeric ions will cross the detection threshold. By increasing the target value proportionally to the increase of the TIC, the ion time is kept constant, and thus the amount of ions in the trap. Using this ap- 
TABLE 1

Influence of the Detector Gain on the Abundance of Selected OPA-Derived Amino Acids, Measured in Zoom-Scan" Mode

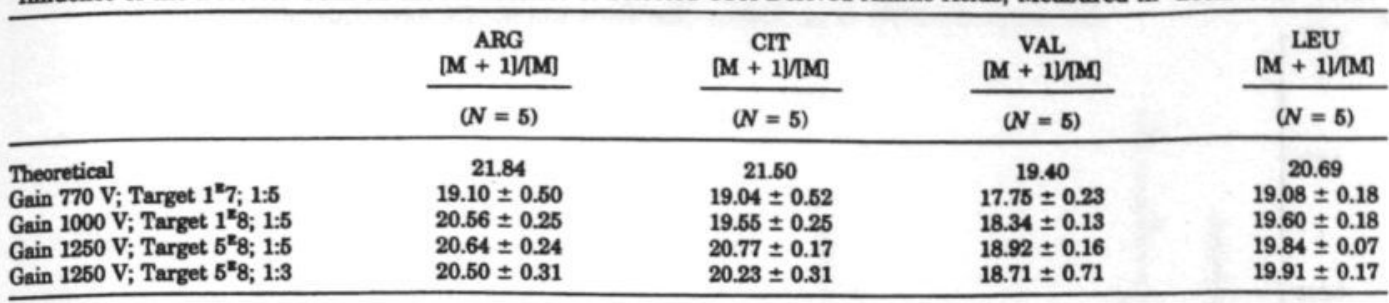

proach, the detection threshold was lowered and a more accurate quantitation of the abundance was obtained, resulting also in a decrease of the coefficient of variation (Table 1).

Increasing the gain from -770 to $-1250 \mathrm{~V}$ resulted in an increase of the signal area by a factor 100. According to the manufacturer, a further increase, although perhaps resulting in an even better estimation of the theoretical abundance and/or a better standard deviation, was expected to result in a more rapid decrease of the electron multiplier performance. We therefore considered $-1250 \mathrm{~V}$ optimal.

For most amino acid derivatives the fluorescent response is comparable (Fig. 3A) In contrast, there is a large difference (up to a factor of 5) in the ionization response between these derivatives (Fig. 3C). Especially the components eluting in the first part of the chromatogram (e.g., citrulline, arginine) tend to have a decreased response. We found that increasing the temperature of the heated capillary increased the absolute response (by as much as 7 times) and decreased the existing response differences. A further increase (up to a factor of 3) of the TIC of especially citrulline and glycine was achieved by the application of $5 \%$ (relative instrument setting) collision energy between the skimmer and the first octapole

In an attempt to minimize these differences even more, the column effluent was mixed with up to $25 \%$ of "makeup" liquids added via a T-piece prior to the ESI inlet. Because an amino acid contains both a carboxylic and an amino function, which can be (de-) protonated, we expected that a change in the $\mathrm{pH}$ would influence the ionization response. However, modification of the $\mathrm{pH}$ to 4 (by addition of acetic acid) or $\mathbf{1 1}$ (by addition of ammonia) led to a disproportional increase of the signals, increasing the relative differences even more. Addition of organic solvents like acetonitrile, methanol, or isopropanol (to compensate for the higher water content of the column effluent at the first part of the chromatogram) had very little effect. Considering these results and the fact that the first eluting amino acid derivatives are the more polar ones, we proposed that it is the hydration of the molecules which interferes with the ionization process.
The result of this process is that the lower responding derivatives and especially arginine require a langer amount to enable a correct isotopic ratio measurement. In Fig. 4, the relation between the injected amount and the isotopic ratio of some example amino acid derivatives is investigated. It is shown that typically more than a 25 pmol injection is required to prevent underestimation of the ratio (for 50 pmol arginine), corresponding to a plasma concentration of $15 \mu \mathrm{M}(5-\mu)$ injection in a threefold dilution).

Subsequently, a calibration curve was constructed in which 5- $\mu$ l mixtures of naturally enriched amino acids with increasing concentrations (5-1000 pmol) were injected in triplicate (not shown). Fluorescence and TICs of both the $[\mathrm{M}+1]^{-}$and $[\mathrm{M}]^{-}$ions (negative ionization) were monitored. A linear correlation was found for all three signals with a typical $R^{2}$ for $[\mathrm{M}+1]^{-}$of 0.9992 and $[\mathrm{M}]^{-}$of 0.9993 and for the fluorescence response was 0.9995 .

To determine the accuracy of the isotopic ratio measurement, enrichment curves were constructed. Herefore, $250 \mu \mathrm{M}$ amino acid standards were prepared, containing $\left[1-{ }^{13} \mathrm{C}\right]$-enriched amino acids (LEU and VAL), [ureido- ${ }^{13} \mathrm{C}-5,5-{ }^{2} \mathrm{H}_{2}$ ]CIT, [phenyl- ${ }^{2} \mathrm{H}_{5}$ ]PHE, and [guanidino- ${ }^{15} \mathrm{~N}_{2}$ ]-enriched arginine. To prohibit an overflow of the chromatographic system, standards were injected in a 1:3 dilution. The enrichment curve was investigated in the range from 0.1 to $5 \%$. A linear correlation was found for all amino acids $\left(R^{2}\right.$ ranging from 0.9984 (CIT, ARG) to 0.9997 (VAL)). Below a $0.5 \%$ enrichment, the precision of especially arginine becomes more variable. We therefore consider measurement of $0.25 \%$ enrichment the lower limit for most amino acids, with the exception of arginine with a lower limit of $0.5 \%$ enrichment.

The variation at plasma concentrations levels was studied by injection of a ( 5 times diluted) $5 \%$ enriched standard solution $(N=10)$, containing all major physiological amino acids (400 pmol injection each component). The coefficient of variation ranged from 1.4 to $5.5 \%$ for the fluorescence signal and from 3.7 to $9.1 \%$ for the total ion current. The standard deviation (SD) of the enrichment varied from $0.1 \%$ (leucine) to $0.5 \%$ (ar- 


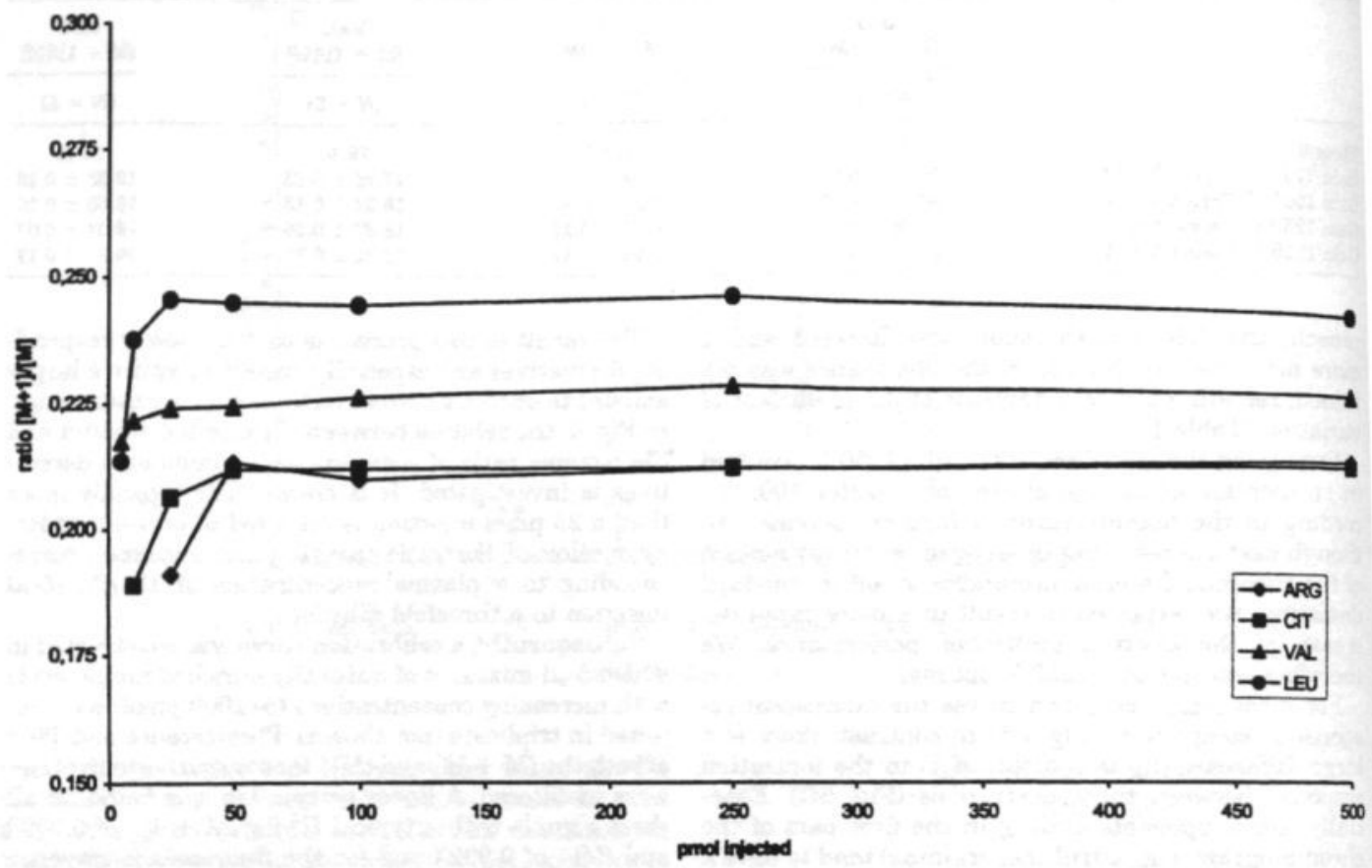

FIG. 4. Relation between the injected amount and isotope ratio measurement of selected amino acid derivatives.

ginine). Also, a standard containing all amino acids at physiological concentrations was prepared with $5 \%$ enrichment and the standard deviation of the isotopic ratio was determined. The highest SD was found for citrulline $(0.8 \%)$, possessing both a low ionization response and a low plasma concentration $(30 \mu \mathrm{M})$ and the lowest SD was found for valine $(0.2 \%)$, which has a four times higher ionization recovery and a six times higher plasma concentration $(200 \mu \mathrm{M})$.

For isotopomeric studies the LCQ facilitates another interesting possibility. The ion trap allows a scan function comparable to a triple-quad measurement. Within one scan window, it is possible to monitor the isotopomeric distribution of two or more components (up to $\mathbf{M}+8$ ) at the same time. This is especially important in case of an incomplete chromatographic separation of two components of interest, but also when studying multiple labeled components. Figure 5 illustrates this, by showing the isotopomeric distribution of the (chromatographically) incompletely separated isoleucine and phenylalanine peaks.

To test the potential of the method described here, a laboratory pig was infused with a mixture of the following tracers: $\left[1-{ }^{13} \mathrm{C}\right]$ glycine, $\left[{ }^{13} \mathrm{C}, 5,5-{ }^{2} \mathrm{H}_{2}\right]$ citrulline, [guanidino- ${ }^{15} \mathrm{~N}_{2}$ ]arginine, [ring-3,5- $\left.{ }^{2} \mathrm{H}_{2}\right]$ tyrosine, $\left[1-{ }^{13} \mathrm{C}\right] \mathrm{va}-$ line, (phenyl $\left.-{ }^{2} \mathrm{H}_{5}\right]$ phenylalanine, $\left[1-{ }^{13} \mathrm{C}\right]$ leucine, and $\left[5,5,5-{ }^{2} \mathrm{H}_{3}\right]$ leucine, according to the operating protocol described previously (21) and the infusion protocol described under Materials and Methods. Arterial blood samples were collected at several time intervals and enrichment levels of all the infused amino acids (of each time point) were determined within one run. Data are presented as the enrichment of the OPA-derivatizated amino acids. It is shown that most of the infused tracen reach steady state within $60-90$ min (Fig. 6), confirming the potential of the here described method.

\section{CONCLUSION}

In view of the results presented above, the here described benchtop LC-MS system can be used to determine isotopic ratios on-line of all physiological important plasma amino acids next to their concentrations in one run. Accurate isotopic ratios can typically be obtained in the range from 25 to 500 pmol injection with accuracy comparable to a GC-MS system (2). Cycle time of the measurement is $\mathbf{4 5}$ min (injection to injection). Considering also the easy and automated derivatization procedure, the method presents an interesting alternative to traditional GC-MS applications. 

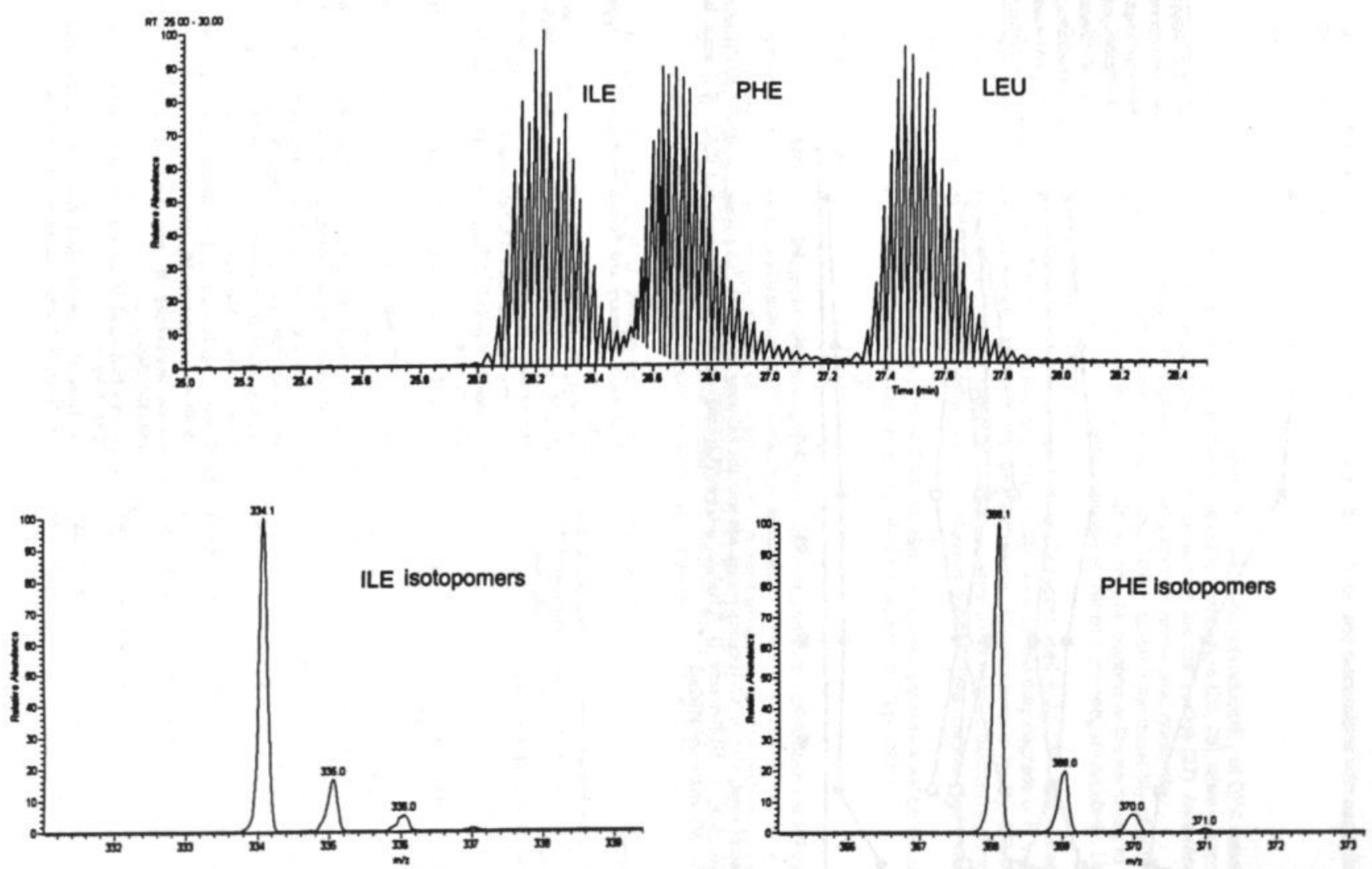

FIG. 5. Application of mass scan filters resulting in completely separated isotopomeric distributions of chromatographically incomplete separated component peaks. 


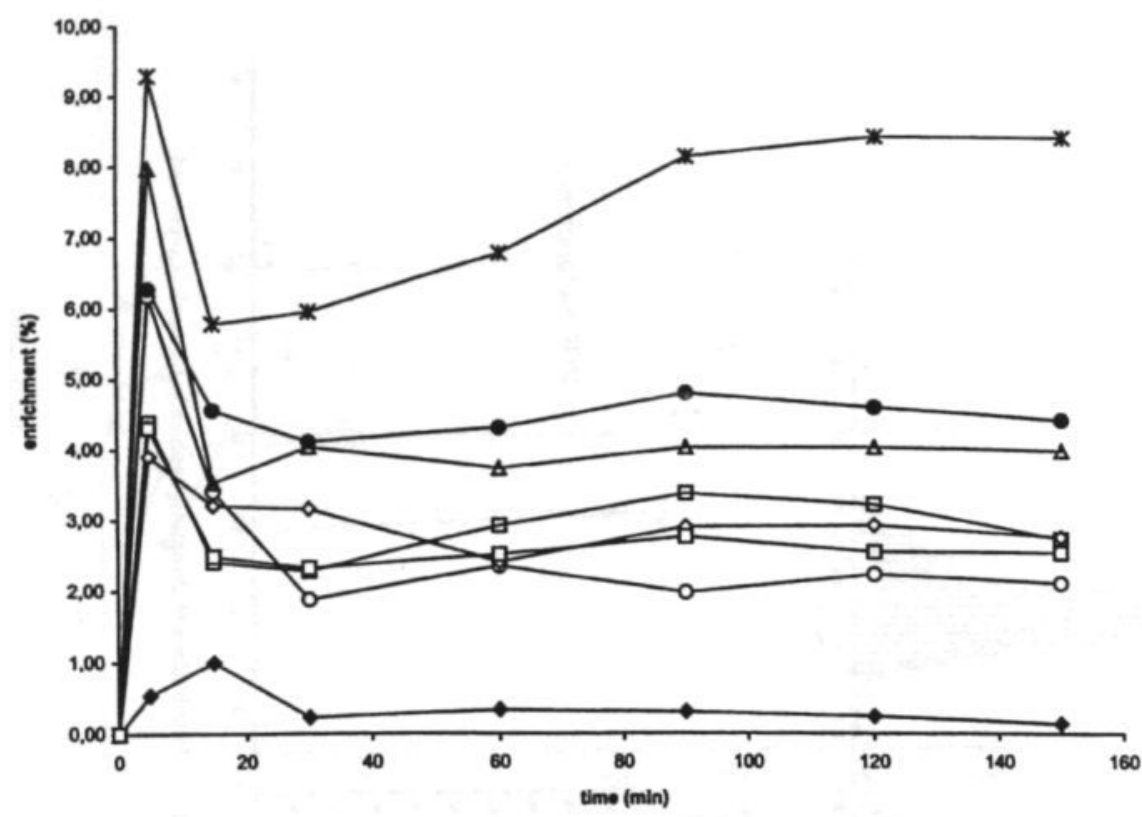

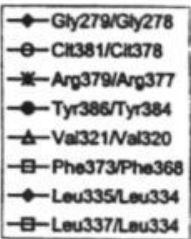

FIG. 6. Determination of steady state in a laboratory pig infused with the following tracers: $\left[1-{ }^{n} \mathrm{C}\right]-$ glycine, $\left[\right.$ ureido- $\left.{ }^{\mathrm{B}} \mathrm{C}, 5,5-{ }^{2} \mathrm{H},\right] \mathrm{citrulline}$,

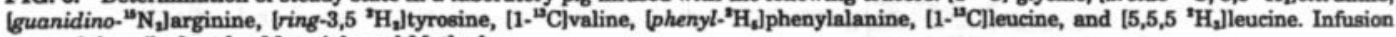
protocol described under Materials and Methods.

\section{ACKNOWLEDGMENTS}

The development of this method was enabled by Grant 902-23-239 from The Netherlands Organization for Scientific Research (NWO) and Maastricht University. Mrs. G. ten Have is greatly acknowledged for performing the animal experimentation.

\section{REFERENCES}

1. Van Eijk, H. M. H., Rooyakkers, D. R., Wagenmakers, A. J. M., Soeters, P. B., and Deutz, N. E. P. (1997) J. Chromatogr. B 691, 287-296.

2. Wolfe, R. (1992) Radioactive and Stable Isotope Tracers in Biomedicine: Principles and Practice of Kinetic Analysis, WileyLiss, New York.

3. Marquez, D, C., Weintraub, S, T., and Smith, P, C. (1994) J. Chromatogr. B 658, 213-221.

4. Patterson, B., Zhang, X., Chen, Y., Klein, S., and Wolfe, R. (1997) Metabolism 46, 943-948.

5. Serimgeour, C. M., Smith, K, and Rennie, M. J. (1988) Biomed. Environ. Mass. Spectrom. 15, 369-374.

6. Silfer, J. A., Engel, M. H., Macko, S. A., and Jumeau, E. A. (1991) Anal. Chem. 68, 370-374.

7. Fürst, P., Pollack, L., Graser, T., Godel, H., and Stehle, P. (1990) J. Chromatogr. 499, 557-569.

8. Deyl, Z., and Hyanek, J. (1986) J. Chromatogr. B 379, 177-250.

9. Schuster, R, and Apfel, A. (1996) A New Technique for the
Analysis of Primary and Secondary Amino Acids. Application note.

10. Van Eijk, H. M. H., Van der Heijden, M. A. H., Van Berlo, C. L. H., and Soeters, P. B. (1988) Clin. Chem. 34, 2510-2513.

11. Van Leuken, R., Duchateau, A., and Kwakkenbos, G. (1995) J. Pharm. Biomed. Anal. 13, 1459-1464.

12. Simpson, R., Spriggle, J., and Veening, H. (1983) J. Chromatogr. 261, 407-414.

13. Goshe, M., and Anderson, V. (1995) Anal. Biochem. 231, 387392.

14. Lagerwerf, F., Wever, R., Van Rijn, H., et al. (1998)Anal. Biochem. 257, 45-52.

15. De Hoffmann, E., Charette, J., and Stroobandt, V. (1996) Mass Spectrometry. Principles and Applications, Wiley, New York.

16. Cole, R. (1997) Electrospray Ionization Mass Spectrometry. Fundamentals, Instrumentation \& Applications, Wiley, New York.

17. Van Bijk, H. M. H., Rooyakkers, D. R., and Deutz, N. E. P. (1993) J. Chromatogr. 620, 143-148.

18. Svedas, V. J. K., Galaev, I. J., Borisov, I. L., and Berezin, I. V. (1980) Anal. Biochem. 101, 188-195.

19. Jabobs, W., Leburg, M., and Madaj, E. (1986) Anal. Biochem. $156,334-340$.

20. Simons, S. S., and Johnson, D. F. (1976) J. Am. Chem. Soc. 98, 7098-7099.

21. Ten Have, G., Bost, M., Suyk-Wierts, J., Van den Boogaard, A., and Deutz, N. (1996) Lab. Anim. 30, 347-358. 


\section{Consequences of the chemistry of OPA based amino acid analysis}

Acknowledgement: For the realization of this section the help of, and discussions with especially Dennis Rooyakkers is greatly acknowledged.

\section{Introduction}

As has been shown in the preceding papers, accuracy and reproducibility of OPA based amino acid analysis can be ensured by automatization of the derivatization procedure $(25,26)$, while a secondary reaction with 9-fluorenylchlororformiate (FMOC) can be used to determine the imino acids (27). As a result of these breakthroughs, the OPA application has gained wide popularity in amino acid research.

However, an often underestimated aspect of the OPA reaction is the instability of both reagent and its derivatives. Most papers, including ours, refer to the subject only by pointing at the necessity to perform the derivatization reaction in a reproducible way and to change or "refresh" the reagent regularly. Unfortunately, this may not be enough to guarantee accurate results.

It is for instance no common knowledge that the chemicals used in the OPA reagent and chromatographic solvents have an expiring day. It is usually believed that they degrade only in the completed derivatization reagent, but are stable in the form supplied by the manufacturers. In reality, OPA crystals are degraded under the influence of light, oxygen and moisture, while thiols may be oxidized to form disulfides. As a result, it may well be possible that a "freshly prepared" reagent does not give a stable chromatographic separation.

In this addendum the chemistry of the OPA reaction and other parameters will be discussed to give a better understanding how each of these factors effect the chromatographic separation.

\section{The OPA reaction}

To get a good insight in possible complications with respect to the OPA-based analysis of amino acids it is necessary to have an understanding of its reaction mechanism. The exact mechanism of the reaction of OPA with amino acids is still not completely elucidated although several pathways have been suggested. Roth initially proposed the formation of one reaction product such as formed with ninhydrin (28). Later, Simons and Johnson $(8,29,30)$ showed that this is not the case. Instead, the reaction results in a general iso-indole structure, which is responsible for the consistently high fluorescent recovery of various amino acid derivatives.

\section{Figure 1: Reaction of an amino acid with o-phthaldialdehyde}

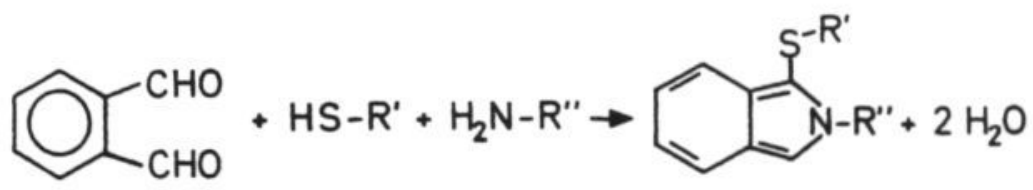

o-phthaldialdehyde

thiol amino acid

fluorescent iso-indole

The time of addition, the concentration and the structure of the thiol used in the OPA reagent were found to be crucial in this reaction. In contrast to what was initially thought, the thiol becomes part of the molecule and its incorporation determines the fluorescent properties of the derivative. If, and to what extent this incorporation takes place is determined by the moment of addition. If the thiol is added to a mixture of OPA and an amino acid solution the fluorescent product is not formed (31).

Apparently, an intermediary structure is formed excluding a coupling later with the thiol. The nature of this structure has been speculated upon, but has not yet been elucidated. Only addition of the thiol together with OPA results in the formation of the fluorescent derivative. The structure and concentration of the thiol used determine the rate of the formation reaction.

The degradation of the derivative and thus loss of its fluorescent character is explained by an intramolecular reaction resulting in excision of the thiol (in this case ethanethiol) (32). 


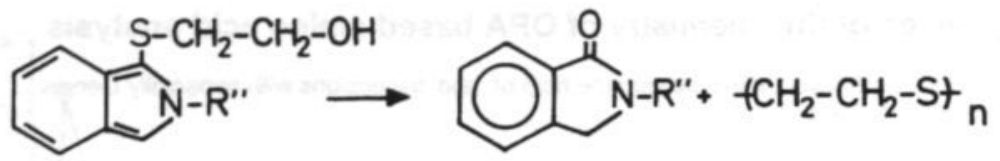

fluorescent derivative

non-fluorescent product polymer

The rate at which the degradation process takes place is also dependent on the structure of the thiol used, the concentration of the derivative and the environment in which it is present $(8,31,33-35)$. The influence of the thiol's structure on the derivative stability is explained by the lower probability for the intra-molecular rearrangement to take place if the oxygen of the thiol is separated from the sulfur by an increasing number of carbon atoms $(31,35)$. Therefore, the derivatives of mercaptoethanol, ethanethiol, 3-mercaptopropionic acid (3MPA) and $n$-acetyl-cystine are believed to possess a decreasing rate of degradation.

Recent results indicate that the general degradation mechanism proposed for mercaptoethanol and ethanethiol might perhaps not apply to 3-MPA derivatives. So perhaps another factor also influences the stability of 3-MPA derivatives. A mass spectrometric analysis of the OPA-derivative of arginine, used as a model for this purpose, indeed showed the presence of the mass of the predicted fluorescent derivative. However, the mass of the degraded derivative suggests that the sulfur from the mercaptopropionic acid is not exchanged for an oxygen from the carboxylic group. Instead, it remains in the derivative structure, while the rest of the 3-MPA molecule is removed (Figure 3 ). The existence of this pathway was already suggested by off-line mass spectrometric studies of the fragmentation route of OPA-amino acid derivatives $(36,37)$.

Figure 3: $\quad$ Full scan mass spectrum of Arginine-OPA-3-MPA (LCQ + mode: $1 \mathrm{~h}$ after formation (panel A) and after complete degradation (Panel B)
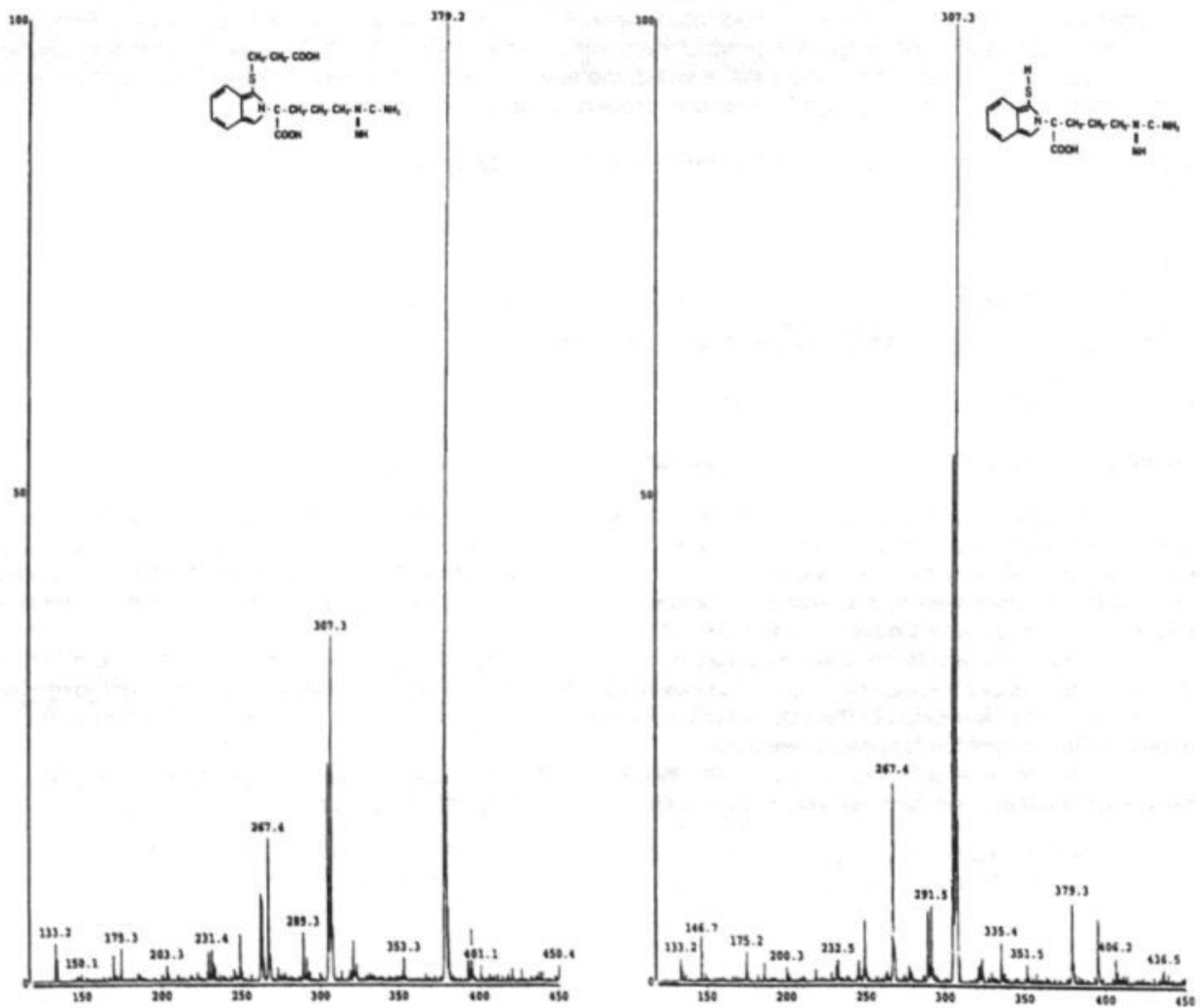
From a practical point of view, it can still be concluded that the OPA-3-MPA derivatives indeed possess an enhanced stability compared to ethanethiol and mercaptoethanol derivatives $(18,32)$. Furthermore, the less pronounced smell of 3-MPA, compared to ethanethiol and mercaptoethanol, makes this compound a more favorable alternative to apply.

However, it cannot be prevented that considerable degradation of the amino acid derivatives takes place within a 24 hour period. The resulting (time dependent) loss in fluorescence prohibits the automated processing of a batch of pre-prepared samples (Figure 4).

Figure 4: UV-trace showing the progressive decay of OPA-arginine from $\mathrm{T}=0 \mathrm{~h}$ to $\mathrm{T}=22 \mathrm{~h}$ at room temperature

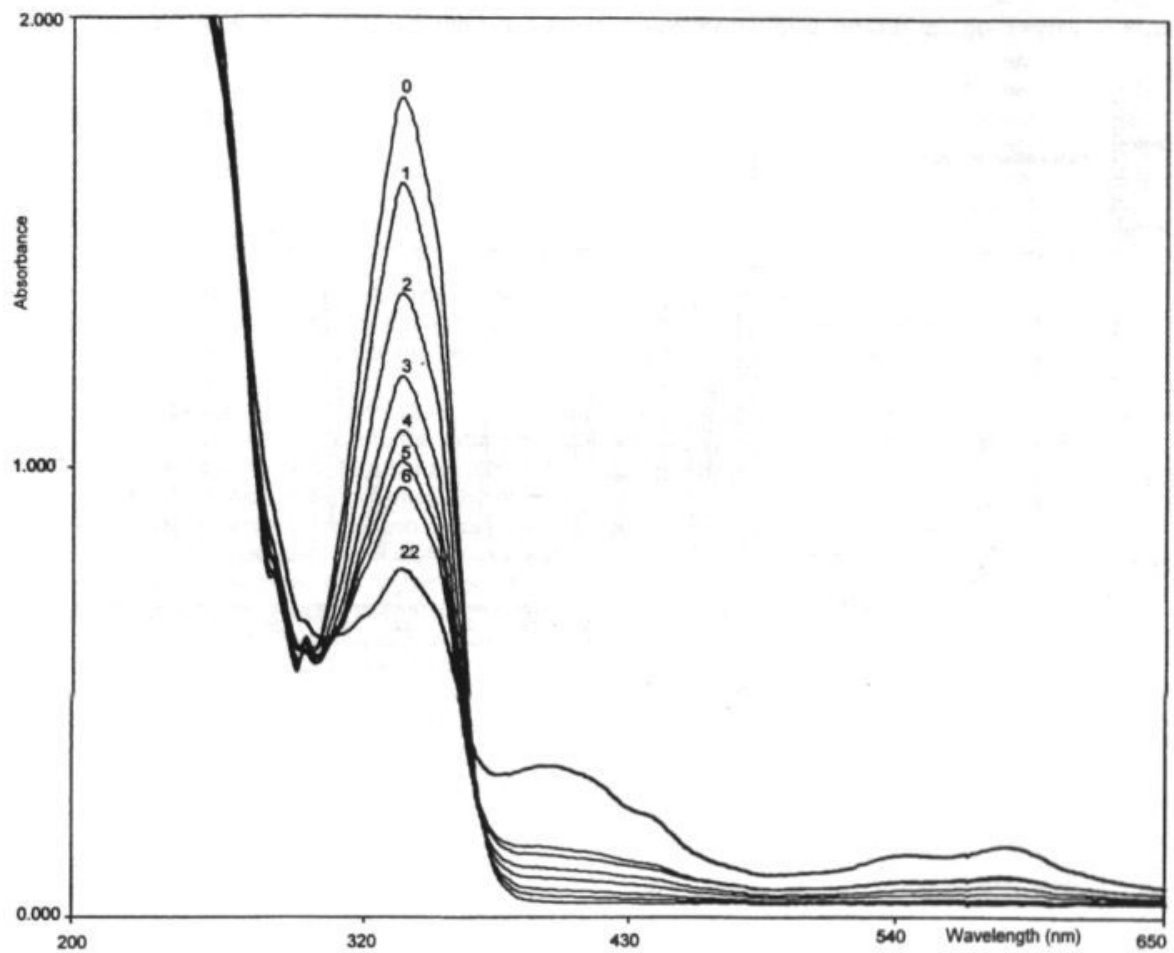

The derivative decay reaction follows an exponential curve and it has been described that the degradation of certain amino acids starts already after $2 \mathrm{~min}$. (32). It is suggested that the presence of the highly concentrated reagent buffer, and the OPA and thiol excess accelerate the onset of the reaction. Therefore, attempts have been made to enhance the stability of the amino acid derivatives by extracting the reagent excess from the reaction mix immediately after completion of the reaction, unfortunately with only little success $(23,24)$. The gain in stability was compensated by a more laborious procedure and a decrease in precision resulting from a variable extraction recovery. Therefore, this adaptation did not become popular.

We have shown that better results can be obtained by minimizing differences in reaction time prior to injection through automatization, thus enabling high precision measurements $(25,26)$. In this way, problems associated with reagent excess, are minimized also as it is washed away directly after injection in a reproducible way by the HPLC solvents, while the amino acid derivatives are retained on the column material. This method also allows the application of a highly concentrated reagent buffer, which is required to compensate for the remaining acid from deproteinized plasma or tissue samples. In this an extra neutralization step in the processing of these samples is prohibited.

Unfortunately, the degradation process does not only cause a decreased fluorescent response, but also interferes with the chromatographic separation. We assume that degraded derivatives and/or reagent are absorbed onto the packing material of the analytical column, resulting in broad irregular shaped peaks. Under normal conditions, this process does not significantly contribute to more dominant factors like dissolution of the silica matrix or stripping of the alkyl chains, which usually determine the column life span. However, both the solid OPA crystals and the 3-MPA are degraded under the influence of oxygen and light. The rate at which this process takes place is dependent on the purity of the starting materials, the specific surface and thus the crystalline form of the OPA and the storage procedure. Especially with respect to OPA crystals, there is a wide range of qualities 
available from different vendors, which unfortunately cannot be distinguished from each other by their purity specifications alone. It is our experience that products with a high specific area should be avoided, but even then a product must be considered expired after one year. Therefore, only recent batches should be purchased. Otherwise, it is not uncommon that one obtains a product which has already expired in the vendors storage The consequence of using OPA-reagent prepared with "degraded" chemicals may well be a irreversible loss in resolution after only a few injections, which can only be solved by exchanging the column. Under these circumstances, it is wise to also use a new batch of chemicals as a restart with "freshly prepared reagent" from degraded chemicals will again result in quick degradation of the performance of the new column.

\section{Figure 5: Effect of the use of degraded OPA chemicals on the chromatography}

Panel A: Physiological amino acid standard (25pmol each component): First injection.

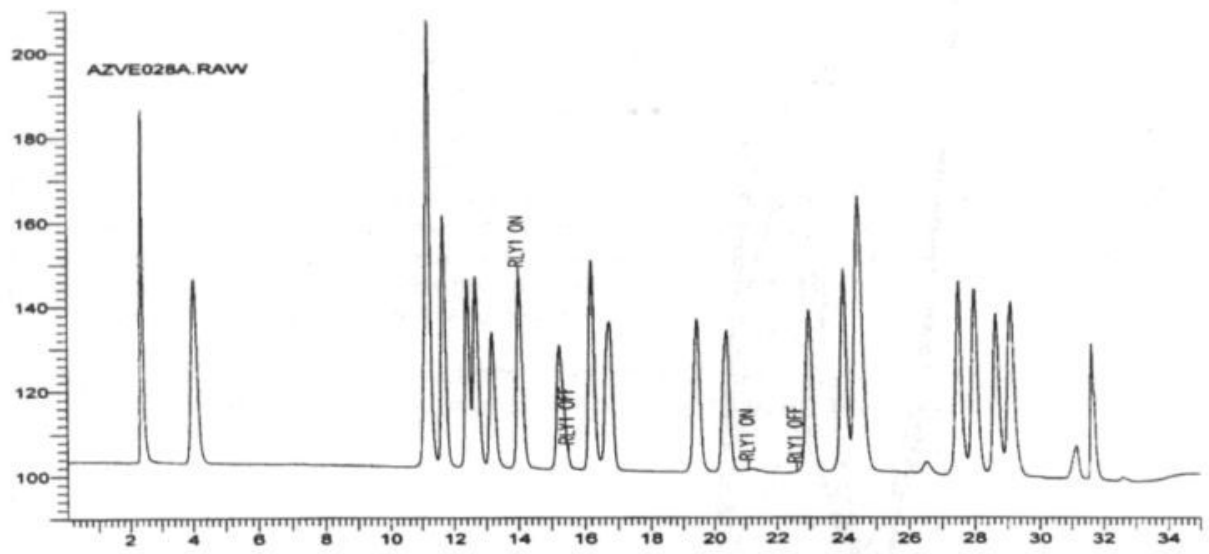

Panel B: Same standard after ten injections

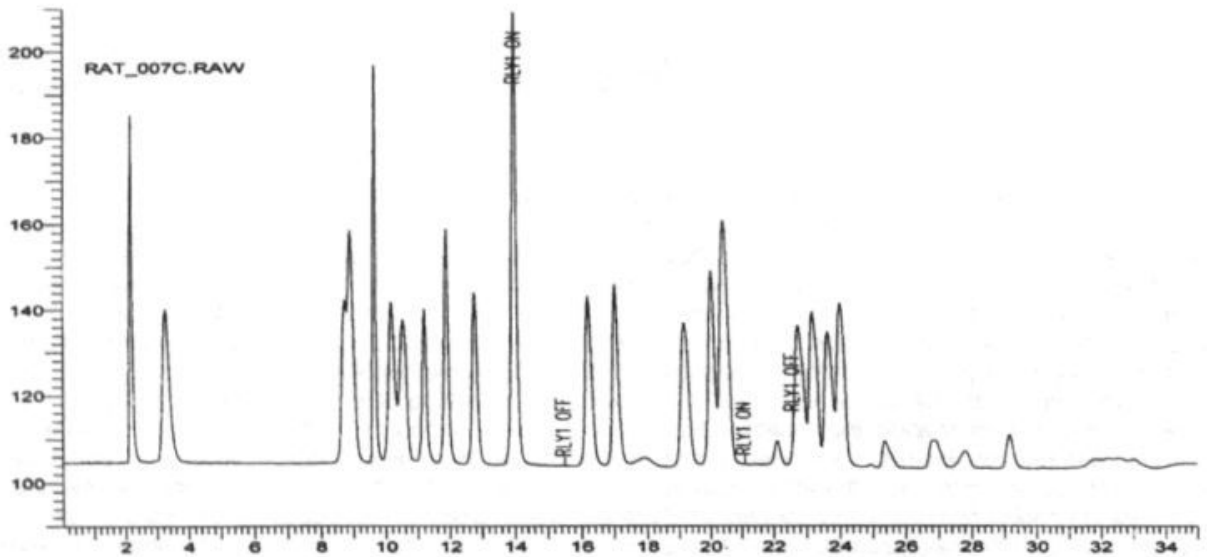

But even if all precautions are taken, some on-column degradation still takes place. This was illustrated in our study on the separation of OPA-polyamines (38). By lowering the column temperature from room temperature to $10^{\circ} \mathrm{C}$, the fluorescent response of these derivatives was enhanced by a factor 4 . Increasing the column temperature to improve the separation of critical components should therefore be considered cautiously. The precision and reproducibility of the analysis will therefore benefit from placing the column at a constant temperature a thermostatic oven. It is also wise to protect the analytical column, using a pre-column filled with the same packing material. 
As is discussed above, the structure of the thiol is of great influence on the stability of the derivatives. But not only the thiol's structure is important. Its absolute concentration and its amount in relation to the OPA concentration are of great influence too. Furthermore, the buffer capacity and derivatization pH are major factors. Below we have summarized some of the OPA reagent prescriptions used by other investigators, showing that there is little agreement on the subject.

Table 1: OPA-reagent prescriptions used in the literature

\begin{tabular}{|c|c|c|c|}
\hline Borate buffer & Thiol & OPA & Ref \\
\hline $0.1 \mathrm{M} ; \mathrm{pH} 9.7$ & Mercaptoethanol (ME):1.2 mM & $1.2 \mathrm{mM}$ & (39) \\
\hline $0.4 \mathrm{M} ; \mathrm{pH} 9.5$ & $\mathrm{ME}: 50 \mathrm{mM}$ & $37 \mathrm{mM}$ & (10) \\
\hline $1.0 \mathrm{M} ; \mathrm{pH} 9.5$ & ME: $60 \mathrm{mM}$ & $18 \mathrm{mM}$ & (40) \\
\hline $1.0 \mathrm{M} ; \mathrm{pH} 9.5$ & Ethanethiol (ET): $20 \mathrm{mM}$ & $4 \mathrm{mM}$ & (41) \\
\hline $0.5 \mathrm{M} ; \mathrm{pH} 10.4$ & 3-Mercaptopropionic acid (3-MPA) $230 \mathrm{mM}$ & $150 \mathrm{mM}$ & (42) \\
\hline $1.0 \mathrm{M} ; \mathrm{pH} 9.5$ & ME, ET or 3-MPA $100 \mathrm{mM}$ & $75 \mathrm{mM}$ & (18) \\
\hline $1.0 \mathrm{M} ; \mathrm{pH} 10.4$ & 3-MPA $50 \mathrm{mM}$ & $35 \mathrm{mM}$ & (26) \\
\hline
\end{tabular}

Our reagent prescription was developed taking the following considerations into account.

A highly concentrated borate buffer $(1 \mathrm{M})$ is required, to ensure complete neutralization of the acid residues from deproteinized plasma samples to a $\mathrm{pH}$ value above 10 , required for a maximal derivatization recovery (32).

To prevent an increased degradation, the absolute OPA concentration was kept low ( $35 \mathrm{mmol} / \mathrm{l})$, while a sufficient OPA excess relative to the total amino acid concentration was ensured by diluting the deproteinized plasma sample a hundred fold. This dilution step not only decreased the amount of acid introduced with the sample, but also minimized the interference of sample protein residues.

Instead of the frequently employed ethanethiol or mercaptoethanol we used 3-mercaptopropionic acid (3MPA), which does not only form derivatives with a better stability, but also has a less pronounced smell $(18,43,44)$. Furthermore, the higher polarity of the formed derivatives results in a reduced requirement of organic solvent for elution from the analytical column and thus it reduced costs.

The 3-MPA concentration was kept at only a mild excess $(30 \%)$ compared to the OPA-concentration, to prevent an enhanced degradation (35).

Constant quality of prepared reagent was ensured by storing reagent-solution in a chilled $\left(4^{\circ} \mathrm{C}\right)$ brown glass $4 \mathrm{ml}$ autosampler vial equipped with a self sealing rubber stopper. In this way degradation through the influence of light, heat and oxygen was minimized, enabling a safe use for at least 4 days (enabling weekendmeasurements). Pure chemicals were stored in amber vials under vacuum in an exciscator placed at room temperature. In this way the action of light, oxygen and moisture was eliminated as much as possible allowing normally a save use for one year.

\section{Chromatography}

\section{Solvent interaction}

Initially, our separation was based on the use of a phosphate buffer in combination with an acetonitril gradient. However, several critical separations could not be accomplished using this solvent system alone. Only the addition of tetrahydrofuran (THF) enabled the separation of these physiologically important amino acids (e.g. isoleucine-tryptophan, asparagine-serine and citrulline-arginine) and thus their quantitation..

Unfortunately, THF progressively forms peroxide upon storage. This peroxide accelerates the on-column degradation of OPA-amino acid derivatives, resulting in irregular shaped peaks which are also seen when degraded reagent is used (Figure 4). The manufacturer rarely provides the peroxide levels. Usually, a one-year expiring period is guaranteed, but although unsaid, this does not apply to the peroxide level, but to the water content. Therefore, the unsuspecting chromatographist, thinking he (or she) is using high quality THF, might be using solvent with a high level of peroxide, thus resulting in poor chromatography. It is our experience that the peroxide build-up may reach values above $10 \mathrm{mg} / \mathrm{l}$ even in unopened nitrogen flushed bottles of the highest quality. It is therefore a necessity to test each bottle before use on peroxide contamination or to use THF stabilized by butylated hydroxy toluene (BHT). Using the latter, one should be aware that BHT has a low solubility in aqueous solvent, carrying the risk of precipitation and thus column blockage, ghost peaks or an irregular baseline.

The use of phosphate buffer in the solvents may also be questioned. There are several papers stating that phosphate has a more pronounced degrading effect on reversed phase column material, compared to competitive buffers like citric acid (45). We have tried both solvent systems and did not observe any increased degradation for this application. 


\section{Choice of columns}

Originally, we started using Spherisorb $\operatorname{ODS}^{\circledR} 3 \mu \mathrm{m}$ columns. As column packing techniques and the production of the bulk material improved, the number of theoretical plates per meter increased. These more efficient columns allowed us to reduce their length from $25 \mathrm{~cm}$ to $15 \mathrm{~cm}$ or even $12.5 \mathrm{~cm}$. This reduction could then be used to increase the flow-rate and gradient steepness, thus shortening the analysis time to a total cycle time of $30 \mathrm{~min}(25)$. Others have described an even further reduction in analysis time down to $17 \mathrm{~min}(46)$. However, the separations then become very critical and column life time decreases. Nevertheless, the increased analysis speed nowadays, allows an almost "bed-side" determination.

Considering the large numbers of samples, which have to be analyzed for our metabolic and clinical studies, our main interest was to have a stable and reliable separation. Instead, we focussed on the search for a more stable packing material, able to withstand the high pH of the reagent buffer when a sample is loaded onto the column. For this we believed Inertsi ${ }^{3}$ to be a good candidate. An application using this packing material initially resulted in a satisfactory separation (not shown), but the column lifetime was much shorter than with the Spherisorb ${ }^{\star}$ material. We proposed that this might be due to metal ions, derived from the autosampler needle, which is gradually affected by the OPA-reagent. These metal ions contaminate the high purity Inertsil ${ }^{9}$ silica, which owes its high pH resistance to the absence of metal ions. The Spherisorb® material has a much higher metal content, making them less susceptible to this type of pollution. Therefore, in this application these columns last longer making them preferable to Inertsi $^{\circ}$.

\section{Detection}

The high fluorescent sensitivity requires a high dilution factor of the samples to prevent detector overflow. This is beneficial, because it reduces the sample requirement and allows the use of low OPA concentrations, thus enhancing reagent stability (see above). However, it also enhances the possible interference with contaminating amino acids from sweat or skin $(2,47)$ and thus care must be taken in preparing the samples for analysis. It has therefore become a standard procedure in our laboratory to include a blank sample in the analysis sequence. 


\section{References}

1. Spackman DH, Stein WH, Moore S. Automatic recording apparatus for use in the chromatography of amino acids. Anal.Biochem. 1958;30:1190-1206.

2. Williams AP. General problems associated with the analysis of amino acids by automated ion-exchange chromatography. J.Chromatogr. 1986;373:175-190.

3. Le Boucher J, Charrett C, Coudray-Lucas C, Giboudeau J, Cynober L. Amino acid determination in biological fluids by automated ion-exchange chromatography: performance of Hitachi L-8500A. Clin.Chem. 1997;43:8:1421-1428.

4. Moller SE. Quantitation of a physiological amino acids by gradient ion-exchange high-performance liquid chromatography. J.Chromatogr. 1993;613:223-230.

5. Udenfriend S, Stein S, Bohlen P, Dairman W, Leimgruber W, Weigele M. Fluorescamine: A reagent for assay of amino acids, peptides,proteins and primary amines in the picomole range. Science 1972;178:871-872.

6. Nakamura H, Pisano JJ. Fluorescamine derivatives of histidine, histamine and certain related imidazoles: unique fluorescence after heating in acid. Arch. Biochem.Biophys. 1976;177:334-335.

7. Vaidyanath $\mathrm{N}$, Birkhahn R, Border JR, et al. A method for determining amino acid concentrations and specific activities of amino acids and some other compounds in biological fluids. Anal.Biochem. 1976;70:479-488.

8. Simons SS, Johnson DF. Ethanethiol: A thiol conveying improved properties to the fluorescent product of ophthalaldehyde and thiols with amines. Anal.Biochem. 1977;82:250-254.

9. Hill DW, Walters FH, Wilson TD, Stuart JD. High performance liquid chromatographic determination of amino acids in the picomole range. Anal.Chem. 1979;51:1338-1341.

10. Lindroth P, Mopper K. High performance liquid chromatographic determination of subpicomole amounts of amino acids by precolumn fluorescence derivatization with o-phthaldialdehyde. Anal.Chem. 1979;51:1667-1674.

11. Broderick GA, Kang JH. Automated simultaneous determination of ammonia and total amino acids in ruminal fluid and in vitro media. J.Diary.Sci. 1980;63:64-75.

12. Jones BN, Paabo S, Stein S. Amino acid analysis and enzymatic sequence determination of peptides by an improved o-phthaldialdehyde precolumn labeling procedure. J.Liq.Chromatogr. 1981;4:565-586.

13. Tapuhi $Y$, Schmidt DE, Lindner W, Karger B. Dansylation of amino acids for high-performance liquid chromatography analysis. Anal.Biochem. 1981;115:123-129.

14. Hill D, Bumworth L, Skea W, Pfeifer R. Quantitative hplc analysis of plasma amino acids as orthophtaldialdehyde/ethanethiol derivatives. J.Liq.Chromatogr. 1982;5:2369-2393.

15. Tumell DC, Cooper DH. Rapid assay for amino acids in serum or urine by pre-column derivatizatioon and reversed phase liquid chromatography. Clin.Chem. 1982;28:527-531.

16. Jones BN, Gilligan JP. o-Phthaldehyde precolumn derivatization and reversed-phase high-performance liquid chromatography of polypeptide hydrolysates and physiological fluids. J.Chromatogr. 1983;266:471-480.

17. Einarsson S, Josefsson B, Lagerkvist S. Determination of amino acids with 9-fluorenylmethylchloroformate and reversed-phase high-performance liquid chromatography. J.Chromatogr. 1983;282:609-618.

18. Godel H, Graser T, Foldi P. Pfaender P. Fürst P. Measurement of free amino acids in human biological fluids by highperformance liquid chromatography. J.Chromatogr. 1984;297:49-61.

19. Eslami M, Stuart JD. Separation of orthophthalaldehyde/ethanol derivatives of taurine and closely eluting amino acids by high performance liquid chromatography. J.Liq.Chromatogr. 1984;7:1117-1131.

20. Heinrikson R, Meredith S. Amino acid analysis by revere-phase high-performance liquid chromatography: precolomn derivatization with phenylisothiocyanate. Analytical biochemistry 1984;136:65-74.

21. Van Berio CLH, De Jonge H, Van de Boogaard AEJM, Van Eijk HMH, Janssen MA, Soeters PB. y-Aminobutyric acid production in small and large intestine of normal and germ-free wistar rats. Infulence of food intake and intestinal flora. Gastroenterology 1987;93:472-479.

Löser C. Wunderlich U. Fölsch UR. Reversed phase liquid chromatographic separation and simultaneous fluorimetric detection of polyamines and their monoacetyl derivatives in human and animal urine, serum and tissue samples: an improved, rapid and sensitive method for routine application. J.Chromatogr. 1988;430:249-262. Heideman RL., Flicking KB, Walker LJ. Free and total putrescine in cerebrospinal fluid quantified by reversed phase liquid chromatography. Clin.Chem. 1984;30:1243-1245.

24. Skaaden T, Greibrokk T. Determination of polyamines by pre-column derivatization with o-phthaldialdehyde and ethanethiol in combination with reversed phase high performance liquid chromatography. J.Chromatogr. 1982;247:111-122. Van Eijk HMH, Rooyakkers DR, Deutz NEP. Rapid routine determination of amino acids in plasma by highperformance liquid chromatography with a 2-3 um Spherisorb ODS II column. J.Chromatogr. 1993;620:143-148. Van Eijk HMH, Van der Heijden MAH, Van Berlo CLH, Soeters PB. Fully automated liquid chromatographic determination of amino acids. Clin.Chem. 1988;34:2510-2513. Schuster R, Apfel A. A new technique for the analysis of primary and secondary amino acids. Application note 1996. Roth M. Fluorescence reaction for amino acids. Anal.Chem. 1971;43:880-882. Simons SS, Johnson DF. The structure of the fluorescent adduct formed in the reaction of o-phthalaldehyde and thiols with amines. J.Am.Chem.Soc. 1976;98:7098-7099.

30. Simons SS, Johnson DF. Reaction of o-phthalaldehyde and thiols with primary amines: Formation of 1-alkyl (and Aryl) thio-2-alkylisoindoles. J.Org.Chem. 1978;43:2886-2891.

31. Alvarez-Coque M, Medina Hernandez M, Villanueva Camanas R, Mongay Fernandez C. Formation and instabilty of ophthalaldehyde derivatives of amino acids. Anal. Biochem. 1989;178:1-7.

32. Graser T. Bestimmung von freien Amino sauren in biologische Materiaal mittels HPLC. Automatisierung und Anwendungsmoglichkeiten der Vorsaulen-Derivatisierung mit o-Phthadialdehyd. Thesis 1987.

33. Svedas VJK, Galaev IJ, Borisov IL, Berezin IV. The interaction of amino acids with o-phthaldialdehyde: A kinetic study and spectrophotometric assay of the reaction product. Anal.Biochem. 1980;101:188-195.

34. Aswad DW. Determination of D- and L-aspartate in amino acid mixtures by high-performance liquid chromatography after derivatization with a chiral adduct of o-phthaldialdehyde. Anal.Biochem. 1984;137:405-409.

35. Jabobs W, Leburg M, Madaj E. Stability of o-phthalaldehyde-derived isoindoles. Anal.Biochem. 1986;156:334-340.

36. Van Leuken R, Duchateau A, Kwakkenbos G. Thermospray liquid chromatography/mass spectrometry study of diastereomeric isoindole derivatives of amino acids and amino acid amides. J.Pharm.Biomed.Anal. 1995;13:14591464. 
37. Simpson R, Spriggie J, Veening H. Off-line liquid chromatographic-mass spectrometric studies of o-hthalaldehydeprimary amine derivatives. J.Chromatogr. 1983:261:407-414.

38. Van Eijk HMH, Rooyakkers DR, Deutz NEP. Automated determination of polyamines by high-performance liquid chromatography with simple sample preparation. J.Chromatogr. A 1996;730:115-120.

39. Lavi L, Holcenberg J. Sensitive analysis of asparagine and glutamine in physiological fluids and cells by precolumn derivatization with phenylisothiocyanate and reversed-phase high-performance liquid chromatography. J.Chromatogr. B 1986:377:155-163.

40. Venkatakrishnan A, Abel M, Campbell R, Donahue E, Uselton T, Flakoll P. Whole blood analysis of gluconeogenic amino acids for estimation of de novo gluconeogenesis using pre-column o-phthalaldehyde derivatization and highperformance liquid chromatography. J.Chromatogr.B 1995;676:1-6.

41. O.Fleury M, Ashley DV. High-performance liquid chromatographic analysis of amino acids in physiological fluids: Online precolumn derivatization with o-phthaldialdehyde. Anal.Biochem. 1983;133:330-335.

42. Carducci C, Birazelli M, Leuzzi V, Santagata G, Serafini P, Antonozzi I. Automated method for the measurement of amino acids in urine by high-performance liquid chromatography. 1996;J.Chromatogr.A:173-180.

43. Füst P, Pollack L, Graser T, Godel H, Stehle P. Appraisal of four Pre-column derivatization methodes for the highpreformance liquid chromatographic determination of free amino acids in biological materials. Journal of chromatography 1990:499:557-569.

44. Graser TA, Godel H, Albers S, Földi P, Fürst P. An ultra rapid and sensitive high-performance liquid chromatographic method for determination of tissue and plasma free amino acids. Anal.Biochem. 1985:151:142-152.

45. Claessens H, Van Straten M, Kirkland J. Effects of buffers on silica-based column stability in reversed-phase highperformance liquid chromatography. J.Chromatogr. A 1996;728:259-270.

46. Teerlink T, Van Leeuwen PAM, Houdijk A. Plasma amino acids determined by liquid chromatography within 17 minutes. Clin.Chem. 1994;40:245-249.

47. Geigy C. Wissenschaftliche tabellen Geigy: Einheiten in Messwesen, Korperflussigkeiten, Organe, Energiehaushalt, Ernahrung. Basel: Ciba-Geigy AG, 1977. 


\section{Sample preparation: An overview}

\section{Introduction}

The influence of the sample preparation process on the outcome of an experiment is an oftenunderestimated aspect of the analytical cycle. Usually, more attention is focussed to the precision of the method itself, as a result of which a method can be very reproducible but does not necessarily reflect the true concentrations of the target metabolite and this also the case for amino acid analysis.

Below, a comprehensive discussion is given which highlights the crucial steps in the sampling process

\section{Collection}

To obtain true plasma amino acids concentrations, it is essential to collect blood samples on ice. Heamolysis must be avoided to prohibit the red blood cell content to mix with plasma. This is usually done by centrifugation. However, the $\mathrm{g}$-force, which may be applied is dependent on the metabolite to be analyzed $(9,10)$. Plasma is preferable for amino acid determination compared to serum, as the latter requires a waiting period during which the clotting process takes place. In this time, enzymatic processes can take place $(4,5,11,12)$. The choice of anticoagulant has to be considered also, as they can influence amino acid concentrations (8). Furthermore, it would not be wise to use a coagulant like ammonium heparin if one would like to determine ammonia concentrations also.

Substrate concentrations in biological samples can otherwise change very rapidly due to enzymatic reactions $(4,5,10-12)$ or spontaneous degradation processes (13-15) induced by a low $\mathrm{pH}$ and/or too high temperature. The preparation of plasma requires the removal of the red blood cells. To minimize enzymatic activity during this procedure, samples have to be kept on ice or must be processed in a chilled $\left(4^{\circ} \mathrm{C}\right)$ centrifuge or in a cold room. Hereafter, plasma is deproteinized and frozen in liquid nitrogen for transport to the laboratory where they are analyzed immediately or stored at $-80^{\circ} \mathrm{C}$ before analysis. The processing of tissue samples this is more laborious, which is therefore difficult to perform in the cause of an experiment. To avoid this, small specimens are usually frozen immediately into liquid nitrogen and processed later in the laboratory. Larger specimens are freeze-clamped first between a liquid nitrogen chilled pair of Wollenberg tongs $(16,17)$ before removal and then transported to the laboratory in liquid nitrogen for further processing. The taking of a representative biopsy from an inhomogeneous matrix such as muscle presents another problem, which is discussed below.

\section{Plasma processing}

The best way to eliminate plasma enzymatic activity is still subject to an ongoing discussion. Most common ways are:

Addition of an acid (3-5, 10, 18-21)

Addition of organic solvent $(10,20-23)$

- Ultracentrifugation $(2,10,20,23,24)$

- Use of "cut-off" filters $(2,10,20,24)$

- Solid phase extraction $(10,25)$

\section{Addition of acid}

This method is based on the unfolding of the quaternary structure of the protein by changing the pH of its solution. Usually 5 -sulfosalicylicacid $(5-S S A)(2,7,10,21,26)$ is applied for this purpose, but other acids, like trichloroaceticacid (TCA) $(7,10)$, and perchloroaceticacid (PCA) $(10,21)$ have been used also. The latter acids are claimed to result in higher free amino acid concentrations, when compared to 5-SSA. It is suggested that this may be due to a loss in recovery when applying the 5-SSA method (10). In contrast, it is also suggested that high amino acid concentrations obtained by a different method as the 5-SSA method may result from at least a partial hydrolysis of plasma proteins, thus increasing free amino acid concentrations [\#!49]. In our view, it can also be hypothesized that amino acids, bound to transport plasma proteins like albumin, are easier released by the action of these acids. A typical example of this is tryptophan, which under physiological conditions is bound to albumin for about half its total concentration (7).

The amount of 5-SSA required for complete deproteinization is also questioned $(2,25)$. The optimal amount is supposed to be $4 \mathrm{mg} 5$-SSA (solid) for $100 \mu \mathrm{l}$ of plasma $(7,26)$. The main reason for using this amount is that in the past, amino acid concentrations were usually determined by ion-exchange chromatography. For this technique, the "loading $\mathrm{pH}^{\prime}$ at which the sample is injected onto the column is very critical. Both a too low and too 
high pH result in a bad separation. The optimal acid amount would precipitate most of the protein and result in an injection pH of about 2.5-3 (2). The amount of protein in the plasma of an overnight fasted subject was hereby considered to be more or less constant. However, when conducting metabolic studies, the effect of feeding is one of the questions to answer. Thus, samples are presented to the laboratory containing a significantly elevated protein content, resulting from the ingested meal, and this cannot be precipitated completely using the standard amount of acid $(2,25)$. This remainder does not affect the more robust ion-exchange separation too much, but a reversed phase separation is much more sensitive towards this problem. A later study showed that the amount of 5-SSA may be increased by as much as a factor 2 without effecting the free amino acid concentrations. This increase resulted in the precipitation of a considerable amount of protein and although it complicates an ionexchange separation, it is beneficial for a reversed phase method. Therefore, we prefer to use $6 \mathrm{mg} 5-\mathrm{SSA} 100 \mu \mathrm{l}$ plasma.

\section{Addition of organic solvent}

The addition of an organic solvent such as acetonitril or methanol also results in the unfolding of the quaternairy structure. Deproteinization using an organic solvent results in a sample matrix, which is more compatible with an RP-HPLC separation. Organic solvents may also be used to extract lipids. The study of plasma samples, obtained from patients receiving oral or intravenous administration of large amounts of nutrition enriched with lipid, enhances the plasma content dramatically. Acid deproteinization does not remove lipid form the plasma samples. This can become a serious problem for an RP-HPLC separation, as the lipid will be bound irreversibly to the column packing material. This can degrade a column in a matter of a few analysis cycles (25). Furthermore, organic solvent addition removes a larger amount of protein (polypeptide), as can be proven by weighing the pellet (not shown). Considering these advantages, organic solvent deproteinization seemes to be favorable.

However, free amino acid concentrations in plasma samples deproteinized with organic solvents are found to be higher compared to those deproteinized with 5-SSA. This makes it difficult to compare data with the literature. A practical disadvantage for using organic solvents is the necessity to prevent their evaporation prior and during the sampling procedure and upon storage. Both considerations make the organic solvent method less attractive.

\section{Ultracentrifugation}

In contrast to the previous methods, ultracentrifugation does not require any addition to the samples. In this way there is no risk of contamination or dilution errors, so in principle this technique would result in the most representative sample. Unfortunately, it requires the presence of a suitable (expensive) centrifuge in the laboratory and it takes a relatively long time to achieve a protein free sample. As has been discussed before, this carries the risk of both an enzymatic and temperature dependent degradation of certain amino acids (e.g. glutamine, arginine).Therefore, this has not become a very popular method in metabolic research.

\section{Cut-off filters}

The working of a cut-off filter is explained by its possession of pores of a selected diameter. These pores allow only molecules below a certain molecular weight to pass, while the larger ones are retained. Usually, the filtration process takes place in a centrifuge, revolving at low speed (1500-3000 rpm). A higher speed could also cause proteins, larger than the cut-off value, to be pressed through the filter-membrane. The method results in purified samples, which are not diluted, and the centrifuge times are usually acceptable. However, only small amounts of sample can be processed, because the smaller the cut-off value, the easier the filter is blocked. Even then, the recovery is usually rather low, which is problematic in metabolic studies involving small laboratory animals. Furthermore, the filters are expensive, compared to first two deproteinization techniques, making them less attractive for this type of research.

\section{Solid phase extraction (SPE)}

Solid phase extraction combines the principles of filtration and absorption in one method. There is a wide range of systems available at the moment and because of their ease of use they are becoming increasingly popular []. Unfortunately, for metabolic research they posses also some negative properties. First is that they hold quite a large internal volume, which is occupied by the equilibration liquid and this dilutes the samples, increasing the risk of contamination and dilution errors. Again, they are relatively expensive.

From a practical point of view, we consider the 5-SSA deproteinization the best option to process plasma samples for amino acid analysis. In contrast to most literature on this subject, we use a $50 \%$ larger amount $(6 \mathrm{mg} / 100 \mu \mathrm{l}$ plasma) to obtain a better deproteinization. The acid is added as a solid, to prevent dilution errors. Test tubes, containing the desired amount, are prepared by filling out a known solution of 5-SSA in water into the tubes and then evaporate the water overnight in an oven set at $50^{\circ} \mathrm{C}$. The dried sample tubes (if closed) can be stored for weeks before use.

However, 5-SSA is not always an ideal choice. Several biochemical determinations (ammonia, urea, lactic acid, glucose, keton bodies etc.) are based on the consumption or production of $\mathrm{NAD}(\mathrm{P}) \mathrm{H}$ by measuring the change in extinction of this component in time. The extinction maximum of $N A D(P) H$ is at $340 \mathrm{~nm}$. At this wavelength, 5-SSA still possesses a considerable absorption (Figure 4). Selecting a higher detection wavelength $(350 \mathrm{~nm})$ minimizes the interference, but not every analysis system is equipped with a suitable monochromator or filter to enable this setting. Therefore, trichloroaceticacid (TCA) is a better candidate for these determinations. 


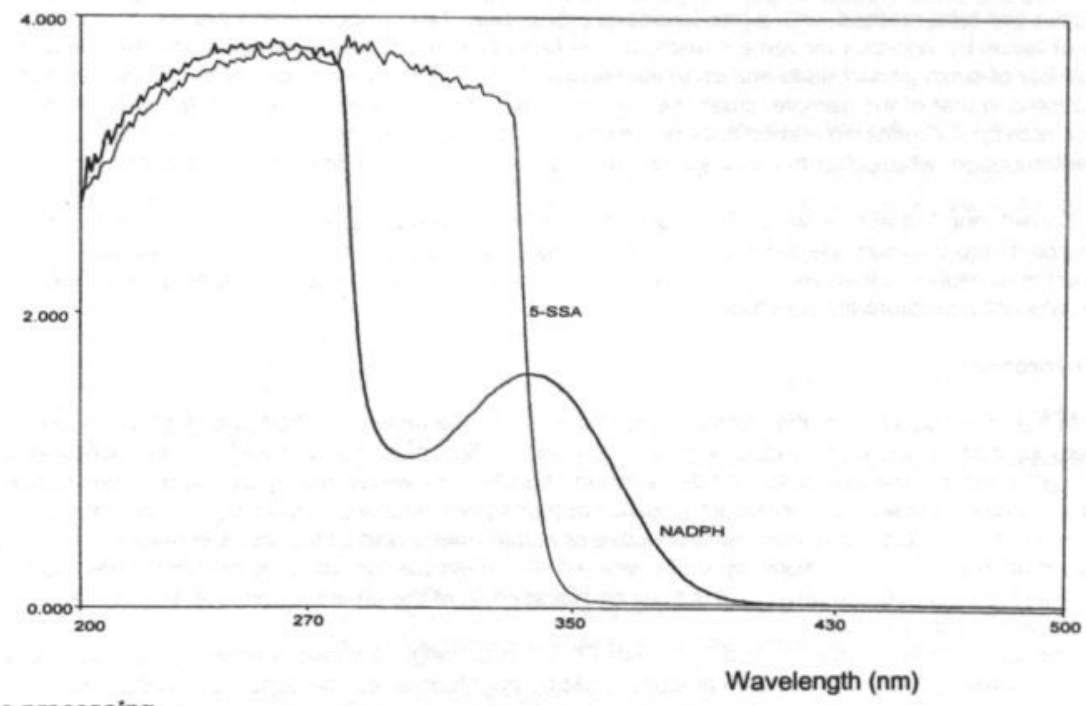

\section{Tissue processing}

The correct sampling and processing of tissue samples is a difficult and laborious job. Starting with the sampling itself it can be imagined that the first difficulty is how to obtain a representative sample. In principle, one likes to estimate the metabolic activity of a whole body compartment, by collecting just a small part of it. Muscle tissue, for example is not a homogeneous pool like blood, but contains contracting fibers, connective tissue and blood vessels. Furthermore, it does make a difference if the sample is taken from a leg muscle or from for instance the heart or the diaphragm. And finally, the larger a sample, the better its concentration estimate will reflect the actual (total) situation, but the more difficult it is to process the sample. difficult task.

Thus, estimation of the metabolic activity of a body compartment by means of tissue sampling remains a summarized.

To prepare a homogeneous sample, several homogenization techniques can be used. Below, some are

- Mechanical fragmentation with a nitrogen chilled mortar and pestle (27-29)

- Mechanical blending using an "Ultra-Turrax" or comparable device $(16,27,28,30)$

- Grinding with a pestle and tube $(27,30)$

- Bead mill homogenization using (27)

Crushing in liquid nitrogen

This technique is usually applied for larger $(>100 \mathrm{mg})$ samples. Tissue specimen are chilled in liquid nitrogen and mechanically crushed in a liquid nitrogen chilled mortar. Next, a portion of the sample powder is weighed into a pre-weighed acid-containing vial, mixed and centrifuged or homogenized even further by ultraturrax mixing (16). The method enables the (visual) removal of connective tissue and blood vessels, but requires a relative large amount of sample. However, the method is laborious, as all materials have to be chilled constantly in liquid nitrogen, which evaporates rather quickly.

\section{Ultra thorax mixing}

This method is usually applied in addition to the first method. The space between the two blades of the blender is relative large, making it difficult to homogenize intact tissue specimens. The "dead volume" of the mixer is also prone to collect remainders from previous samples and/or liquid used to rinse the instrument $(30)$. This increases the risk of carryover from previous samples

\section{The pestle and tube}

This system is based on crushing a tissue sample between the wall of a grounded-glass tube and a motor driven tight fitting glass or Teflon ${ }^{\circ}$. The method provides a thorough homogenization, but is very laborious (30). 


\section{Bead mill homogenization}

This principle is relative new for the processing of animal tissue. It was designed originally for the disruption of yeast and microorganisms. However, it potentially combines the thorough homogenization, obtained by the pestle and tube method, with a less laborious processing. The principle of this system is to crush small amounts of tissue by vigorous movement (using a mini bead beater) of a vial containing not only the sample, but also a number of small glass beads and an extracting solution. The shearing forces of the moving beads, which size is adapted to that of the sample, crush the sample cells, releasing their content into the extraction solution. Enzymatic activity is eliminated immediately by using an acidic extraction solution. The processed sample only needs centrifugation, whereafter the desired metabolites can be analyzed directly in the supernatant (27).

Considering the above, we prefer to use the bead mill homogenization. It enables an easy processing of tissue samples, and because the sample vial is closed during the whole procedure, there is no risk of contamination or dilution. However, optimal results are obtained with small tissue samples (below $100 \mathrm{mg}$ ), but this is usually not a problem for our studies.

\section{Protein hydrolysis}

In the previous section, the attention was focussed on the analysis of free amino acid concentrations. Organ balance was estimated by measuring the inflow and outflow of free amino acid concentrations in an attempt to get insight in the synthesis and degradation of protein. However, this approach provides only the resultant of these processes. The introduction of tracer technology enabled us to move a step further.

Measurement of the incorporation rate of radioactive or stable amino acid isotopomers in selected proteins can reveal information about the fractional synthetic rate (FSR). To enable this, proteins of interest have to be purified (section 4) and the constituting amino acids must be released from the protein backbone. For the latter process, acid hydrolysis is usually used.

The standard technique for acid hydrolysis $(7,31)$ is to weight a known amount into a thick walled glass tube, which is already filled with a known amount of $6 \mathrm{M}$ hydrochloric acid. The upper part of the tube is then held into a flame and a capillary is drawn. Next, the sample is frozen in liquid nitrogen, whereafter the tube is evacuated using a vacuum pump. Nitrogen is flushed into the tube while the sample is thawed and the process of freezing and thawing is repeated twice, all with the purpose to eliminate oxygen. Next, the tubes are flame-sealed under vacuum and heated overnight $(18 \mathrm{~h})$ in an oven set at $110^{\circ} \mathrm{C}$. Hereafter, the hydrochloric acid has to be removed, before the liberated amino acids can be quantitated.

Although this laborious and time-consuming process is applicable for a regular quality control in the food industry, it is not suited very well for our purpose. A more suitable technique for our purpose is gas-phase hydrolysis as can be performed with an adapted microwave oven (32). Although these systems have a high sample throughput and result in a high recovery (typical above $90 \%$ ), they are rather expensive (>Dfl $40.000,-)$. Considering this, a cheaper alternative was developed, based on the gas-phase hydrolysis principle. In this concept, a stainless steel outer vial was used for structural strength, equipped with a chemical inert Teflon ${ }^{\circ}$ inner vial. In this vial a Teflon ${ }^{\circ}$ rack was placed, capable of holding 7-15 glass sample tubes (section 3). Pouring $20 \mathrm{ml}$ of $6 \mathrm{M}$ hydrochloric acid on the bottom, closing it and heating it to $150^{\circ} \mathrm{C}$ in an oven for 5-6h performed hydrolysis. The high temperature enables the evaporating hydrochloric acid gas to break the peptide bonds of the freezedried protein at an enhanced rate, without diluting the sample. The absence of water and the short reaction time minimizes the degradation of liberated amino acids, resulting also in an comparable overall recovery (Table 1). Furthermore, the liberated amino acids can now directly react with a derivatization reagent, without the necessity to remove a large excess of hydrochloric acid.

Table 1: $\quad$ Comparisation of gas-phase and liquid-phase hydrolysis.

Recovery expressed as a percentage of theoretical (albumin, $\mathrm{N}=6$ ) or as percentage of manufacturer data (caseinate and soy protein, $\mathrm{N}=3$ ))

\begin{tabular}{|c|c|c|c|c|c|c|c|c|c|c|c|c|c|c|c|}
\hline & ASX & GLX & SER & HIS & GLY & THR & ARG & ALA & TYR & VAL & MET & ILE & PHE & LEU & LYS \\
\hline ALBUMIN GAS & 87.5 & 95.4 & 74.9 & 79.2 & 136.3 & 86.1 & 70.2 & 68.9 & 72.2 & 71.1 & 46.4 & 97.2 & 70.1 & 84.2 & 96.1 \\
\hline ALBUMIN LIQUID & 81.6 & 88.2 & 61.2 & 72.2 & 114.2 & 71.8 & 67.8 & 82.4 & 72.6 & 74.2 & 60.2 & 56.7 & 72.5 & 78.1 & 84.2 \\
\hline & 6.5 & 100.2 & 67.5 & 100.8 & 107.8 & 75.9 & 87.0 & 108.7 & 82.8 & 98.7 & 46.6 & 103.2 & 92.6 & 94.5 & 101.4 \\
\hline CASEI & 88.5 & 101.1 & 80.4 & 98.9 & 105.4 & 90.9 & 95.5 & 95.3 & 89.8 & 98.3 & 60.1 & 101.1 & 94.5 & 93.8 & 92.8 \\
\hline SOY PROTEIN G & 4.0 & 96.1 & 67.2 & 91.4 & 97.4 & 81.3 & 73.3 & 104.5 & 53.6 & 96.2 & 45.0 & 96.9 & 79.3 & 88.8 & 89.0 \\
\hline $\begin{array}{l}\text { SOY PROTEIN } \\
\text { LIQUID }\end{array}$ & 82.8 & 95.7 & 78.0 & 93.0 & 91.8 & 86.4 & 88.3 & 93.6 & 75.1 & 89.6 & 55.0 & 92.6 & 84.5 & 87.1 & 88.5 \\
\hline
\end{tabular}

However, one should consider that some amino acids are degraded (partially) by acid hydrolysis (methionine, glutamine, asparagine, tryptophane, cyst(e)ine), if no precautions are taken $(33,34)$. Usually, a base hydrolysis is applied to enable accurate determination of tryptophan (23), while amino acids like glutamine require special procedures (35). Sulfur-containing amino acids require oxidation prior to acid hydrolysis to prohibit their degradation (23) 


\section{References}

1. Verbiese-Genard N, Hanocq M, Alvoet C, Molle L. Degradation study of catecholamines, indole amines and some of their metabolites in different extraction media by chromatography and elextrochemical detection. Anal.Biochem. 1983:134:170-175.

2. Hubbard RW, Chambers JG, Sanchez A, Slocum R, Lee P. amino acid analysis of plasma: studies in sample preparation. J.Chromatogr. 1988;431:163-169.

3. Ukida M, Schaffer K, Bode JC. Effect of storage at $-20^{\circ} \mathrm{C}$ on the concentration of amino acids in plasma. J.Clion.Chem.Clin.Biochem. 1981:19:1193-195.

4. Sahai S, Uhlhaas S. Stability of amino acids in human plasma. Clin.Chem.Acta 1985:148:255-259.

5. Schaefer A, Piquard F. Haberey P. Plasma amino acids analysis: Effects of delayed sample preparation and of storage. Clin.Chim.Acta 1987;164:163-169.

6. Armstrong MD, Stave U. A study of plasma free amino acid levels. I. Study of factors affecting validity of amino acid analyses. Metabolism 1973:22:549-560.

7. Williams AP. General problems associated with the analysis of amino acids by automated ion-exchange chromatography. J.Chromatogr. 1986;373:175-190.

8. Chuang C, Lin S, Lin Y, Huang F. Effects of anticolagulants in amino acid analysis: Comparisations of heparin, EDTA, and sodium citrate in vacutainer tubes for plasma preparation. Clin.Chem. 1998;44:1052-1058.

9. Picard M, Olichon D, Gombert J. Determination of serotonin in plasma by liquid chromatography with electrochemical detection. J.Chromatogr.B 1985;341:445-451.

10. Fekkes D. Sate-of-the-art of high-performance liquid chromatographic analysis of amino acids in physiological samples. J.Chromatogr.B 1996;682:3-22.

11. Wang SR, Chen ML, Huang MH, Lin HY, Tsai JJ, Kuo BIT. Plasma arginase concentration measured by an enzyme linked immunosorbent assey (ELISA) in normal adult population. Clin.Biochem. 1993;26:455-460.

12. Godel H, Graser T, Földi P. Pfaender P, Fürst P. Measurement of free amino acids in human biological fluids by highperformance liquid chromatography. J.Chromatogr. 1984;297:49-61.

13. Tritsch GL, Moore GE. Spontaneous decomposition of glutamine in cell culture media. Ex.Cell.Res. 1962;28:360-364.

14. Kahn K, Hardy G, McElroy B, Elia M. The stability of L-glutamine in total parenteral nutrition solutions. Clin.Nutr. 1991;10:193-198.

15.

Kahn K, Elia M. Factors affecting the stability of I-glutamine in solution. Clin.Nutr. 1991;10:186-192.

16. Lazzarino G, Nuutinen M, Tavazzi B, Di Pierro D, Giardina B. A method for preparing freeze-clamped tissue samples for metabolite analysis. Anal.Biochejm. 1989;181:239-241.

17. Wollenberger A, Ristau O, Schoffa G. Pflugers Arch.Gesamte Physiol. 1960;270:399-412.

18. Hommes FA. Techniques in diagnostic human biochemical genetics: A laboratory manual. New York: Wiley Liss, 1991:

19. Vaidyanath N, Birkhahn R, Border JR, et al. A method for determining amino acid concentrations and specific activities of amino acids and some other compounds in biological fluids. Anal.Biochem. 1976;70:479-488.

20. Cohen S. Strydom D. Amino acid analysis utilizing phenylisothiocyanate derivatives. Anal.Biochem. 1988;174:1-16.

21. Qureshi G, Qureshi A. Determination of free amino acids in biological samples: Problems of quantitation. J.Chromatogr.B 1989;491:281-289. Alfredsson G, Wiesel FA, Lindberg M. Glutamate and glutamine in cerebrospinal fluid and serum from healthy volunteers-analytical aspects. J.Chromatogr. 1988;424:378-384.

23. Sarwar G, Botting HG. Evaluation of liquid chromatographic analysis of nutritionally important amino acids in food and physiological samples. J.Chromatogr.B. 1993;615:1-22.

24. Liu $\mathrm{H}$, Worthen $\mathrm{H}$. Measurement of free amino acid levels in ultrafiltrates of blood plasma by high-performance liquid chromatography with automatic pre-column derivatization. J.Chromatogr. B 1992;579:215-224. De Jonge L, Breuer M. Modification of the analysis of amino acids in pig plasma. J.Chromatogr. B 1994;652:90-96. Bremer HJ, Duran M, Kamerling JP. Przyrembel H, Wadman SK. Amino acid analysis of physiologicals. Disturbances of amino acid metabolism: Clinical chemistry and diagnosis. Baltimore: Urban and Schwarzenberg, 1981:502-505. (Slocum., Cummings, eds.

27. Hopkins T. Physical and chemical cell disruption for the recovery of intracellular proteins. In: Seetharam R, Sharma S, eds. Purification and analysis of recombinant proteins. New York: Marcel Dekker Inc., 1991:57-.

28. Palmero S, De Marchis M, Prati M, Fugassa E. HPLC analysis of free amino acids and amino acids of total proteins in cultured cells: An Application to the study of rat sertoli cell protein metabolism. Anal. Biochem. 1992;202:152-158. Cronholm T, Norsten C. Gas chromatography-mass spectrometry of carboxylic acids in tissues as their tert.butyldimethylsilyl derivatives. J.Chromatogr. 1985;344:1-9.

30. Grace M, Fletcher L, Powers S, Hughes M, Coombes J. A comparisation of maximal bioenergetic enzyme activities obtained with commonly used homogenization techniques. J.SportsMed.Phys. Fitness 1996;36:281-286.

31. Gehrke CW, Wall LL, Absheer JS, Kaiser FE, Zumwalt RW. Sample preparation for chromatography of amino acids: Acid hydrolysis of proteins. J.Assoc. Off.Anal.Chem. 1985;68:811-821.

32. Yu HMA, J., Chiou SH, Wang KT. Determination of amino acids on merrifield resin by microwave hydrolysis. J.Chromatogr. 1988;456:357-362.

33. Yamada H, Moriya H, Tsugita A. Development of an acid hydrolysis method with high recoveries of tryptophan and cysteine for microquanties of protein. Anal.Biochem. 1991:198:1-5.

34. FAO. Protein quality evaluation, food and nutrition paper 151. In: Nations FaaootU, ed. Joint FAO WHO expert consultation. Rome, 1991.

35. Soby LM, Johnson P. Determination of asparagine and glutamine in polypeptides using bis(1,1trifluoroacetoxy)iodobenzene. Anal.Biochem. 1981:113:149-153. 


\section{Addendum to Chapter 4}

\section{Determination of amino acid specific activity and enrichment}

Acknowledgement:For the last two parts, the help of, and discussions with Heleen Erkens, Dennis Rooyakkers, Gabrie ten Have, Frank van der Vegt and Ton wagenmakers are greatly acknowledged.

\section{Introduction}

This section is divided into two parts. The first part discusses analytical aspects with respect to liquid scintillation counting, while the second part provides additional data which were acquired to enable a more efficient sample introduction into the isotope ratio mass spectrometer (IRMS).

\section{Liquid scintillation counting}

\section{Scintillation cocktail selection}

In order to select the best scintillation cocktail for our application, 5 different products (Formula 989 , Hionic Fluor, Ultima Gold AF, Ultima Gold XR and Ulimaflo M; Packard, Groningen, Netherlands) were examined for their ability to dissolve our solvents for counting efficiency and sensitivity towards chemoluminescence.

Solubility was tested by the addition of increasing amounts of scintillation fluid to a fixed amount of solvent. Only Ultima Gold XR and Ultimaflo were capable of forming a homogenic solution in a 2:1 dilution with our solvents (Table 1).

Table 1: Solubility test for different scintillation cocktails

\begin{tabular}{llllll}
\hline Ratio buffer/cocktail & & \multicolumn{4}{l}{ Scintillation cocktails } \\
\hline & Formula 989 & Ultimaflo AF & Ultima gold XR & Ultimaflo M & Hionic Fluor \\
& Insoluble & Insoluble & slight & insoluble & Insoluble \\
2 & Insoluble & Soluble & soluble & insoluble & Insoluble \\
3 & Insoluble & Soluble & soluble & insoluble & Insoluble \\
4 & Insoluble & Soluble & soluble & insoluble & Slight \\
5 & Insoluble & Soluble & soluble & insoluble & Slight \\
10 & Insoluble & Soluble & soluble & insoluble & Soluble \\
\hline
\end{tabular}

At a 2:1 dilution with scintillation fluid, counting efficiency was best for Ultima Gold XR (34.5\%) compared to Ultimaflo AF (26.6\%). Ultimaflo AF also exhibited a more pronounced chemoluminescence (Figure 1), which generates additional "counts", resulting in an overestimation of the actual radioactivity.

Figure 1: Change of activity in time

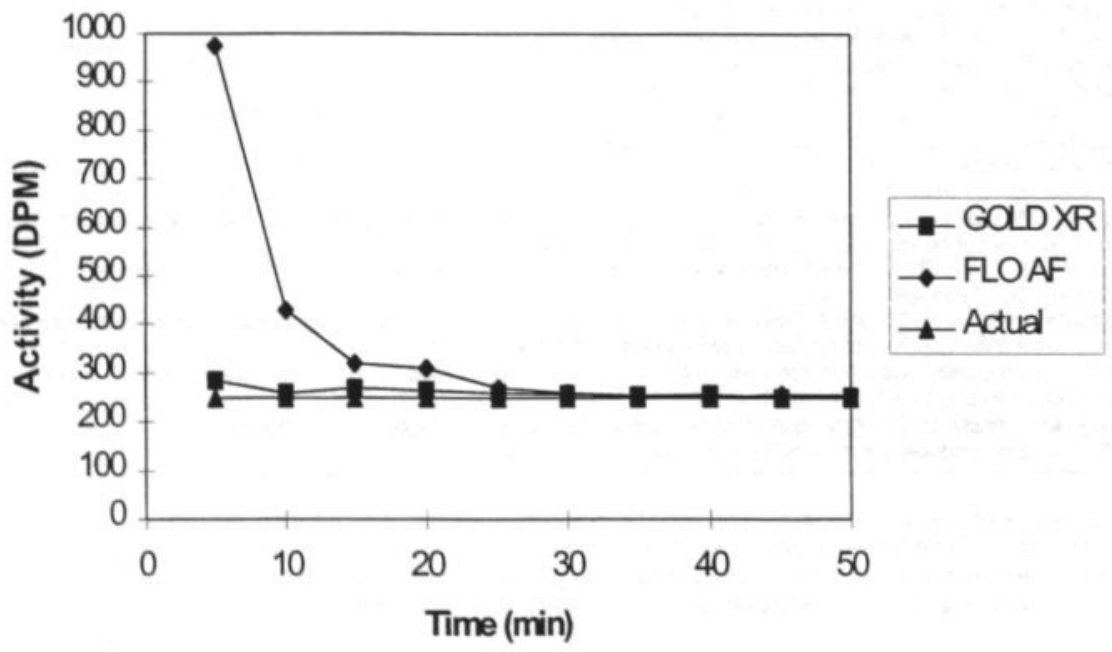




\section{Counting accuracy}

After selection of the scintillation cocktail, attention was focussed on the counters accuracy, because the addition of buffer causes quenching effects which may result in an underestimation of the actual activity. For this, various tritium labeled amino acid batches were mixed with a fixed amount of scintillation fluid (12ml) and diluted progressively with solvent B (Table 2).

Table 2: Influence of buffer dilution on the recovery of tritium activity

\begin{tabular}{|c|c|c|c|c|c|c|c|c|c|c|}
\hline & \multicolumn{5}{|c|}{ Activity (DPM) } & \multicolumn{5}{|c|}{ Percentage of undiluted (\%) } \\
\hline tracer & $0 \mathrm{ml}$ & $2 \mathrm{ml}$ & $4 \mathrm{ml}$ & $6 \mathrm{ml}$ & $8 \mathrm{ml}$ & $0 \mathrm{ml}$ & $2 \mathrm{ml}$ & $4 \mathrm{ml}$ & $6 \mathrm{ml}$ & $8 \mathrm{ml}$ \\
\hline water & 237816 & 236152 & 226477 & 221065 & 213269 & 100 & 99 & 95 & 93 & 90 \\
\hline GLN 1 & 250189 & 249685 & 245068 & 239497 & 226937 & 100 & 100 & 98 & 96 & 91 \\
\hline GLN 2 & 228213 & 225421 & 219188 & 220226 & 208157 & 100 & 99 & 96 & 97 & 91 \\
\hline GLN 3 & 288790 & 284819 & 280002 & 275757 & 266359 & 100 & 99 & 97 & 95 & 92 \\
\hline PHE 1 & 252517 & 254679 & 244074 & 243543 & 231608 & 100 & 101 & 97 & 96 & 92 \\
\hline PHE 2 & 257661 & 251135 & 248525 & 246323 & 238691 & 100 & 97 & 96 & 96 & 93 \\
\hline ARG 1 & 90964 & 90066 & 90403 & 86353 & 82581 & 100 & 99 & 99 & 95 & 91 \\
\hline ARG 2 & 226840 & 227108 & 226336 & 219506 & 212504 & 100 & 100 & 100 & 97 & 94 \\
\hline LEU & 218136 & 219048 & 210095 & 208232 & 200153 & 100 & 100 & 96 & 95 & 92 \\
\hline VAL & 229553 & 230868 & 227426 & 219843 & 202767 & 100 & 101 & 99 & 96 & 88 \\
\hline mean & & & & & & 100 & 99 & 97 & 96 & 91 \\
\hline
\end{tabular}

Above a 6:1 dilution a systematic decrease in activity recovery was observed. At the 2:1 dilution used for our samples, the mean deviation was $4 \%$. As a result, accurate comparing of infusion stock solutions and samples can only be obtained if both are diluted to the same extent. A further dilution resulted in an increasing deviation and at the end in incomplete mixing of scintillation fluid and buffer. In view of the chromatographic requirements, a 2:1 dilution was therefore considered optimal for this application.

However, another complication may arise when using tritium labeled amino acids. The preparation of a solution results in an interaction with water molecules. This may result in the exchange of tritium with water hydrogen atoms, thus lowering the amino acids specific activity and increasing the activity of water. This is especially the case when working with glutamine, an amino acid which is known to decompose spontaneously (15). Therefore, we determined the chemical purity of amino acid stock solutions and the amount of tritium label incorporated in the water fraction. This was done by collecting the unretained (water) fraction eluting from the chromatograph and the component peak and comparing these with the total activity of the stock solution over a period of time.

The results clearly indicate a time-related decay of the specific activity of glutamine and arginine but not of phenylalanine, an amino acid known to be stable. Glutamine decay could be accounted for mostly by the tritium exchange with water molecules, but for arginine this could only partly explain the change in specific activity. A large portion $(10 \%)$ could not be recovered in the water fraction and a chemical decomposition is therefore likely.

Table 3: Influence of storage on tracer purity

\begin{tabular}{lrrrrrrr}
\hline Tracer & Age & Fraction & Water & Total & Stock & Recovery & Purity \\
\hline & Months & DPM & DPM & DPM & DPM & $\%$ & $\%$ \\
GLN & 7 & 195235 & 24055 & 219290 & 212018 & 103 & 89 \\
GLN & 4.5 & 182843 & 16709 & 199552 & 201751 & 99 & 92 \\
GLN & 2.5 & 223847 & 16826 & 240673 & 240233 & 100 & 93 \\
PHE & 4 & 214581 & 763 & 215344 & 219402 & 98 & 100 \\
PHE & 0.5 & 218718 & 744 & 219462 & 218151 & 101 & 100 \\
ARG & 16 & 65872 & 2184 & 68056 & 78018 & 87 & 84 \\
ARG & 6 & 175458 & 4410 & 179868 & 193103 & 93 & 91 \\
\hline
\end{tabular}

\section{Influence of counting principle}

The results described above were all obtained using Beckman scintillation counters. However, most manufacturers use their own (patented) methods to correct for the effects of quenching. It is known that these differences in approach may require an adaptation of the counters calibration procedure $(13,16)$, especially when measuring heavily quenched tritium samples such as obtained by the methods described in this section. 
In Table 4 the results of two counting systems from different manufacturers measuring in standard mode calibrated samples, diluted in an 2:1 mixture of Ultima Gold XR and solvent containing an increasing percentage of organic modifier.

Table 4: Influence of efficiency correction method

\begin{tabular}{clllllllll}
\hline \% modifier & Actual & \multicolumn{3}{c}{ Wallac Win Spectral 1414 } & \multicolumn{3}{c}{ Packard Tri-Carb 1900 } \\
\hline & DPM & CPM & efficiency \% & DPM & deviation \% & CPM & Efficiency \% & DPM deviation \% \\
& & & & & & & & & \\
0 & 190855 & 56164 & 34.46 & 163018 & 14.6 & 57026 & 31.37 & 181768 & 4.8 \\
5 & 190855 & 54876 & 34.03 & 161251 & 15.5 & 55934 & 30.82 & 181496 & 4.9 \\
12.5 & 182043 & 52302 & 33.05 & 158255 & 13.1 & 52452 & 29.48 & 177887 & 2.2 \\
25 & 182043 & 51549 & 32.66 & 157847 & 13.3 & 51797 & 29.40 & 176185 & 3.2 \\
\hline
\end{tabular}

These results indicate that although the same counts per minute (CPM) were found, the systems use a different efficiency calculation method which more or less underestimates the actual activity. Especially the Wallac correction method, which basically compares the sample's spectrum with library spectra, is sensitive to deviations. Each new application employing a different scintillation cocktail, a different dilution factor of the buffer with the cocktail, a different buffer composition and a different type of vial, therefore requires the recording of a new quenching correction curve to obtain true activities.

But even then, heavily quenched samples mask the sample spectrum, thus an relative high activity (>1000 DPM) is required before Wallacs systems quality parameter (SAQUM) reaches a value above $95 \%$ indicating a correct measurement (Figure 2).

Figure 2: Relation between radioacitivity and Wallac's SAQUM parameter

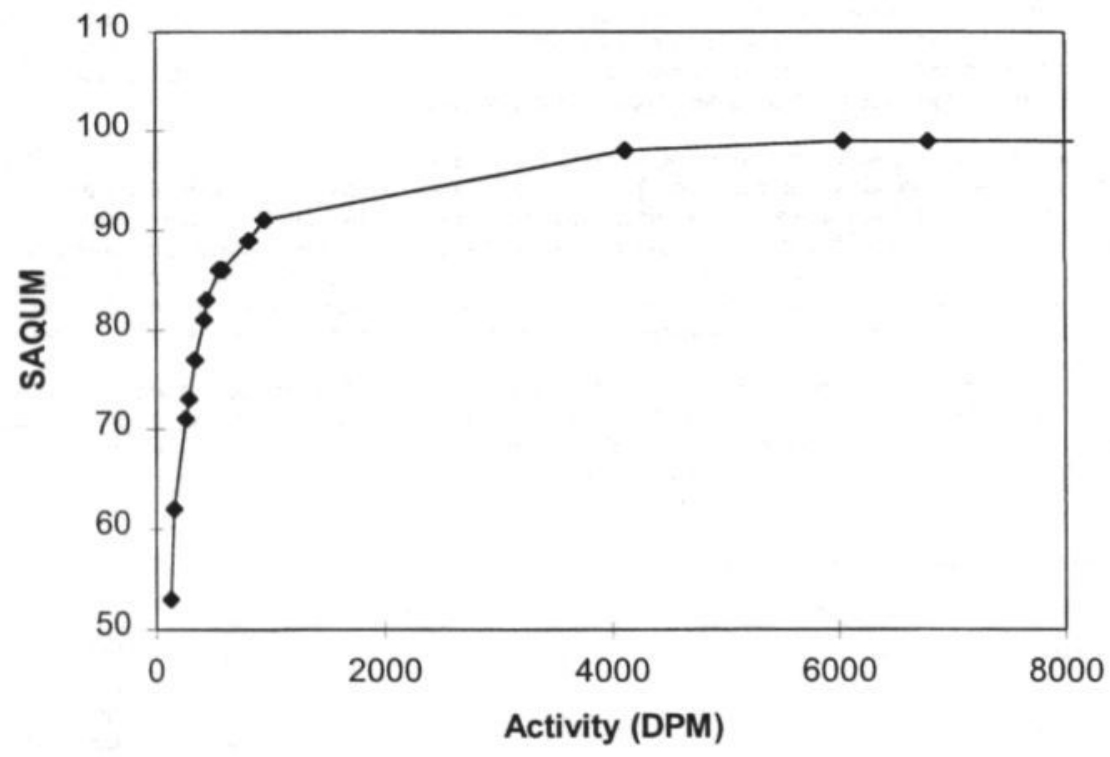

Correction of the sample spectra by the subtraction of a blank spectrum enhances the SAQUM parameter, but results in a deviation of the internal quenching parameter SQPI. Because our metabolic studies are performed with only a few hundred DPM in each collected amino acid fraction, it may be clear that a careful system calibration is required to obtain true specific activities.

\section{Stable isotope measurements}

\section{IRMS optimization}

Large volume injection: We originally used a minimum of $500 \mathrm{nmol}$ leucine, which was processed by the ninhydrin decarboxylation reaction in a $2 \mathrm{ml}$ vial. After reaction, $100 \mu \mathrm{l}$ of leucine derived $\mathrm{CO}_{2}$ was injected from the vials headspace into the GC-IRMS system. This amount resulted in a satisfactory measurement of the ${ }^{13} \mathrm{C}$ enrichment. 
Using the chromatographic methods described above, isolation of 500nmol approaches the upper limit. We therefore tried to reduce this amount by collecting a larger headspace volume from the decarboxylation vial. Injection of the complete vial headspace using a syringe would create a vacuum in the vial, increasing the risk of air contamination, sucked in through the penetrated septum. Also, the water from the ninhydrin reagent buffer would evaporate resulting in an instable IRMS signal. Altematively, a dual needle system would be required to flush out the leucine derived $\mathrm{CO}_{2}$ into the $\mathrm{GC}$ system, but unfortunately such a system is not commercially available.

We therefore equipped the sample syringe with a gas-tight valve (SGE, Bester, Amstelveen, The Netherlands), thus preventing inflow of air into the syringe. However, a large volume withdrawal still created a low enough vacuum to suck air into the vial through the penetrated septum. To prohibit this, the syringe was filled with the same volume of helium as was intended to be withdrawn from the sample vial for injection. This volume was injected into the vial, after which the sample was withdrawn and injected.

A progressive increase in sample volume however, only gave a proportional increase in the IRMS response until $500 \mu \mathrm{l}$ injection (Figure 3).

Figure 3: Relation between injected volume and mass spectrometer response

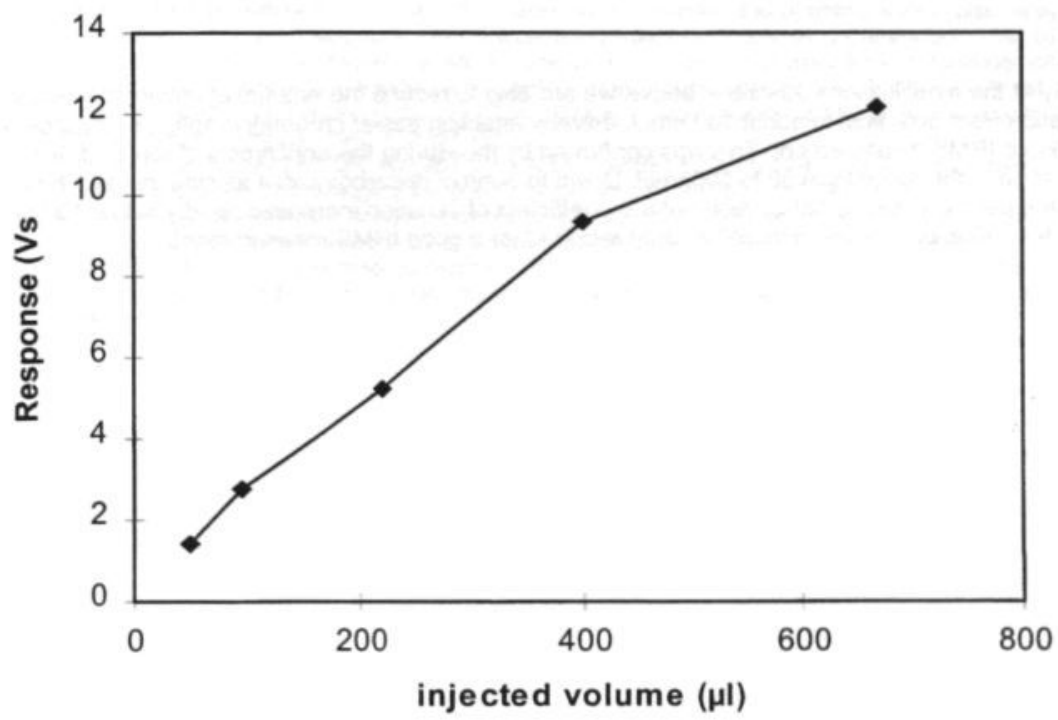

We hypothesized that above this volume, the over-pressure created in the vial, and transferred to the syringe probably resulted in a larger split-off percentage at the inlet splitter of the GC system. This was because the effect was more pronounced if a sample was injected quickly instead of gently, resulting in a larger deviation of the recorded peak area. We therefore decided the maximal injection volume to be $500 \mu \mathrm{L}$. In this way, the response was increased approximately a four-fold.

Influence of Blank value: We tried to lower the blank value to its minimum. A major contamination was found to be the air dissolved in the citric acid solution used for decarboxylation. Degassing of this solution with helium, resulted in a reduction by $21 \%$ of the blank value. The importance of the blank value and its effect on the samples delta measurement becomes clear by the construction of a calibration curve using a large volume injection (500 $\mu \mathrm{l})$ in the range from 50 to $500 \mathrm{nmol}$ decarboxylated leucine.

Table 5: Influence of blank correction

\begin{tabular}{|c|c|c|c|c|c|c|c|c|c|c|}
\hline & \multicolumn{2}{|c|}{ Blank } & \multicolumn{2}{|c|}{$50 \mathrm{nmol}$} & \multicolumn{2}{|c|}{$100 \mathrm{nmol}$} & \multicolumn{2}{|c|}{$200 \mathrm{nmol}$} & \multicolumn{2}{|c|}{$500 \mathrm{nmol}$} \\
\hline & Mean & s.d. & mean & s.d. & Mean & s.d. & mean & s.d. & mean & s.d. \\
\hline Area & 0.70 & 0.07 & 2.70 & 0.28 & 4.72 & 0.21 & 8.70 & 0.50 & 20.86 & 0.60 \\
\hline delta measured & -37.18 & 2.08 & 312.65 & 9.07 & 371.89 & 6.90 & 407.46 & 3.12 & 430.29 & 0.67 \\
\hline delta calculated & & & 433.73 & 25.69 & 441.56 & 11.13 & 445.60 & 5.47 & 446.20 & 0.67 \\
\hline
\end{tabular}


The measured sample's enrichment, expressed in "delta's" (16), is underestimated when analyzing small amounts of leucine derived $\mathrm{CO}_{2}$. This is because the blank $\mathrm{CO}_{2}$ dilutes the sample, thus causing this underestimation. The following equation correct for this effect:

Corrected delta $=($ sample delta $\times$ sample area $)-($ blank delta $\times$ blank area $)$

(sample area - blank area)

In this way, the measured sample enrichment can be obtained (Table 2). However, it may be clear that variations in response, both for blank and sample measurement, result in variations in the calculated delta value. And, the higher the blank response (compared to the sample response), the greater the risk of over or under correction.

Therefore, we tried to lower the blank value even more. It was found that air, captured between both seals of the syringe plunger accounted for another major part of the remaining blank. By exchanging the syringe for a model equipped with a massive plunger (Hamilton) the blank could be reduced by another $48 \%$ so that the original blank value of $0.887 \mathrm{Vs}$ was reduced to only $0.367 \mathrm{Vs}(\mathrm{N}=5)$. The remaining part was explained by leakage through the septa and contaminations in the ninhydrin.

\section{Conclusions}

By way of the modifications described above we are able to reduce the amount of amino acid required for decarboxylation from $500 \mathrm{nmol}$ to about $100 \mathrm{nmol}$, thereby enabling easier chromatography procedures, while maintaining reliable IRMS measurement. This was confirmed by measuring the enrichment of the liberated $\mathrm{CO}_{2}$ from natural leucine in the range from 50 to $500 \mathrm{nmol}$. Down to $50 \mathrm{nmol}$ decarboxylated leucine the enrichment (expressed as the per mil value) is still correct, but the coefficient of variation increased rapidly below $100 \mathrm{nmol}$ (12). We consider $100 \mathrm{nmol}$ to be the minimal amount required for a good IRMS measurement. 


\section{References}

1. Berthold HK, Jahoor F, Klein PD, Reeds PJ. Estimates of the effect of feeding on whole-body protein degradation in women vary with the amino acid used as tracer. J.Nutr. 1995;125:2516-2527.

2. Cayol M, Tauveron I, Rambourdin F, et al. Whole-body protein turnover and hepatic protein synthesis are increased by vaccination in man. Clin.Sci. 1995;89:389-396.

3. Balagopal P. Ford GC, Ebenstein DB, Nadeau DA, Nair KS. Mass spectrometric methods for determination of [13C]leucine enrichment in human muscle protein. Anal.Biochem. 1996;239:77-85.

4. De Feo P. Haymond M. Principles and calculations of the labelled leucine methodology to estimate protein kinetics in humans. Diab. Nutr.Metab. 1994;7:165-184.

5. Lecavalier L, Horber FF, Haymond MW. Determination of plasma concenytrations and $3 \mathrm{H}$ specific activity of phenylalanine in plasma using high-performance liquid chromatography. J.Chromatogr. 1989;491:410-417.

6. Suzuki O, Yagi K. A fluorometric assay for b-phenylethylamine in rat brain. xxox 1976:192-200.

7. Scrimgeour CM, Smith K, Rennie MJ. Automated measurement of $13 \mathrm{C}$ enrichment in carbon dioxide derived from submicromole quantities of L-(1-13C)-leucine. Biomed.environ.mass.spec. 1988;15:369-374.

8. Van Eijk HMH, Huinck MPL, Rooyakkers DR, Deutz NEP. Automated simultaneous isolation and quantitation of labeled amino acid fractions from plasma and tissue by ion-exchange chromatography. J.Chromatogr.B $1994 ; 660: 251-257$

9. Van Eijk HMH, Rooyakkers DR, Deutz NEP. Rapid routine determination of amino acids in plasma by highperformance liquid chromatography with a 2-3 um Spherisorb ODS II column. J.Chromatogr. 1993;620:143-148.

10. Tessari P, Inchiostro S, Vettore M, Sabadin L, Biolo G. A fast high-performance liquid chromatographic method for the measurement of plasma cocnantration and specific activity of phenylalanine. Clin. Biochem. 1991:24:425-428.

11. Jenssen T, Nurjhan N, Perriello G, Bucci A, Toft I, Gerich J. Determination of $14 \mathrm{C}$ glutamine specific activity in plasma. J.Liq.Chromatogr. 1993;17:1337-1348.

12. Van Eijk HMH, Rooyakkers DR, Wagenmakers AJM, Soeters PB, Deutz NEP. Isolation and quantitation of isotopically labeled amino acids from biological samples. J.Chromatogr.B 1997:691:287-296.

13. Kessler M. Liquid scintillation analysis: Science and Technology. Meriden: Packard Instrument Co., 1989:

14. Friedman M, Sigel SW. A kinetic study of the ninhydrin reaction. Biochemistry 1966;5:478-484.

15. Tritsch GL, Moore GE. Spontaneous decomposition of glutamine in cell culture media. Ex.Cell.Res. 1962;28:360-364.

16. Wolfe R. Radioactive and stable isotope tracers in biomedicine: Principles and practice of kinetic analysis. New York: Wiley-Liss Inc., 1992. 


\section{Summary}

The study of amino acid metabolism requires analytical techniques to study the metabolites of interest. In most research protocols, attention is mainly focussed on operating techniques, stratification into study groups, differences in treatment etc. and only marginally on the underlying techniques, used to collect them. However, the accuracy of the techniques used, determines to a major extent the outcome of these studies. To develop a truly working analytical method to provide the desired (accurate) data, many pitfalls have to be overcome. This thesis intends to give an overview of the techniques, developed in our laboratory to study changes in amino acid metabolism resulting from nutrition during health and disease.

In the Introduction the line our research has followed during the last 10 years is described as well as the questions, which arose and the techniques which were developed to answer these.

In chapter 1, the basic analytical techniques are outlined which enable high sensitivity measurements of amino acid concentrations in biological matrices like plasma and tissue. Although traditional ion-exchange chromatography is capable of providing this information, this method is slow, expensive and lacks sensitivity. Therefore, the first goal was to develop a (chromatographic) method, which would overcome these problems. The basis of these techniques is the reaction of amino acids with o-phthaldialdehyde (OPA) to form highly fluorescent iso-indoles. The resulting methods made the automated high-precision measurement (coefficient of variation typically below $3 \%$ ) possible of all major physiological amino acids, with a cycle rate of $35 \mathrm{~min}$ (injection to injection). Shorter cycle times are possible also, but result in less precision.

Soon after the successful development of these methods, it was recognised that plasma amino acid concentrations alone do not give an in-depth insight in the ongoing regulatory metabolic processes. In an attempt to unravel these processes we tried to study amino acid metabolites, which can be used as one of the markers for tissue proliferation (polyamines), muscle degradation (3-methyl-histidine) and hepatic encephalopathy ( $\gamma$-aminobutyricacid: GABA). In chapter 2 the problems are discussed, associated with the determination of these metabolites. The basic problem which had to be solved, was how to exclude the presence of interfering (and much higher concentrated) amino acids, without the need to apply a laborious extraction procedure. This was achieved by designing special gradient-programs. In the case of the polyamine determination, a new column packing material was applied. The basis of the underlying analytical methods was the OPA derivatization.

When we had the analytical tools available to determine the actual amino acid concentrations in a given biological sample, we realised that this is not a guarantee to obtain the true body concentrations at the moment of sampling. In the literature there is still an ongoing discussion, which is the best sample processing method. Enzymatic processes affect free amino acid concentrations (arginine, citrulline and ornithine), while techniques used for deproteinization affects the degradation rate of other amino acids (glutamine, asparagine). In chapter 3 , it is shown that failure to perform correct sampling and processing procedures can result in a drastic change in concentrations prior to the analysis itself. In this chapter it is also shown that the 
impact of factors like nutrition, gender and age on amino acid concentrations must be considered in the formation of (patient) control groups. These factors can result in a shift of the "normal" amino acid concentrations, creating a bias, that makes it difficult to correctly establish the study effects.

In chapter 4 tracer technology is introduced to distinguish between the processes of protein synthesis, degradation and the intake of nutrition. To get a better insight if and how these processes change under the influence of disease, it is necessary to tag the amino acids of interest. The most common form of tagging is to use radioactive or stable isotopes, incorporated into the amino acid of interest. Radioactive labels can be detected and quantitated more easily, but cannot be used in research protocols involving human volunteers. In these studies, stable isotopes must be used, but they require expensive and complicated equipment (a mass spectrometer) for their detection.

In chapter 5 a direct approach to study protein synthesis is discussed, in contrast to the previous sections, in which indirect techniques to measure protein synthesis are used, through measurement of the precursor pool. A direct measurement of protein synthesis can only be obtained by isolating a target protein with a high degree of purity. This approach was used to study albumin synthesis rate. For this application, a method was developed, combining a sequence of chromatographic techniques, resulting in the automated isolation of high-purity albumin. Together with the hydrolysis and isotopic enrichment measurement procedures described in the previous section, it allowed the direct measurement of albumin synthesis rate.

Finally, in chapter 6 a direct coupling of liquid chromatography and mass spectrometry is investigated. Although the previous methods facilitate both direct and indirect measurement of protein synthesis, they still require a laborious analytical procedure. Recently however, the direct coupling of a liquid-chromatograph, operated under normal flow conditions, with a mass-spectrometer (LC-MS) has become available. Using this technique, we were able to develop an "on-line" measurement of both the enrichment and concentration of each major physiological amino acid. The precision of the resulting method is comparable to GC-MS.

The thesis is completed by a number of addenda. These are intended to provide the reader with additional data, preventing or solving technical problems in the performance of one of the analytical methods, described in this thesis. 


\section{Samenvatting}

Veel research protocollen die handelen over het aminozuur metabolisme richten de aandacht voornamelijk op (proefdier)model ontwikkeling, operatie technieken, stratificatie van populaties in groepen, verschillen in behandelwijze en voeding. De analytische technieken die ingezet worden om deze data te verzamelen, worden vaak slechts marginaal belicht. De inzet en ontwikkeling van een adequate analytische techniek vergt echter minimaal even veel aandacht als de opzet van een research protocol. Immers, een onvolkomenheid in of zelfs ongeschiktheid van een toegepaste methode kan er gemakkelijk toe leiden dat belangrijke gegevens niet beschikbaar komen of tot een verkeerde conclusie kunnen leiden. Daarom, is in ons laboratorium getracht om een solide (analytische) basis te creeeren van technieken om veranderingen in het aminozuur metabolisme te bestuderen die ontstaan als gevolg van de inname van voeding bij gezonde en zieke proefdieren en mensen.

In de Introductie wordt een overzicht gegeven van de lijn waarlangs onze research zich heeft ontwikkeld gedurende de laatste 10 jaar. Door de toenemende kennis ontstond een toenemende vraag naar meer en meer gespecialiseerde analytische technieken. De ontwikkeling hiervan leidde vervolgens weer tot een toenemende kennis, waardoor de cirkel rond was.

In hoofdstuk 1 worden de basale (chromatografische) analytische methodieken beschreven die ontwikkeld zijn om een snelle en gevoelige bepaling van aminozuur concentraties in biologische monsters zoals plasma en weefsel mogelijk te maken. Dit, omdat de reeds bekende ionenwisselings technieken relatief ongevoelig, traag en duur zijn. De basis voor deze technieken is de reactie van aminozuren met o-phthaldialdehyde (OPA) die resulteerd in de vorming van hoogfluorescerende iso-indolen. Met de ontwikkelde methoden is het mogelijk om op een volledig geautomatiseerde manier de concentraties van alle fysiologisch belangrijke aminozuren te bepalen in $35 \mathrm{~min}$. durende cycli met een gemiddelde variatiecoefficient van $3 \%$ of minder. Een snellere analysecyclus behoort tot de mogelijkheden, maar gaat ten koste van de robuustheid.

Echter, de bepaling van plasma aminozuur concentraties alleen geeft geen duidelijk beeld van de deelprocessen die ze sturen. Om meer inzicht te krijgen in de rol van deze deelprocessen werden technieken ontwikkeld om de concentraties van aminozuur metabolieten te bepalen die kunnen dienen als een "marker" voor processen als weefsel proliferatie (polyamines), spierweefsel degradatie (3methylhistidine) en hepatische encephalopathy ( $y$-amino boterzuur: GABA). In hoofdstuk 2 worden de problemen bediscussieerd, die overwonnen moesten worden om de bepaling van deze metabolieten mogelijk te maken. Het belangrijkste probleem hierbij was het uitsluiten van de interferentie van de (veel hoger geconcentreerde) aminozuren, zonder toepassing van een arbeidsintensieve extractie procedure. Dit werd bereikt door toepassing van speciale gradient programma's en, in het geval van de polyamine bepaling, de toepassing van een nieuw kolom pakking materiaal. De basis van deze technieken was de OPA derivatisering.

De gerealiseerde toename van zowel de precisie als de analytische capaciteit maakte het mogelijk om meer aandacht te besteden aan het monster 
opwerkingsproces. In de literatuur wordt nog steeds een discussie gevoerd wat de beste methode hiervoor is. Enzymatische processen veranderen de concentraties van sommige aminozuren(arginine, ornithine, citrulline), terwijl de ontledingssnelheid van andere aminozuren (asparagine, glutamine) versneld kan worden door de inwerking van onteiwittingstechnieken. In hoofdstuk 3 wordt aangetoond dat het niet toepassen van een adequate opwerk en bewaar procedure kan leiden tot een veranderende aminozuur concentratie. Verder wordt in dit hoofdstuk aangetoond dat er rekening moet worden gehouden met factoren zoals voeding, geslacht en leeftijd bij de samenstelling van patient controle groepen. Deze factoren beinvloeden de "normale" aminozuur concentraties, waardoor er een zekere extra "ruis" onstaat, die het moeilijk maakt om de resultaten van de studie te evalueren.

In hoofdstuk 4 wordt de tracer technologie geintroduceerd. Het gebruik hiervan maakt het mogelijk om te discrimineren tussen eiwit synthese en degradatie. Dit gebeurt door een gegeven aminozuur te labelen wordt met een radioactief of stabiel isotoop. Het percentage radioactief gelabelde aminozuren kan eenvoudig bepaald worden met vloeistofscintillatie telling, maar deze isotopen kunnen niet gebruikt worden voor studies in de mens. Hiervoor is het gebruik van stabiele isotopen noodzakelijk. Deze isotopen vergen echter de inzet van dure en gecompliceerde apparatuur (massaspectrometers).

In hoofdstuk 5 wordt een andere benadering om eiwitsynthese te bepalen bediscussieerd. In tegenstelling tot de indirecte methoden, die gebruik maken van metingen van de precursorpool, is hier getracht om de direkte incorporatie van gelabelde aminozuren in een doeleiwit (albumine) te meten. Om dit mogelijk te maken is het nodig om het doeleiwit met een hoge zuiverheid te isoleren. Dit is bereikt door de aaneenschakeling van een aantal chromatografische technieken, met als resultaat een geautomatiseerde procedure voor de isolatie van albumine met een hoge zuiverheid. Gekoppeld aan een gasfase hydrolyse methode en de isotoopverrijkings meetmethode die beschreven is in het vorige hoofdstuk, kan hierdoor de direkte incorporatie van gelabeld leucine in albumine worden gemeten.

Tenslotte wordt in hoofdstuk 6 beschreven welke mogelijkheden de direkte koppeling vloeistofchromatografie-massaspectrometrie biedt. Hoewel de hiervoor beschreven methodieken de mogelijkheden bieden om op een direkte en indirekte manier de eiwitsynthese te meten, vergen ze wel een arbeidsintensieve monstervoorbewerking. Recent is het echter mogelijk geworden om de relatief hoge eluens flow van een vloeistofchromatograaf direkt te introduceren in een massaspectrometer. Door toepassing van dit systeem werd de "on-line" meting van zowel de concentratie als de verrijking van alle fysiologisch belangrijke aminozuren mogelijk. De precisie van deze methode is vergelijkbaar met die van een GC-MS analyse.

Het proefschrift wordt gecompleteerd met een aantal addenda, die de lezer van extra gegevens voorziet om voorkomende technische en meet problemen, die kunnen optreden bij gebruik van bovenstaande analysetechnieken, te identificeren en op te lossen. 


\section{Dankwoord}

Begin 1981 startte ik als analist op contractbasis in een researchgroep van de vakgroep Algemene Heelkunde, geleid (met lange ij of korte ei, dat varieerde weleens) door Peter Soeters. De toenmalige werkplek besloeg anderhalve laboratoriumtafel, in een ruimte die we deelden met Bernadette Kop en Marie-Louise en die organisatorisch was ondergebracht bij de afdeling Biochemie.

Samen met mijn collega studente Henny Goossens(-Hodemakers tegenwoordig) begonnen we onder de begeleiding van Mieke Janssen en Jurjen de Boer aan de moeilijke taak vorm te geven aan metabool onderzoek, zoals Peter Soeters zich dat voorstelde. Hoewel het behelpen was in vele opzichten, heb ik vele goede herinneringen en contacten aan deze tijd over gehouden. De vriendelijke sfeer die het gastheerschap van de Biochemie met zich mee bracht reken ik daar zeker bij. Hiervoor mijn dank aan allen van deze afdeling.

In de daarop volgende jaren heb ik vele mensen zien komen (en weer gaan). Hen allen te bedanken voor hun bijdrage aan mijn vorming en de totstandkoming van dit boekje is vrijwel onbegonnen werk. Toch wil ik een aantal mensen in het bijzonder noemen.

Peter Soeters, jouw bezielende inspiratie is steeds een drijvende kracht geweest. Je aanmoediging om toch telkens weer iets verder te kijken heeft mij uiteindelijk gebracht tot het schrijven van dit proefschrift. Je vaderlijke oor hielp mij door menig moeilijk moment. Alleen maakte je neiging om tot in de kleine uurtjes door te filosoferen over de papoea's van Nieuw Guinea menige vergadering tot een vermoeiende bezigheid.

Mick Deutz. Je komst alweer zoveel jaar geleden bracht de structurering waar we allen behoefte aan hadden. Mede dankzij jouw organisatorische talenten en je dynamiek is het metabole lab uitgegroeid tot een researchunit die zich mag laten zien.

Mijn collegae uit verleden Henny, Marion en Annemie. Bedankt voor de gezellige sfeer. Mieke. Al zijn wij elkaar de laatste jaren wat meer uit het oog verloren, toch wil ik je bedanken voor al je hulp bij de eerste stappen die ik zette aan het begin van mijn carrière. Zonder jou was ik nooit zover gekomen.

Dennis. Onze discussies leken vaak wat heftig. Ze inspireerden ons beiden. Menig goed idee is hieruit geboren. Ik wens je veel plezier in je nieuwe werkkring Goede herinneringen bewaar ik ook aan de samenwerking met promovendi en AIO's. Jurjen de Boer, Rob Oostenbroek, Paul van Leeuwen, Charles van Berlo (die mij stimuleerde tot het schrijven van mijn eerste artikel), Ivo de Blaauw, Cees DeJong en Carlo Welters om maar een aantal namen te noemen. Of collega promovendi van nu Steven OldeDamink, Maaike Bruins en Marcella Hallemeesch.

Wim Buurman. Altijd wist je weer een onverwachte invalshoek te vinden tijdens discussies en vergaderingen. De mensen van jouw lab zal ik mij altijd als vriendelijke buren blijven herinneren. De vele vlaaien mis ik nog steeds.

Alle mensen van de instrumentele dienst. Met name de mensen van onderhoud en reparatie, Maurice, Wiel, Hein en Eugene. Als ik er echt niet meer uitkwam wisten zij altijd wel een oplossing te verzinnen.

Paul Verjans. Altijd was je wel bereid om mij op te halen. Ik mis onze ochtend en namiddag gesprekken. 
Heleen Huyten-Erkens en Jos Kop hebben menige lastige (tel)vraag tot een goed einde gebracht.

Ton Wagenmakers, je beschouwende houding ten aanzien van de Biochemie en het instrument massa spectrometrie lokte vele discussies uit. Ik denk dat we hier allen van leerden.

Helma, dank voor het in goede banen leiden van het promotieproces.

Jean, mijn nieuwe collega. Als je zo snel door blijft leren als je nu doet, loop je mij in een jaar voorbij.

De vakgroep Chirurgie en in het bijzonder Prof. Dr. G. Kootstra dank ik voor de geboden mogelijkheden.

Mijn familie en die van Peggy. Samen hebben jullie ons geholpen onze dromen waar te maken. We zouden het niet alleen hebben kunnen doen.

Pap en mam, jullie opoffering in het verleden heeft deze toekomst voor ons mogelijk gemaakt. Altijd schoven jullie je eigen noden aan de kant ten voordele van ons. Pap, je ziekte heeft een voortijdig einde aan jouw carrière gemaakt. Des te meer besefte je het belang ervan en stimuleerde je mij om door te zetten op moeilijke momenten. Hoe kan ik je hier ooit voor bedanken.

Mijn schoonouders, pap en mam Bijsmans, betere schoonouders had ik mij niet kunnen wensen. Samen hebben we al heel wat meegemaakt, samen zullen we nog veel meemaken. Veel hadden jullie voor ons over. Nooit deden wij tevergeefs een beroep op jullie.

En natuurlijk Peggy. Jij zette mijn leven op zijn kop. Altijd weer zorgde je ervoor dat thuis alles op rolletjes liep. Altijd stimuleerde je mij ook om alle karwijtjes te doen waar ik eigenlijk geen zin in had. Samen zijn we nu bezig onze droom waar te maken. Hopelijk krijgen we daar nu wat meer tijd voor. 


\section{Curriculum Vitae}

Hans van Eijk was born on August $16^{\text {th }}, 1959$ in Heerlen, The Netherlands. From 1971-1975 he attended MAVO-4 at St.-Janscollege in Hoensbroek. From 1975-1978 he went to Sittard to attend the Zuidlimburgse Laboratoriumschool HBO-A, chemical-analytical direction. In the year 1978 he entered HBO-B with the same graduate direction and concluded this study in 1980.

In 1981 he started working at Maastricht University (at that time: University of Limburg), at the Department of Surgery (at that time headed by Prof. Dr. C. Greep) under supervision of (again that time) dr. P.B. Soeters. In 1983 his employment at the Department of Surgery was changed to an indefinite time at the Academical Hospital Maastricht (now headed by Prof. Dr. G. Kootstra) under the supervision of Prof. dr. P.B. Soeters and later also dr. N.E.P. Deutz at which he is working still at the time.

From 1984 to present he attended several company training courses, several modules at the Open University and the radiation course at Delft University (level 5B).

Between 1994 and 1995, he followed a post HBO study at the Higher Laboratory School in Sittard, resulting in his BSc. Degree, enabling the route to a PhD study. From this time, the major part of this thesis was written.

Presently, he is still employed at the Department of Surgery, under the supervision of Prof. dr. P.B. Soeters and dr. N.E.P. Deutz. 
1. Van Leeuwen PAM, Van de Boogaard AEJM, Janssen MA, De Boer JEG, Van Elik HMH, Soeters PB. Ammonia production and glutamine metabolism in the small and large intestine of the rat and the influence of lactulose and neomycin. In: Advances in hepatic encephalopathy and urea cycle diseases. Basel: Karger; 1984, p. 154-162.

2. De Boer JEG, Goossens HM, Van Dongen JJ, Van Eilk HMH, Janssen MA, Van Leeuwen PAM, et al. Activity of branched chain oxo acid dehydrogenase (BCOA-DH) in adipose tissue and diaphragm of rats: the influence of portacaval shunt (PCS). In: Advances in hepatic encephalopathy and urea cycle diseases. Basel: Karger; 1984. p. 555-562.

3. Soeters PB, Van Leeuwen PAM, Janssen MA, De Boer JEG, Goossens HM, Van Elik HMH, et al. Metabolic generation of ammonia and amino acids in the intestinal wall and the influence of neomycin and lactulose. In: Advances in hepatic encephalopathy and urea cycle diseases. Basel: Karger; 1984. p. 147-153.

4. Van Berlo CLH, De Jonge H, Van de Boogaard AEJM, Van Eilik HMH, Janssen MA, Soeters PB. y-Aminobutyric acid production in small and large intestine of normal and germ-free wistar rats. Infulence of food intake and intestinal flora. Gastroenterology 1987;93:472-479.

5. Van Eijk HMH, Van der Heijden MAH, Van Berio CLH, Soeters PB. Fully automated liquid chromatographic determination of amino acids. Clin.Chem. 1988;34:2510-2513.

6. Van Berlo CLH, Van de Boogaard AEJM, Van der Heijden MAH, Van Elik HMH, Janssen MA, Bost MCF, et al. Is increased ammonia liberation after bleeding in the digestive tract the consequence of complete absence of isoleucine in hemoglobin? A study in pigs. Hepatology 1989;10:315-323.

7. Vente JP, Von Meyenfeldt MF, Van Eiik HMH, Van Berlo CLH, Gouma DJ, Van der Linden CJ, et al. Plasma amino acid profiles in sepsis and stress. Ann.Surg. 1989;209:57-62.

8. Bosman DK, Deutz NEP, De Graaf AA, Van de Hulst RWN, Van Eijk HMH, Bovee WMMJ, et al. Changes in brain metabolism during hyperammonemia and acute liver failure: Results of a comparative 1H-NMR spectroscopy and biochemical investigation. Hepatology 1990;12:281290.

9. Van Eijk HMH, Deutz NEP, Wagenmakers AJM, Soeters PB. 3-Methylhistidine determined in plasma by "High-Performance" Liquid Chromatography. Clin.Chem. 1990;36:556-559.

10. Bosman DK, Deutz NEP, M.A.W.Maas MAW, Van Eiik HMH, Smit JJH, De Haan JG, et al. Amino acid release from cerebral cortex in experimental acute liver failure, studied by in vivo cerebral cortex microdialysis. J.Neurochem. 1992;59:591-599.

11. Van Eijk HMH, Rooyakkers DR, Deutz NEP. Rapid routine determination of amino acids in plasma by high-performance liquid chromatography with a 2-3 um Spherisorb ODS II column. J.Chromatogr. 1993;620:143-148.

12. Van Eijk HMH, DeJong CHC, Deutz NEP, Soeters PB. Influence of storage conditions on normal plasma amino acid concentrations. Clin.Nutr. 1994;13:374-380.

13. Van Eijk HMH, Huinck MPL, Rooyakkers DR, Deutz NEP. Automated simultaneous isolation and quantitation of labeled amino acid fractions from plasma and tissue by ion-exchange chromatography. J.Chromatogr.B 1994;660:251-257.

14. Van Eijk HMH, Rooyakkers DR, Deutz NEP. Automated determination of polyamines by highperformance liquid chromatography with simple sample preparation. J.Chromatogr. A 1996;730:115-120.

15. Rooyakkers DR, Van Eijk HMH, Deutz NEP. Simple and sensitive multi-sugar-probe gut permeability test by high-performance liquid chromatography with fluorescence labelling. J.Chromatogr.A 1996;730:99-105.

16. Van Eijk HMH, Rooyakkers DR, Wagenmakers A.JM, Soeters PB, Deutz NEP. Isolation and quantitation of isotopically labeled amino acids from biological samples. J.Chromatogr.B 1997;691:287-296.

17. Van Eijk HMH, Rooyakkers DR, Soeters PB, Deutz NEP. Determination of amino acid isotope enrichment using Liquid Chromatography-Mass Spectrometry. Anal.Biochem. 1999;271:8-17.

18. Van Eijk HMH, Rooyakkers DR, Van Acker BAC, Soeters PB, Deutz NEP. Autoamted isolation of high purity plasma albumin for isotope ratio measurements. J.Chromatogr.B.1999: in press. 
